\title{
SERIES
}

Alpine Forschungsstelle Obergurgl

Band 3

innsbruck university press

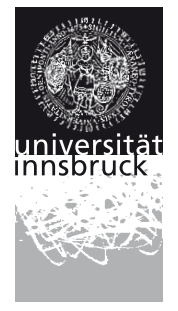


Eva-Maria Koch, Brigitta Erschbamer (Hg.)

\section{Klima, Wetter, Gletscher im Wandel}




\section{Eva-Maria Koch}

Alpine Forschungsstelle Obergurgl, Universität Innsbruck

\section{Brigitta Erschbamer}

Alpine Forschungsstelle Obergurgl, Universität Innsbruck Institut für Botanik, Universität Innsbruck

Diese Publikation wurde mit finanzieller Unterstützung aus den Fördermitteln des Vizerektorates für Forschung und des Universitätszentrums Obergurgl der Leopold-Franzens-Universität Innsbruck gedruckt.

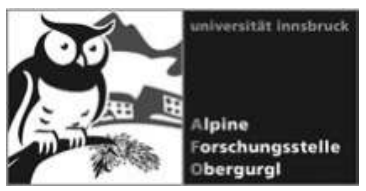

(C) innsbruck university press, 2013

Universität Innsbruck

Alle Rechte vorbehalten.

Das Werk ist urheberrechtlich geschützt. Die Rechte für Nachdruck, Übersetzung sowie die Entnahme von Abbildungen und Bildern liegen bei den Herausgeberinnen bzw. bei den jeweiligen AutorInnen. Die in den Beiträgen geäußerten Meinungen müssen nicht mit denen der Herausgeberinnen übereinstimmen.

Umschlag: Ivan Leuzzi

Umschlagmotiv: Der Wasserfallferner im Rotmoostal

Foto: Eva-Maria Koch (18.08.2009)

Layout: Carmen Drolshagen

Produktion: Sterndruck GmbH, Fügen

www.uibk.ac.at/iup

www.uibk.ac.at/afo

ISBN 978-3-902811-89-9 


\section{Inhaltsverzeichnis}

Einleitung

Eva-Maria Koch, Brigitta Erschbamer

Kapitel 1 I Temperatur und Niederschlag an der

Wetterstation Obergurgl, 1953 - 2011

Michael Kuhn, Ekkehard Dreiseitl, Markus Emprechtinger

Kapitel 2 | Langzeitmonitoring von Gletschermassenbilanzen

und -längenänderungen in Tirol

Andrea Fischer, Lea Hartl

Kapitel 3 | Gletscher in Tirol, ihre Verteilung und jüngsten Veränderungen

Jakob Abermann, Michael Kuhn, Astrid Lambrecht, Lea Hartl

Kapitel 4 I Zur Geschichte des Vernagtferners - Gletschervorstöße

und Seeausbrüche im vergangenen Jahrtausend

Kurt Nicolussi

Kapitel 5 I Das Potential historischer Karten zur Rekonstruktion des Gletscherrückgangs im Gurgler Tal 95

André Baumeister 
Inhaltsvzerzeichnis

Kapitel 6 I Die Ötztaler Ache

Das hydrographische Regime der Ötztaler Ache

Wolfgang Gattermayr

Die Lebewelt der Ötztaler Ache

Daniel Erhart

Kapitel 7 I Das Mikroklima waldfreier Standorte in der subalpinen, alpinen und subnivalen Stufe in Obergurgl

Lea Hartl, Rüdiger Kaufmann, Nikolaus Schallhart, Brigitta Erschbamer

Kapitel 8 I Mikroklima und Biotemperaturen auf der 1971er Moräne des Rotmoosferner-Gletschervorfeldes (Obergurgl, Ötztal)

Brigitta Erschbamer

Anhang 


\section{Einleitung}

„Nichts ist so beständig wie der Wandel“ - das erkannte der griechische Philosoph Heraklit von Ephesus bereits um ca. 500 v. Chr. Und diesen fortlaufenden Wandel kann man auch in den Alpen in vielerlei Hinsicht erkennen.

Manche Veränderungen sind deutlich wahrzunehmen wie etwa das Abschmelzen der Gletscher. Jedes Jahr kann man in den Alpen beobachten, wie sich die Eisflächen der Gletscher weiter zurückziehen und Fels- und Moränenflächen freigeben. Andere Veränderungen verlaufen mehr im Stillen. Ein Beispiel ist das fortschreitende Auftauen von Permafrostböden im Gebirge. Diese Veränderung ist auf den ersten Blick vielleicht nicht so offensichtlich, für die Umwelt aber nicht weniger bedeutend, weil es durch das Auftauen beispielsweise vermehrt zu Steinschlag, Felssturz und Murgängen kommen kann.

Um Veränderungen des Klimas und der Gletscher in den Zentralalpen aufzuzeichnen und belegen zu können, werden seit Jahrzehnten von Wissenschaftlerinnen und Wissenschaftlern der Universität Innsbruck und auch anderer Universitäten im inneren Ötztal zahlreiche Daten erhoben. Sowohl Vent als auch Obergurgl zählen zur Plattform „Tyrolean Alps“ im LTER/LTSER-Langzeitforschungsprogramm in Österreich (LTER = Long-Term Ecosystem Research; LTSER = Long-Term Socio-economic and Ecosystem Research, http://131.130.57.239/LTER_cms/index. php). Die Alpine Forschungsstelle Obergurgl ist bestrebt, das Langzeit-Untersuchungsprogramm im inneren Ötztal aufrecht zu erhalten, wenn sich auch die Suche der Finanzierung von Langzeitprogrammen sehr schwierig gestaltet.

Im vorliegenden dritten Band der Serie „Lebensräume im inneren Ötztal“ wurden verschiedene Langzeitdatenreihen zusammengestellt und aufbereitet. Sie zeigen die Veränderungen im Verlauf der Jahrzehnte in alpinen Lebensräumen und beleuchten den Einfluss des Wandels auf die Natur. Welche Rolle dabei der Mensch und sein Verhalten spielen, wird in unserem Band nicht beleuchtet. Dies wäre ein interessantes Thema für ein weiteres Buch unserer Serie.

Der vorliegende Band „Klima, Wetter, Gletscher im Wandel“ wird eröffnet mit einer genauen Darstellung des Klimas in Obergurgl, wobei vor allem die Entwicklung der Temperatur und des Niederschlags von 1953 bis 2011 präsentiert wird (Kapitel 1, $\rightarrow$ S. 11). An dieser Stelle soll allen, die in der Vergangenheit die Wetterbeobachtungen an der Alpinen Forschungsstelle Obergurgl durchgeführt und die Daten (Abb. 1) gesammelt haben, gedankt werden. Dieser Dank gilt in besonderer Weise Herrn Johannes Malaun (1953-64), Frau Inge Klotz (1965-75), Mitarbeitern des Instituts für Meteorologie und Geophysik der Universität Innsbruck (1976-77) und Herrn Meinhard Strobl (1978-2011, Abb. 2). 


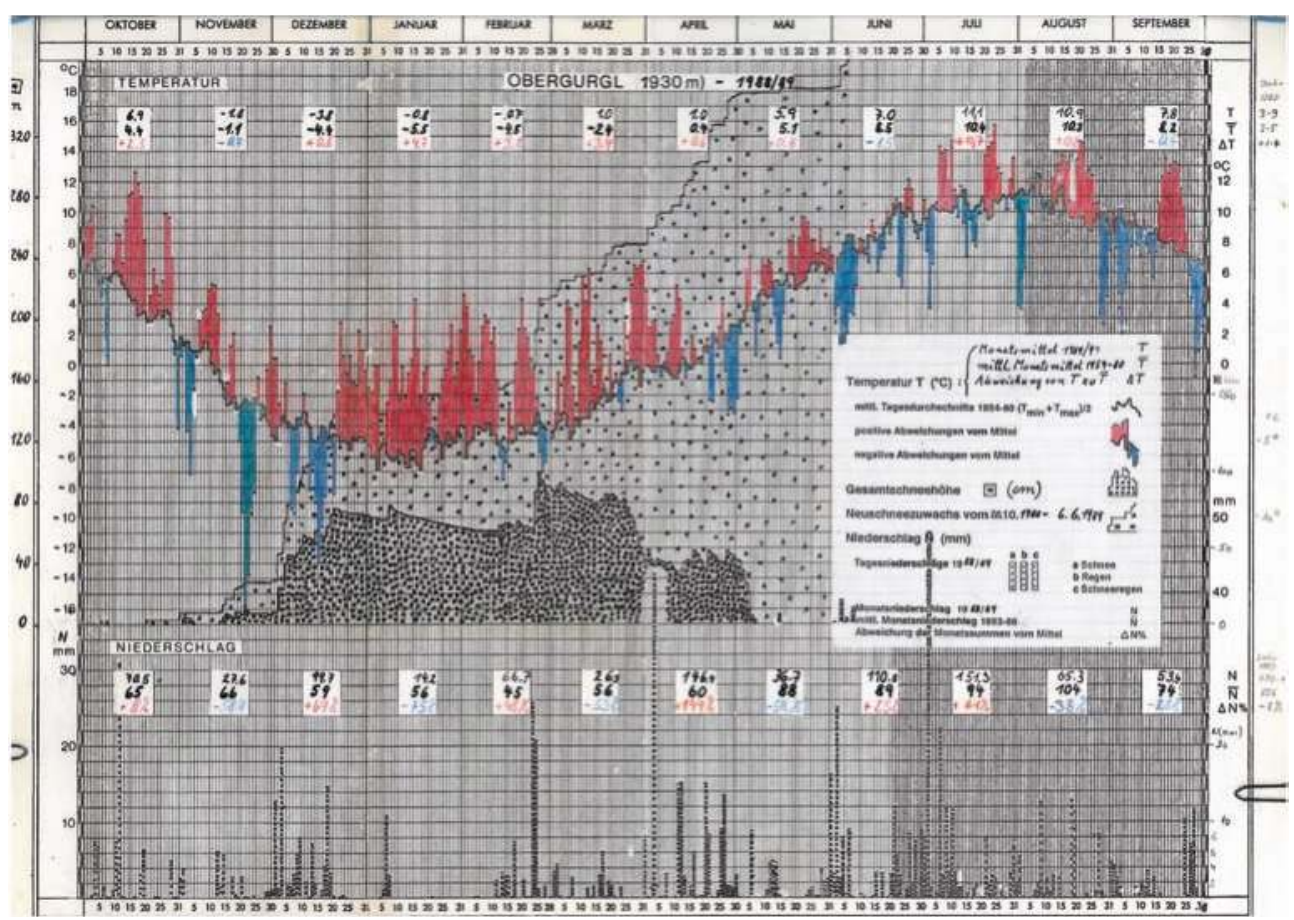

Abb. 1: Der handschriftlich geführte Klimadatenbogen von der Wetterstation an der Alpinen Forschungsstelle Obergurgl (Ausarbeitung: Meinhard Strobl) zeigt für das Massenhaushaltsjahr 1988-1989 einen sehr warmen Winter

Kapitel $2(\rightarrow$ S. 31) und $3(\rightarrow$ S. 49) dieses Buches widmen sich dem Langzeitmonitoring von Gletschermassenbilanzen und -längenänderungen in Tirol. Das Monitoring der Gletscher gibt den seit Jahren deutlichen Rückgang der Eisflächen in konkreten Zahlen wieder und erklärt, welche Faktoren dabei entscheidend sind.

In Kapitel $4(\rightarrow$ S. 69) wird anhand eines Beispieles aus dem inneren Ötztal dargestellt, dass Gletscher nicht immer nur auf Rückzug waren. Der Beitrag behandelt die historischen Vorstöße des Vernagtferners, der noch vor ca. 120 Jahren im Venter Tal einen großen Eissee aufgestaut hat.
Historische Daten bilden auch die Grundlage für Kapitel 5 ( $\rightarrow$ S. 95), in dem der Gletscherrückgang im Gurgler Tal bis heute rekonstruiert wird. Dabei wird beleuchtet, welches Potential historische Karten zur Rekonstruktion des Gletscherrückgangs haben. Dass die abschmelzenden Gletscher auch den Wasserhaushalt einer Region stark beeinflussen, behandelt Kapitel $6(\rightarrow$ S. 119). In diesem Beitrag wird die Hydrographie der Ötztaler Ache diskutiert und dabei unter anderem auf das Pegelwesen, das Einzugsgebiet, die Lebewelt, den Einfluss der Vergletscherung auf die Abflüsse und das Hochwassergeschehen eingegangen. 


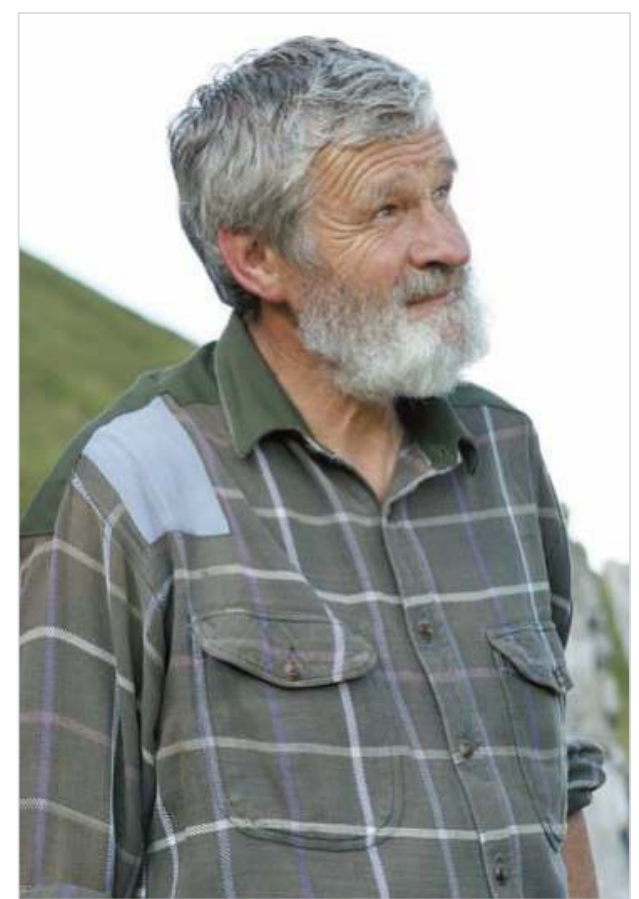

Abb. 2: Der Wandel geht auch an der Alpinen Forschungsstelle Obergurgl nicht spurlos vorüber. Der langjährige Wetterwart, Meinhard Strobl, ist 2011 in Pension gegangen. Durch seine Wetterbeobachtungen über mehr als 30 Jahre hinweg konnten zahlreiche Erkenntnisse über das Klima des inneren Ötztals gewonnen werden (Foto: EvaMaria Koch)

Aber nicht nur der makroklimatische Wandel ist für die Lebensräume und die Lebewelt der Alpen von Bedeutung. Auch die mikroklimatischen Verhältnisse (z. B. Lufttemperatur in $2 \mathrm{~m}$ Höhe, relative Feuchte, Bodentemperatur und -feuchte in $10 \mathrm{~cm}$ Tiefe) ändern sich. Kapitel 7 ( $\rightarrow$ S. 165) zeigt, welche Veränderungen das Mikroklima seit 2000 an waldfreien Standorten in der subalpinen, alpinen und subnivalen Stufe im Raum Obergurgl aufweist und welchen Einfluss dies auf den Zeitpunkt der Ausaperung hat.

In Kapitel 8 ( $\rightarrow$ S. 187) wird das Mikroklima im Gletschervorfeld des Rotmoostales am Beispiel der Moräne, die seit 1971 eisfrei ist, präsentiert. In dem Beitrag wird zudem erläutert, welche möglichen Auswirkungen die mikroklimatischen Bedingungen beispielsweise auf die Keimung, das Wachstum und die Reproduktion von Pflanzen haben.

Wie auch schon in den ersten beiden Publikationen soll auch in unserem dritten Band ein Einblick in die Forschung im inneren Ötztal gegeben werden. Dieses Buch soll dabei Wissenschaftlerinnen und Wissenschaftlern verschiedener Fachrichtungen, aber auch Studierenden und interessierten Laien als wertvolles Nachschlagwerk dienen, um den Wandel der Umweltfaktoren im Laufe der Zeit anhand konkreter Beispiele besser nachvollziehen und verstehen zu können.

Wir bedanken uns herzlich bei allen Autorinnen, Autoren, Gutachterinnen und Gutachtern für ihre Mitarbeit und Unterstützung, ohne die dieses Werk nicht möglich gewesen wäre.

Eva-Maria Koch \& Brigitta Erschbamer Alpine Forschungsstelle Obergurgl, Universität Innsbruck Homepage: www.uibk.ac.at/afo 


\title{
Kapitel 1 I Temperatur und Niederschlag an der Wetterstation Obergurgl, 1953-2011
}

\author{
Michael Kuhn, Ekkehard Dreiseitl, Markus Emprechtinger
}

\section{Zusammenfassung}

Mit dem vorliegenden Bericht sollen die Temperatur- und Niederschlagsdaten der Station Obergurgl $\left(1938 \mathrm{~m}, 11^{\circ} 01,5^{\prime} \mathrm{E}, 46^{\circ} 52^{\prime} \mathrm{N}\right)$ allen BenutzerInnen und InteressentInnen verfügbar gemacht werden. Der praktische $\mathrm{Zu}$ griff auf diese und weitere Daten erfolgt über den Pangea Server des Alfred Wegener Instituts, zu dem Links angegeben werden. Ihre Entstehung, Repräsentativität, Genauigkeit, Fehlergrenzen und ihre Anwendbarkeit werden erläutert. Die Möglichkeit der Extrapolation der Daten der Station auf andere Plätze in der weiteren Umgebung von Obergurgl wird gezeigt. Dazu gehören auch die Unterschiede zum Klima anderer Standorte: lokal (Talboden, Hang, Gipfel), regional (Obergurgl / Vent; nördlich oder südlich des Alpenhauptkamms; Alpenrand oder -zentrum) und im Bezug auf die Seehöhe (Vergleich ostalpiner Berg- und Talstationen). Die Änderungen von Temperatur und Niederschlag zeigen, wie dem langfristigen linearen Trend kurzfristige
Schwankungen überlagert sind, und wie diese je nach Jahreszeit verschieden verlaufen.

\section{Abstract}

The present report intends to provide and to interpret the records of temperature and precipitation of the weather station of Obergurgl (1938 $\left.\mathrm{m}, 11^{\circ} 01.5^{\prime} \mathrm{E}, 46^{\circ} 52^{\prime} \mathrm{N}\right)$. The data are stored on the Pangea Server of the Alfred Wegener Institute, links are given in the reference list. In this report the most salient features of temperature and precipitation are presented and the methods of data processing and limits of data application are explained. Ways of extrapolating these records over distance and elevation are suggested. Emphasis is given to the discussion of long term temperature trends and shorter fluctuation on a seasonal basis, and to the effects of screening and of elevation in the precipitation fields. 


\section{1. Übersicht}

Von 1953 bis 2011 wurden an der Station Obergurgl Temperaturen der Luft und des Bodens, Luftdruck, Feuchte, Windgeschwindigkeit und Windrichtung laufend registriert, die entsprechenden Instrumente wurden dreimal täglich kontrolliert, wobei auch noch die Bewölkung, die Sichtweite und die Bodenbeschaffenheit festgestellt wurden. Der Niederschlag, die Neuschnee- und Gesamtschneehöhe wurden jeden Morgen notiert. Diese Messungen folgen internationalen Vereinbarungen und den Vorschriften des österreichischen Wetterdienstes (Klinger 1986). Sie sind direkt vergleichbar mit den Daten der Stationen des Hydrographischen Dienstes.

\section{Die Wetterstation. Instrumente, Be- obachtungen}

Die Station (Abb. 1) liegt in 1938 m Höhe bei der Alpinen Forschungsstelle, Universitätszentrum Obergurgl (Abb. 2, 3), am Rand eines asphaltierten Parkplatzes $\left(11^{\circ} 01,5^{\prime} \mathrm{E}\right.$, $\left.46^{\circ} 52^{\prime} \mathrm{N}\right)$. Sie ist mit den Standardgeräten des österreichischen Wetterdienstes ausgerüstet, die Beobachtungen erfolgen wie zuvor beschrieben. In den Wintern 1953-70 wurde die Wetterhütte von den Beobachtern vor Ort innen mit Gazetüchern ausgekleidet, um das Eindringen von Treibschnee zu verhindern. Die dadurch entstandenen Fehler in der Temperatur wurden mit einem Vergleich der korrekt gemessenen Temperaturen von Obergurgl

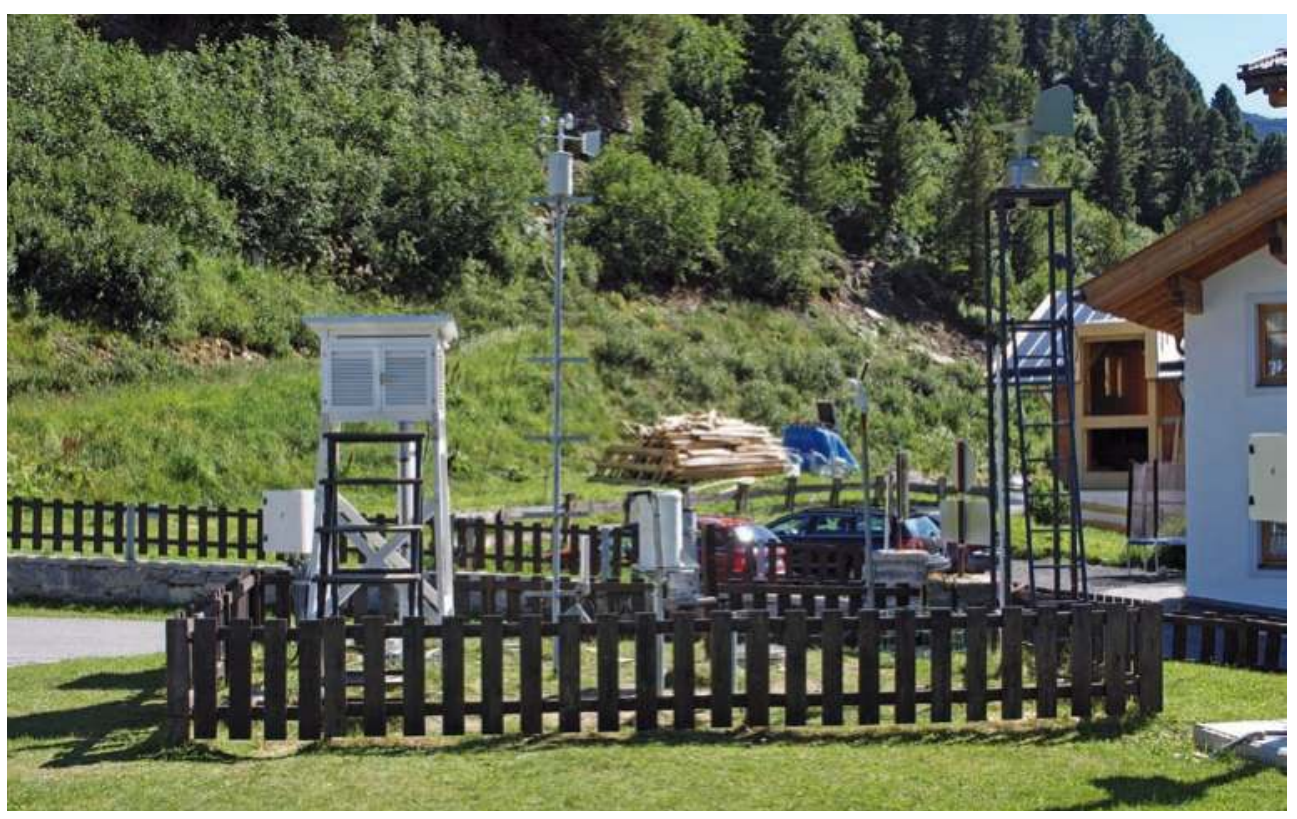

Abb. 1: Die Wetterstation der ZAMG (Zentralanstalt für Meteorologie und Geodynamik) an der Alpinen

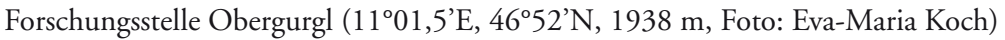




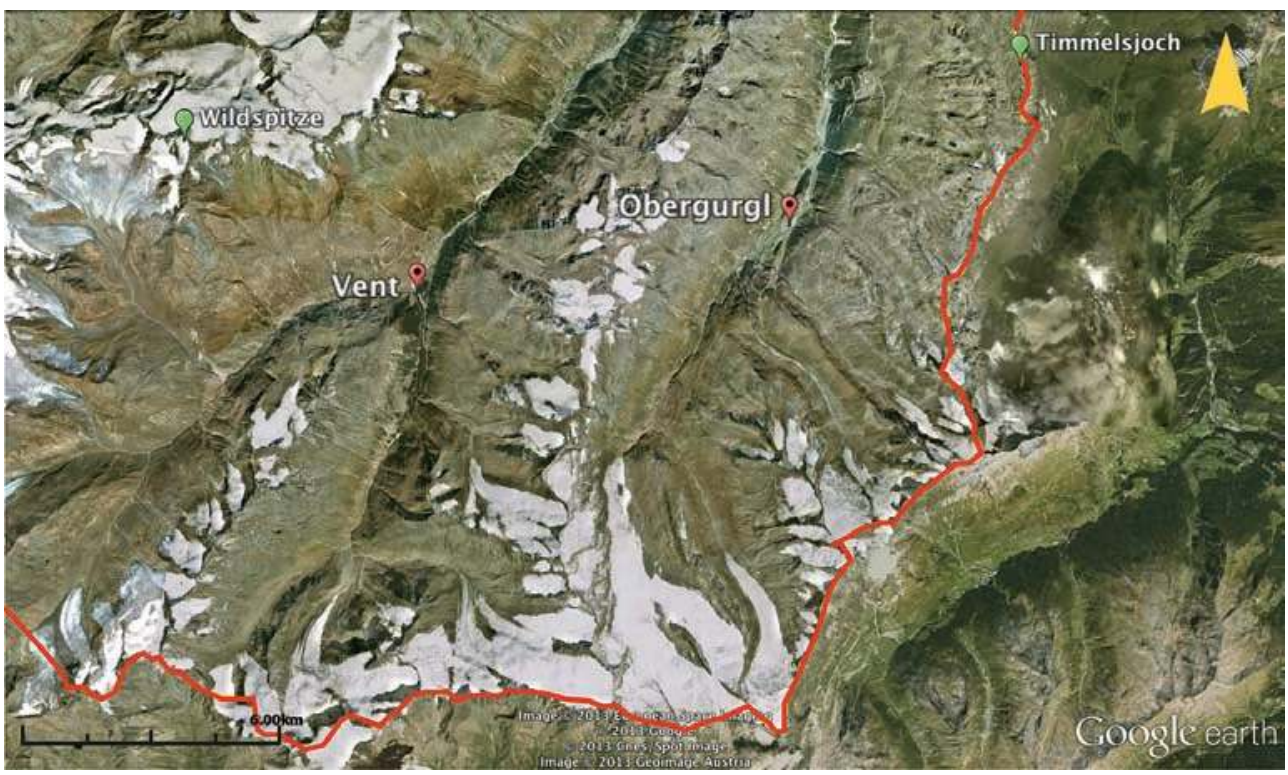

Abb. 2: Die Lage von Obergurgl aus der Sicht von Google Earth. Obergurgl liegt näher am Alpenhauptkamm, der hier rot eingezeichnet ist, als Vent im Nachbartal. Das bedeutet, dass es vom Wolkenstau bei Süd- und Südwestwinden um etwa ein Viertel mehr Jahresniederschlag bekommt als Vent

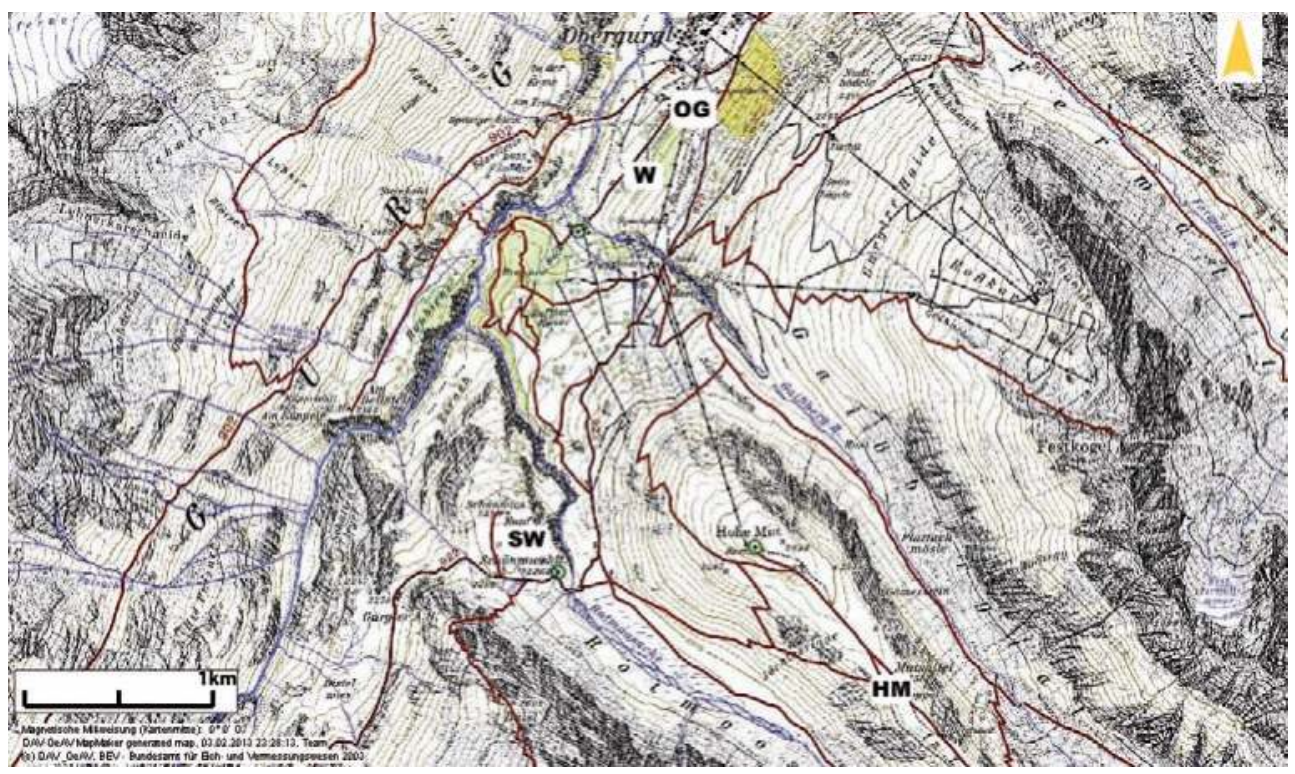

Abb. 3: Ausschnitt aus der Alpenvereinskarte, Blatt Obergurgl. Neben der Wetterstation Obergurgl OG $(1938 \mathrm{~m})$ sind auch drei Stationen des Man and Biosphere Projekts (MaB) eingetragen, die von 1978 bis 1981 aktiv waren. W: Station Wiese 1960 m, SW: Station Schönwies 2310 m, HM: Station Hohe Mut 2560 m 
und Vent (Abb. 2) aus den Jahren 1971-80 nachträglich korrigiert. Seit 1999 läuft neben den täglichen drei Terminbeobachtungen eine teilautomatische Wetterstation (TAWES), die ihre Messungen an die Zentralanstalt für Meteorologie und Geodynamik (ZAMG) in Wien überträgt.

\section{Kleiner Führer durch die Geschich- te der Mittelbildung}

Die Wetterbeobachtungen werden im Österreichischen Wetterdienst zu bestimmten Terminen durchgeführt: um $7 \mathrm{~h}, 14 \mathrm{~h}$ und 19 h bzw. 21 h MEZ. Die seit 1980 wieder eingeführte Sommerzeit (SZ) wird bei den selbstschreibenden Geräten nicht berücksichtigt, die Augenbeobachtungen erfolgen um $8 \mathrm{~h}, 15 \mathrm{~h}$ und $20 \mathrm{~h} \mathrm{SZ}$, also beim gleichen Sonnenstand wie zu den Beobachtungen $7 \mathrm{~h}$, 14 h, 19 h MEZ.
Die aus diesen Termin- und den Extremwerten (Maximum und Minimum) gebildeten Mitteltemperaturen stellen eine Näherung an das „wahre Mittel“ dar, das aus den 24 Stundenwerten gerechnet wird und für alle Zwecke hinreichende Genauigkeit hat. Die heutigen digitalen Datenerfassungen wie die TAWES liefern diese wahren Tagesmittel.

In den hier diskutierten Zeitreihen befindet sich eine Unstetigkeitsstelle im Jahre 1971, als die Zentralanstalt für Meteorologie und Geodynamik und der Hydrographische Dienst ihre Beobachtungstermine umstellten: mit dem 1.1.1971 wurde die $21 \mathrm{~h}$-Beobachtung durch den Termin $19 \mathrm{~h}$ ersetzt. Dadurch ergaben sich bei den Langzeitreihen Inhomogenitäten, die anhand der Temperatur im Folgenden erklärt werden sollen.

Mittelbildung der Temperatur bis einschl. 31.12.1970:

Tagesmittel $=(\mathrm{T} 7+\mathrm{T} 14+\mathrm{T} 21) / 3$, wobei $\mathrm{T} 7$ die Temperatur zur Zeit der Frühbeobachtung bedeutet,

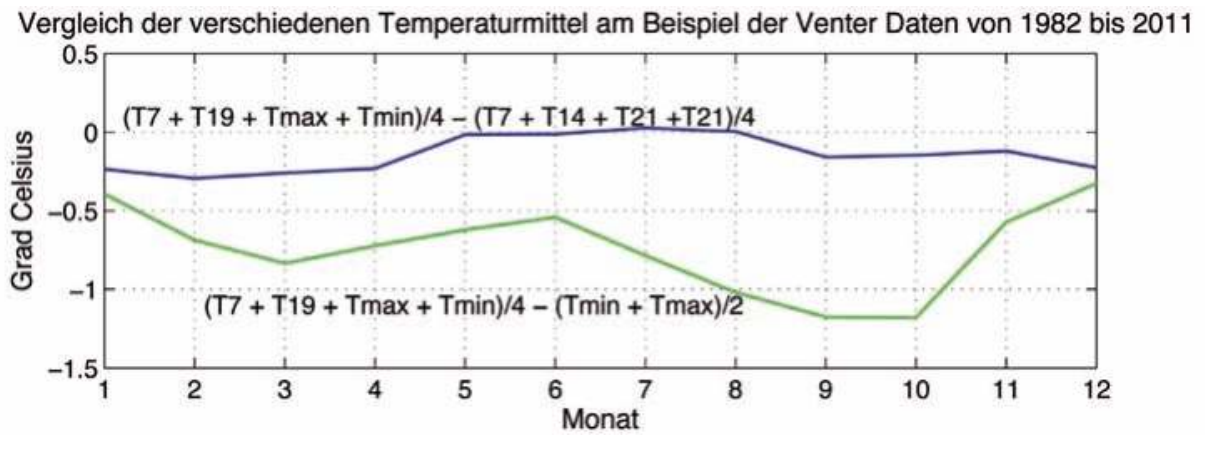

Abb. 4: Differenzen der verschiedenen Temperaturmittel am Beispiel der Venter Daten von 1982 bis 2011 
Monatsmittel $=(\mathrm{T} 7+\mathrm{T} 14+\mathrm{T} 21+\mathrm{T} 21) / 4$, in der Literatur meist als Klimamittel bezeichnet.

Mittelbildung seit 1.1.1971:

Tagesmittel $=(\operatorname{Tmax}+\operatorname{Tmin}) / 2$

Monatsmittel $=(\mathrm{T} 7+\mathrm{T} 14+\mathrm{Tmax}+\mathrm{Tmin}) / 4$

Um Klarheit und Vergleichbarkeit zu ermöglichen, werden im folgenden Textauch seit 1953 nur die Temperaturmittel $(\operatorname{Tmax}+\operatorname{Tmin}) / 2$ verwendet. Der mittlere Fehler der Messungen wird als 0,1 bis $0,2{ }^{\circ} \mathrm{C}$ angenommen.

Detailuntersuchungen (Siogas 1972, Böhm 1992) haben gezeigt, dass die Differenzen der Mittelbildungen für Stationen in verschiedenen Höhenlagen im Bereich von 0,2 bis $1,5^{\circ} \mathrm{C}$ liegen und deshalb bei der Homogenisierung von Zeitreihen zu berücksichtigen sind. Da für die Station Vent auf vergleichbarer Höhe mit Obergurgl über eine Zeitspanne von 30 Jahren sowohl die $19 \mathrm{~h}$ als auch die $21 \mathrm{~h}$ Terminwerte vorliegen (Institute of Meteorology and Geophysics 2013 a, b), sei hier beispielhaft in Abb. 4 der Jahresgang dieser Differenzen für Vent wiedergegeben. Derselbe Datensatz ist auch die Grundlage für die Tab. 1. Abb. 4 und Tab. 1 zeigen, dass die Mittelbildung mit (Tmax+Tmin)/2 deutlich höhere Werte ergibt, also Achtung bei Vergleichen!

\section{Diagramme der Temperatur und des Niederschlags der einzelnen Jahre 1953-2011}

Die Diagramme (Abb. 5), die für jedes Jahr von 1953 bis 2011 auf dem Pangea Server liegen (Institute of Meteorology and Geophysics 2013 a), verwenden Ablesungen des Maximumthermometers und des Minimumthermometers zum Abendtermin [Monatsmittel werden aus $(\operatorname{Tmax}+\operatorname{Tmin}) / 2$ in ${ }^{\circ} \mathrm{C}$ berechnet] sowie Tageswerte des Niederschlags aus Handablesung des Ombrometers (Gebirgsregenmesser mit $500 \mathrm{~cm}^{2}$ ).

Tab. 1: Die verschiedenen Temperaturmittel am Beispiel der Venter Daten von 1982 bis 2011

\begin{tabular}{|c|c|c|c|c|c|c|c|c|c|c|c|c|c|}
\hline & Jan & Feb & Mar & Apr & Mai & Jun & Jul & Auf & Sep & Okt & Nov & Dez & Jahr \\
\hline$(\mathrm{T} 7+\mathrm{T} 19+\mathrm{Tmin}+\mathrm{Tmax}) / 4$ & $-5,8$ & $-6,0$ & $-3,0$ & 0,5 & 5,6 & 8,7 & 10,8 & 10,2 & 6,9 & 3,5 & $-2,0$ & $-5,1$ & 2,0 \\
\hline$(\mathrm{T} 7+\mathrm{T} 14+\mathrm{T} 21+\mathrm{T} 21) / 4$ & $-5,6$ & $-5,7$ & $-2,7$ & 0,7 & 5,7 & 8,7 & 10,8 & 10,2 & 7,1 & 3,7 & $-1,8$ & $-4,9$ & 2,2 \\
\hline$(\operatorname{Tmin}+\operatorname{Tmax}) / 2$ & $-5,4$ & $-5,4$ & $-2,2$ & 1,2 & 6,3 & 9,2 & 11,6 & 11,3 & 8,1 & 4,7 & $-1,4$ & $-4,8$ & 2,8 \\
\hline
\end{tabular}




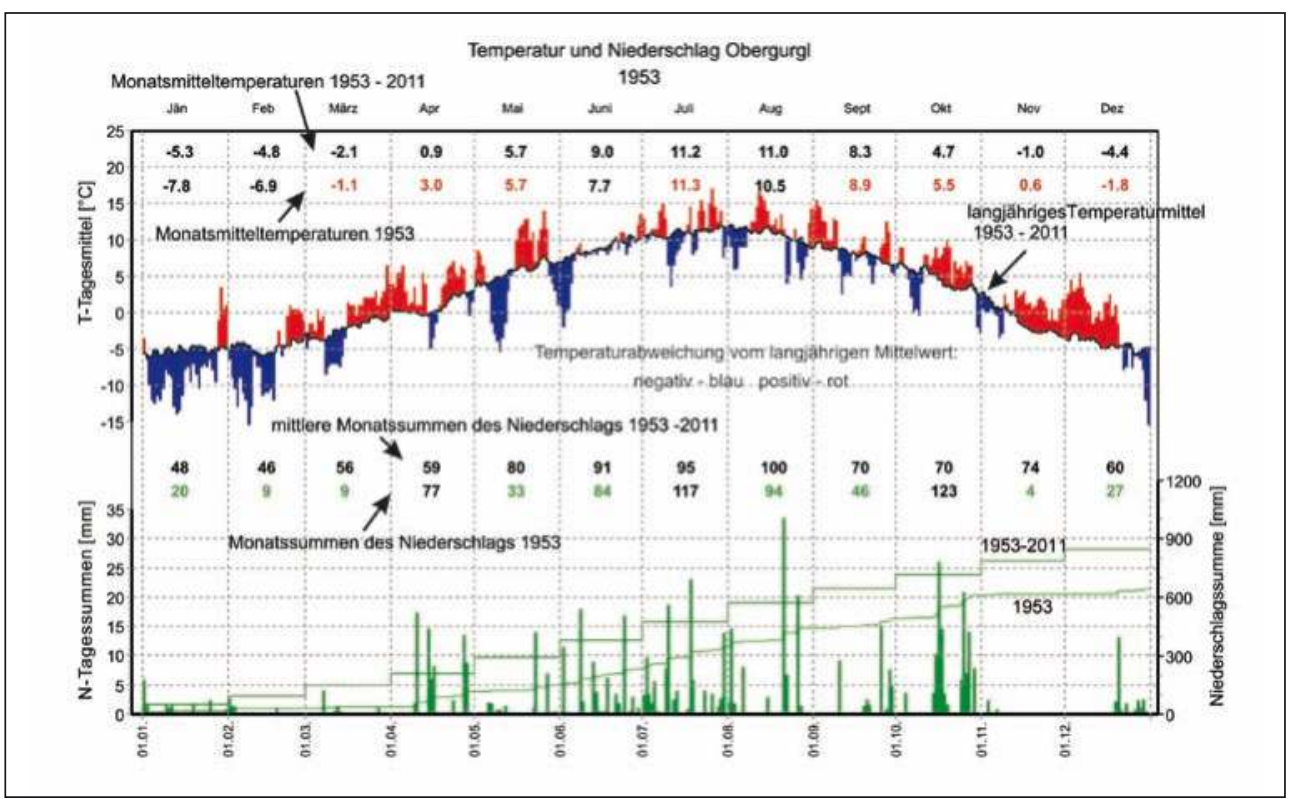

Abb. 5: oben - Monatsmittel der Temperatur (Tmax+Tmin)/2 der gesamten Periode 1953-2011, Monatsmittel des laufenden Jahres in Zahlen, schwarze Kurven der Tagesmittel 1953-2011, dazu Tagesmittel des laufenden Jahres. Rot ausgefüllt sind positive Abweichungen, blau negative; unten - Mittlere Monatssummen des Niederschlags der Periode 1953-2011, darunter Monatssummen des laufenden Jahres. Die Tagessummen des Niederschlags sind im laufenden Jahr als grüne Säulen (linke Skala), ihre Aufsummierung und die Summierung der Monatsmittel der Periode 1953-2011 als Stufen (rechte Skala) zu lesen

5. Die Temperaturen und ihre Extremwerte

Die Monatsmittel der Temperaturen (Tmax + Tmin) $/ 2$ von Obergurgl sind in Tab. 2 zusammengefasst. Die Extremwerte und die Mittel $(\operatorname{Tmax}+\operatorname{Tmin}) / 2$ der Stationen Obergurgl, Vent und Innsbruck sind in der Abb. 6 gegenübergestellt. Ihnen allen gemeinsam ist, dass die absoluten Maxima und Minima, da sie für jeden Tag des Jahres nur einen, von den anderen unabhängigen Wert darstellen, stark schwanken. Die Monatsmittel der Extremwerte der 59 Jahre sind dagegen ausgeglichener und liegen viel näher aneinander. Die Mitteltemperaturen, die als Mittel aus Maxima und Minima berechnet werden, haben verständlicherweise einen ganz ähnlichen Verlauf wie die Extremwerte. 
Kapitel 1 I Temperatur und Niederschlag an der Wetterstation Obergurgl, 1953-2011

Tab. 2: Monatsmittel der Temperaturen (Tmax+Tmin)/2 von Obergurgl, 1953-2011

\begin{tabular}{|c|c|c|c|c|c|c|c|c|c|c|c|c|c|}
\hline \multicolumn{14}{|c|}{ Temperaturmonatsmittel in ${ }^{\circ} \mathrm{C}$} \\
\hline $\mathrm{JZ}$ & JAN & FEB & MAR & APR & MAI & JUN & JUL & AUG & SEP & OKT & $\mathrm{NOV}$ & DEZ & JAHR \\
\hline 1953 & $-7,8$ & $-6,9$ & $-1,1$ & 3,0 & 5,7 & 7,7 & 11,3 & 10,5 & 8,9 & 5,5 & 0,6 & $-1,8$ & 3,0 \\
\hline 1954 & $-9,4$ & $-6,6$ & $-1,0$ & $-0,6$ & 3,8 & 8,9 & 8,0 & 9,0 & 8,3 & 4,1 & $-1,2$ & $-3,8$ & 1,6 \\
\hline 1955 & $-4,0$ & $-6,4$ & $-3,3$ & 0,5 & 4,7 & 8,8 & 10,1 & 9,0 & 7,0 & 2,9 & $-1,9$ & $-2,3$ & 2,1 \\
\hline 1956 & $-4,5$ & $-13,8$ & $-3,6$ & $-0,2$ & 5,6 & 6,1 & 10,5 & 9,9 & 9,7 & 2,9 & $-3,7$ & $-5,6$ & 1,1 \\
\hline 1957 & $-5,8$ & $-2,5$ & 1,6 & 1,1 & 2,9 & 9,5 & 9,9 & 9,5 & 7,2 & 5,5 & $-0,1$ & $-5,2$ & 2,8 \\
\hline 1958 & $-6,5$ & $-2,3$ & $-5,3$ & $-0,6$ & 8,5 & 8,2 & 11,4 & 11,7 & 9,8 & 2,9 & $-0,4$ & $-4,3$ & 2,8 \\
\hline 1959 & $-7,4$ & $-2,9$ & 0,9 & 2,1 & 5,9 & 9,0 & 11,8 & 9,6 & 9,2 & 4,5 & $-2,5$ & $-4,7$ & 3,0 \\
\hline 1960 & $-7,0$ & $-3,8$ & $-1,0$ & 0,5 & 6,2 & 9,9 & 8,6 & 10,0 & 6,2 & 2,8 & $-1,3$ & $-4,9$ & 2,2 \\
\hline 1961 & $-6,0$ & $-2,6$ & $-0,8$ & 4,6 & 4,2 & 10,1 & 9,3 & 10,7 & 11,9 & 5,3 & $-0,8$ & $-4,3$ & 3,5 \\
\hline 1962 & $-5,1$ & $-6,8$ & $-6,0$ & 0,4 & 4,1 & 7,9 & 10,0 & 12,2 & 8,0 & 4,7 & $-3,7$ & $-7,8$ & 1,5 \\
\hline 1963 & $-11,0$ & $-8,7$ & $-2,5$ & 2,2 & 5,0 & 9,0 & 11,8 & 10,3 & 8,5 & 4,7 & 0,6 & $-7,5$ & 1,9 \\
\hline 1964 & $-6,1$ & $-4,4$ & $-2,5$ & 2,0 & 7,2 & 10,7 & 11,8 & 9,8 & 8,6 & 1,5 & $-0,4$ & $-5,6$ & 2,7 \\
\hline 1965 & $-5,2$ & $-11,1$ & $-3,1$ & $-0,8$ & 3,8 & 10,2 & 9,8 & 9,6 & 6,7 & 6,9 & $-2,2$ & $-4,6$ & 1,7 \\
\hline 1966 & $-7,5$ & 0,0 & $-3,3$ & 2,8 & 5,4 & 10,2 & 9,7 & 9,7 & 10,8 & 5,9 & $-4,8$ & $-5,8$ & 2,8 \\
\hline 1967 & $-6,3$ & $-4,7$ & $-1,2$ & $-0,1$ & 5,5 & 7,6 & 12,6 & 11,1 & 8,1 & 7,3 & 0,4 & $-7,3$ & 2,8 \\
\hline 1968 & $-8,4$ & $-4,0$ & $-3,0$ & 2,3 & 4,8 & 8,4 & 9,9 & 8,8 & 7,2 & 6,5 & $-0,1$ & $-6,2$ & 2,2 \\
\hline 1969 & $-5,9$ & $-8,8$ & $-3,4$ & $-0,1$ & 7,0 & 7,0 & 11,4 & 9,0 & 9,4 & 7,2 & $-1,2$ & $-9,8$ & 1,8 \\
\hline 1970 & $-5,3$ & $-7,2$ & $-6,0$ & $-1,8$ & 3,2 & 10,1 & 10,6 & 10,4 & 9,5 & 4,0 & 0,9 & $-5,8$ & 1,9 \\
\hline 1971 & $-4,9$ & $-5,8$ & $-6,8$ & 3,0 & 6,9 & 7,5 & 11,9 & 13,0 & 6,8 & 5,8 & $-2,0$ & $-1,4$ & 2,8 \\
\hline 1972 & $-5,1$ & $-2,3$ & 0,2 & 0,2 & 4,4 & 7,9 & 9,8 & 10,1 & 4,5 & 2,7 & $-0,7$ & $-1,9$ & 2,5 \\
\hline 1973 & $-3,8$ & $-6,6$ & $-3,8$ & $-2,5$ & 6,3 & 9,7 & 9,8 & 12,7 & 8,8 & 3,5 & $-1,3$ & $-5,2$ & 2,3 \\
\hline 1974 & $-2,1$ & $-3,5$ & $-0,8$ & 0,3 & 4,2 & 7,1 & 10,4 & 11,9 & 7,9 & $-2,8$ & $-2,4$ & $-3,0$ & 2,3 \\
\hline 1975 & $-2,4$ & $-3,6$ & $-3,0$ & 0,6 & 5,6 & 7,1 & 10,9 & 10,5 & 10,5 & 3,4 & $-1,7$ & $-3,2$ & 2,9 \\
\hline 1976 & $-5,2$ & $-2,5$ & $-3,6$ & 0,9 & 6,2 & 9,9 & 11,1 & 8,1 & 5,7 & 5,8 & $-2,5$ & $-6,8$ & 2,3 \\
\hline 1977 & $-5,2$ & $-3,6$ & 1,1 & $-0,4$ & 4,9 & 8,5 & 10,5 & 9,1 & 6,7 & 6,9 & $-2,0$ & $-2,4$ & 2,8 \\
\hline 1978 & $-5,1$ & $-4,8$ & $-2,3$ & $-0,7$ & 3,3 & 7,6 & 9,8 & 9,7 & 7,4 & 4,5 & 1,4 & $-2,7$ & 2,3 \\
\hline 1979 & $-7,9$ & $-4,0$ & $-1,7$ & $-1,5$ & 4,7 & 9,1 & 9,6 & 9,6 & 8,1 & 6,2 & $-2,5$ & $-3,0$ & 2,2 \\
\hline 1980 & $-7,0$ & $-3,3$ & $-2,3$ & $-2,4$ & 3,5 & 7,0 & 9,3 & 12,3 & 9,4 & 2,9 & $-1,2$ & $-6,2$ & 1,8 \\
\hline 1981 & $-8,2$ & $-6,4$ & 0,3 & 2,9 & 5,1 & 9,2 & 9,6 & 11,2 & 8,3 & 3,2 & $-2,5$ & $-7,0$ & 2,1 \\
\hline 1982 & $-3,6$ & $-4,5$ & $-3,3$ & $-0,5$ & 5,9 & 10,1 & 12,4 & 10,8 & 10,9 & 4,3 & 1,1 & $-4,1$ & 3,3 \\
\hline 1983 & $-2,1$ & $-7,4$ & $-0,8$ & 1,7 & 4,4 & 9,6 & 14,8 & 11,3 & 9,0 & 5,2 & 0,8 & $-3,8$ & 3,6 \\
\hline 1984 & $-6,0$ & $-7,6$ & $-4,8$ & $-0,9$ & 3,1 & 7,9 & 10,9 & 10,3 & 6,3 & 5,3 & 2,6 & $-3,1$ & 2,0 \\
\hline 1985 & $-9,5$ & $-4,8$ & $-3,5$ & 0,4 & 5,8 & 7,4 & 12,9 & 10,8 & 10,2 & 5,9 & $-4,0$ & $-1,5$ & 2,5 \\
\hline 1986 & $-6,8$ & $-9,1$ & $-1,5$ & 0,2 & 8,0 & 8,9 & 10,6 & 11,3 & 9,1 & 6,3 & 0,8 & $-4,2$ & 2,8 \\
\hline
\end{tabular}




\begin{tabular}{|c|c|c|c|c|c|c|c|c|c|c|c|c|c|}
\hline \multicolumn{14}{|c|}{ Temperaturmonatsmittel in ${ }^{\circ} \mathrm{C}$} \\
\hline 1987 & $-6,9$ & $-3,3$ & $-6,5$ & 1,4 & 2,7 & 7,7 & 12,1 & 10,8 & 11,3 & 6,4 & $-0,7$ & $-1,6$ & 2,8 \\
\hline 1988 & $-2,6$ & $-5,4$ & $-4,7$ & 2,4 & 7,3 & 8,0 & 12,1 & 11,6 & 8,4 & 6,9 & $-1,8$ & $-3,8$ & 3,2 \\
\hline 1989 & $-0,8$ & $-0,7$ & 1,2 & 1,0 & 5,9 & 7,0 & 11,1 & 11,0 & 7,8 & 5,6 & $-1,0$ & $-1,2$ & 3,9 \\
\hline 1990 & $-2,6$ & $-0,4$ & 0,5 & 0,0 & 6,9 & 8,7 & 11,7 & 12,1 & 7,0 & 6,6 & $-2,1$ & $-7,2$ & 3,4 \\
\hline 1991 & $-3,3$ & $-6,4$ & 1,2 & $-0,3$ & 1,5 & 8,3 & 13,0 & 12,5 & 10,3 & 3,8 & $-1,1$ & $-4,7$ & 2,9 \\
\hline 1992 & $-3,1$ & $-3,7$ & $-1,8$ & 0,7 & 7,3 & 8,7 & 12,3 & 14,4 & 8,8 & 1,9 & 0,7 & $-3,2$ & 3,6 \\
\hline 1993 & $-2,3$ & $-3,9$ & $-3,2$ & 1,9 & 7,6 & 9,7 & 10,2 & 11,8 & 7,0 & 4,0 & $-2,4$ & $-3,2$ & 3,1 \\
\hline 1994 & $-3,9$ & $-4,6$ & 2,0 & 0,0 & 6,6 & 9,7 & 14,1 & 13,1 & 8,8 & 4,4 & 2,6 & $-1,8$ & 4,3 \\
\hline 1995 & $-7,2$ & $-1,9$ & $-4,1$ & 1,5 & 5,8 & 7,1 & 14,0 & 10,2 & 5,7 & 8,6 & $-1,9$ & $-4,4$ & 2,8 \\
\hline 1996 & $-2,1$ & $-6,9$ & $-3,8$ & 1,8 & 6,1 & 10,5 & 10,6 & 10,0 & 4,8 & 3,5 & $-1,4$ & $-3,7$ & 2,5 \\
\hline 1997 & $-2,0$ & $-1,8$ & 0,2 & $-1,1$ & 6,0 & 9,0 & 9,9 & 12,2 & 10,6 & 4,5 & 0,0 & $-3,3$ & 3,7 \\
\hline 1998 & $-3,7$ & 0,4 & $-2,6$ & 1,2 & 6,5 & 10,3 & 12,1 & 12,4 & 7,5 & 3,4 & $-4,3$ & $-4,6$ & 3,2 \\
\hline 1999 & $-3,0$ & $-7,5$ & $-1,6$ & 1,3 & 7,6 & 8,3 & 11,9 & 11,6 & 10,2 & 5,0 & $-3,2$ & $-5,2$ & 3,0 \\
\hline 2000 & $-5,7$ & $-3,7$ & $-1,8$ & 2,1 & 7,9 & 10,9 & 9,4 & 12,6 & 8,8 & 5,2 & $-1,0$ & $-2,1$ & 3,6 \\
\hline 2001 & $-4,8$ & $-4,5$ & 0,6 & $-0,6$ & 8,3 & 8,1 & 11,9 & 13,1 & 4,7 & 8,3 & $-1,6$ & $-7,5$ & 3,0 \\
\hline 2002 & $-3,6$ & $-1,2$ & 0,0 & 1,0 & 6,9 & 12,1 & 11,8 & 11,0 & 6,0 & 4,4 & 0,4 & $-3,1$ & 3,8 \\
\hline 2003 & $-6,6$ & $-7,1$ & $-0,5$ & 0,8 & 8,4 & 14,2 & 12,7 & 15,2 & 7,8 & 0,9 & 1,2 & $-3,1$ & 3,7 \\
\hline 2004 & $-7,3$ & $-4,6$ & $-3,0$ & 1,2 & 4,2 & 8,9 & 10,7 & 12,0 & 8,3 & 6,2 & $-1,2$ & $-3,3$ & 2,7 \\
\hline 2005 & $-6,6$ & $-9,3$ & $-2,4$ & 1,6 & 6,8 & 10,4 & 11,3 & 9,3 & 8,9 & 7,1 & $-1,7$ & $-7,8$ & 2,3 \\
\hline 2006 & $-6,0$ & $-5,7$ & $-3,9$ & 2,1 & 6,3 & 10,6 & 14,8 & 8,3 & 11,3 & 7,8 & 1,0 & $-1,1$ & 3,8 \\
\hline 2007 & $-1,6$ & $-1,4$ & $-1,1$ & 6,1 & 7,7 & 11,0 & 11,9 & 11,0 & 6,2 & 3,7 & $-2,6$ & $-4,6$ & 3,9 \\
\hline 2008 & $-2,8$ & $-1,6$ & $-3,1$ & 0,5 & 7,3 & 11,0 & 11,3 & 12,1 & 7,1 & 5,6 & $-0,9$ & $-4,5$ & 3,5 \\
\hline 2009 & $-6,1$ & $-6,3$ & $-3,1$ & 3,6 & 8,6 & 9,4 & 12,1 & 13,6 & 9,6 & 3,7 & 0,8 & $-6,4$ & 3,3 \\
\hline 2010 & $-7,3$ & $-5,9$ & $-2,9$ & 2,2 & 5,0 & 9,8 & 13,5 & 10,8 & 6,9 & 3,2 & $-1,2$ & $-7,3$ & 2,2 \\
\hline 2011 & $-5,0$ & $-2,6$ & $-0,5$ & 4,3 & 8,0 & 10,0 & 9,7 & 13,1 & 10,2 & 4,6 & 3,9 & $-3,4$ & 4,4 \\
\hline Mittel & $-5,3$ & $-4,8$ & $-2,1$ & 0,9 & 5,7 & 9,0 & 11,2 & 11,0 & 8,3 & 4,7 & $-1,0$ & $-4,4$ & 2,8 \\
\hline
\end{tabular}

Die absoluten Minima haben im Winter an allen drei Stationen eine starke Varianz, die damit erklärt werden kann, dass die extrem kalten Luftmassen von Russland und Ukraine nur sehr selten mit Ostwinden nach Tirol kommen, damit im Winter nur in wenigen Jahren starke Abkühlung bringen, im Sommer aber unauffällig bleiben, weil ihr Ursprungsgebiet dann ähnliche Temperaturen wie die Alpen hat.
Die Schwankungen der Winterminima scheinen an den drei Stationen Obergurgl, Vent und Innsbruck von ähnlicher Größe zu sein, es fällt aber auf, dass Obergurgl und Vent Anfang März eine positive Spitze in ihren absoluten Minima haben, die in Innsbruck nicht vorkommt, die aber in den beiden Ötztaler Stationen selbst im mittleren Maximum bemerkbar ist. Andererseits treten die „Eisheiligen" Mitte Mai in den drei Stationen nicht 

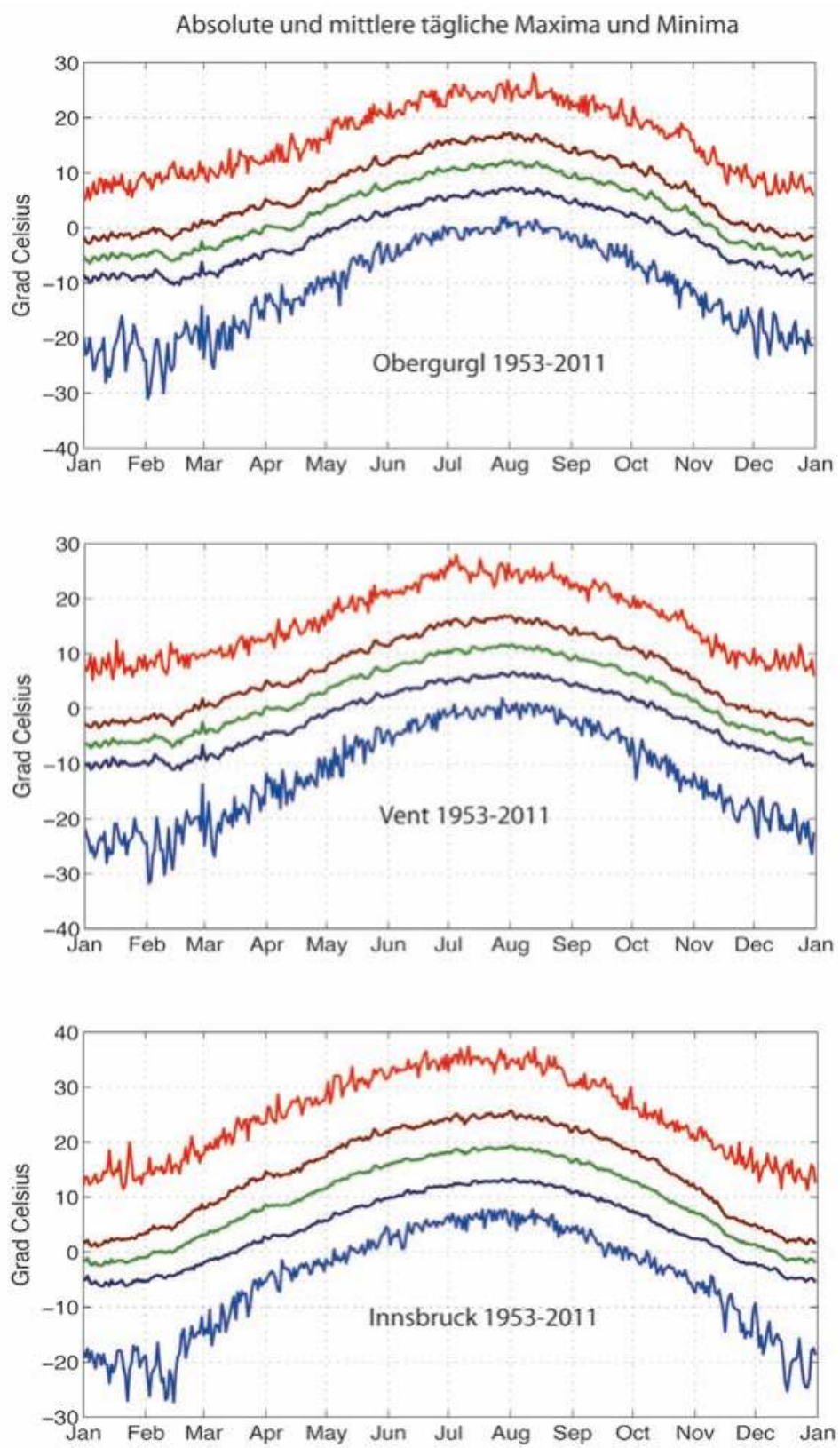

Abb. 6: Absolute und mittlere tägliche Maxima und Minima und Mittelwerte der Temperatur (Tmax+Tmin)/2 der Stationen Obergurgl (1938 m), Vent (1890 m) und Innsbruck (580 m) über die Periode 1953-2011 
in Erscheinung. Positive Abweichungen der Temperatur Ende Mai sind in Obergurgl und Vent auffällig.

\section{Trends in der Temperatur, Vergleich mit anderen Stationen}

Bei der Analyse der Trends in den Temperaturreihen wurde Wert darauf gelegt, kurzfristige Schwankungen auszuschließen. Die einzelnen Jahresmitteltemperaturen wurden daher in zehnjährig übergreifende oder gleitende Mittel zusammengefasst: Mittel 1953 bis 1962, Mittel 1954 bis 1963 usw. In Abb. 7 wurde das Jahresmittel mit den Monaten Januar bis Dezember berechnet, das Sommermittel mit den Monaten April bis September und das Wintermittel von Oktober bis März. Die Jahresmittel (Januar bis Dezember) von Obergurgl in Abb. 7 haben einen ganz ähnlichen linearen Trend wie die Halbjahresmittel (April bis September bzw. Oktober bis März), die Steigungen der Geraden unterscheiden sich nicht signifikant. Im Verlauf der geglätteten Mittelwerte der drei Perioden gibt es dagegen deutliche Unterschiede: Jahreswerte scheinen von einem tiefen Niveau in den Achtzigerjahren auf ein höheres anzusteigen, Sommerwerte steigen seit dem Dekadenmittel 1972-81 fast kontinuierlich an, Winterwerte steigen mit Unterbrechungen bis $1987-$ 96 an und fallen bis $2001-2010$ um fast $1^{\circ} \mathrm{C}$ ab. Dabei muss man berücksichtigen, dass die Extremwerte von zehnjährig geglätteten Mit- teln nicht immer mit den Extremwerten der Einzeljahre übereinstimmen. Die jahreszeitlichen Trends sind in Obergurgl und Vent sehr ähnlich, in Innsbruck haben sie einen glatteren Verlauf, dort ist die Abnahme der Wintertemperaturen im letzten Jahrzehnt schwächer (Institute of Meteorology and Geophysics 2013d).

Abb. 8 zeigt die Abweichung der gleitenden Dekadenmittel der Lufttemperatur vom langfristigen Mittel für das Jahr, den Sommer und den Winter. Dass hier die Jahreshälften eine größere Amplitude haben als das Jahr, ist statistisch zu erwarten.

Die kühlen Sommer der 1960er und 70er Jahre waren zugleich niederschlagsreich. Zusammen mit milden, schneereichen Wintern waren das Bedingungen, in denen die Ötztaler Gletscher so wie die meisten Alpengletscher anwachsen und vorstoßen konnten. Die darauf folgende Erwärmung hat diesen Vorstoß schon lange aufgezehrt.

Der Trend der Temperaturen kommt auch in den ungeglätteten Dekadenmitteln (Tab. 3) zum Ausdruck. Hier liegen die Temperaturen der letzten Dekade durchwegs über denen der ersten. Das Jahresmittel ist von der ersten zur vierten in Obergurgl um $1,0{ }^{\circ} \mathrm{C}$, in Vent um $1,1^{\circ} \mathrm{C}$ und in Innsbruck um $1,3{ }^{\circ} \mathrm{C}$ gestiegen.

Die Differenzen zwischen dem wärmsten und dem kältesten Monat sind in Innsbruck deutlich größer als an den besser durchlüfteten Höhenstationen Obergurgl und Vent. Bei den Gipfelstationen Sonnblick, Zugspitze und Patscherkofel (Abb. 9) sind diese Differenzen nur noch ca. $13{ }^{\circ} \mathrm{C}$. 
Kapitel 1 I Temperatur und Niederschlag an der Wetterstation Obergurgl, 1953-2011
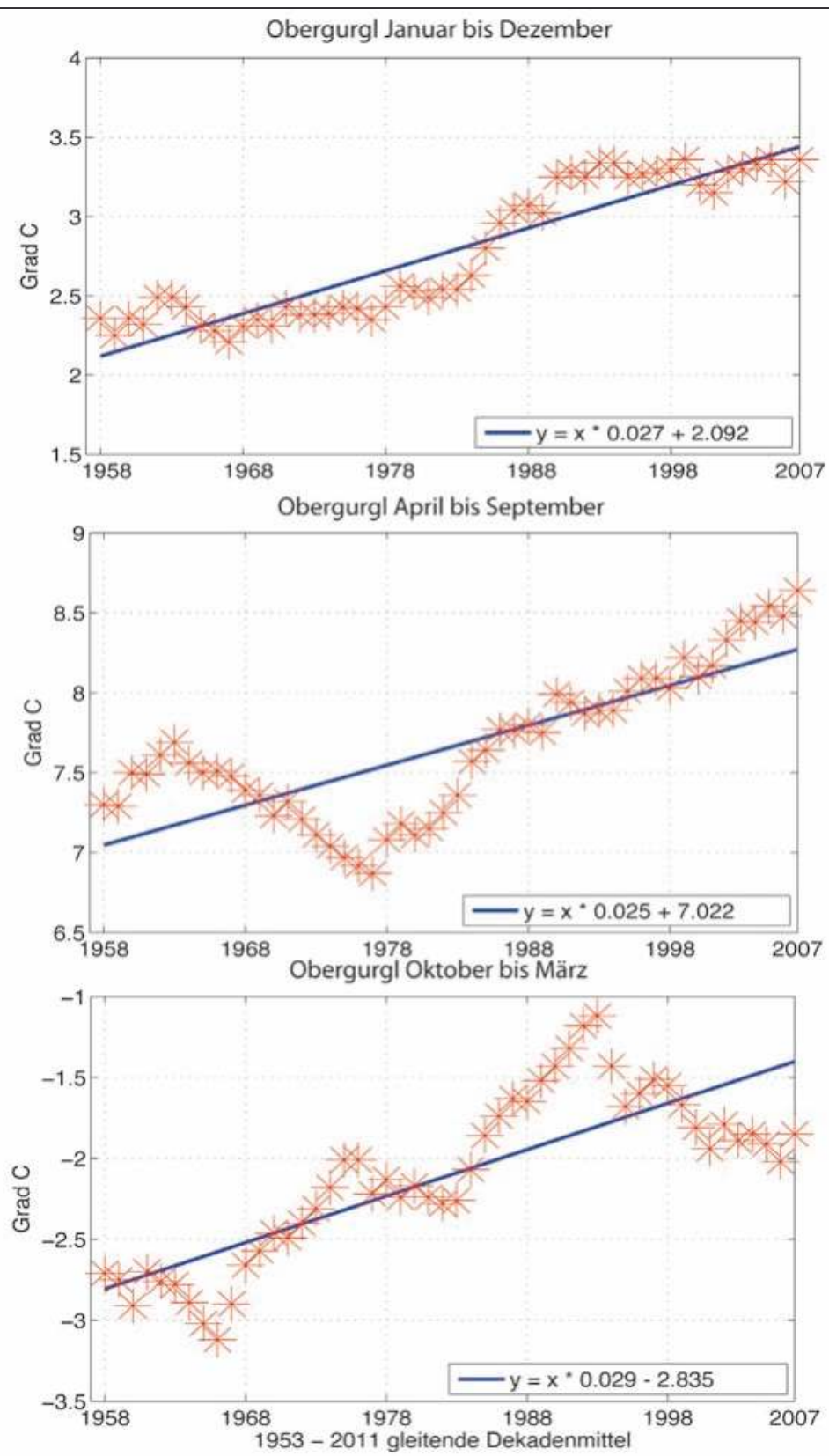

Abb. 7: Trend der Temperaturen (Tmax+Tmin)/2 der Station Obergurgl mit zehnjährig übergreifenden Mitteln (rote Kreuze) und dem linearen Trend (schwarze Linie). Der Wert 1958 gilt für das Mittel 1953-1962, der Wert 2007 für das Mittel 2002-2011. Sommerhalbjahr April-September, Winterhalbjahr Oktober-März 


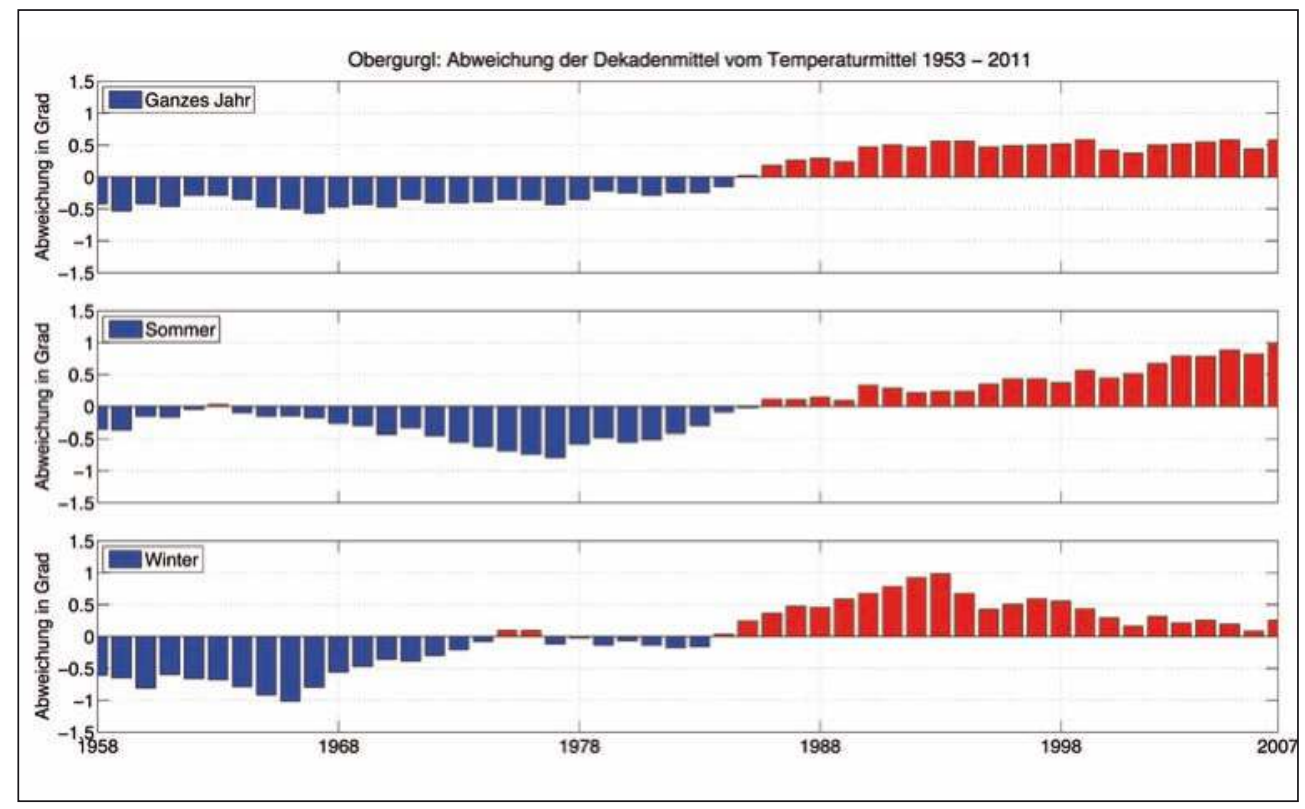

Abb. 8: Abweichung der gleitenden Dekadenmittel 1953-62 bis 2002-2011 von der Mitteltemperatur der Periode 1953-2011. Der Wert 1958 gilt für das Mittel 1953-1962, der Wert 2007 für das Mittel 20022011. Es lässt sich keine wesentlich andere Aussage als in Abb. 7 machen. Hier wird aber deutlich, dass die Kombination von milden (schneereichen) Wintern mit kühlen (niederschlagsreichen) Sommern Ende der 60er, Anfang der 70er Jahre die Gletscher der Ötztaler Alpen anwachsen ließ und danach dort ein starker Gletscherrückgang eintrat

\section{Niederschlag}

Tab. 4 zeigt die Monats- und Jahressummen des Niederschlags von Obergurgl. Im Vergleich zur Temperatur, die in den Alpen homogen verteilt ist, ist der Niederschlag zeitlich und räumlich sehr variabel. Obergurgls geringster Jahresniederschlag war $564 \mathrm{~mm}$ im Jahr 1976, der höchste war 1242 mm im Jahr 2002; zweimal hat es Monatssummen über $300 \mathrm{~mm}$ gegeben (Mai 1983, November 2002), einmal nur $1 \mathrm{~mm}$ (Oktober 1995). Die im langjährigen Mittel trockensten Mo- nate sind Januar und Februar, die geringsten Einzelwerte hat der Oktober.

Wenn sich bei Südföhn Wolken am Alpenhauptkamm stauen, hängen sie oft so weit über den Kamm nach Norden, dass sie das Gebiet von Obergurgl mit Niederschlag versorgen. Vent im Nachbartal ist gerade außerhalb dieser Stauzone, sodass es trockener bleibt (Abb. 2 und 10). Abb. 10 zeigt auch, dass es gerade die föhnreichsten Monate (März, April, Oktober, November) sind, in denen Obergurgl deutlich mehr Schnee und Regen bekommt als Vent. 
Kapitel 1 I Temperatur und Niederschlag an der Wetterstation Obergurgl, 1953-2011

Tab. 3: Monatsmittel der Temperatur der Station Obergurgl für 4 Dekaden in ${ }^{\circ} \mathrm{C}$ und Vergleich der Daten von Obergurgl, Vent und Innsbruck. Delta T entspricht der Differenz zwischen dem wärmsten und dem kältesten Monat

\begin{tabular}{|c|c|c|c|c|c|c|c|c|c|c|c|c|}
\hline \multicolumn{13}{|l|}{ Obergurgl } \\
\hline$(\operatorname{Tmin}+\operatorname{Tmax}) / 2$ & Jan. & Feb. & März & Apr. & Mai & Juni & Juli & Aug. & Sep. & Okt. & Nov. & Dez. \\
\hline $1972-1981$ & $-5,2$ & $-4,1$ & $-1,6$ & $-0,3$ & 4,8 & 8,3 & 10,1 & 10,5 & 7,7 & 3,6 & $-1,5$ & $-4,1$ \\
\hline 1982-1991 & $-4,4$ & $-5,0$ & $-2,2$ & 0,5 & 5,2 & 8,4 & 12,2 & 11,3 & 9,0 & 5,6 & $-0,5$ & $-3,5$ \\
\hline $1992-2001$ & $-3,8$ & $-3,8$ & $-1,6$ & 0,9 & 7,0 & 9,2 & 11,6 & 12,1 & 7,7 & 4,9 & $-1,3$ & $-3,9$ \\
\hline 2002-2011 & $-5,3$ & $-4,6$ & $-2,1$ & 2,4 & 6,9 & 10,8 & 12,0 & 11,6 & 8,2 & 4,7 & 0,0 & $-4,5$ \\
\hline \multirow[t]{2}{*}{$1972-2011$} & $-4,7$ & $-4,4$ & $-1,9$ & 0,9 & 6,0 & 9,2 & 11,5 & 11,4 & 8,2 & 4,7 & $-0,8$ & $-4,0$ \\
\hline & & \multicolumn{4}{|c|}{ Obergurgl } & \multicolumn{3}{|c|}{ Vent } & \multicolumn{4}{|c|}{ Innsbruck } \\
\hline \multicolumn{2}{|c|}{$(\operatorname{Tmin}+\operatorname{Tmax}) / 2$} & \multicolumn{2}{|c|}{ Jahr } & \multicolumn{2}{|l|}{ Delta T } & Jahr & \multicolumn{2}{|r|}{ Delta T } & \multicolumn{2}{|r|}{ Jahr } & \multicolumn{2}{|c|}{ Delta T } \\
\hline \multicolumn{2}{|l|}{$1972-1981$} & \multicolumn{2}{|c|}{2,4} & \multicolumn{2}{|l|}{15,7} & 1,9 & \multicolumn{2}{|r|}{16,3} & \multicolumn{2}{|r|}{9,4} & \multicolumn{2}{|c|}{18,3} \\
\hline \multicolumn{2}{|l|}{ 1982-1991 } & \multicolumn{2}{|c|}{3,0} & \multicolumn{2}{|l|}{17,1} & 2,5 & \multicolumn{2}{|r|}{17,7} & \multicolumn{2}{|r|}{9,8} & \multicolumn{2}{|c|}{18,7} \\
\hline \multicolumn{2}{|l|}{$1992-2001$} & \multicolumn{2}{|c|}{3,3} & \multicolumn{2}{|l|}{16,0} & 2,8 & \multicolumn{2}{|r|}{16,5} & \multicolumn{2}{|r|}{10,4} & \multicolumn{2}{|c|}{17,0} \\
\hline \multicolumn{2}{|l|}{ 2002-2011 } & \multicolumn{2}{|l|}{3,4} & \multicolumn{2}{|l|}{17,3} & 3,0 & \multicolumn{2}{|r|}{17,9} & \multicolumn{2}{|r|}{10,7} & \multicolumn{2}{|c|}{20,7} \\
\hline \multicolumn{2}{|l|}{$1972-2011$} & 3,0 & & 16,1 & & 2,6 & & 16,8 & & 10,1 & & 9,4 \\
\hline
\end{tabular}

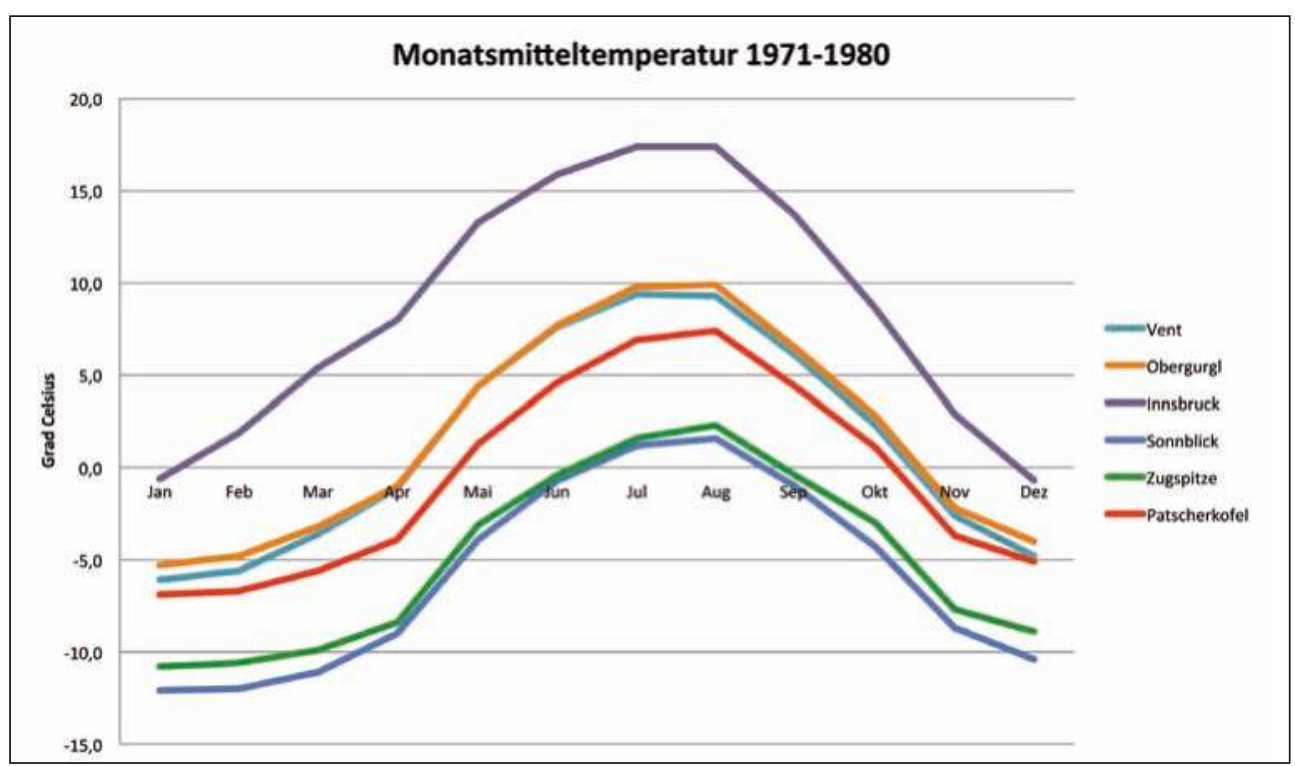

Abb. 9: Mittlerer Jahresgang der Temperatur an Stationen in verschiedener Höhenlage. Für diese Stationen waren nur die Klimamittel (T7+T19+Tmin+Tax)/4 verfügbar (s. Tab. 1) 
M. Kuhn, E. Dreiseitl, M. Emprechtinger

Tab. 4: Monats- und Jahressummen des Niederschlags von Obergurgl

\begin{tabular}{|c|c|c|c|c|c|c|c|c|c|c|c|c|c|}
\hline \multicolumn{14}{|c|}{ Niederschlag Obergurgl in $\mathrm{mm}$} \\
\hline $\mathrm{JZ}$ & JAN & FEB & MAR & APR & MAI & JUN & JUL & AUG & SEP & OKT & $\mathrm{NOV}$ & DEZ & JAHR \\
\hline 1953 & 20 & 9 & 9 & 77 & 33 & 84 & 117 & 94 & 46 & 123 & 4 & 27 & 643 \\
\hline 1954 & 51 & 18 & 21 & 42 & 89 & 105 & 110 & 134 & 68 & 23 & 9 & 135 & 805 \\
\hline 1955 & 17 & 55 & 23 & 40 & 51 & 61 & 87 & 59 & 92 & 23 & 31 & 47 & 586 \\
\hline 1956 & 47 & 14 & 76 & 55 & 76 & 134 & 104 & 117 & 124 & 104 & 40 & 14 & 905 \\
\hline 1957 & 35 & 79 & 21 & 55 & 66 & 141 & 143 & 128 & 67 & 24 & 85 & 29 & 873 \\
\hline 1958 & 62 & 91 & 48 & 99 & 65 & 124 & 120 & 97 & 54 & 126 & 61 & 142 & 1089 \\
\hline 1959 & 38 & 15 & 56 & 78 & 86 & 92 & 77 & 51 & 11 & 90 & 71 & 99 & 764 \\
\hline 1960 & 67 & 49 & 83 & 61 & 36 & 83 & 110 & 113 & 256 & 188 & 84 & 96 & 1226 \\
\hline 1961 & 26 & 119 & 26 & 41 & 116 & 80 & 104 & 70 & 16 & 87 & 74 & 76 & 835 \\
\hline 1962 & 98 & 79 & 67 & 107 & 135 & 45 & 85 & 86 & 78 & 26 & 101 & 92 & 999 \\
\hline 1963 & 50 & 33 & 110 & 64 & 71 & 95 & 83 & 155 & 67 & 22 & 89 & 35 & 874 \\
\hline 1964 & 19 & 43 & 104 & 49 & 53 & 117 & 86 & 120 & 34 & 128 & 82 & 73 & 908 \\
\hline 1965 & 31 & 16 & 60 & 63 & 161 & 109 & 125 & 84 & 191 & 2 & 65 & 89 & 996 \\
\hline 1966 & 34 & 52 & 61 & 47 & 94 & 97 & 131 & 220 & 48 & 77 & 176 & 83 & 1120 \\
\hline 1967 & 59 & 60 & 73 & 67 & 79 & 103 & 69 & 110 & 82 & 31 & 56 & 26 & 815 \\
\hline 1968 & 105 & 14 & 34 & 47 & 70 & 113 & 101 & 101 & 66 & 24 & 137 & 38 & 850 \\
\hline 1969 & 58 & 40 & 37 & 41 & 64 & 107 & 74 & 93 & 33 & 2 & 55 & 28 & 632 \\
\hline 1970 & 24 & 140 & 82 & 76 & 41 & 45 & 61 & 194 & 63 & 58 & 45 & 29 & 858 \\
\hline 1971 & 30 & 58 & 64 & 34 & 78 & 82 & 65 & 73 & 39 & 5 & 94 & 41 & 663 \\
\hline 1972 & 28 & 32 & 14 & 115 & 66 & 119 & 165 & 55 & 38 & 62 & 61 & 14 & 769 \\
\hline 1973 & 44 & 27 & 41 & 52 & 60 & 79 & 88 & 79 & 76 & 85 & 81 & 76 & 788 \\
\hline 1974 & 46 & 29 & 75 & 58 & 55 & 67 & 70 & 111 & 71 & 44 & 72 & 80 & 778 \\
\hline 1975 & 66 & 9 & 111 & 78 & 94 & 69 & 103 & 156 & 68 & 51 & 105 & 15 & 925 \\
\hline 1976 & 46 & 17 & 7 & 29 & 60 & 16 & 110 & 36 & 52 & 137 & 26 & 28 & 564 \\
\hline 1977 & 104 & 74 & 59 & 114 & 133 & 88 & 81 & 101 & 25 & 26 & 30 & 34 & 869 \\
\hline 1978 & 54 & 36 & 60 & 24 & 95 & 64 & 91 & 67 & 61 & 75 & 17 & 27 & 671 \\
\hline 1979 & 32 & 47 & 134 & 76 & 74 & 125 & 58 & 102 & 153 & 39 & 142 & 119 & 1101 \\
\hline 1980 & 30 & 38 & 49 & 26 & 64 & 87 & 75 & 38 & 21 & 178 & 48 & 57 & 711 \\
\hline 1981 & 114 & 19 & 123 & 25 & 141 & 78 & 169 & 64 & 145 & 138 & 53 & 91 & 1160 \\
\hline 1982 & 111 & 8 & 32 & 11 & 48 & 103 & 105 & 137 & 33 & 80 & 42 & 49 & 759 \\
\hline 1983 & 81 & 20 & 41 & 60 & 311 & 46 & 38 & 79 & 59 & 29 & 61 & 61 & 886 \\
\hline 1984 & 32 & 106 & 30 & 62 & 115 & 72 & 27 & 67 & 141 & 78 & 26 & 39 & 795 \\
\hline 1985 & 59 & 38 & 50 & 68 & 98 & 103 & 90 & 181 & 35 & 22 & 50 & 33 & 827 \\
\hline 1986 & 182 & 37 & 34 & 106 & 100 & 76 & 73 & 121 & 38 & 31 & 16 & 70 & 884 \\
\hline
\end{tabular}


Kapitel 1 | Temperatur und Niederschlag an der Wetterstation Obergurgl, 1953-2011

\begin{tabular}{|c|c|c|c|c|c|c|c|c|c|c|c|c|c|}
\hline \multicolumn{14}{|c|}{ Niederschlag Obergurgl in $\mathrm{mm}$} \\
\hline 1987 & 50 & 119 & 55 & 49 & 113 & 92 & 85 & 144 & 48 & 55 & 89 & 46 & 945 \\
\hline 1988 & 34 & 39 & 99 & 18 & 72 & 107 & 82 & 129 & 40 & 71 & 28 & 100 & 819 \\
\hline 1989 & 14 & 67 & 26 & 146 & 37 & 111 & 150 & 63 & 53 & 14 & 53 & 53 & 787 \\
\hline 1990 & 13 & 136 & 42 & 62 & 42 & 122 & 68 & 40 & 43 & 82 & 71 & 59 & 780 \\
\hline 1991 & 33 & 18 & 37 & 44 & 116 & 96 & 100 & 26 & 49 & 60 & 56 & 114 & 749 \\
\hline 1992 & 8 & 39 & 133 & 68 & 17 & 139 & 103 & 63 & 36 & 127 & 111 & 66 & 910 \\
\hline 1993 & 33 & 29 & 37 & 84 & 65 & 76 & 119 & 84 & 79 & 204 & 25 & 79 & 914 \\
\hline 1994 & 90 & 28 & 36 & 69 & 86 & 71 & 85 & 77 & 94 & 22 & 70 & 48 & 776 \\
\hline 1995 & 92 & 39 & 67 & 58 & 61 & 123 & 126 & 105 & 87 & 1 & 44 & 74 & 877 \\
\hline 1996 & 21 & 23 & 41 & 41 & 104 & 81 & 92 & 144 & 41 & 166 & 171 & 18 & 943 \\
\hline 1997 & 12 & 37 & 46 & 60 & 55 & 150 & 81 & 67 & 23 & 62 & 90 & 65 & 748 \\
\hline 1998 & 32 & 12 & 44 & 123 & 30 & 119 & 119 & 77 & 94 & 137 & 57 & 32 & 876 \\
\hline 1999 & 46 & 136 & 67 & 62 & 141 & 110 & 76 & 97 & 135 & 49 & 93 & 63 & 1075 \\
\hline 2000 & 43 & 64 & 137 & 61 & 50 & 97 & 140 & 117 & 103 & 180 & 201 & 21 & 1214 \\
\hline 2001 & 35 & 0 & 79 & 85 & 24 & 138 & 119 & 108 & 67 & 35 & 69 & 44 & 803 \\
\hline 2002 & 10 & 58 & 89 & 62 & 176 & 97 & 95 & 124 & 98 & 43 & 335 & 55 & 1242 \\
\hline 2003 & 55 & 14 & 7 & 32 & 59 & 61 & 90 & 94 & 23 & 163 & 89 & 122 & 809 \\
\hline 2004 & 81 & 64 & 48 & 59 & 67 & 73 & 96 & 54 & 67 & 80 & 61 & 38 & 788 \\
\hline 2005 & 63 & 49 & 23 & 61 & 50 & 38 & 99 & 171 & 66 & 97 & 42 & 75 & 834 \\
\hline 2006 & 31 & 61 & 54 & 59 & 96 & 74 & 83 & 102 & 43 & 65 & 29 & 32 & 729 \\
\hline 2007 & 56 & 42 & 72 & 10 & 101 & 83 & 76 & 158 & 94 & 19 & 82 & 28 & 821 \\
\hline 2008 & 62 & 8 & 48 & 81 & 88 & 93 & 157 & 76 & 71 & 59 & 125 & 95 & 963 \\
\hline 2009 & 27 & 71 & 100 & 53 & 21 & 66 & 125 & 84 & 51 & 33 & 103 & 72 & 806 \\
\hline 2010 & 25 & 30 & 38 & 21 & 125 & 92 & 51 & 232 & 97 & 83 & 121 & 80 & 995 \\
\hline 2011 & 25 & 31 & 37 & 8 & 54 & 119 & 84 & 86 & 123 & 76 & 13 & 110 & 766 \\
\hline Mittel & 48 & 46 & 56 & 59 & 80 & 91 & 95 & 100 & 70 & 70 & 74 & 60 & 848 \\
\hline
\end{tabular}

Der Vergleich der Monatssummen verschiedener Höhenstationen in Abb. 10 zeigt, dass, anders als bei der Temperatur, selbst die Dekadenmittel verschiedene Größe und verschiedenen zeitlichen Verlauf haben. Auch wenn Niederschlagsmessungen auf Gipfeln aerodynamisch gestört sind, stimmen die Größenordnungen der Werte von Zugspitze und Sonnblick. Sie sind so hoch, weil die
Stationen nicht durch höhere Gipfel abgeschirmt sind (Fliri 1975). Der Patscherkofel bei Innsbruck wird im Norden und Süden von höheren Gebirgsketten abgeschirmt, sodass sich sein Niederschlag kaum von dem der Stadt unterscheidet. Diese Unterschiede im Niederschlag sind höher als die erwähnten Messfehler von Gipfelstationen. 


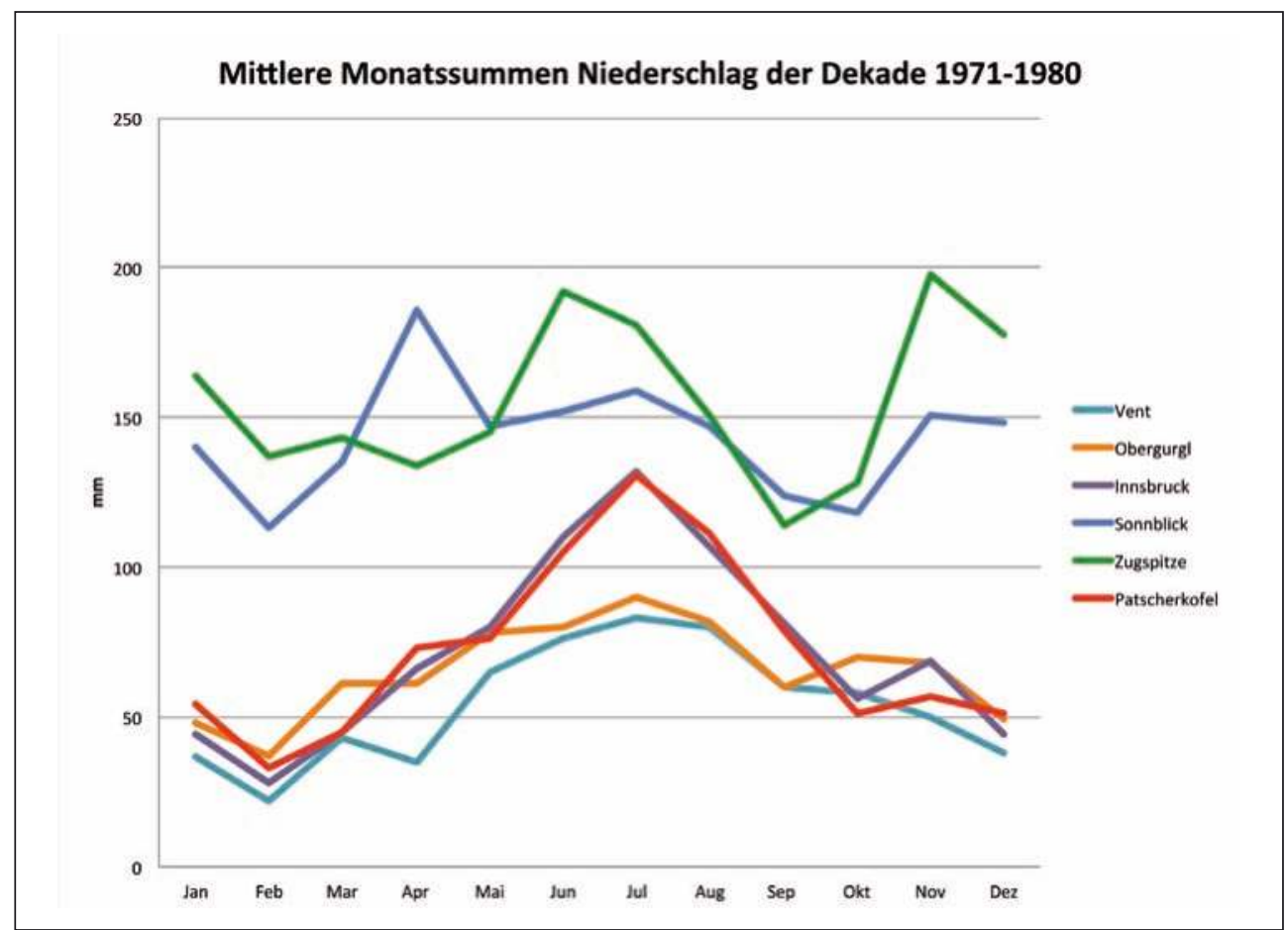

Abb. 10: Mittlere Monatssummen des Niederschlags von Obergurgl (1971-80) im Vergleich zu anderen Höhenstationen

\section{Höhengradienten des Niederschlags und der Temperatur}

Das Klima der Alpen, ausgedrückt z.B. durch Temperatur und Niederschlag, ist im lokalen Maßstab $(<1 \mathrm{~km})$ keine lineare Funktion der Höhe, des Abstands vom Alpenrand, oder der Exposition, hier ist die lokale Topographie mit ihrem Einfluss auf den Wind und die Strahlungsbilanz wichtiger als die Höhe. In einem regionalen Maßstab von 10-100 km kann aber die Abhängigkeit von der Höhe, der Exposition (N/S) oder von der Vegetati- on einheitlich sein. Den Einfluss des Abstands vom Alpenrand, der Abschirmung durch höhere Berge und den der Höhe hat Fliri (1975) ausführlich erklärt und belegt.

Wetterstationen und Totalisatorenmessungen in der weiteren Umgebung von Obergurgl zeigen in den tieferen, abgeschirmten Tälern keine Zunahme des Niederschlags mit der Höhe. Erst ab etwa 1800 m Höhe nimmt der Niederschlag bis zu den höchsten Messpunkten zu (Abb. 11). In diesem Bereich ist die $\mathrm{Zu}$ nahme in den vier Tälern ähnlich, rund 100 mm Jahresniederschlag pro 100 m Seehöhe. Aus meteorologischer Sicht sollte diese $\mathrm{Zu}$ - 


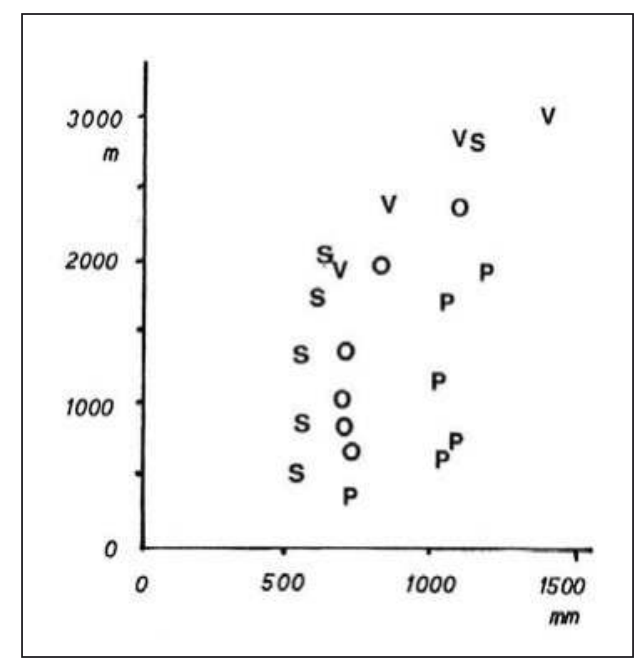

Abb. 11: Jahresniederschlag in der weiteren Umgebung von Obergurgl. S: Stationen im Schnalstal, P: Passeiertal, O: Ötztal bis Schönwies (s. Abb. 2), V: Vent bis zum Hintereisferner (Kuhn et al. 1982)

nahme bei den konvektiven Niederschlägen im Sommer geringer sein als bei den mehr advektiven im Winter.

Die Höhengradienten der Temperatur sind über weite Flächen einheitlich. Sie sind jahreszeitlich und tageszeitlich von der Stabilität der Atmosphäre bestimmt, gering in den Wintermonaten und während der Nacht, weil dann in den Tälern Inversionen auftreten, maximal beim wolkenfreien Überströmen der Gebirgsketten, zum Beispiel bei Föhn (der trockenadiabatische Temperaturgradient ist $-1{ }^{\circ} \mathrm{C}$ pro $100 \mathrm{~m}$ ) oder bei trockener, konvektiver Durchmischung der atmosphärischen Grenzschicht. In Wolken oder im Niederschlag gilt der sogenannte feuchtadiabatische Gradient von rund $-0,6{ }^{\circ} \mathrm{C}$ pro $100 \mathrm{~m}$. Monatliche Mittelwerte sind von der Häufigkeit des Auftretens dieser verschiedenen Bedingungen abhängig, sie sind in den Alpen erstaunlich homogen.

Dazu sollen zwei Beispiele gegeben werden: Abb. 12 zeigt vertikale Temperaturgradienten in Vorarlberg, Tirol und Salzburg, die jeweils nur aus einer Tal- und einer Bergstation gebildet wurden (Kuhn 1997).

Tab. 5 wurde von Martin Ortner (unpubl. Daten) mit Temperaturgradienten von 22 vergletscherten Tiroler Einzugsgebieten aus dem Datensatz des Histalp Projekts (Auer et al. 2007) berechnet. Aus dieser Arbeit werden das Gebiet der Ötztaler Ache als repräsentativ für den Bereich nördlich des Alpenhauptkamms und das der Passer (Timmelsjoch bis Meran) für den südlichen Bereich genommen. Die Unterschiede zwischen Nord und Süd sind gering, aber signifikant. Die Werte von Stubai, Ötztal, Pitztal, Kaunertal im Norden und für Etsch, Passer, Talfer und Mareiterbach im Süden unterscheiden sich jeweils nur um $0,01{ }^{\circ} \mathrm{C}$ pro $100 \mathrm{~m}$. Die Werte im trockenen Süden liegen um $0,05^{\circ} \mathrm{C}$ pro $100 \mathrm{~m}$ näher am trockenadiabatischen Temperaturgradienten. Bei der Modellierung verschiedener Tiroler Einzugsgebiete fand Kuhn (2010) im März Zunahmen des Niederschlags mit der Höhe von 5 - $9 \%$, im Juli nur $2-7 \%$ pro $100 \mathrm{~m}$ Höhe. 


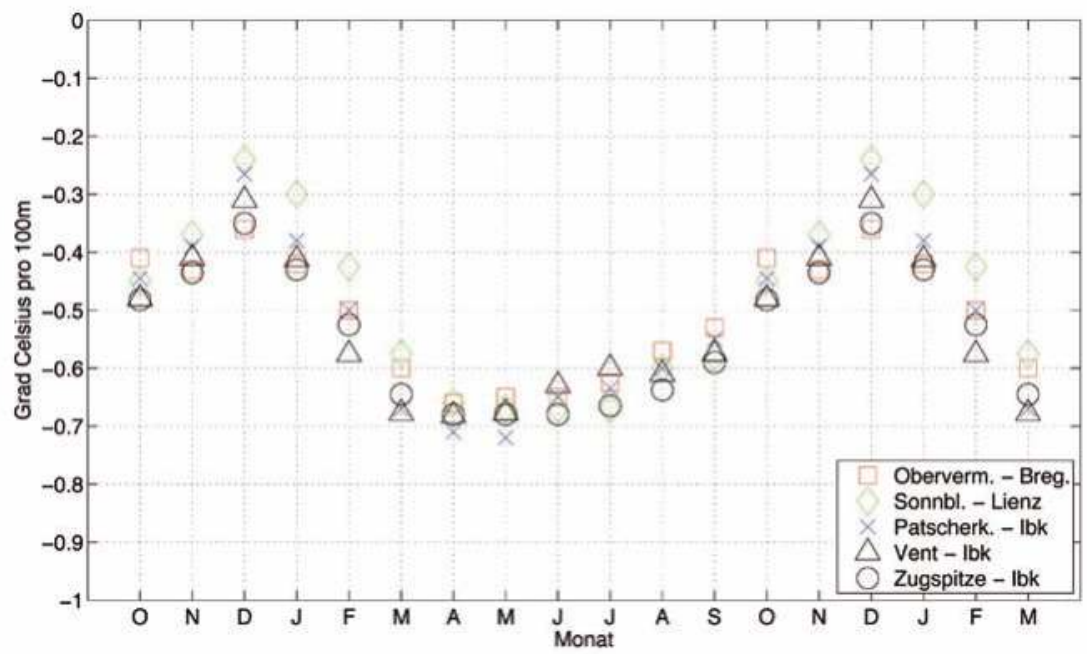

Abb. 12: Vertikale Temperaturgradienten zwischen Berg- und Talstationen Obervermunt/Bregenz, Sonnblick/Lienz, Patscherkofel/Innsbruck, Vent/Innsbruck und Zugspitze/Innsbruck (Kuhn 1997)

Tab. 5: Mittlere monatliche vertikale Temperaturgradienten $\left({ }^{\circ} \mathrm{C}\right.$ pro $\left.100 \mathrm{~m}\right)$ für die Einzugsgebiete der Ötztaler Ache und der Passer. Aus Histalpdaten 1969-97 (Auer et al. 2007), bearbeitet von Martin Ortner

\begin{tabular}{llllllllllllll}
\hline & Jan & Feb & Mar & Apr & Mai & Jun & Jul & Aug & Sep & Okt & Nov & Dez \\
\hline Ötztaler Ache & $-0,41$ & $-0,48$ & $-0,59$ & $-0,64$ & $-0,65$ & $-0,65$ & $-0,62$ & $-0,60$ & $-0,56$ & $-0,49$ & $-0,45$ & $-0,39$ \\
Passer & $-0,43$ & $-0,52$ & $-0,63$ & $-0,69$ & $-0,69$ & $-0,71$ & $-0,68$ & $-0,65$ & $-0,60$ & $-0,51$ & $-0,46$ & $-0,42$ \\
\hline
\end{tabular}

9. Mikrometeorologie und Energiebilanzen

In der näheren Umgebung von Obergurgl hat es mehrere intensive mikrometeorologische Programme gegeben. Die Forstliche BundesVersuchsanstalt Mariabrunn hat an der Waldgrenze am Ausgang des Königstals langjährige ökologische Untersuchungen angestellt, die unter anderem von Aulitzky (1961, 1963) veröffentlicht wurden. Im Internationalen Man and Biosphere Projekt wurden von 1978 bis 1981 Messungen von Temperatur, Niederschlag, Feuchte, Bodentemperaturen und Strahlungs- und Energiebilanz an den drei Stationen Wiese, Schönwies und Hohe Mut (Abb. 2) durchgeführt (Patzelt 1987, Rott 1979, Staudinger 1978, 1987; Kuhn 1997, Fischer 2010). Im Gletschervorfeld des Rot- 
moosferners wird derzeit eine Reihe von mikrometeorologischen Messungen durchgeführt (Koch \& Erschbamer 2010, Erschbamer, Kapitel 8 in diesem Band). Außerdem besteht ein mikrometeorologisches Messnetz entlang der Monitoring-Standorte von der subalpinen bis zur subnivalen Höhenstufe in Obergurgl (Hartl et al., Kapitel 7 in diesem Band).

\section{Literaturverzeichnis}

Auer, I., Böhm, R. et al. (2007) HISTALP - Historical instrumental climatological ssurface time series of the greater Alpine region 1760-2003. International Journal of Climatology 27: 17-46.

Aulitzky, H. (1961) Die Bodentemperaturen in der Kampfzone oberhalb der Waldgrenze und im sub-alpinen LärchenZirbenwald. In: Ökologische Untersuchungen in der subalpinen Stufe- Teil 1. Mitteilungen der Forstlichen BundesVersuchsanstalt 59: 153-208.

Aulitzky, H. (1963) Grundlagen und Anwendungen des vorläufigen Wind-SchneeÖkogrammes. In: Ökologische Untersuchungen in der subalpinen Stufe - Teil 2. Mitteilungen der Forstlichen BundesVersuchsanstalt 60: 765-834.

Böhm, R. (1992) Lufttemperaturschwankungen in Österreich seit 1775. Österreichische Beiträge zu Meteorologie und Geophysik. Wien, $95 \mathrm{~S}$.
Fischer, A. (2010) Klima und Gletscher in Obergurgl. Alpine Forschungsstelle 1, innsbruck university press, Innsbruck, S. 53-72.

Fliri, F. (1975) Das Klima der Alpen im Raum von Tirol. Universitätsverlag Wagner, Innsbruck, $454 \mathrm{~S}$.

Institute of Meteorology and Geophysics (2013 a) Climate Data Obergurgl, 1953-2011, University of Innsbruck, http://doi.pangaea.de/10.1594/PANGAEA.806635

Institute of Meteorology and Geophysics (2013 b) Climate Data Vent, Ötztal, 1935-2011, University of Innsbruck, http://doi.pangaea.de/10.1594/PANGAEA.806582

Institute of Meteorology and Geophysics (2013 c) Climate Data Obergurgl, Ötztal, 1953-2011 Klimadiagramme Obergurgl, University of Innsbruck, http:// doi.pangaea.de/10.1594/PANGAEA

Klinger, E. (1986) Die Wetterbeobachtungen an Klimastationen. Zentralanstalt für Meteorologie und Geodynamik, Wien, $107 \mathrm{~S}$.

Koch, E.-M. \& Erschbamer, B. (2010) Glaziale und periglaziale Lebensräume im Raum Obergurgl. Alpine Forschungsstelle Obergurgl 1, innsbruck university press, Innsbruck, $304 \mathrm{~S}$.

Kuhn, M., Nickus, U. \& Pellet, F. (1982) Die Niederschlagsverhältnisse im Inneren Ötztal. DWD. Internationale Tagung für Alpine Meteorologie, Berchtesgaden 1982, S. 235-237. 
Kuhn, M. (1997) Meteorologische und klimatische Bedingungen für die Flora von Nordtirol, Osttirol und Vorarlberg. In: Flora von Nordtirol, Osttirol und Vorarlberg, Polatschek, A. (Hg.), Verlag des Tiroler Landesmuseums Ferdinandeum, S. 26-42.

Kuhn, M. (2010) Rain and snow at high elevation. In: Plants in Alpine Regions, Lütz, C. (Hg.), Springer Verlag Wien, New York, S. 1-10.

Patzelt, G. (1987) MaB Projekt Obergurgl. Veröffentlichungen des Österreichischen MaB-Programms, Universitätsverlag Wagner, Innsbruck, $350 \mathrm{~S}$.

Rott, H. (1979) Vergleichende Untersuchungen der Energiebilanz im Hochgebirge. Archiv für Meteorologie Geophysik und Bioklimatologie Ser. A, 28 (2-3): 211 232.

Siogas, L. (1972) Vergleich von Temperaturmittelbildungen mit dem wahren Mittel für das Observatorium Innsbruck-Universität. Wetter und Leben 24: 17-22.

Staudinger, M. (1978) Die Strahlungsbilanz zweier hochalpiner Stationen während der Vegetationsperiode. Veröffentlichungen der Schweizerischen Meteorlogische Zentralanstalt Zürich, 40: 236-239.

Staudinger, M. (1987) Verdunstungsbestimmung während der Vegetationsperiode durch Energiebilanzmessungen In: $\mathrm{MaB}$ Projekt Obergurgl. Patzelt, G. (Hg.), Veröffentlichungen des Österreichischen MaB-Programms, Universitätsverlag Wagner, Innsbruck, $350 \mathrm{~S}$.

\section{Verzeichnis der Autoren}

Michael Kuhn

Institut für Meteorologie und Geophysik

Universität Innsbruck

Innrain 52, 6020 Innsbruck

Michael.Kuhn@uibk.ac.at

\section{Ekkehard Dreiseitl}

Institut für Meteorologie und Geophysik

Universität Innsbruck

Innrain 52, 6020 Innsbruck

Ekkehard.Dreiseitl@uibk.ac.at

Markus Emprechtinger

Institut für Meteorologie und Geophysik

Universität Innsbruck

Innrain 52, 6020 Innsbruck

Markus.Emprechtinger@uibk.ac.at 


\title{
Kapitel 2 | Langzeitmonitoring von Gletschermassen- bilanzen und -längenänderungen in Tirol
}

\author{
Andrea Fischer, Lea Hartl
}

\section{Zusammenfassung}

$3 \%$ der Landesfläche Tirols ist vergletschert. Seit dem Hochstand zum Ende der kleinen Eiszeit um 1850 verloren die Gletscher 50 \% ihrer Fläche und hinterließen neue Flächen für die Besiedelung durch Lebewesen. Diese Änderungen der Gletscherfläche gehen mit klimatischen Änderungen und Änderungen der lokalen Hydrologie einher, die ihrerseits auch die mikroklimatischen Bedingungen für die Lebewesen beeinflussen.

Die Daten zur Änderung der Gletscher werden im Rahmen von 54 Längenmonitoringprojekten und fünf Langzeitreihen der Gletschermassenbilanz erhoben. Die Temperatur während der Ablationsperiode (Mai bis September) ist zwischen 1901 und 2008 um $1,6{ }^{\circ} \mathrm{C}$ gestiegen. Die Akkumulation in den Wintermonaten (Oktober bis April) zeigt in diesem Zeitraum keine signifikanten Trends. Wann und wie stark die einzelnen Gletscher auf klimatische Änderungen reagieren, hängt von ihren topographischen Eigenschaften ab. Die Längenmessungen spiegeln einen Gletscherrückzug wider, unterbrochen von Wachstumsperioden in den 1920er und 1980er Jahren. Die Massenbilanzmessungen zeigen zunehmende Massenverluste während der letzten Jahrzehnte.

\section{Abstract}

$3 \%$ of the area of Tyrolean territory is covered by glaciers. After the end of the Little Ice Age about 1850 , these glaciers retreated by about $50 \%$ of their initial area providing open ground for succession of biota. The changes of glacier area take place simultaneously with changes in climate and local hydrology.

The annual glacier changes are recorded by 54 length monitoring and five long term mass balance programs. Between 1901 and 2008, the temperature during the ablation season (May to September) increased by $1.6^{\circ} \mathrm{C}$. In the same period, winter (October to April) accumulation showed no significant trends. The reaction of glaciers to the climate signal differs in timing and magnitude in relation to their topographic properties. The measurement of length changes show a general glacier retreat, but also advances in the 1920s and 1980s. The mass balance measurements show an increase in mass loss in the last decades. 


\section{Einleitung}

Aufgrund des Klimawandels ziehen sich die Gletscher weltweit zurück (Lemke et al. 2007). Gletscherinventare und Moränen des letzten Gletschermaximums während der kleinen Eiszeit (LIA, Little Ice Age) um 1850 zeigen, dass die österreichischen Gletscher seit damals 50 \% ihrer Fläche verloren haben (Gross 1987, Patzelt 1980, Lambrecht \& Kuhn 2007, Abermann et al. 2009). Der Rückzug der Gletscher gibt Flächen für die Besiedlung durch Lebewesen frei und verändert die lokale Hydrologie und das Mikroklima. Vor allem in Tirol ist die Sukzession von Pflanzen im Bereich schwindender Gletscher seit Jahrzehnten gut dokumentiert (z.B. Klebelsberg 1913, Friedel 1939, Gams 1939, Janetschek 1949, Kaufmann 2001, Erschbamer et al. 2008).

Seit Jahrhunderten werden die Tiroler Gletscher beobachtet und untersucht. Besonders das innere Ötztal kann als Wiege der ostalpinen Gletscherforschung bezeichnet werden. Die erste skizzierte Karte des Vernagtferners entstand 1601 (Simony 1863, Richter 1892, Nicolussi 1990) und auch aus dem 19. Jahrhundert sind zahlreiche Gletscherbeschreibungen erhalten (Schlagintweit 1850, Sonklar 1857, 1860, 1877). Die Eisseen des Gurglerund Vernagtferners in den Ötztaler Alpen überfluteten mehrfach bewohntes Gebiet und ihr Zustand wurde schon früh regelmäßig dokumentiert (Meixner \& Siegl 2010).

Mit der Erstellung detaillierter Karten und Geschwindigkeitsmessungen an einzelnen
Gletschern begann Ende des 19. Jahrhunderts die Zeit systematischer glaziologischer Untersuchungen. Eisgeschwindigkeiten wurden am Hintereis- und Hochjochferner (Ötztaler Alpen) gemessen und Hintereis- (1894), Hochjoch- (Gruber 1913), Gepatsch- (1886/87), Vernagt- (1888) und Jamtalferner (publiziert 1909), sowie die Zunge des Alpeiner Ferners (1892) wurden kartiert. In Kombination mit den geomorphologischen Daten der LIA Moränen und jener von 1920 und 1980, sowie den Gletscherinventaren von 1969, 1998 und 2006, geben diese Karten Aufschluss über Änderungen der Gletscherflächen und -volumina. Einige Monitoringprojekte dokumentieren die jährlichen Gletscheränderungen in Tirol. Seit 1891 werden die Längenänderungen von etwa $10 \%$ der Gletscher systematisch durch den Österreichischen Alpenverein dokumentiert. Die ersten Massenbilanzmessungen wurden 1894/95 am Hintereisferner durchgeführt (Hess 1904). Über 50 Jahre später begannen 1952/53 jährliche Bilanzmessungen am Hintereis- und Kesselwandferner in den Ötztaler Alpen. So entstand die weltweit längste Massenbilanzzeitreihe. Aktuell werden im Rahmen von Langzeitmonitoringprojekten am Hintereis-, Kesselwand-, Vernagt- und Jamtalferner, sowie am Mullwitzkees jährlich Massenbilanzmessungen durchgeführt. Die Reihen an Hintereis-, Kesselwand- und Jamtalferner sind Teil der LTER (Long-term Ecological Research) Plattform Tyrolean Alps.

Verschiedene Publikationen beschäftigen sich mit dem Zusammenhang zwischen Gletschermassenbilanzen und dem Wachstum von 
Bäumen (Nicolussi 1994, Nicolussi \& Patzelt, 1996, 2001, Nicolussi et al. 2005). Dementsprechend können Modellierungen früherer Massenbilanzen und Gletschergrößen Hinweise auf das vorherrschende Klima geben und wiederum mit dendochronologischen Proxydaten verglichen werden. Da Langzeitmessungen atmosphärischer Parameter fast ausschließlich an Wetterstationen in Tallagen stattfanden, können glaziologische Daten wichtige Informationen über das historische Klima in hochalpinen Regionen liefern, wobei hier besonders Sommertemperaturen, Niederschlag und Schneebedeckung hervorzuheben sind (z.B. Kerschner \& Ivy-Ochs 2007).

Dieser Artikel fasst die glaziologischen Zeitreihen Tirols zusammen und vergleicht sie mit Klimadaten. Messungen und Methoden wer- den im Hinblick auf zukünftige ökologische Anwendungsbereiche beschrieben.

\section{Material und Methoden}

\section{Untersuchungsgebiet}

Etwa $33,5 \mathrm{~km}^{2}$ der Tiroler Alpen sind von Gletschern bedeckt. Das entspricht ca. $3 \%$ der Fläche Tirols. Jährliche Längenänderungen werden an 54 Tiroler Gletschern gemessen und fünf Gletscher sind Teil von Massenbilanz-Monitoringprojekten (Abb. 1).

Alle 5 Massenbilanzgletscher befinden sich nahe am Alpenhauptkamm. Der Vernagt-

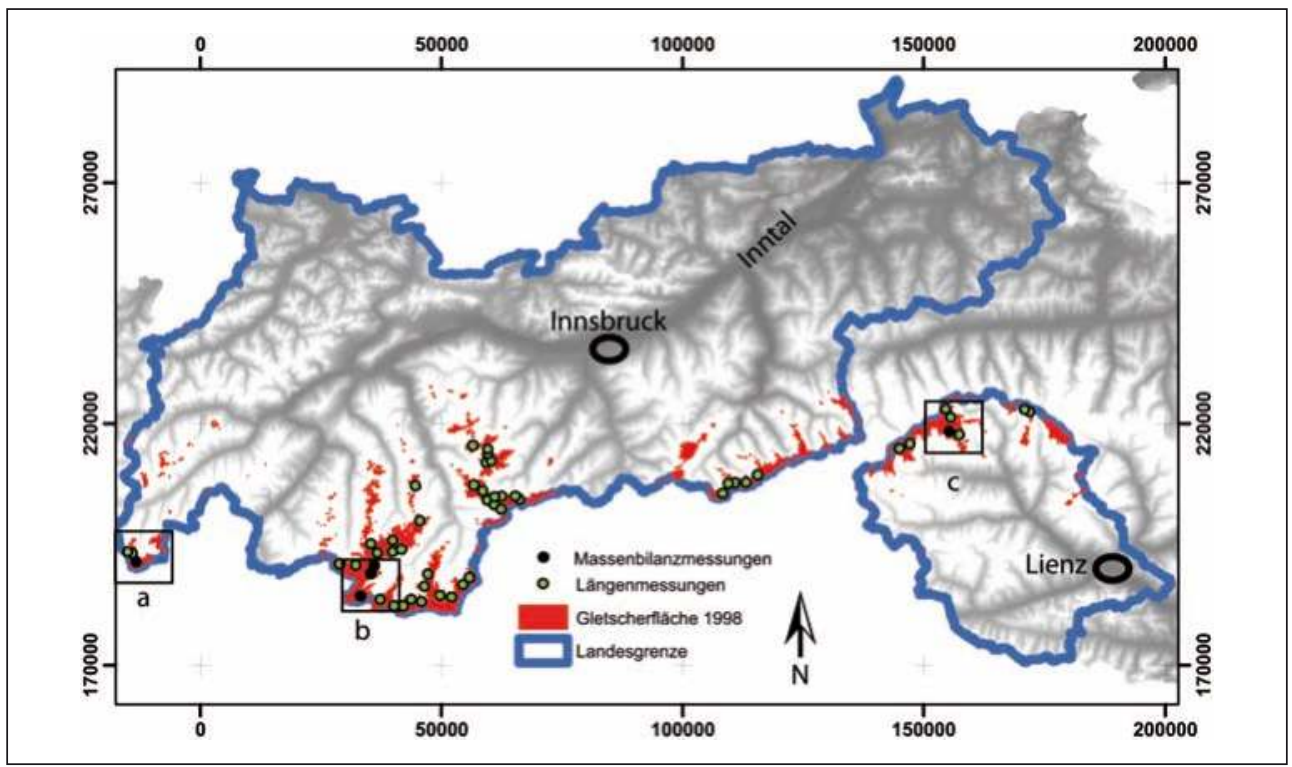

Abb. 1: Gletscher (rot) bedecken $3 \%$ der Fläche Tirols (blau). An 54 Gletschern (grün) wird jährlich die Länge gemessen, an fünf Gletschern (schwarz) wird auch die Massenbilanz erhoben. Die Daten sind in Gauss-Krüger Projektion auf dem Höhenmodell von Jarvis et al. (2006) dargestellt 
ferner, der Hintereisferner und der benachbarte Kesselwandferner liegen in den Ötztaler Alpen, der Jamtalferner liegt etwa $50 \mathrm{~km}$ westlich davon in der Silvretta und das Mullwitzkees befindet sich $140 \mathrm{~km}$ östlich in der Venediger Gruppe.

Der Hintereisferner ist ein typischer Talgletscher mit einer Fläche von etwa $7,8 \mathrm{~km}^{2}$ (2450-3700 m). Der Vernagtferner $\left(8,8 \mathrm{~km}^{2}\right.$, 2770-3630 m) hat eine ähnliche Fläche, unterscheidet sich aber in seiner Topographie: Der Gletscher ist nach Osten ausgerichtet und die Zunge wird aus drei großen Becken gespeist. Der Kesselwandferner $(3,9$ km², 2700 $3500 \mathrm{~m}$ ) befindet sich zwischen Vernagt- und Hintereisferner. Der Hauptteil des Gletschers liegt auf einem relativ flachen Plateau über 3000 m. Das Plateau war über eine schnell abschmelzende Spaltenzone mit einer kleinen Zunge verbunden. 2012 hat die Zunge die Verbindung zum Hauptgletscher verloren. Die drei Ötztaler Gletscher erhalten weniger Jahresniederschlag als der Jamtalferner (3,5 km², 2400-3200 m), ein Talgletscher, dessen Zunge sich aus drei Firnbecken speist. Das Mullwitzkees (3,2 km², 2690-3400 m) in der Venedigergruppe ist südexponiert. Die Zunge des Mullwitzkees bildet das so genannte Zettalunitzkees.

Der Hintereis-, Kesselwand- und Vernagtferner werden seit über einem Jahrhundert glaziologisch untersucht (z.B. Finsterwalder 1897, Blümcke \& Hess 1899, Hess 1904, Srbik 1936, 1941a, Hoinkes 1970, Lang \& Patzelt 1971, Schlosser 1997, Span et al. 1997, Kuhn et al. 1999, Fischer \& Markl 2009, Fischer 2010).

\section{Massenbilanzmessungen}

Die Massenbilanz eines Gletschers ist die $\mathrm{Zu}$ nahme oder der Verlust von im Gletscher über eine bestimmte Zeit gespeichertem Wasser. In mittleren Breiten wird die Bilanz meist über das hydrologische Jahr hinweg gemessen, also vom 1. Oktober bis zum 30. September des Folgejahres.

Während Längen- und Flächenänderungen von Gletschern durch eine Reihe von Faktoren, wie Klima, Eisdicke, Massenbilanz und Fließgeschwindigkeit beeinflusst werden, hängt die jährliche Änderung der Massenbilanz hauptsächlich von Klimaänderungen ab.

Die direkte glaziologische Methode (Hoinkes 1970) ist die am häufigsten verwendete Methode um die Massenbilanz zu messen. Am Ende des hydrologischen Jahres wird die Abla-

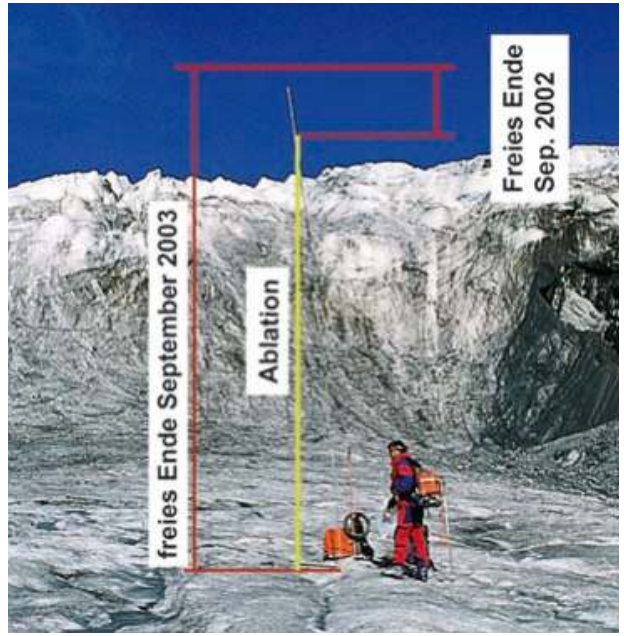

Abb. 2: Die direkte oder glaziologische Methode der Massenbilanzmessung beruht auf der Messung der Ablation an Pegeln und der Akkumulation an Schneeschächten, die über den Gletscher verteilt sind (Foto: Andrea Fischer) 
tion durch Ablesen im Voraus gebohrter Ablationspegel festgestellt (Abb. 2). Die Anzahl der Pegel wird für jeden Gletscher je nach Variabilität der Oberflächenbilanz gewählt (Fountain \& Vecchia 1999, Pelto 2000). Um die Akkumulation von Schnee und den Wassergehalt des Schnees zu messen, werden im Akkumulationsgebiet mehrere Schächte gegraben und die Schneedecke untersucht.

Die gemessenen Massenbilanzdaten werden anschließend über den gesamten Gletscher interpoliert. In die Interpolation fließen zusätz- liche Informationen aus Karten der Schneebedeckung, aus Webcam-Bildern und Beobachtungen zu Akkumulation durch Lawinen ein (Fischer \& Markl 2009).

Die Gletscheroberfläche wird aus topographischen Karten bestimmt und für Hintereis-, Kesselwand-, Jamtalferner und Mullwitzkees werden jährliche Flächenänderungen gemessen. Die Gesamtmassenbilanz B für einen Gletscher wird in Bezug auf die Gletscherfläche in $\mathrm{m}^{3}$ oder $\mathrm{kg}$ berechnet. Um verschiedene Gletscher besser vergleichen zu können,
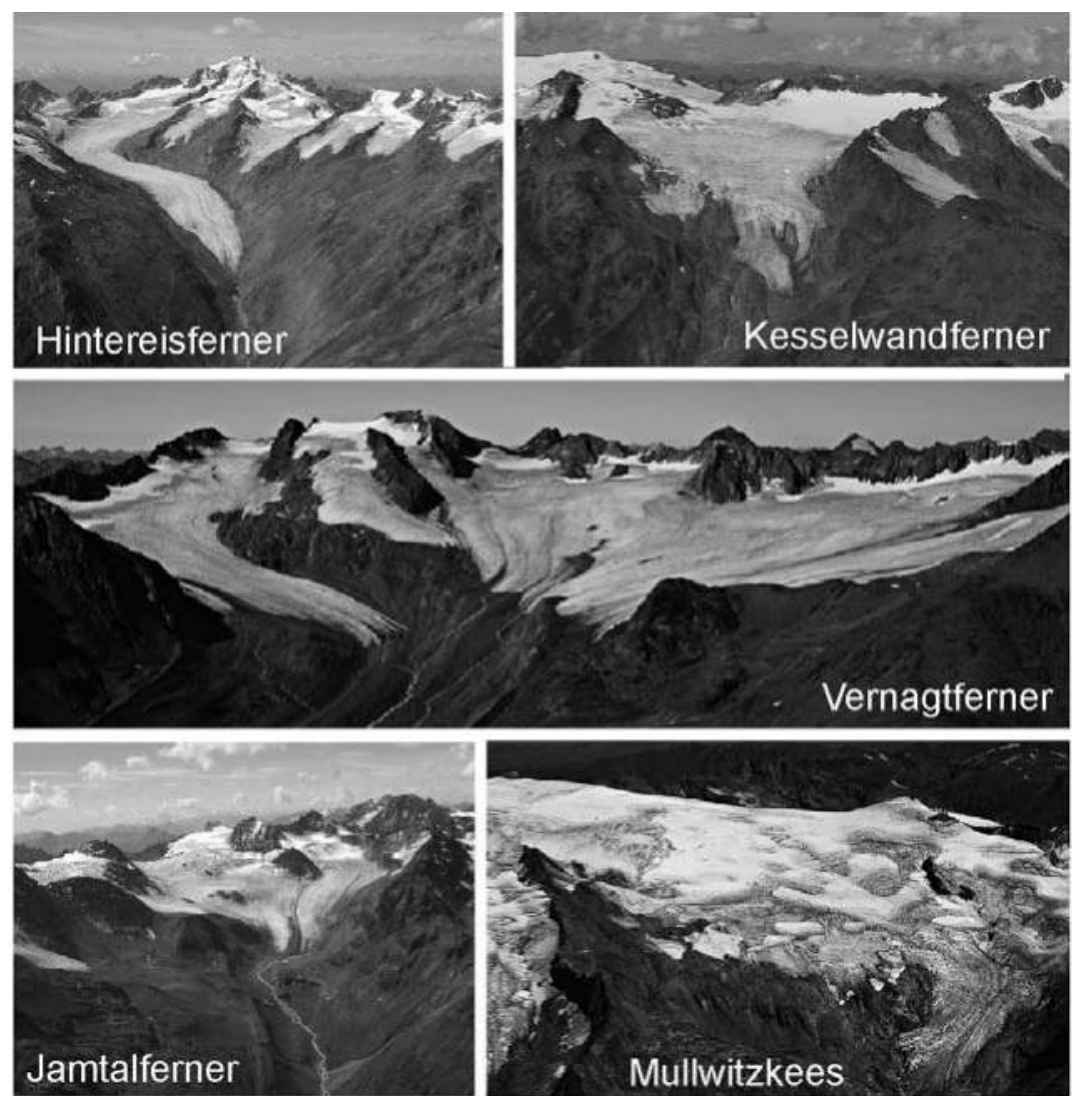

Abb. 3: An fünf Tiroler Gletschern werden Massenbilanzen erhoben. Hintereis-, Kesselwand- und Jamtalferner sind dabei Teil der LTER-Plattform Tyrolean High Alps (Fotos: Andrea Fischer) 
wird die spezifische Massenbilanz b berechnet, als Massenbilanz B geteilt durch Gletscherfläche A:

$$
\mathrm{b}=\mathrm{B} / \mathrm{A}
$$

Die spezifische Massenbilanz wird in $\mathrm{kg} / \mathrm{m}^{2}$ (Wassermasse pro Einheitsfläche) oder $\mathrm{mm}$ Wasseräquivalent (mm w.e.) angegeben. Letztere Einheit ist besonders für hydrologische Anwendungen nützlich, da die Bilanzwerte direkt mit dem Niederschlag verglichen werden können, der auch in $\mathrm{mm}$ oder Liter $/ \mathrm{m}^{2}$ angegeben wird.

Abb. 3 zeigt die fünf Tiroler Gletscher mit Langzeitmessreihen der Massenbilanz. Auf jedem dieser Gletscher sind zwischen 15 und
50 Ablationspegel installiert und jedes Jahr werden 5-10 Schächte gegraben (Reinwarth \& Escher-Vetter 1999, Fischer \& Markl 2009). In Abb. 4 ist das Netzwerk aus Pegeln und Schächten am Hintereisferner zu sehen, sowie die Gletschergrenzen zwischen 1953 und 2003. Der Umriss des LIA Maximums ist zu Vergleichszwecken auch gezeigt.

Die meisten Gletscher werden am oder um den 1. Mai untersucht, um die Winterakkumulation festzustellen. Dabei wird auch die Schneehöhe in bestimmten Höhenlagen gemessen.

Wie bei allen Langzeitmessungen haben sich Messinstrumente und -methoden seit Beginn der Messungen verändert. Die Massenbilanz-

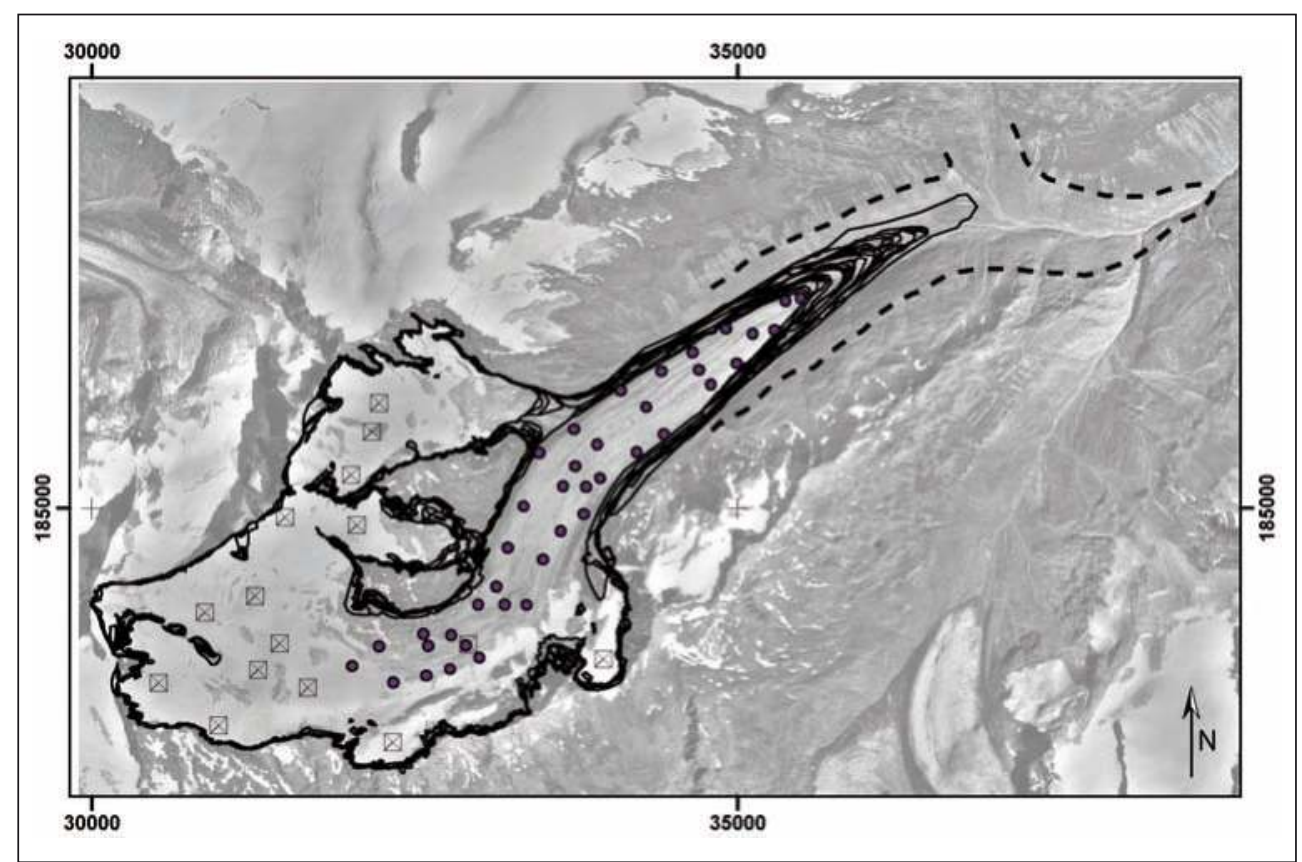

Abb. 4: Karte des Hintereisferners mit Lage der Schneeschächte (Quadrate) und Ablationspegel (Punkte) sowie den Gletschergrenzen des LIA (strichlierte Linie) und den Gletschergrenzen 1953 bis 2003 (durchgezogene Linie) 
zeitreihe des Hintereisferners wurde homogenisiert, um diesen Veränderungen Rechnung zu tragen (Fischer 2010).

\section{Messung der Längenänderung}

Die Längenänderung von Gletschern ist der am längsten und häufigsten dokumentierte glaziologische Parameter. Der Abstand mehrerer Fixpunkte zur Gletscherzunge wird am Ende der Ablationsperiode in einer bestimmten Richtung gemessen (Abb. 5). Die jährliche Längenänderung wird als Mittelwert des Unterschiedes der Distanz zwischen den
Fixpunkten und der Zunge von einem Jahr zum Folgejahr berechnet. Die Fixpunkte sind farbig markiert. Der Name des Punktes und die Richtung, in die gemessen wird, sind an den Punkten vermerkt. Mit Hilfe der Gletscherjahresberichte für jeden Gletscher, die vom Österreichischen Alpenverein archiviert werden, kann die Position der Zunge anhand dieser Markierungen rekonstruiert werden. In Österreich werden seit 1890 systematische Messungen von Gletscherlängenänderungen durchgeführt (Richter 1894). Die ersten Messungen und die Ergebnisse daraus wurden von Fritzsch (1898) zusammengestellt. Die bis 1975 verfügbaren Daten sind in zwei Abhand-

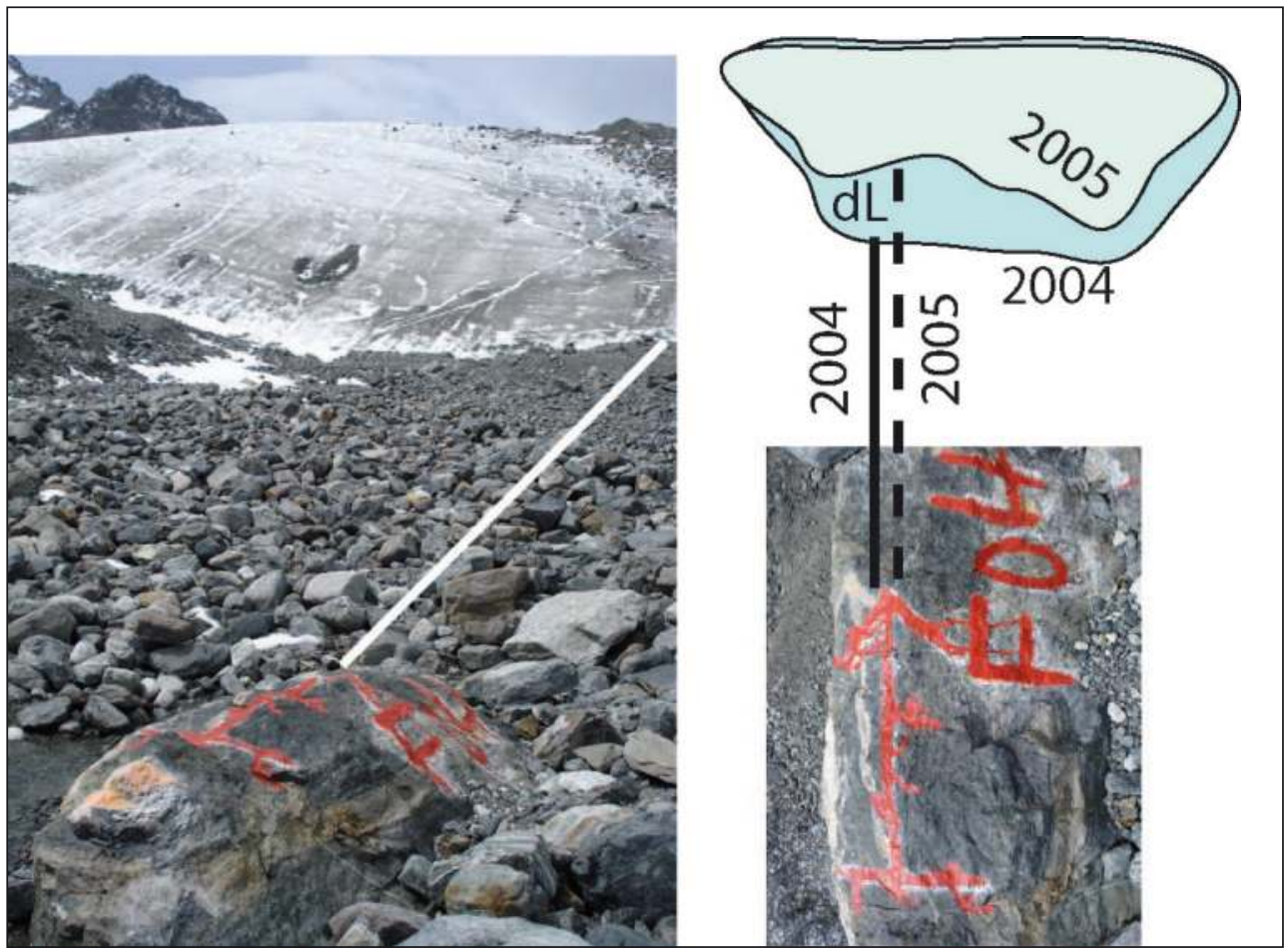

Abb. 5: Die Messung der Längenänderung wird seit 1891 mit derselben Methode durchgeführt (Fotos: Andrea Fischer) 
lungen von Patzelt $(1970,1977)$ und in einer von Klebelsberg (1943) zusammengefasst. Im Magazin des Österreichischen Alpenvereins werden jährliche Berichte veröffentlicht (z.B. Patzelt 2005, Patzelt 2006). Zusätzlich $\mathrm{zu}$ den Längenänderungsmessungen enthält der Gletscherbericht Fotodokumentationen und Berichte über besondere Ereignisse wie das Abreißen von Nebengletschern, Felsstürze, Seenbildung oder das Einstürzen ganzer Gletscherzungen.

Abgesehen von Aufzeichnungen im Zusammenhang mit den katastrophalen Ausbrüchen der Gletscherseen am Vernagtferner 1600, um 1680, nach 1770 und 1845/48 (Nicolussi 1990), stammen einige der ältesten Gletscherbeobachtungen (Diener 1885) aus den Zillertaler Alpen (Zemmgrund). Die Karten von Ygl (1604/05, Kinzl 1962), Burgklechner (1608-1620, Richter 1902) und jene der zweiten (1806-1896, Franziszeiische Landesaufnahme) und dritten (1869-1887, Franzisko-Josephinische Landesaufnahme) Landesaufnahme sind für alle beobachteten Gletscher Quellen weiterer Informationen über Zungenposition und Gletscherfläche (Arnberger 1970).

\section{Klimadaten}

Es gibt mehrere Langzeitklima- und Abflussmessreihen in Tirol. Für die Gletscher besonders relevant sind die im inneren Ötztal (Ekhart 1939, Finsterwalder 1891, Haeuser 1932). Die längste Zeitreihe stammt von der Klimastation der Universität Innsbruck, kür- zere Reihen existieren für Obergurgl (Patzelt 1987), Vent, Galtür und Lienz. Gegenwärtig betreibt die Zentralanstalt für Meteorologie und Geodynamik (www.zamg.ac.at) ein Netzwerk von Klimastationen und automatischen Wetterstationen. Der Hydrographische Dienst des Landes Tirol betreibt Abfluss- und Niederschlagspegel, sowie automatische Wetterstationen (http://gis.lebensministerium.at/ eHYD, HZB 2002).

Einige der Langzeitstationen wurden seit Beginn der Messungen verlegt und Instrumente, Beobachter und Methoden haben sich geändert. Dadurch entstehen Sprünge in den Messreihen, die korrigiert werden müssen, um die Klimaänderung von Änderungen der Messtechnik unterscheiden zu können. Im Rahmen des HISTALP Projekts (Auer et al. 2007) wurden im Zuge einer sogenannten Homogenisierung Langzeitklimareihen korrigiert. Die Daten wurden anschließend verwendet um einen Rasterdatensatz von Temperatur und Niederschlag für den Alpenraum und seine Umgebung zu erstellen.

Die Station in Vent wird vom Institut für Meteorologie und Geophysik der Universität Innsbruck als Teil des Langzeitmonitorings an Hintereis- und Kesselwandferner betrieben. Die Lufttemperatur wird in einer Stevenson Wetterhütte gemessen, für den Niederschlag gibt es eine Niederschlagswaage und einen manuellen Regenmesser. Im Einzugsgebiet der Rofenache in Vent, wo der Abfluss gemessen wird, werden sechs manuelle Regenmesser betrieben, um die Niederschlagssumme festzustellen. Der höchstgelegene Regenmesser befindet sich in $2970 \mathrm{~m}$ Höhe. 


\section{Ergebnisse}

\section{Klimadaten}

Die Klimastation in Vent (1908 m) verzeichnet einen Anstieg der Lufttemperatur während der Ablationsperiode von Mai bis September, aber keine signifikanten Trends im Winterniederschlag (Abb. 6).

Die maximale mittlere Sommertemperatur trat mit $10,6{ }^{\circ} \mathrm{C}$ im Extremsommer 2003 auf und lag damit 2,6 ${ }^{\circ} \mathrm{C}$ über dem Mittel der Jahre 1961-1990 (man verwendet immer mindestens 30-jährige Mittel zur Berechnung eines klimatischen Durchschnittswertes).
Während der Ablationsperiode von 1947 war es mit einer mittleren Temperatur von $10,0^{\circ} \mathrm{C}$ nur geringfügig kälter. Die Minimumtemperatur zwischen 1901 und 2008 wurde 1910 mit $6,1{ }^{\circ} \mathrm{C}$ erreicht. Das Niederschlagsmittel in der Akkumulationsperiode von 1961-1990 beträgt in Vent $261 \mathrm{~mm}$. In $2970 \mathrm{~m}$ fallen im Schnitt $716 \mathrm{~mm}$, also wesentlich mehr als im Tal. Der Niederschlagsgradient zwischen der Station im Tal und höheren Lagen variiert von Jahr zu Jahr. Dies ist zum Teil dadurch zu erklären, dass anströmende Luftmassen durch die umliegenden Berge kleinräumig modifiziert werden, wodurch es zu orographischen Niederschlagsereignissen kommt.

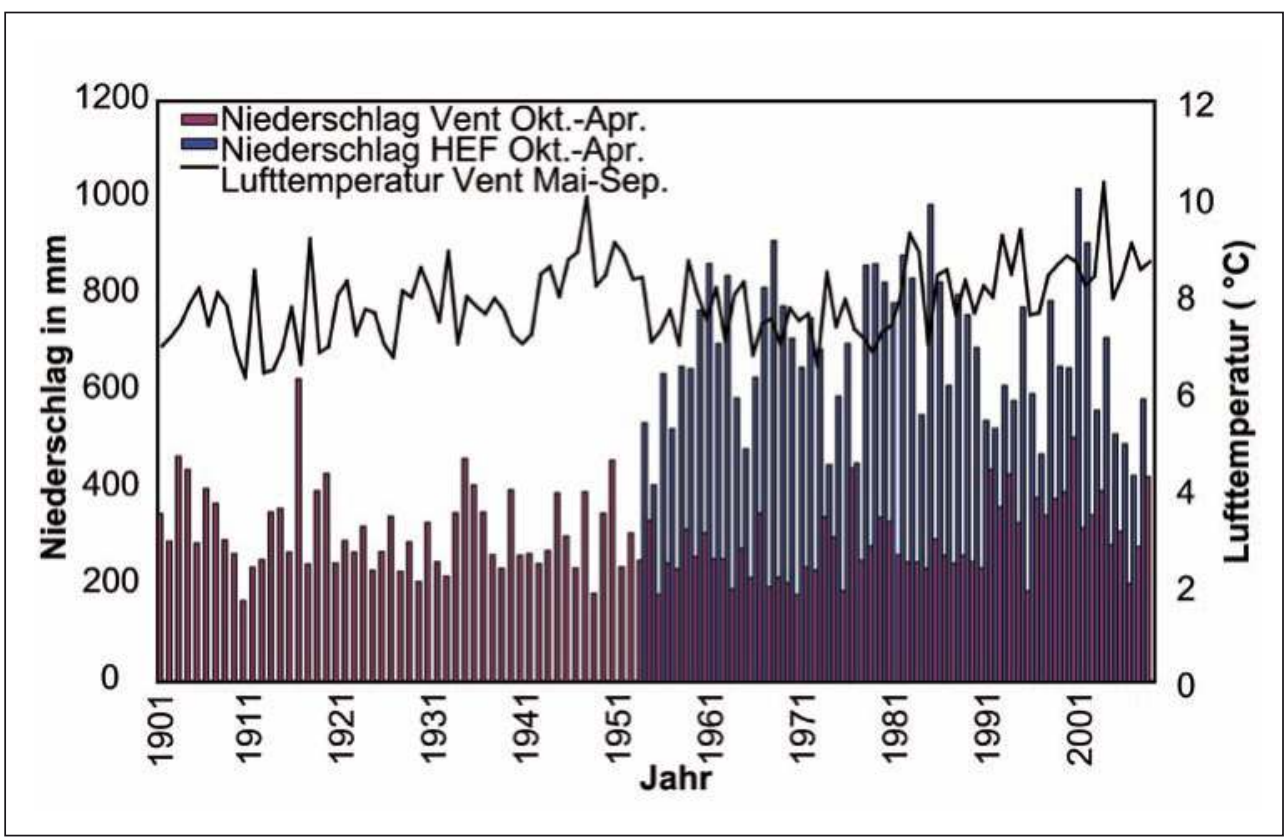

Abb. 6: Mittel der Lufttemperatur (schwarze Linie) in der Ablationssaison (Mai bis September) in Vent, Niederschlagssumme (rote Balken) in der Akkumulationssaison (Oktober bis April) in Vent 1901-2008. Der Winterniederschlag an der Station Hintereisferner (blaue Balken) ist signifikant höher als der in Vent gemessene 
Die Unsicherheit der Niederschlagsmessung im Hochgebirge wird aufgrund der starken Winde während der Niederschlagsereignisse und dem hohen Anteil festen Niederschlags auf $30 \%$ geschätzt. Von 1901 bis 2008 lag der Niederschlag während der Akkumulationsperiode in Vent zwischen $168 \mathrm{~mm}$ und $625 \mathrm{~mm}$. Das gleitende Zehnjahresmittel der Temperatur während der Ablationsperiode erreicht im Intervall 1907-1916 ein Minimum von 7, $1^{\circ} \mathrm{C}$ und in den letzten zehn Jahren ein Maximum von 8,7 ${ }^{\circ} \mathrm{C}$. Zwischen 1947 und 1959, sowie seit 1988 erreicht das gleitende Mittel Werte über $8,0^{\circ} \mathrm{C}$. Während dieser Perioden waren also in jedem Jahr die jeweils 10 vorangegangenen Jahre wärmer als $8,0^{\circ} \mathrm{C}$.

\section{Längenänderungen}

Abb. 7 zeigt beispielhaft für Längenänderungsmessungen, die an über 50 Tiroler Gletschern durchgeführt werden, die Längenänderungen am Hintereis-, Kesselwand-, Jamtalund Vernagtferner, sowie am Zettalunitzkees (Zunge des Mullwitzkees). Vor allem während der Kriegsjahre sind einige Datenlücken vorhanden. Es gibt auch bisher keine Datenreihe homogenen Formats, da der Fokus der frühen Beobachtungen auf der Anzahl vorstoßender, stagnierender und schrumpfender Gletscher lag, nicht auf dem quantitativen Ausmaß der Veränderungen. In manchen Fällen wurde in Zweijahresperioden gemessen und es ist unklar, wie die Änderungen auf einzelne Jahre

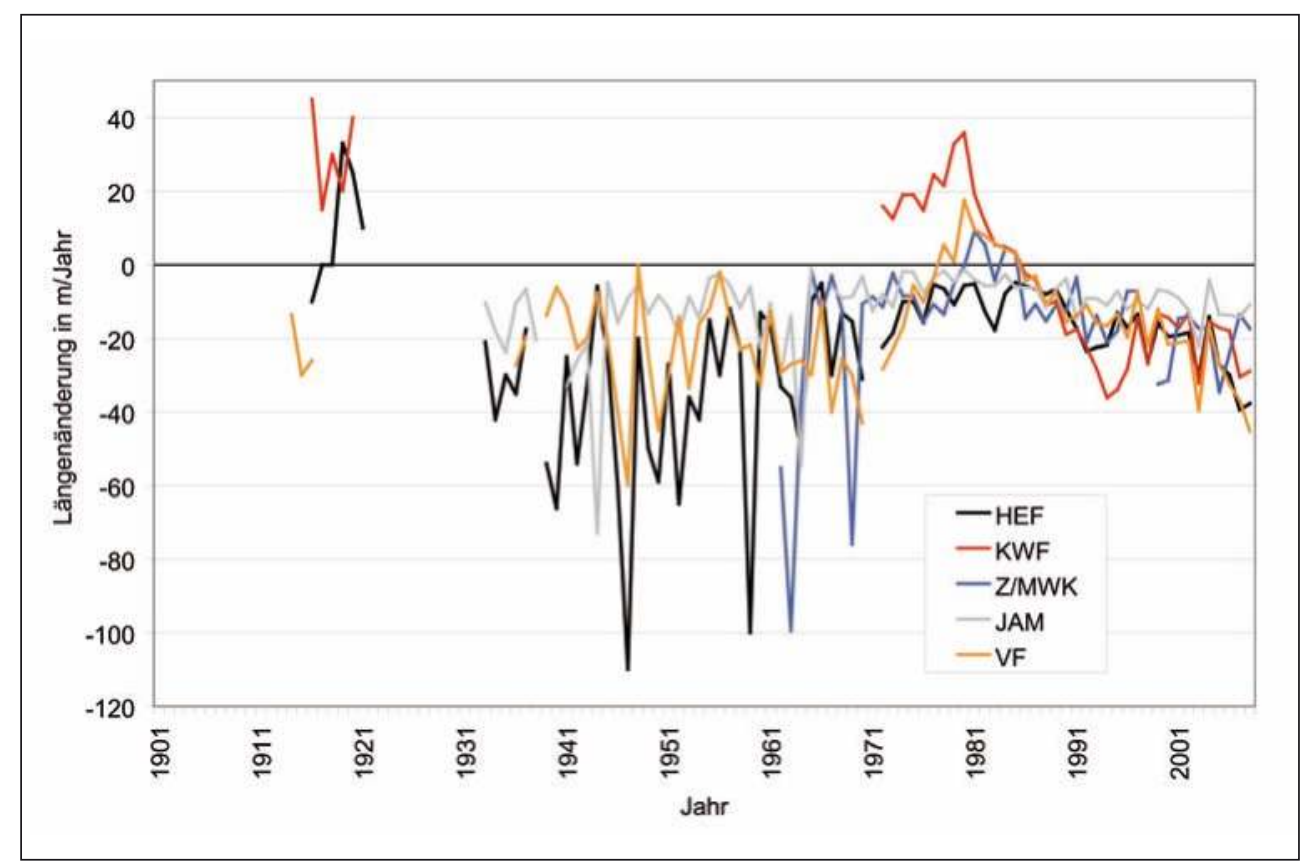

Abb. 7: Längenänderungen von Hintereisferner (HEF), Kesselwandferner (KWF), Zettalunitz/Mullwitzkees (Z/MWK), Jamtalferner (JAM) und Vernagtferner (VF) 
umverteilt werden könnten. Nichtsdestotrotz sind die Längenmessungen eine einzigartige Datenreihe, die die Reaktion der Gletscher auf den Klimawandel dokumentiert. Aus Abb. 7 wird deutlich, dass die Gletscher unterschiedlich auf die gleichen Klimasignale reagieren. Der Hintereisferner zieht sich in den 1940ern und 1950ern stärker zurück als die anderen Gletscher. In den 1960ern zieht sich dagegen das Zettalunitz-/Mullwitzkees am schnellsten zurück und der Hintereisferner verliert nur langsam an Länge. $\mathrm{Zu}$ begründen ist dies nicht durch Unterschiede im Klimasignal, sondern durch die Mechanismen des Gletscherrückzugs. An den Zungen der Talgletscher der Ostalpen ist das Eis üblicherweise zwischen 70 und $270 \mathrm{~m}$ dick. Wenn dieses Eis schmilzt und der Eisfluss Richtung Zunge aufgrund geringer Akkumulationsraten abnimmt, wird die Zunge über Jahre oder Jahrzehnte hinweg langsam dünner. Erreicht das Eis eine kritische Dicke einiger Meter, fällt die Zunge über einen sehr kurzen Zeitraum in sich zusammen. Die Länge ändert sich daher einige Zeit sehr stark, bis sich eine neue Gletscherstirn stabilisiert hat. Es handelt sich hierbei um einen normalen Rückzugsmechanismus von Talgletschern, der im letzten Jahrzehnt, sowie in den 1930ern und 1940ern beobachtet wurde (z.B. Srbik 1941b).

Einige der in Abb. 7 gezeigten Gletscher stoßen während der kühleren 1970er und 1980er vor, manche jedoch nicht. Der Kesselwandferner gewann in dieser Periode insgesamt 600 m Länge, während sich der Hintereisferner weiter zurückzog. Auch dies ist nicht auf das an beiden Gletschern gleiche
Klimasignal zurückzuführen, sondern vor allem auf die unterschiedliche Topographie der Gletscher. Die Akkumulation in höheren Lagen des Hintereisferners erreichte die Zunge nicht, während die Akkumulation im Firnbecken des Kesselwandferners schnell an die kurze, steile Zunge weitergegeben wurde, was die Reaktionszeit auf das Klimasignal verkürzte.

\section{Massenbilanz}

Die kumulative Summe der spezifischen Massenbilanzen (Abb. 8) war während der Messperiode am Hintereis-, Kesselwand-, Jamtal- und Vernagtferner und am Mullwitzkees negativ. Es ging wesentlich mehr Masse durch die Eisschmelze verloren, als durch Akkumulation von Schnee gewonnnen wurde. In den meisten Jahren ist die Massenbilanz des Hintereisferners stärker negativ als die der anderen Gletscher. Die große, bis in tiefe Lagen reichende Zunge macht den Hintereisferner besonders anfällig für warme, trockene Perioden. Der benachbarte Kesselwandferner erfährt das gleiche Klima, liegt aber höher und hat ein großes Akkumulationsgebiet und eine kleine Ablationszone. Es ist daher nicht verwunderlich, dass die Massenbilanzen hier üblicherweise am positivsten ausfallen. Wie auch die Längenänderungen sind die Massenbilanzen das Ergebnis eines Zusammenspiels von Klima und Gletschertopographie. Für Hintereis- und Kesselwandferner wird dies von Kuhn et al. (1985) genauer besprochen. Nach dem Beginn der Messungen 1953 ver- 


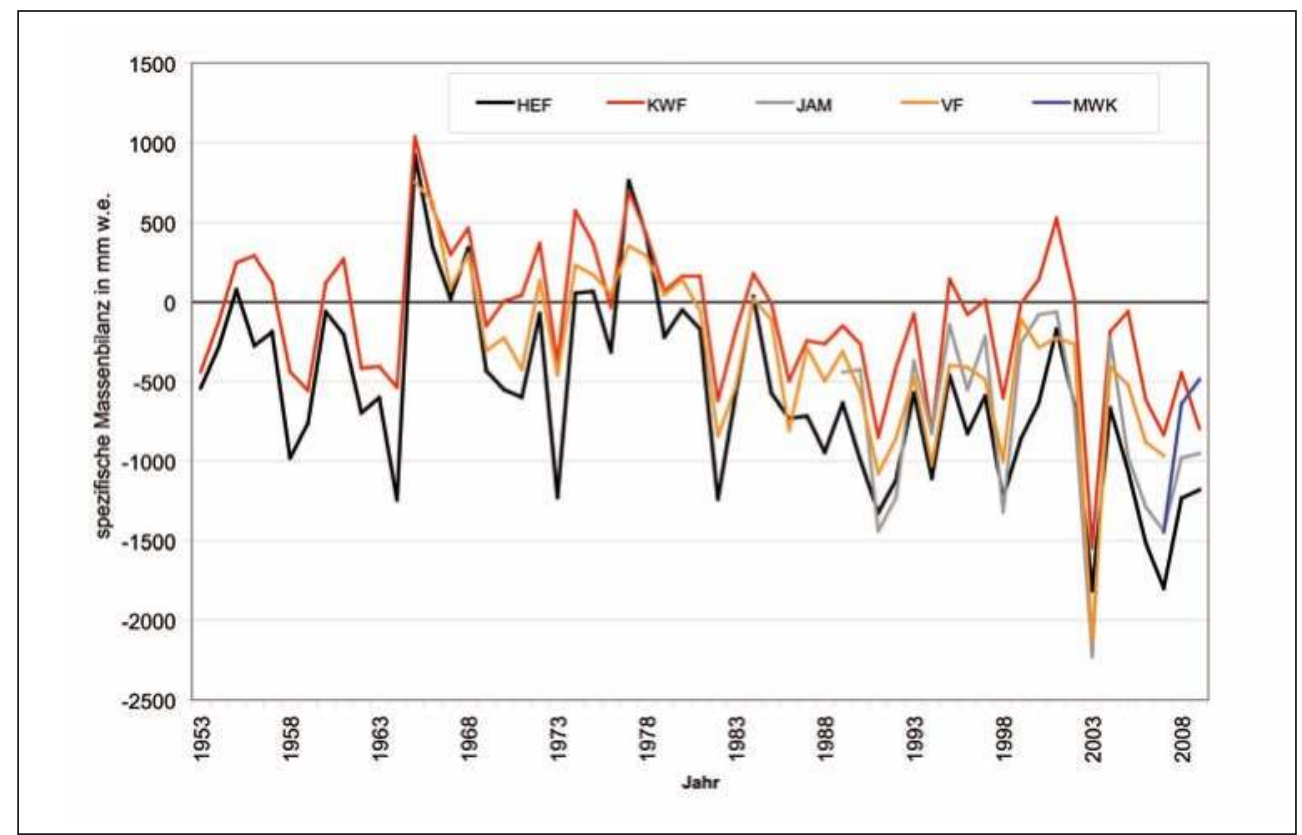

Abb. 8: Spezifische Massenbilanz des Hintereisferners (HEF), Kesselwandferners (KWF), Mullwitzkees (MWK), Jamtalferners (JAM) und Vernagtferners (VF)

loren Hintereis- und Kesselwandferner Masse. In den 1960er und 1970er Jahren verzeichneten diese beiden Gletscher ebenso wie der Vernagtferner Massengewinne. Nach 1982 zeigte nur noch der Kesselwandferner Massengewinne. Er erreichte 1985 seine maximale Fläche. Der extrem warme Sommer 2003 verursachte stark negative Massenbilanzen. Während der Ablationsperiode von 2003 verschwanden Teile des Firns im Akkumulationsgebiet, was zu einer Abnahme der mittleren Albedo der Gletscheroberfläche führte. Deswegen und aufgrund weiterer warmer Sommer nach 2003 waren die Massenbilanzen der letzten zehn Jahre stärker negativ als jene früherer Jahrzehnte.

\section{Diskussion}

Während der letzten 100 Jahre stieg das gleitende Zehnjahresmittel der Temperatur der Ablationsperiode (Mai bis September) in Vent in einer Höhe von $1908 \mathrm{~m}$ um 1,6 ${ }^{\circ} \mathrm{C}$. Der Niederschlag während der Akkumulationsperiode zeigt keine signifikanten Trends. Die Reaktion eines Gletschers auf klimatische Veränderungen hängt von den individuellen Charakteristika des Gletschers ab. Längenänderungen werden von der Massenbilanz beeinflusst, aber auch die Eisdicke, die Neigung des Gletschers und die Eisgeschwindigkeit spielen eine Rolle. Die Eisdicke wiederum ist durch die Geschichte des Gletschers bedingt. 
Gletscher befinden sich zu jedem Zeitpunkt in einem von drei möglichen Stadien. Ist der Gletscher im Gleichgewicht mit dem Klima, verändert er seine Form nicht. Wird das Klima wärmer oder trockener, verliert der Gletscher Masse und die Zunge zieht sich zurück. Wird das Klima kühler oder feuchter, wächst der Gletscher. In beiden Fällen ändert sich die Massenbilanz schneller als die Länge der Zunge. Je größer und flacher ein Gletscher ist, desto langsamer reagiert er auf ein neues Klima. Je größer die klimatische Veränderung ist, desto länger braucht der Gletscher, bis er erneut ein Gleichgewichtsstadium erreicht.

Die fünf detailliert besprochenen Gletscher zeigen unterschiedliche Reaktionen auf ähnliche klimatische Veränderungen. Wenn wir das Klima mit Hilfe der Gletscher verstehen wollen, muss eine große Anzahl von Gletschern untersucht werden. Nur Trends, die an Gletschern in verschiedenen Höhen und mit unterschiedlicher Topographie auftreten, sind verlässliche Klimaindikatoren.

Sollen Klimaveränderungen an einem einzelnen Gletscher untersucht werden, müssen Daten verwendet werden, die an diesem Gletscher erhoben wurden, da es sehr schwer ist, von der Massenbilanz oder der Rückzugsrate eines Gletscher auf die eines anderen zu schließen.

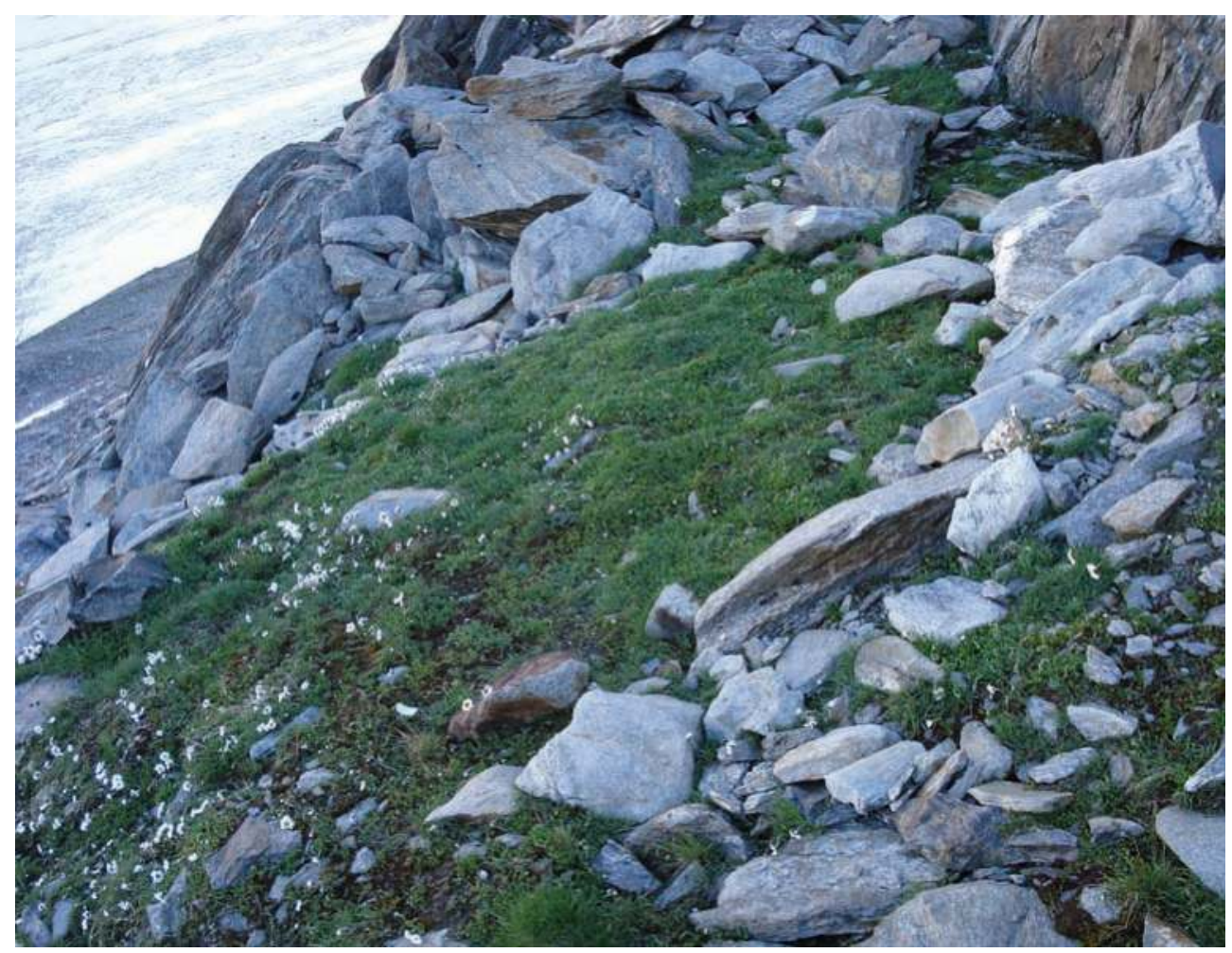

Abb. 9: Flächen unterhalb der Station Hintereisferner auf 3050 m Seehöhe (Foto: Andrea Fischer) 
Das Netzwerk der Längenmessungen an Tiroler Gletschern dokumentiert den Gletscherrückzug seit 1890 in einer einzigartigen $\mathrm{Da}$ tenreihe außergewöhnlich gut. Diese Daten sind als Grundlage für Sukzessionsstudien im Gletschervorfeld von großem Wert, da sich die Gletscher nicht kontinuierlich zurückziehen, sondern wechselweise sehr aktive sowie kaum bewegte Phasen durchleben.

Aktuell verändert sich die Gletscherfläche nicht nur im Bereich der Stirn, sondern auch in höheren Lagen. Änderungen dort werden während der Massenbilanzmessungen dokumentiert. Diese geben zusätzlich Auskunft über die Höhe der Winterschneedecke und das zur Verfügung stehende Schmelzwasser in der Ablationsperiode. Eine Untersuchung der sich ändernden Bedingungen für Lebewesen in höheren Lagen wäre ein interessantes Anwendungsgebiet dieser Daten (Abb. 9). In Kombination mit dendrochronologischen Daten (Nicolussi \& Patzelt 2001, Nicolussi et al. 2005, Nicolussi \& Thurner 2012) könnte so mehr über das Klima und die Ökologie seit dem Ende der letzten Eiszeit vor mehr als 10000 Jahren in Erfahrung gebracht werden.

\section{Literatur}

Abermann, J., Lambrecht, A., Fischer, A. \& Kuhn, M. (2009) Quantifying changes and trends in glacier area and volume in the Austrian Ötztal Alps (1969-1997-
2006). The Cryosphere 3: 205-215. doi:10.5194/tc-3-205-2009

Arnberger, E. (1970) Die Kartographie im Alpenverein. Wissenschaftliche Alpenvereinshefte 22, $253 \mathrm{~S}$.

Auer, I., Böhm R, Jurkovic, A., Lipa, W., Orlik, A., Potzmann, R., Schöner, W., Ungersböck, M., Matulla, C., Briffa, K., Jones, P. D., Efthymiadis, D., Brunetti, M., Nanni, T., Maugeri, M., Mercalli, L., Mestre, O., Moisselin, J.M., Begert, M., Müller-Westermeier, G., Kveton, V., Bochnicek, O., Stastny, P., Lapin, M., Szalai, S., Szentimrey, T., Cegnar, T., Dolinar, M., Gajic-Capka, M., Zaninovic, K., Majstorovic, Z. \& Nieplova, E. (2007) HISTALP - Historical instrumental climatological surface time series of the greater Alpine region 1760-2003. International Journal of Climatology 27: $17-46$.

Blümcke, A. \& Hess, H. (1899) Untersuchungen am Hintereisferner. Wissenschaftliche Ergänzungshefte zur Zeitschrift des Deutschen und Österreichischen Alpenvereins 1/2: 1-87.

Diener, C. (1885) Studien an den Gletschern des Schwarzensteingrundes. Zeitschrift des DÖAV 16: 66-78.

Ekhart, E. (1939) Die klimatischen Verhältnisse des Venter Tales. Das Venter Tal. Zweig Mark Brandenburg d. DAV, München, S. 13-36.

Erschbamer, B., Niederfriniger Schlag, R. \& Winkler E. (2008) Colonization processes on a central Alpine glacier foreland. 
Journal of Vegetation Science 19: 855862.

Finsterwalder, S. (1891) Die Pegelstation Vent. Mitteilungen des DÖAV 7(17): 65-66.

Finsterwalder, S. (1897) Der Vernagtferner. Seine Geschichte und seine Vermessung in den Jahren 1888 und 1889. Wissenschaftliche Ergänzungshefte zur Zeitschrift des Deutschen und Österreichischen Alpenvereins 1 (1): 112.

Fischer, A. \& Markl, G. (2009) Mass balance measurements on Hintereisferner, Kesselwandferner and Jamtalferner 2003 to 2006: database and results. Zeitschrift für Gletscherkunde und Glazialgeologie 42/1: 47-83.

Fischer, A. (2010) Glaciers and climate change: Interpretation of 50 years of direct mass balance of Hintereisferner. Global and Planetary Change 71/1-2: 13-26.

Fountain, A. \& Vecchia, A. (1999) How many stakes are required to measure the mass balance of a glacier? Geographical Annals 81A: $563-568$.

Friedel, H. (1939) Die Pflanzenbesiedlung im Vorfeld des Hintereisferners. Zeitschrift für Gletscherkunde 26: 215-239.

Fritzsch, M. (1898) Verzeichnis der bis zum Sommer 1896 in den Ostalpen gesetzen Gletschermarken. DÖAV, Wien, 129 S.

Gams, H. (1939) Die Pflanzendecke der Venter Täler. Das Venter Tal. Zweig Mark Brandenburg d. DAV, München: 56-63.

Gross, G. (1987) Der Flächenverlust der Gletscher in Österreich 1850-1920-1969.
Zeitschrift für Gletscherkunde und Glazialgeologie 23 (2): 131-141.

Gruber, O. (1913) Der Hochjochferner im Jahre 1907. Seine Vermessung in den Jahren 1907 und 1908. Zeitschrift für Gletscherkunde 7: 1-36.

Haeuser, J. (1932) Niederschlagsmessungen am Hintereis- und Vernagtferner. Meteorologische Zeitschrift 49: 314-315.

Hess, H. (1904) Die Gletscher. Friedrich Vieweg und Sohn, Braunschweig, $426 \mathrm{~S}$.

Hoinkes, H. (1970) Methoden und Möglichkeiten von Massenhaushaltsstudien auf Gletschern. Zeitschrift für Gletscherkunde und Glazialgeologie 6: 37-90.

HZB (2002) Hydrographisches Jahrbuch von Österreich. Hydrographisches Zentralbüro / Bundesministerium für Land- und Forstwirtschaft, Umwelt und Wasserwirtschaft, Abteilung VII/3 - Wasserhaushalt, Wien: Hydrograph. Zentralbüro. - CD-ROM

Janetschek, H. (1949) Tierische Successionen auf hochalpinem Neuland. Nach Untersuchungen am Hintereis-, Niederjochund Gepatschferner in den Ötztaler Alpen. Schlern-Schriften 7: 215.

Jarvis, A., Reuter, H., Nelson, A. \& Guevara, E. (2006). Hole-filled seamless SRTM data V3. International Centre for Tropical Agriculture (CIAT), http://srtm.csi. cgiar.org, last access: 1 May 2006.

Kaufmann, R. (2001) Invertebrate succession on an alpine glacier foreland. Ecology 82: 2261-2278. 
Kerschner, H. \& Ivy-Ochs, S. (2007) Palaeoclimate from glaciers: Examples from the Eastern Alps during the Alpine Lateglacial and early Holocene. Global and Planetary Change 60 (1-2): 58-71.

Kinzl, H.(1962) Die Karte von Tirol des Warmund Ygl 1604/05. Innsbruck, 54 S.

Klebelsberg, R. v. (1943) Die Alpengletscher in den letzten 30 Jahren (1911-1941). Petermanns Mitteilungen 89: 23-32.

Klebelsberg, R. v. (1913) Das Vordringen der Hochgebirgsvegetation in den Tiroler Alpen. Österreichische Botanische Zeitschrift, $23 \mathrm{~S}$.

Kuhn, M., Markl, G., Kaser, G., Nickus, U., Obleitner, F. \& Schneider, H. (1985) Fluctuations of climate and mass balance: Different responses of two adjacent glaciers. Zeitschrift für Gletscherkunde und Glazialgeologie 21: 409-416.

Kuhn, M., Dreiseitl, E., Hofinger, S., Markl, G., Span, N. \& Kaser, G. (1999) Measurements and Models of the Mass Balance of Hintereisferner. Geografiska Annaler 81 A (4): 659-670.

Lambrecht, A. \& Kuhn, M. (2007) Glacier changes in the Austrian Alps during the last three decades, derived from the new Austrian glacier inventory. Annals of Glaciology 46: 177-184.

Lang, H. \& Patzelt, G. (1971) Die Volumenänderungen des Hintereisferners (Ötztaler Alpen) im Vergleich zur Massenänderung im Zeitraum 1953-64. Zeitschrift für Gletscherkunde und Glazialgeologie VII (1-2): 229-238.
Lemke, P., Ren, J., Alley, R.B., Allison, I., Carrasco, J., Flato, G., Fujii, Y., Kaser, G., Mote, P., Thomas, R.H. \& Zhang, T. (2007) Observations: Changes in Snow, Ice and Frozen Ground. In: Climate Change 2007 - The Physical Science Basis. Contribution of Working Group I to the Fourth Assessment Report of the Intergovernmental Panel on Climate Change, Solomon, S., Qin D., Manning M., Chen Z., Marquis M., Averyt K.B., Tignor M. \& Miller H.L. (Hg.) Cambridge University Press, Cambridge, United Kingdom and New York, NY, USA, S. 338-383.

Meixner, W. \& Siegl, G. (2010) Historisches zum Thema Gletscher, Gletschervorfeld und Obergurgl. In: Glaziale und periglaziale Lebensräume im Raum Obergurgl, Koch, E.-M. \& Erschbamer, B. (Hg.), Alpine Forschungsstelle Obergurgl 1, innsbruck university press, Innsbruck, S. 9-25.

Nicolussi, K. (1990) Bilddokumente zur Geschichte des Vernagtferners im 17. Jahrhundert. Zeitschrift für Gletscherkunde und Glazialgeologie 26 (2): 97-119.

Nicolussi, K. (1994) Jahrringe und Massenbilanz; dendroklimatologische Rekonstruktion der Massenbilanzreihe des Hintereisferners bis zum Jahr 1400 mittels Pinus cembra-Reihen aus den Ötztaler Alpen, Tirol. Zeitschrift für Gletscherkunde und Glazialgeologie 30: 11-52.

Nicolussi, K. \& Patzelt, G. (1996) Reconstructing glacier history in Tyrol by means 
of tree-ring investigations, Zeitschrift für Gletscherkunde und Glazialgeologie 32: 207-215.

Nicolussi, K. \& Patzelt, G. (2001) Untersuchungen zur holozänen Gletscherentwicklung von Pasterze und Gepatschferner (Ostalpen). Zeitschrift für Gletscherkunde und Glazialgeologie 36: 1-87.

Nicolussi, K., Kaufmann, M., Patzelt, G., van der Plicht, J. \& Thurner, A. (2005) Holocene tree-line variability in the Kauner Valley, Central Eastern Alps, indicated by dendrochronological analysis of living trees and subfossil logs. Vegetation History and Archaeobotany 14: 221-234.

Nicolussi, K. \& Thurner, A. (2012) Jahresringuntersuchungen an rezentem und subfossilem Holzmaterial aus dem Raum Obergurgl - Klimaanalysen und holozäne Waldentwicklung. In: An den Grenzen des Waldes und der menschlichen Siedlung, Koch, E.-M. \& Erschbamer, B. (Hg.), Alpine Forschungsstelle Obergurgl 2, innsbruck university press, Innsbruck: $147-162$.

Patzelt, G. (1970) Die Längenmessungen an den Gletschern der österreichischen Ostalpen 1890-1969. Zeitschrift für Gletscherkunde und Glazialgeologie 6/1-2: 151-159.

Patzelt, G. (1977) Statistik der Längenmessungen an den österreichischen Gletschern 1960 bis 1975 . Zeitschrift für Gletscherkunde und Glazialgeologie 12/1: 91-94.

Patzelt, G. (1980) The Austrian Glacier inventory: Status and first results. IAHS Publ. 126: 181-183.
Patzelt, G. (1987) MaB-Projekt Obergurgl. Veröffentlichungen des Österreichischen $\mathrm{MaB}$ Programms, Universitätsverlag Wagner, Innsbruck, $350 \mathrm{~S}$.

Patzelt, G. (2005) Gletscherbericht 2003/ 2004. Sammelbericht über die Gletschermessungen des Österreichischen Alpenvereins im Jahre 2004. Mitteilungen des Österreichischen Alpenvereins Jg. 60 (130), 2/05: 24-31.

Patzelt, G. (2006) Gletscherbericht 2004/ 2005. Sammelbericht über die Gletschermessungen des Österreichischen Alpenvereins im Jahre 2005. Bergauf 2/2006: 6-11.

Pelto, M. S. (2000) The impact of sampling density on glacier mass balance determination. Hydrological Processes 14/18: 3215-3225.

Reinwarth, O. \& Escher-Vetter, H. (1999) Mass balance of Vernagtferner, Austria, from 1964/65 to 1996/97: Results for three sections and the entire glacier. Geografiska Annaler 81 A (4): 743-751.

Richter, E. (1885) Beobachtungen an den Gletschern der Ostalpen. II. Die Gletscher der Ötztaler Gruppe im Jahre 1883. Zeitschrift des Deutschen und Österreichischen Alpenvereins 16: 54-65.

Richter, E. (1892) Urkunden über die Ausbrüche des Vernagt- und Gurglergletschers im 17. und 18. Jahrhundert. Forschungen zur deutschen Landes- und Volkskunde 6: 345-440.

Richter, E. (1894) Die wissenschaftliche Erforschung der Ostalpen seit der Gründung des Österreichischen und Deutschen 
Alpenvereins. Zeitschrift des Deutschen und Österreichischen Alpenvereins 25: $1-94$.

Richter, E. (1902) Mathias Burgklechners Tirolische Landtafeln 1608, 1611, 1620. Wien, $35 \mathrm{~S}$.

Schlagintweit, K. \& Schlagintweit, A. (1850) Untersuchungen über die physikalische Geographie der Alpen in ihren Beziehungen zu den Phänomenen der Gletscher, zur Geologie, Meteorologie und Pflanzengeographie. Leipzig, $600 \mathrm{~S}$.

Schlosser, E. (1997) Numerical simulations of Hintereisferner, Ötztal Alps, since AD 1850. Annals of Glaciology 24: 199-202. Simony, F. (1863) Beitrag zur Kunde der Ötztaler Alpen. Mitteilungen des Deutschen und Österreichischen Alpenvereins 1: 1-24.

Sonklar, K. v. (1857) Das Ötztaler Eisgebiet. Mitteilungen der Geographischen Gesellschaft Wien, S. 1-15.

Sonklar, K. v. (1860) Die Ötztaler Gebirgsgruppe, mit besonderer Rücksicht auf Orographie und Gletscherkunde. Gotha, 292 S.

Sonklar, K. v. (1877) Studie über den Gurgler Gletscher in der Ötztaler Gebirgsgruppe. Zeitschrift des Deutschen und Österreichischen Alpenvereins 8: 1-14.

Span, N., Kuhn, M. \& Schneider, H. (1997) 100 years of ice dynamics of Hintereisferner, Central Alps, Austria, 1894-1994. Annals of Glaciology 24: 297-302.

Srbik, R. v. (1936) Ein Vierteljahrhundert Ötztaler Gletschermessungen. Zeitschrift für Gletscherkunde 24: 188-191.
Srbik, R. v. (1939) Die Gletscher der Gurgler Tales. Festschrift des Zweiges Karlsruhe des DÖAV, 18 S.

Srbik R. v. (1941a) Aus der Frühzeit der Gletscherforschung südlich Vent. Zeitschrift für Gletscherkunde 27: 332-336.

Srbik, R. v. (1941 b) Die Gletschereinbrüche am Schalf- und Marzellferner (Ötztaler Alpen). Zeitschrift für Gletscherkunde 27: 329- 331

\section{Verzeichnis der Autorinnen}

Andrea Fischer

Institut für Meteorologie und Geophysik

Universität Innsbruck

Innrain 52, 6020 Innsbruck

Andrea.Fischer@uibk.ac.at

Institut für Gebirgsforschung

Mensch und Umwelt

Österreichische Akademie der Wissenschaften

Technikerstraße 25, 6020 Innsbruck

Lea Hartl

Alpine Forschungsstelle Obergurgl

Universität Innsbruck

Gaisbergweg 3, 6456 Obergurgl

Lea.Hartl@student.uibk.ac.at 


\section{Kapitel 3 | Gletscher in Tirol, ihre Verteilung und juiingsten Veränderungen}

Jakob Abermann, Michael Kuhn, Astrid Lambrecht, Lea Hartl

\section{Zusammenfassung}

In diesem Beitrag werden die Gletscherbedeckung Tirols und deren Veränderungen behandelt. Dabei wird ein Schwerpunkt auf Untersuchungen und Daten gelegt, die über die gesamte Eisbedeckung Aufschluss geben (z. B. Gletscherinventare), und weniger auf Studien einzelner Gletscher, wie etwa Untersuchungen von Längenänderungen und Massenbilanzen eingegangen. Seit dem letzten Gletschermaximum am Ende der kleinen Eiszeit (Little Ice Age, LIA) um 1850 haben die Tiroler Gletscher signifikant an Fläche und Volumen verloren. Allerdings konnten kleine Vorstöße in den 1870ern, 1920ern und 1980ern verzeichnet werden. 1969, im Jahr des ersten Gletscherinventars, war in Nord- und Osttirol eine Fläche von 393 km² eisbedeckt. 1997 hatte sich dort die Eisbedeckung auf $325 \mathrm{~km}^{2}$ reduziert. In den letzten Jahren (zwischen 1997 und 2006) wird eine Beschleunigung des Rückzugs beobachtet, die auf positive Temperaturanomalien zurückgeführt wird.

Des Weiteren wird der Zusammenhang zwischen den topographischen Eigenschaften der Gletscher (z. B. Größe; Ausrichtung; mi- nimale, maximale und mittlere Meereshöhe) und ihren Veränderungen quantifiziert. Zwei Drittel der gesamten Gletscherfläche haben eine Exposition von Nordwest über Nord bis Nordost. Die geringsten Verluste sind auf Gletschern mit Exposition nach Westen zu verzeichnen. Ein Zusammenhang zwischen diesen Eigenschaften und klimatischen Parametern wurde festgestellt und quantifiziert. Geringere mittlere Meereshöhen werden hauptsächlich durch erhöhte Winterniederschläge und kühlere Sommertemperaturen bedingt.

\section{Abstract}

The glacier cover in Tyrol and its change with time is reviewed. A variety of data is used and emphasis is put on the data that allow for the assessment of total ice coverage (i.e. glacier inventories) in contrast to studies that deal with selected glaciers only (i.e. length change, mass balance). Since their maximum extent at the end of the Little Ice Age around 1850, area and volume of the Tyrolean glaciers reduced significantly. Small advances in the 1870s, 
1920s and 1980s are reported. In 1969, the year with the first complete glacier inventory, an area of $393 \mathrm{~km}^{2}$ in Tyrol (North and East Tyrol) was covered with ice. This was reduced to $325 \mathrm{~km}^{2}$ by 1997 . In very recent years (i.e. between 1997 and 2006) an accelerated retreat is observed, which is mainly attributed to positive temperature anomalies.

The relationship between the glaciers' characteristics (e.g. size, orientation, minimum, maximum and median elevation) and their changes is quantified. Two thirds of the total glacier area are exposed towards the sector from northwest over north to northeast. The smallest loss of ice thickness occurred in the west-exposed sector. A relationship between these characteristics and mean climatic values was found and quantified. Larger mean winter precipitation values coincide with generally cooler summer temperatures and are a primary reason for lower median elevations.

\section{Einleitung}

Die Tiroler Gletscher und ihre Veränderungen im Zuge klimatischer Schwankungen waren und sind Gegenstand zahlreicher Studien (z.B. Hoinkes 1970, Kuhn et al. 1997, Schöner \& Böhm 2007, Abermann et al. 2011a). Gletscherschwankungen in Tirol sind für Anwendungsbereiche wie Wasserkraft (Kuhn 2003, Lambrecht \& Mayer 2009, Leonhard et al. 2009) und Tourismus (Olefs \& Fischer
2008, Fischer et al. 2010) von großer Bedeutung und liefern wichtigen Input für andere Forschungsfelder, wie z. B. Botanik (Raffl et al. 2006), Archäologie (Bonani et al. 1994) oder Zoologie (Kaufmann et al. 2002). Das Ziel modernen Gletschermonitorings ist es, zum Verständnis des Zusammenhangs zwischen Klima und Gletscher beizutragen, indem so viel Information wie möglich aus verschiedenen räumlichen und zeitlichen Skalen zusammengetragen und kombiniert wird (Paul 2007, Zemp et al. 2007).

Kenntnis von Gletscherschwankungen im Untersuchungsgebiet wurde mit Hilfe folgender Quellen erlangt: Gemälde (Nicolussi 1993), schriftliche Aufzeichnungen (Walcher 1773), Karten (Richter 1888), Baumringe (Nicolussi et al. 2005), Längenänderungs- und Massenbilanzmessungen (Fischer \& Markl 2008; Fischer, Kapitel 2 in diesem Buch), digitale Höhenmodelle (DEMs) einzelner Gletscher in 10-Jahres-Intervallen (Rentsch et al. 2004) und Gletscherinventare verschiedener Jahre (Patzelt 1980, Gross 1987, Lambrecht \& Kuhn 2007, Abermann et al. 2009, Kuhn et al. 2008b). Während Gemälde, Karten und Baumringe lediglich Informationen über einen bestimmten Gletscher zu einem bestimmten Zeitpunkt liefern, gibt es Zeitreihen der Längenänderungen von 54 Gletschern, die teilweise bis 1891 zurückreichen (Fischer, Kapitel 2 in diesem Buch). Allerdings beschränken sich die Längenmessungen auf eine begrenzte Gruppe von Gletschern, die vor allem auf Grund ihrer Erreichbarkeit und weniger wegen ihrer Repräsentanz ausgewählt wurden. 
Außerdem ist der Zusammenhang zwischen klimatischen Schwankungen und Längenänderungen auf Grund der unterschiedlichen Reaktionszeiten verschiedener Gletscher sehr kompliziert, was die Ableitung klimatischer Informationen aus diesen Daten schwierig macht. Jährliche Massenbilanzmessungen erlauben es, das Wetter einer Saison und den resultierenden Bilanzterm in direkten Bezug zur Gletschermasse zu setzen. Auf Grund des hohen Arbeitsaufwands beschränken sich die Massenbilanzmessungen auf einige wenige Gletscher im Untersuchungsgebiet wie etwa Jamtalferner, Hintereisferner, Kesselwandferner, Vernagtferner und Mullwitzkees (Fischer, Kapitel 2 in diesem Buch). Auch die Massenbilanzdaten sind auf Grund der wenigen untersuchten Gletscher nur bedingt repräsentativ (Fountain et al. 2009). Gletscherinventare bieten Momentaufnahmen der Fläche und der Oberflächentopographie sämtlicher Gletscher des Untersuchungsgebiets. Inventare verschiedener Jahre erlauben daher detaillierte Rückschlüsse auf Flächenänderungen und, sind digitale Höhenmodelle (DEMs) vorhanden, auch auf Volumenänderungen. Gletscherinventare werden im Abstand von einigen Jahrzehnten erstellt und implizieren daher ein vereinfachtes Massenbilanzsignal. Anhand einer Reihe von Inventaren kann auf klimatische Veränderungen rückgeschlossen werden. Außerdem können jährliche Massenbilanzen einzelner Gletscher rekonstruiert werden (Abermann et al. 2011b).

In dieser Studie werden die Ergebnisse des letzten vollständigen Tiroler Gletscherinven- tars von 1998 gezeigt und Zusammenhänge zwischen Exposition, Fläche und charakteristischen Höhen (z. B. Minimum, Maximum und Median der Meereshöhe) der Gletscher untersucht. Des Weiteren werden Flächenund Volumenänderungen zwischen 1969 und 1998 quantifiziert und besprochen. $\mathrm{Zu}-$ sätzlich werden erste Ergebnisse eines neuen Gletscherinventars von 2006 gezeigt, um den beschleunigten Gletscherrückzug zu verdeutlichen. Dieser Artikel gibt einen Überblick über die Gletscher Tirols und über jüngste Veränderungen in Relation zu klimatischen Parametern und rundet die Arbeit von Fischer (Kapitel 2 in diesem Buch) ab, in der Daten einzelner Gletscher in hoher zeitlicher Auflösung präsentiert werden.

\section{Untersuchungsgebiet}

Die 620 Tiroler Gletscher umfassen nach dem Gletscherinventar von 1998 eine Gesamtfläche von $325 \mathrm{~km}^{2}$. Das entspricht etwa $3 \%$ der Fläche Tirols und etwa 69 \% der Gesamtgletscherfläche Österreichs. In Abb. 1 ist die Lage der Gletscher mit Höheninformationen im Hintergrund dargestellt. Die stärkste Vergletscherung findet sich im Süden des Landes entlang des Alpenhauptkamms (Gipfel bis knapp $3800 \mathrm{~m}$ ). In tiefer liegenden, niederschlagsreichen Gebieten im Nordwesten und Norden des Landes befinden sich einige sehr kleine Gletscher, wie etwa der Miemin- 


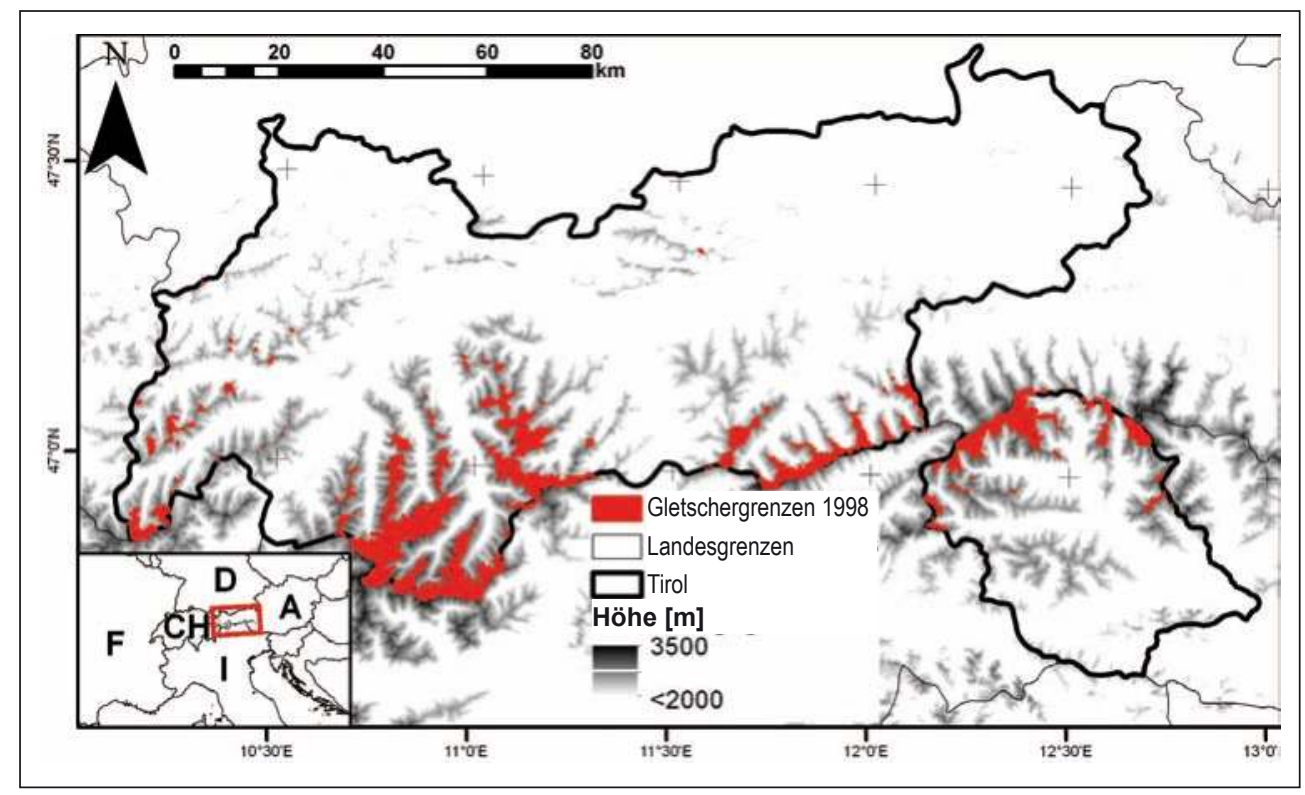

Abb. 1: Das Untersuchungsgebiet: Gletscher in Tirol (rot), Gebiete über $2000 \mathrm{~m}$ sind grau schattiert. Im Hintergrund liegt ein ASTER Höhenmodell von 1998

ger Schneeferner (Abb. 2b). Die Gletscher in diesem Gebiet werden durch Lawinen und Winddrift gespeist und reagieren weniger stark auf Änderungen der Temperatur als große Gletscher wie beispielsweise der Gepatschferner (Abb 2c).

Abb. 2 zeigt beispielhaft verschiedene Gletschertypen im Untersuchungsgebiet. In Abb. $2 \mathrm{a}$ ist ein Talgletscher zusehen, in $2 \mathrm{~b}$ ein Kargletscher und in $2 c$ ein, mit einer weißen Ellipse markierter, regenerierter Gletscher. Abb. $2 \mathrm{~d}$ zeigt mehrere interessante Phänomene: Ein Talgletscher mit vielen Spalten im linken Drittel des Bildes, ein kleiner Hängegletscher (weißer Pfeil) und ein von einer Moräne aufgestauter See (Kreuz). In Abb. 2e ist ein Plateau-artiger Gletscher zu sehen.

\section{Klima}

Tirol hat ein moderates Klima, das maßgeblich vom atlantischen Regime (milde Winter, kühle Sommer), vom kontinentalen Regime (kalte Winter, heiße Sommer) und vom mediterranen Regime (milde Winter, heiße Sommer) beeinflusst wird. Staueffekte an der Topographie können Niederschlagsmengen erhöhen oder verringern und beeinflussen die Temperatur. Wettersysteme, die sich den Alpen nähern, werden orographisch gehoben und es kommt zu Stauniederschlägen an den Hängen. Im Gegenzug ist es in inneralpinen Tälern auf Grund von Lee-Effekten (z.B. Föhn) und topographischer Abschattung relativ trocken (Fliri 1975). Die Temperaturver- 


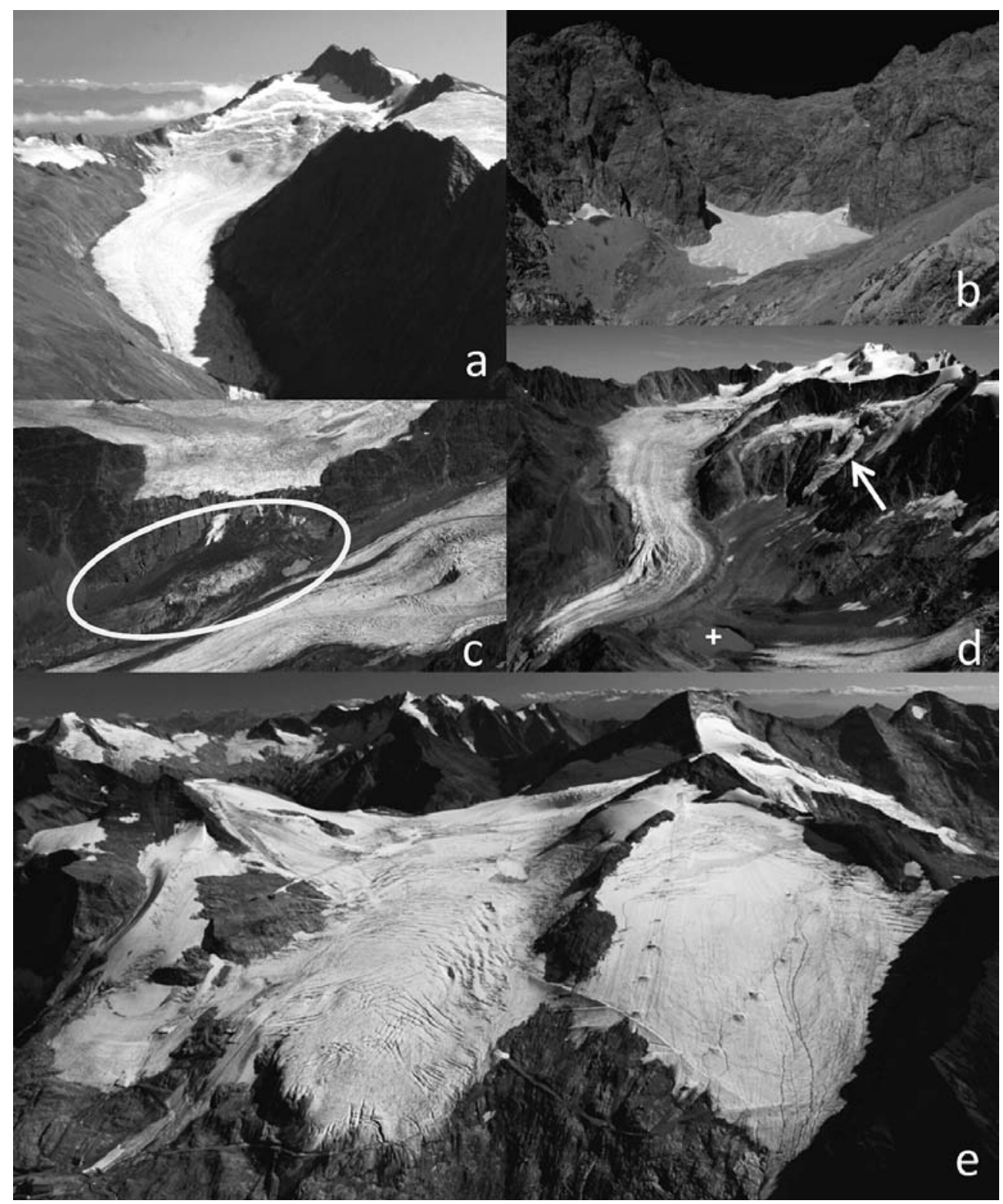

Abb. 2: Beispiele verschiedener Gletschertypen in Tirol: a) Langtaler Ferner, b) Mieminger Schneeferner, c) der westliche Rand des Gepatschfernes über dem Langtauferer Ferner - die Ellipse markiert einen regenerierten Teil des Geptaschferners, d) Taschachferner - das Kreuz markiert einen kürzlich entstandenen Gletschersee, der Pfeil markiert einen Hängegletscher an der Seite des Taschachferners, e) Gefrorener Wand Kees (Fotos: Jakob Abermann, Sep. 2008) 


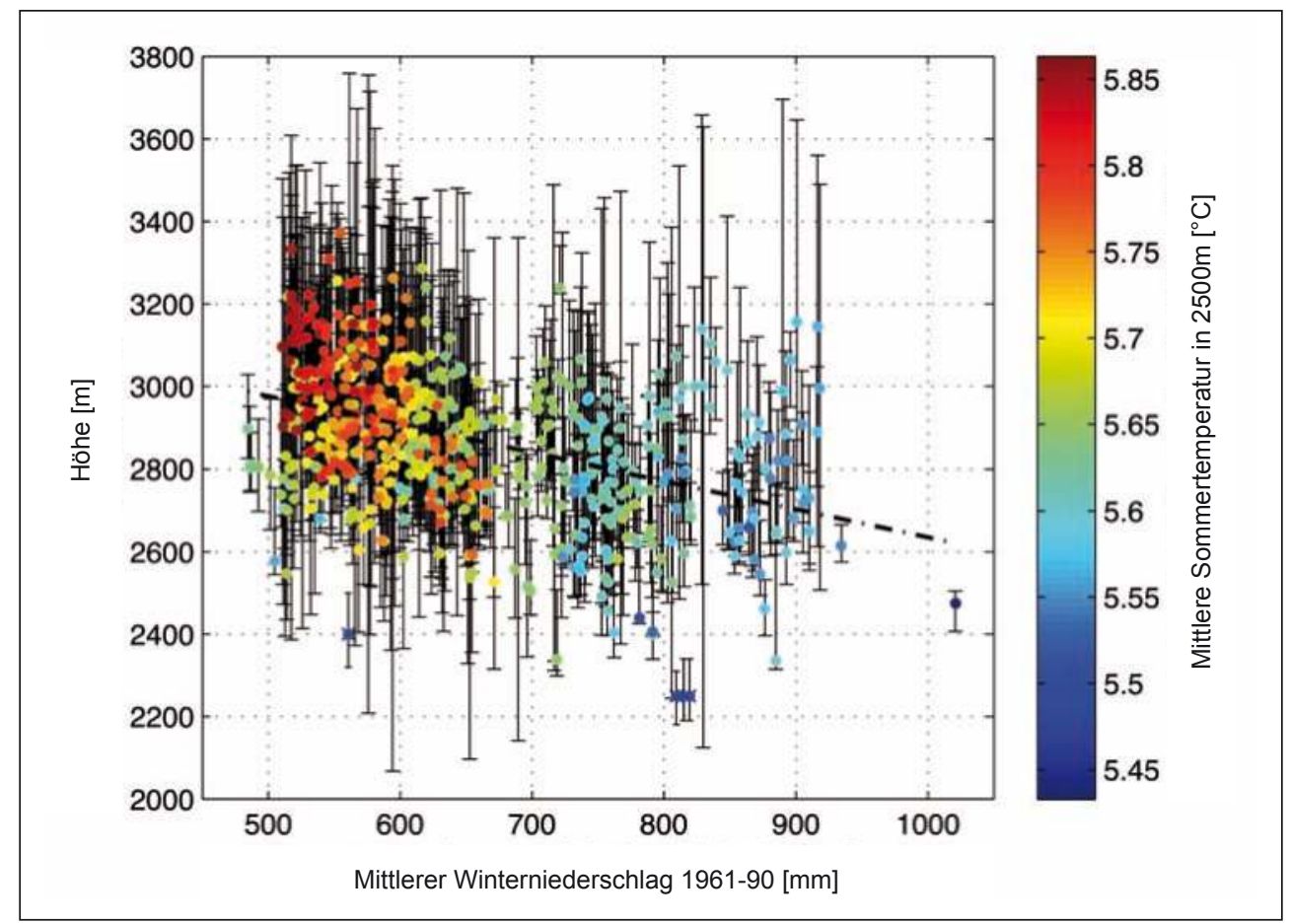

Abb. 3: Das Verhältnis zwischen mittlerem Winterniederschlag, Median- (Punkt), Maximal- und Minimalhöhe (oberer und unterer Querbalken) der Gletscher und der mittleren Sommertemperatur (Juni - August, Farbcode) in $2500 \mathrm{~m}$ Meereshöhe von allen Gletschern des Untersuchungsgebietes. Die gestrichelte Linie zeigt die Regressionsgerade zwischen Winterniederschlag und Median der Meereshöhe

teilung ist in erster Linie eine Funktion der Meereshöhe, jedoch beeinflussen Lee-Effekte stark die Sonnenscheindauer und damit auch die Temperatur. Vergleicht man Temperaturdaten gleicher Höhenlagen im Norden und Süden, zeigt sich ein schwacher, aber signifikanter Nord-Süd Gradient mit wärmeren Temperaturen im Süden. Dies ist auf maritime Einflüsse im Süden während des Winters zurückzuführen, sowie auf subtropische Hochdruckgebiete, die im Sommer den Süden des Landes erreichen (Abermann et al. 2011a).
Abb. 3 fasst die Lage der Gletscher in Relation zu den wichtigsten klimatischen Parametern zusammen. Die Temperaturdaten stammen aus den 700 und 850 hPa Druckniveaus des ERA40 Reanalyseprojekts (Uppala et al. 2005), während der mittlere Winterniederschlag mit Hilfe der HISTALP Datenbank (Efthymiadis et al. 2006) quantifiziert wurde. Details zur Berechnung des Winterniederschlags finden sich in Abermann et al. (2011a). Die maximalen und minimalen Meereshöhen stammen aus dem Österreichischen Gletscherinventar von 1998 (Lambrecht \& Kuhn 2007). Die 
Abbildung zeigt den Zusammenhang zwischen dem mittleren Winterniederschlag und dem Median der Meereshöhe. Der Korrelationskoeffizient beträgt $-0,43$ und ist statistisch signifikant (die schwarze gestrichelte Linie zeigt die lineare Regression). Der Median der Meereshöhe ist an den Gletschern der trockenen, inneralpinen Gebiete wesentlich höher. Außerdem sind diese Gletscher allgemein höheren Sommertemperaturen ausgesetzt (s. Farbcode). Die schwarzen Balken im Hintergrund stellen die vertikale Ausdehnung der Gletscher dar. Gletscher in sehr trockenen Gebieten, d. h. mit weniger als $650 \mathrm{~mm}$ Winterniederschlag, befinden sich auch in relativ warmen Gegenden, können aber durch die große Höhe der Gipfel bis in niedrige Lagen vordringen. Es ist genug Platz für große Akkumulationsgebiete vorhanden und es kann Masse in niedrige Höhenzonen transportiert werden.

Entsprechend der Langzeittemperatur- und Niederschlagskurven für das Ötztal (Fischer, Abb. 6, Kapitel 2 in diesem Buch) ist quantitativ festzustellen, dass die Temperatur in der ersten Hälfte des 20. Jahrhunderts anstieg, abgesehen von einer kurzen Unterbrechung um 1915. In den frühen 1950er Jahren kehrt sich dieser Trend um und bis in die 1970er Jahre werden negative Temperaturanomalien verzeichnet. Nach 1975 ist ein signifikanter, allmählicher Anstieg zu sehen. Die Niederschlagsdaten weisen keinen allgemeinen Trend auf, allerdings wurden einige Schwankungen dokumentiert. In jüngster Zeit gab es überdurchschnittlich viel Niederschlag. Abermann et al. (2011b) zeigt, dass sich die Tem- peratur im Untersuchungsgebiet einheitlicher geändert hat, als der Niederschlag.

\section{Gletscher-Fluktuationen}

Dank der dritten militärischen Landesaufnahme von 1870 (Abb. 4) und der Arbeit von Richter (1888) sind die Schwankungen der Tiroler Gletscher in vergangener Zeit gut bekannt.

Eine detaillierte Studie zu Gletscherflächenänderungen in Österreich von Gross (1987) hat gezeigt, dass sich die Gesamtgletscherfläche zwischen dem Maximum der kleinen Eiszeit und 1895 um $20 \%$ verringert hat, um dann bis etwa 1925 ungefähr konstant zu bleiben. Aufgrund des bereits erläuterten Temperaturanstiegs Anfang des 20. Jahrhunderts schrumpften die Gletscher bis 1969 auf eine Fläche von nur $56 \%$ des LIA- Maximums (Gross 1987).

Das erste vollständige Gletscherinventar Österreichs wurde 1969 an der Universität Innsbruck zusammengestellt (Gross 1987, Patzelt 1978, 1980). Anhand von Luftbildern aller österreichischen Gletscher wurden photogrammetrische Gletscherkarten erstellt. Diese Karten enthalten Höhenlinien, Gletschergrenzen und Schneegrenzen in Skalen von 1:10000 und 1:5000 (Kuhn et al. 2009, Lambrecht \& Kuhn 2007). Im Jahr 1969 betrug die Gesamteisbedeckung Tirols laut diesem Inventar $393 \mathrm{~km}^{2}$. 


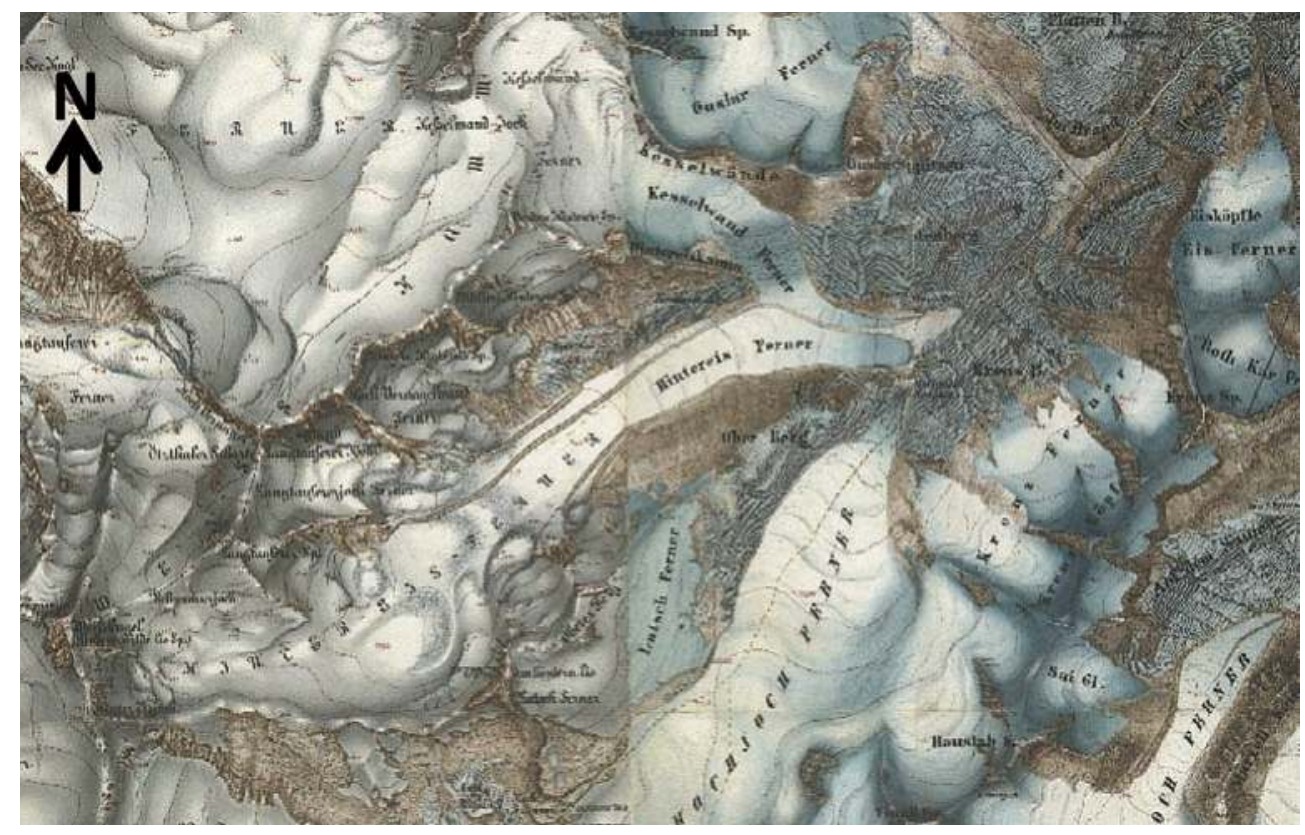

Abb. 4: Gletschergrenzen des Hintereisferners und des Kesselwandferners aus der dritten Landesaufnahme von 1870 (Abbildung: www.tiris.at)

Während einer Periode von den späten 1960er Jahren bis etwa 1985 wurde der allgemeine Rückzugstrend des 20. Jahrhunderts von einem deutlichen Gletschervorstoß in den Alpen unterbrochen (Patzelt 1985). Seitdem schrumpfen die Gletscher ununterbrochen. In den letzten Jahren hat die Geschwindigkeit des Rückzugs zugenommen (Abermann et al. 2009). Die Gewinne an Fläche, Masse und Volumen nach 1969 gingen schnell wieder verloren und die Änderungen waren so stark negativ, dass ein neues Inventar geplant wurde. Die Aufnahme von Luftbildern der ersten Gebiete erfolgte 1996 (z. B. Lechtaler Alpen) und dauerte bis zum Jahr 2002 (z. B. Verwall und Samnaun) an (Lambrecht \& Kuhn 2007). Die meisten Gletscher (73 \% der Glet- scher in Österreich und $81 \%$ der österreichischen Gletscherfläche) konnten jedoch 1997 (z.B. Stubaier und Ötztaler Alpen) und 1998 beflogen werden.

Eine neue Technik zur halbautomatischen Erstellung von DEMs auf Basis von Luftbildern wurde entwickelt. Details hierzu finden sich in Eder et al. (2000) und Würländer \& Eder (1998). Die so entstandenen hochqualitativen DEMs haben eine mittlere vertikale Genauigkeit von $\pm 0,7 \mathrm{~m}$ (Abermann et al. 2010) in einem 10 m Raster, das später auf ein $5 \mathrm{~m}$ Raster interpoliert wurde.

Die Gletschergrenzen wurden manuell auf Basis von Orthofotos erstellt. Außerdem wurde im Rahmen der Arbeiten zum neuen Inventar das alte von 1969 digitalisiert. Glet- 
schergrenzen beider Inventare, sowie zusätzliche Informationen wie Einzugsgebiet, IDNummer, Name, Gebiet und Exposition von Akkumulations- und Ablationsgebiet wurden in einem Geoinformationssystem (GIS) zusammengeführt. Verwandte Größen wie Flächen-Höhen-Verteilungen und minimale, maximale sowie mittlere Meereshöhe der Gletscher wurden ebenso erfasst (Lambrecht \& Kuhn 2007). Um für einen bestimmten Zeitabschnitt Vergleichbarkeit zu schaffen, präsentieren Lambrecht $\&$ Kuhn (2007) eine zeitliche Homogenisierung für 1998 auf Basis eines Gradtagmodells. Auf diese Weise wurde berechnet, wie groß jene Gletscher 1998 waren, die in einem anderen Jahr (d.h. zwischen 1996 und 2002) aufgenommen wurden. Die so berechnete Gesamtfläche von 1998 betrug $325 \mathrm{~km}^{2}$. Die Summe aller Eisflächen, die modifiziert wurden, beträgt $1,5 \%$ der Gesamtfläche. Es wird angenommen, dass der eingeführte Fehler in der Größenordnung von 0,1 \% liegt (Lambrecht \& Kuhn 2007).

\section{Gletscherausdehnung und Zusammenhang mit topographischen Eigenschaften}

Im folgenden Abschnitt werden die topographischen Eigenschaften der Tiroler Gletscher von 1998, sowie deren Änderungen zwischen 1969 und 1998 präsentiert. Die Abbildungen 5 a-c zeigen wichtige Parameter wie Fläche 1969 und 1998 (Abb. 5a), Anzahl 1998 (Abb. 5b), Maximum, Median und Minimum der Meereshöhe der Gletscher 1998 (Abb. 5c) in Relation zur Exposition der Gletscher. Zwei
Drittel der gesamten Gletscherfläche sind nach NW über $\mathrm{N}$ bis $\mathrm{NO}$ ausgerichtet (Abb. $5 \mathrm{a}$ und b). Ursache dafür ist einerseits, dass auf der geographischen Breite Tirols nördlich ausgerichtete Flächen beschatteter sind und weniger Globalstrahlung erhalten. Andererseits sind die Gletscher auf der Südseite der Silvretta sowie der Ötztaler, Stubaier und Zillertaler Alpen nicht im Österreichischen Inventar erfasst, sondern in den Schweizer (Kääb et al. 2002) und Südtiroler (Knoll et al. 2009) Gletscherinventaren. Da die benachbarten Gletscher bezüglich Exposition sehr ähnlich verteilt sind (d.h. maximale Fläche im nördlichen Sektor, z.B. Knoll et al. 2009), würde sich die Form der Linien in Abb. 5 nicht wesentlich ändern, wenn man die Schweizer und Südtiroler Gletscher mit einbeziehen würde. Die Anzahl der Gletscher pro Expositionsklasse ist nur für 1998 dargestellt (Abb. 5b), da sich dieser Wert seit dem letzten Inventar kaum verändert hat.

Maximum, Median und Minimum der Meereshöhe sind an jenen Gletschern niedriger, die in ihrer Exposition über eine NordKomponente verfügen (Abb. 5c). Aufgrund der topographischen Abschattung und des Einfallwinkels in nördlichen Sektoren ist hier weniger Energie für Schmelzprozesse vorhanden, als auf Flächen gleicher Höhe mit anderer Ausrichtung. Die mittleren Meereshöhen der Gletscher liegen zwischen $2600 \mathrm{~m}$ und $2800 \mathrm{~m}$.

Abb. 5d-f zeigen die Beziehung zwischen den von 1969 bis 1998 beobachteten Änderungen und der Exposition der Gletscher. 


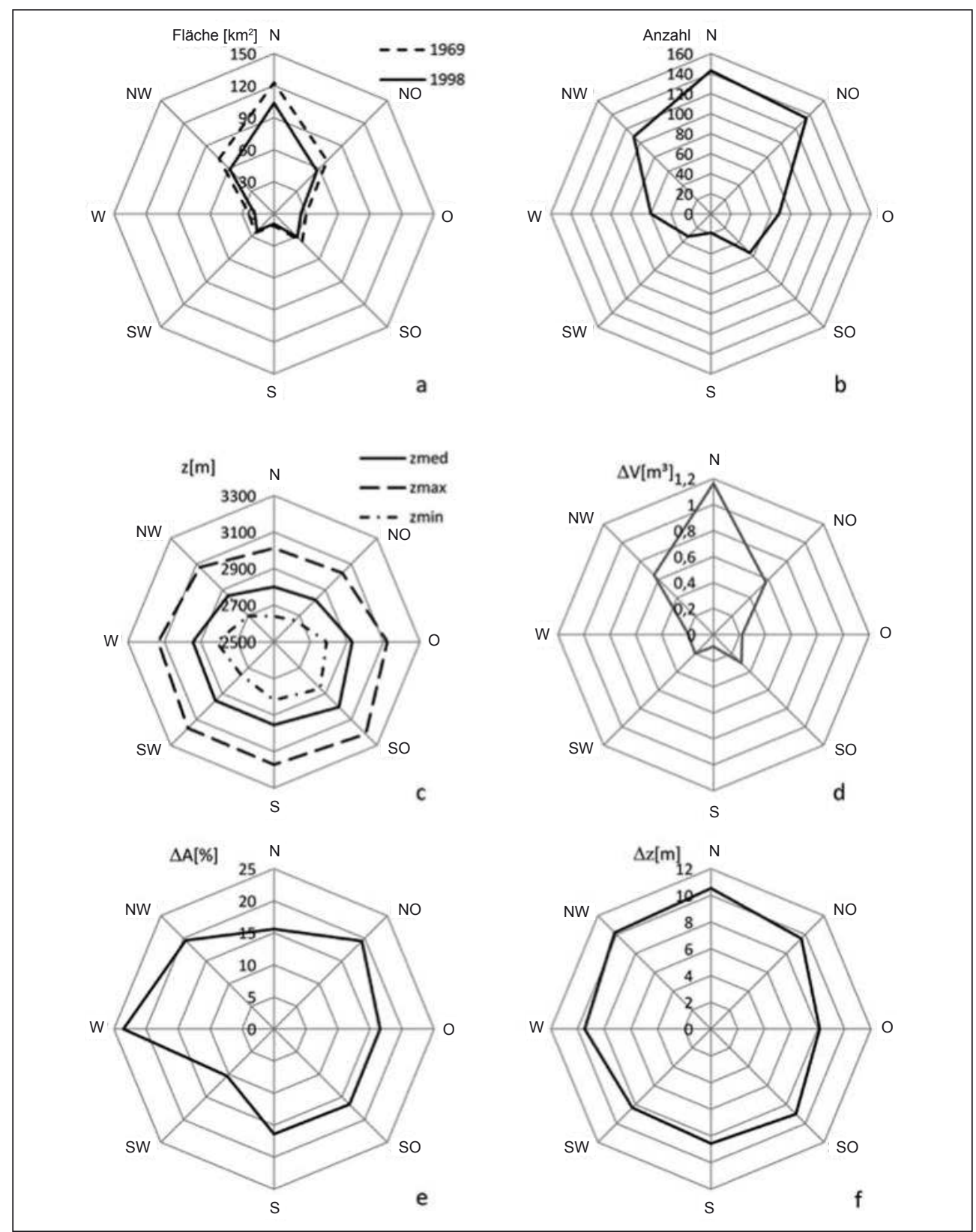

Abb. 5: Charakteristika der Tiroler Gletscher als Funktion der Exposition: a) Gletscherfläche 1969 und 1998, b) Anzahl der Gletscher 1998, c) Mittleres Minimum (zmin), Maximum (zmax) und Median der Höhe (zmed) 1998, d) Volumenverlust $(\Delta \mathrm{V})$ zwischen 1969 und 1998, e) relativer Flächenverlust $(\Delta \mathrm{A})$ zwischen 1969 und 1998, f) mittlerer Dickenverlust ( $\Delta$ z) zwischen 1969 und 1998 
Die absolute Volumensänderung ist in Abb. $5 d$ dargestellt. Wie erwartet ähnelt die Kurvenform jener der Flächenverteilung und kann, wenn nötig, für absolute Werte verwendet werden. Um Unterschiede in den Volumenänderungen auf „normalisierte“ Weise zu vergleichen, ist die mittlere Änderung der Eisdicke (Abb. 5f) besser geeignet. Dieser Wert ergibt sich, wenn man die gesamte Volumenänderung zwischen zwei Zeitpunkten durch das arithmetische Mittel der Gletscherflächen zu diesen Zeitpunkten dividiert. Durchschnittlich kam es zwischen 1969 und 1998 zur Verringerung der mittleren Eismächtigkeiten von 8-10 m. Die geringsten Verluste verzeichnen dabei die Gletscher mit östlicher Ausrichtung (8 m).
Mit über $20 \%$ Verlust waren die relativen Flächenänderungen auf westlich exponierten Gletschern am größten (Abb. 5e). Das ist auf sehr kleine, dünne Gletscher zurückzuführen, die schnell große Teile ihrer Fläche verloren haben. Absolut ist dies jedoch nicht signifikant (Abb. 5a). Am geringsten waren die Verluste mit nur - $10 \%$ auf Gletschern mit südwestlicher Exposition. Nördlich exponierte Gletscher weisen Verluste zwischen $15 \%$ und $20 \%$ auf und sind damit repräsentativ für die allgemein beobachteten Flächenänderungen. Den größten Anteil der Tiroler Gletscherfläche (134 km² im Jahr 1998, Abb. 6) bilden Gletscher mit einer Fläche von einem bis $5 \mathrm{~km}^{2}$. Nur neun Gletscher sind größer als $5 \mathrm{~km}^{2}$, dennoch machen sie über ein Viertel

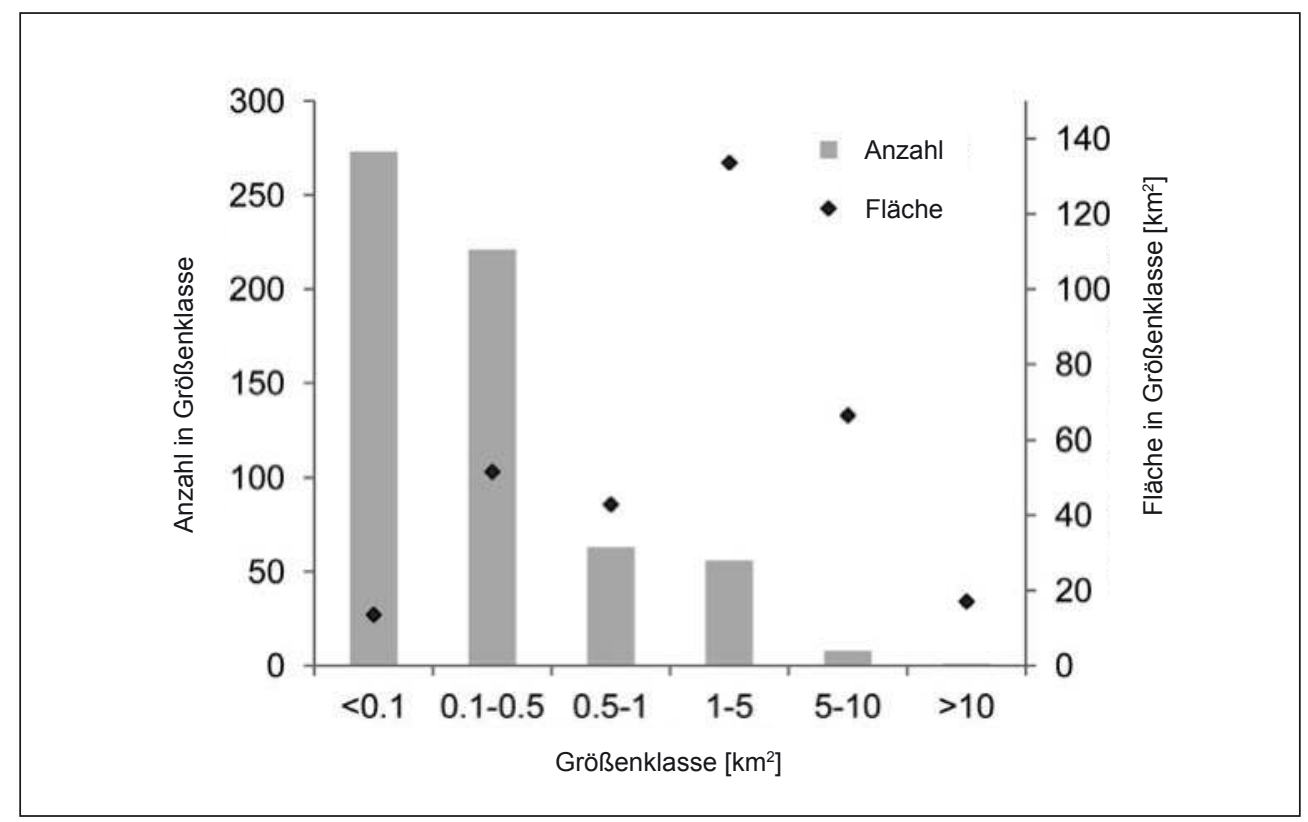

Abb. 6: Anzahl der Gletscher in den Größenklassen (linke Achse); Gletscherfläche 1998 als Funktion der Größenklasse (rechte Achse) 
der Gesamtfläche aus. Die meisten Gletscher fallen jedoch in die kleinste Größenklasse; 273 Gletscher sind kleiner als $0,1 \mathrm{~km}^{2}$. Diese kleinen Gletscher bilden dennoch einen signifikanten Anteil der Gesamtgletscherfläche, was für das im Folgenden besprochene, aktuellste Gletscherinventar von Bedeutung ist (Abermann et al. 2009).

Abb. 7 zeigt die Abhängigkeit des mittleren Minimums, Maximums und Medians der Meereshöhe der Gletscher von der Größenklasse der Gletscher. Die Streuung der Werte nimmt mit der Größe ab, wie in Abermann et al. (2011b) exemplarisch gezeigt wird. Die großen Gletscher befinden sich in Gebieten mit hohen Bergen, daher sind die maximalen Höhen groß. Die Akkumulationsgebiete dort können eine große Ausdehnung erreichen und die resultierende Dynamik sorgt für ge- ringe Minimalhöhen. Die Gletscher zwischen 5 und $10 \mathrm{~km}^{2}$ Größe haben die höchsten Medianwerte (durchschnittlich knapp über $3000 \mathrm{~m})$. Zur größten Klasse $\left(>10 \mathrm{~km}^{2}\right)$ gehört nur ein Gletscher in Tirol, der $17 \mathrm{~km}^{2}$ große Gepatschferner in den Ötztaler Alpen. Analog zu den besprochenen Betrachtungen bezüglich der Exposition zeigt Abb. 8 die Abhängigkeit der Gletscheränderungen zwischen 1969 und 1998 von der Größe der Gletscher. Die kleinste Klasse zeigt mit insgesamt $-51 \%$ die größten relativen Flächenänderungen. Gletscher größer als $5 \mathrm{~km}^{2}$ hingegen verloren nur zwischen 4 bis $11 \%$ ihrer Fläche. Für mittlere Dickenänderungen gilt der Umkehrschluss: Große Gletscher haben mit bis $\mathrm{zu}-12 \mathrm{~m}$ wesentlich mehr verloren, als Gletscher, die weniger als $1 \mathrm{~km}^{2}$ groß sind $(-8 \mathrm{~m})$. Die Erklärung hierfür liegt in der

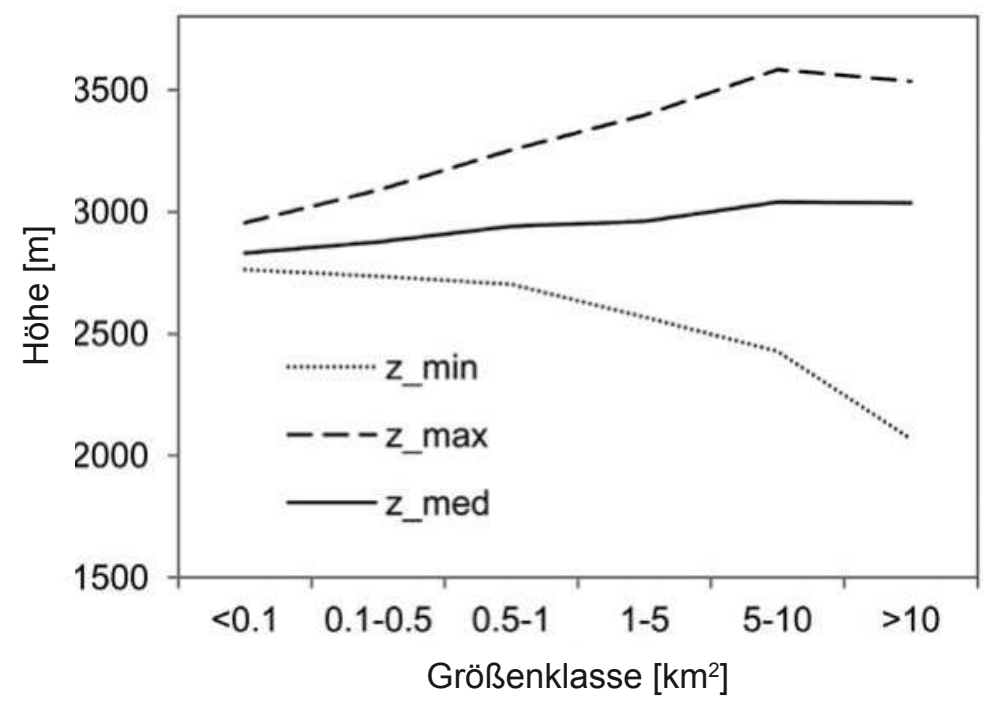

Abb. 7: Mittleres Minimum (zmin), Maximum (zmax) und Median (zmed) der Meereshöhe der Gletscher 1998 als Funktion der Größenklasse 


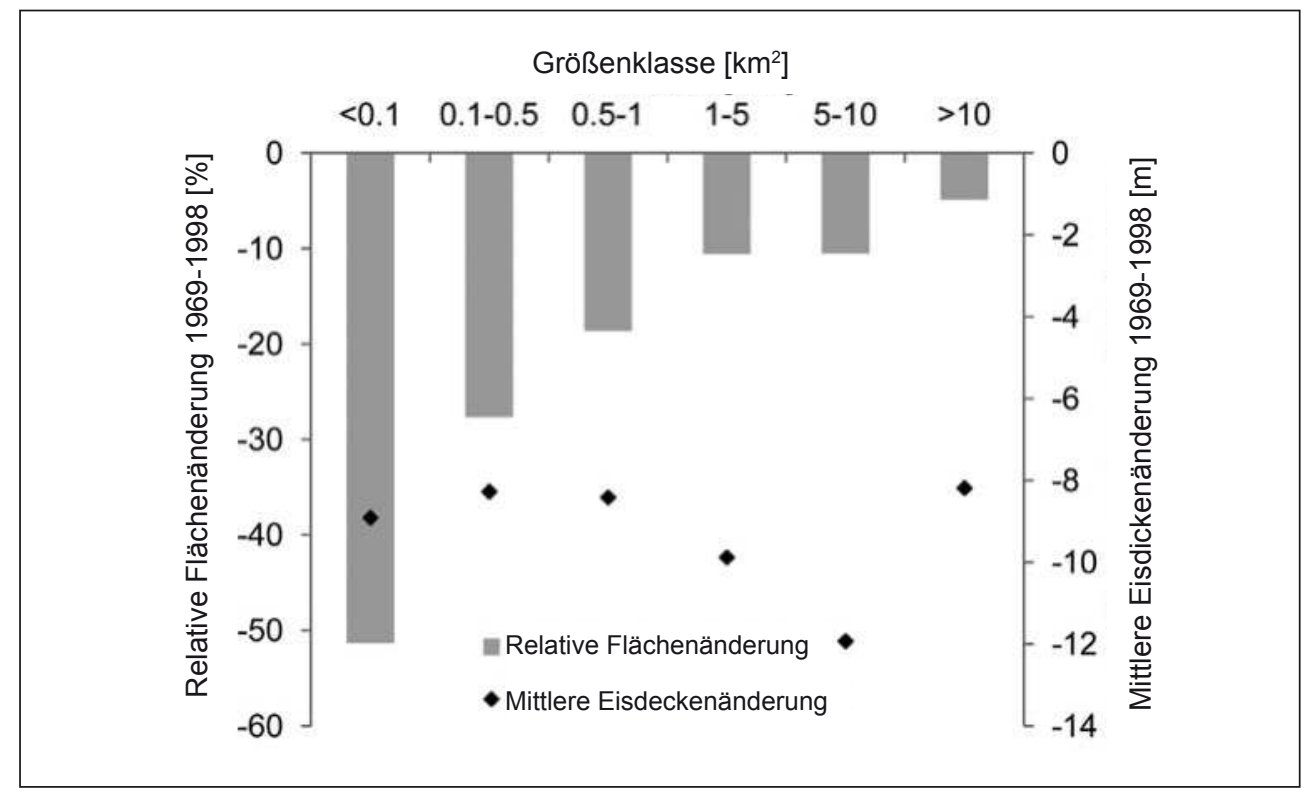

Abb. 8: Relative Flächenänderung zwischen 1969 und 1998, bezogen auf die Fläche von 1969 und die mittlere Eisdickenänderung

Geometrie der Gletscher: Der gleiche mittlere Dickenverlust bedeutet für kleine Gletscher einen größeren relativen Flächenverlust, da ihre Zungen im Allgemeinen dünner sind. Details hierzu finden sich in Abermann et al. (2011a). Der Gepatschferner, der größte Gletscher Tirols, hat im Schnitt nur $8 \mathrm{~m}$ seiner Mächtigkeit verloren. Dies ist auf den hohen Anteil der Akkumulations- an der Gesamtfläche zurückzuführen, wodurch die unteren Teile über eine starke Dynamik mit Eis versorgt werden.

\section{Jüngste Gletscheränderungen}

Während der letzten 15 Jahre war ein sehr starker Gletscherrückzug zu beobachten. Eine Reihe von Jahren mit negativen Massenbilanzen und die entsprechend großen Flächenund Volumenänderungen machten die Erstellung eines neuen Gletscherinventars notwendig. DEMs aus Airborne Laser Scanning (ALS, flugzeuggestütztes Laserscanning)-Daten wurden verwendet, um die Gletscherausdehnung im Jahr 2006 in den Ötztaler Alpen (Abermann et al. 2009), den Stubaier Alpen (Seiser 2010) und in West-Tirol (Goller 2010) zu bestimmen. Abb. 9a zeigt als Beispiel die Flächenänderungen, analysiert aus den drei Gletscherinventaren, für den Wasserfall- und 

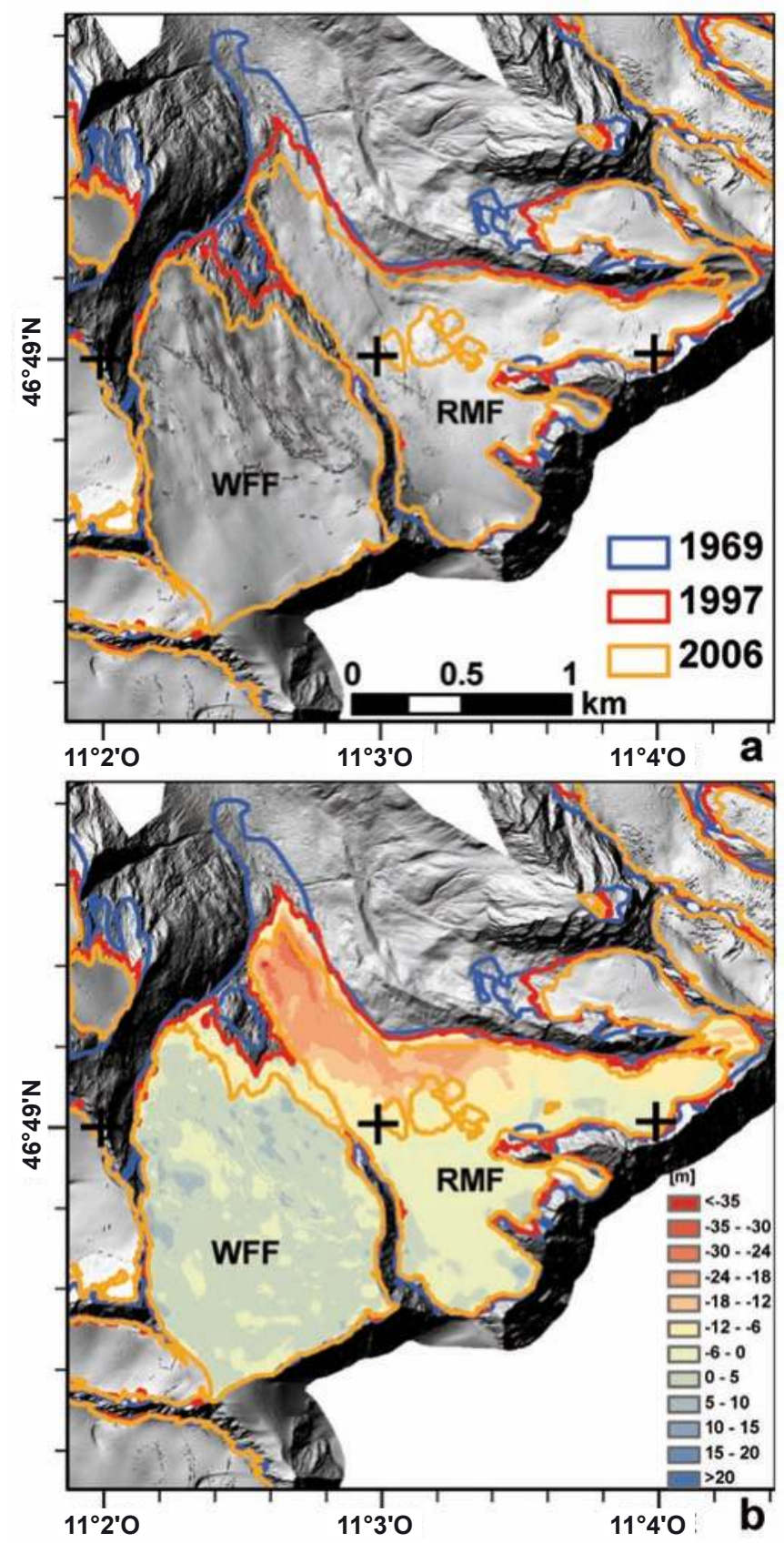

Abb. 9: a) ALS-DEM des Wasserfall- (WFF) und Rotmoosferners (RMF) und die jeweiligen Gletschergrenzen von 1969, 1997 und 2006; b) Eisdickenänderungen zwischen 1997 und 2006 (aus: Abermann et al. 2009) 
Rotmoosferner im inneren Ötztal. Letzterer wurde als Beispiel ausgewählt, da hier zahlreiche ökologische Gletschervorfeld-Studien unternommen wurden (z.B. Raffl et al. 2006, Koch \& Erschbamer 2010). Zu beachten sind die in den letzten Jahren freigelegten Felsen am Rotmoosferner (RMF) und der geringe Dickenzuwachs am Wasserfallferner (WFF), der möglicherweise auf Veränderungen in der Dynamik, im Zuge des Aufspaltens des zusammenhängenden Gletschersystems RMF und WFF in zwei separate Gletscher, zurückzuführen ist.

Abermann et al. (2009) haben anhand der drei verfügbaren Inventare die Raten der Flächen- und Volumenänderungen verschiedener Zeitabschnitte verglichen. Es zeigt sich, dass Änderungsraten im Allgemeinen zwischen 1998 und 2006 stark zugenommen haben (verglichen mit den Jahren 1969 bis 1998). Dies ist im Wesentlichen durch die im Alpenraum besonders starke Zunahme der Oberflächentemperatur bedingt. Auch die Sonnenscheindauer hat in hohen Lagen signifikant zugenommen, wodurch sich die kurzwellige Einstrahlung in diesen Gebieten erhöht (Auer et al. 2007). Die Raten der Volumenänderung nahmen wesentlich mehr zu als die Raten der Flächenänderung. Dies wird auf die geometrischen Eigenschaften der Gletscher zurückgeführt.

Die beiden am stärksten vergletscherten Regionen in Tirol sind die Ötztaler (Abermann et al. 2009) und Stubaier Alpen (Seiser 2010). Zusammen machen sie etwa 51\% der Tiroler Gletscherfläche aus. Im Vergleich dieser beiden Regionen zeigte sich ein interessanter Gradient. Während zwischen 1969 und 1998 die Dickenverluste beider Regionen etwa gleich waren $(-8,2 \mathrm{~m}$ in den Stubaier Alpen und $-8,3 \mathrm{~m}$ in den Ötztaler Alpen), waren in der Periode von 1998 bis 2006 die Verluste in den Ötztaler Alpen um 2 m größer, als jene in den Stubaier Alpen. Abermann et al. (2010) zeigen einen möglichen Zusammenhang mit positiven Anomalien des Winterniederschlags, die in den Stubaier Alpen größer waren, als in den Ötztaler Alpen. Die Temperatur entwickelte sich in beiden Regionen ähnlich. Kuhn et al. (2009) zeigten, dass die

Tab. 1: Tiroler Gletscher im österreichischen Vergleich: Anzahl, Flächen-, Volumen- und Eisdickenänderungen

\begin{tabular}{l|c|c}
\hline & Tirol & Österreich \\
\hline Gletscheranzahl & 622 & 896 \\
\hline Fläche $1969\left[\mathrm{~km}^{2}\right]$ & 393,3 & 567,1 \\
\hline Fläche $1998\left[\mathrm{~km}^{2}\right]$ & 325,1 & 469,7 \\
\hline Relative Flächenänderung [\%] & $-17,3$ & $-17,2$ \\
\hline Volumensänderung $\left[\mathrm{km}^{3}\right]$ & $-3,4$ & $-4,9$ \\
\hline Durchschnittliche Eisdickenänderung $[\mathrm{m}]$ & $-9,4$ & $-9,5$ \\
\hline
\end{tabular}


mittleren Höhen und die Höhen der Gleichgewichtslinie der Gletscher in den Stubaier Alpen geringer sind, als jene der Ötztaler Gletscher.

Die qualitativen Ergebnisse zu Untersuchungen der Gletscheränderungen in Tirol passen gut zu Studien aus anderen vergletscherten Teilen der Alpen. Aus Tab. 1 wird deutlich, dass die Änderungen in Tirol jenen in ganz Österreich sehr ähnlich und damit für Österreich repräsentativ sind.

\section{Literatur}

Abermann, J., Lambrecht, A., Fischer, A. \& Kuhn, M. (2009) Quantifying changes and trends in glacier area and volume in the Austrian Ötztal Alps (1969-19972006). The Cryosphere 3 (2): 205-215.

Abermann, J., Seiser, B. \& Fischer, A. (2010) Towards a third Austrian glacier inventory: First results and a climatic interpretation. Geophysical Research Abstracts 12, EGU2010-12379, EGU General Assembly 2010, Vienna, Austria.

Abermann, J., Kuhn, M. \& Fischer, A. (2011a) Climatic controls of glacier distribution and glacier changes in Austria. Annals of Glaciology 52 (59): 83-90.

Abermann, J., Kuhn, M. \& Fischer, A. (2011b) A reconstruction of annual mass balances of Austria’s glaciers from 1969 to 1998. Annals of Glaciology 52 (59): 127-134.
Auer, I., Böhm, R., Jurkovic, A., Lipa, W., Orlik, A., Potzmann, R. \& Schöner, W. (2007) HISTALP - historical instrumental climatological surface time series of the Greater Alpine Region. International Journal of Climatology 27 (1): 17-46.

Bonani, G., Ivy, S., Hajdas, I., Niklaus, T.R., Suter, M. et al. (1994) AMS 14C age determinations of tissue, bone and grass samples from the Ötztal Ice Man. Radiocarbon 36: 247-250.

Eder, K., Würländer, R. \& Rentsch, H., (2000) Digital photogrammetry for the new glacier inventory of Austria. IAPRS International Archives of Photogrammetry and Remote Sensing 33: 1 - 15.

Efthymiadis, D., Jones, P.D., Briffa, K.R., Auer, I., Böhm, R., Schöner, W., Frei, C. \& Schmidli J. (2006) Construction of a 10-min-gridded precipitation data set for the Greater Alpine Region for 18002003. Journal of Geophysical Research 111 (D01105): 1-22.

Fischer, A. \& Markl, G. (2008) Mass balance measurements on Hintereisferner, Kesselwandferner, and Jamtalferner 2003 to 2006. Database and results. Zeitschrift für Gletscherkunde und Glazialgeologie 42 (1): 47-83.

Fischer, A., Olefs, M. \& Abermann, J. (2010) Glaciers, snow and ski tourism in Austria's changing climate. Annals of Glaciology 52 (58): 89-96.

Fliri, F. (1975) Das Klima der Alpen im Raume von Tirol. Universitätsverlag Wagner, Innsbruck-München, 442 S. 
Fountain, A.G., Hoffman, M.J., Granshaw, F. \& Riedel, J. (2009) The 'benchmark glacier' concept does it work? Lessons from the North Cascade Range, USA. Annals of Glaciology 50: 163-168.

Goller, M. (2010) Gletscherinventar von Vorarlberg und Westtirol von 2006. Bachelorarbeit, Universität Innsbruck.

Gross, G. (1987) Der Flächenverlust der Gletscher in Österreich 1850-1920-1969. Zeitschrift für Gletscherkunde und Glazialgeologie 23 (2): 131-141.

Hoinkes, H. (1970) Methoden und Möglichkeiten von Massenhaushaltsstudien auf Gletschern. Ergebnisse der Meßreihe Hintereisferner (Ötztaler Alpen) 19531968. Zeitschrift für Gletscherkunde und Glazialgeologie 6: 37-90.

Kääb, A., Paul, F., Maisch, M. \& Häberli, W. (2002) The new remote-sensing-derived Swiss Glacier Inventory: II. First results. Annals of Glaciology 34: 362-366.

Kaufmann, R., Fuchs, M. \& Gosterxeier, N. (2002) The soil fauna of an alpine glacier foreland: colonization and succession. Arctic, Antarctic, and Alpine Research 34 (3): 242-250.

Koch, E.-M. \& Erschbamer, B. (2010) Glaziale und periglaziale Lebensräume im Raum Obergurgl. Alpine Forschungsstelle Obergurgl 1, Innsbruck University Press, Innsbruck.

Kuhn, M., Schlosser, E. \& Span, N. (1997) Eastern alpine glacier activity and climatic records since 1860. Annals of Glaciology 24: 54-59.
Kuhn, M. (2003) Redistribution of snow and glacier mass balance from a hydrometeorological model. Journal of Hydrology 282: 95-103.

Kuhn, M., Abermann, J., Bacher, M. \& Olefs, M. (2009) The transfer of mass-balance profiles to unmeasured glaciers. Annals of Glaciology 50 (6): 185-190.

Kuhn, M., Lambrecht, A., Abermann, J., Patzelt, G. \& Gross, G. (2008) Die österreichischen Gletscher 1998 und 1969, Flächen und Volumenänderungen. Vienna, Austrian Academy of Sciences Press.

Knoll, C. \& Kerschner, H. (2009) A glacier inventory for South Tyrol, Italy, based on airborne laser-scanner data. Annals of Glaciology 50 (53): 46-52.

Lambrecht, A. \& Kuhn, M. (2007) Glacier changes in the Austrian Alps during the last three decades, derived from the new Austrian glacier inventory. Annals of Glaciology 46: 177-184.

Lambrecht, A. \& Mayer, C. (2009) Temporal variability of the non-steady contribution from glaciers to water discharge in western Austria. Journal of Hydrology 376 (3-4): 353-361.

Leonhard, G., Olefs, M., Neubarth, J., Thieken, A., Schönlaub, H., Schöberl, F. \& Kuhn, M. (2009) Auswirkungen einer möglichen Klimaänderung auf ein alpines Speicherkraftwerk. Dresdener Wasserbauliche Mitteilungen 39: 475-485.

Nicolussi, K. (1993) Bilddokumente zur Geschichte des Vernagtferners im 17. Jahrhundert. Zeitschrift für Gletscherkunde und Glazialgeologie 26 (2): 97-119. 
Nicolussi, K., Kaufmann, M., Patzelt, G., van der Plicht, J. \& Thurner, A. (2005) Holocene tree-line variability in the Kauner Valley, Central Eastern Alps, indicated by dendrochronological analysis of living trees and subfossil logs. Vegetation History and Archaeobotany 14 (3): 221 234.

Olefs, M. \& Fischer, A. (2008) Comparative study of technical measures to reduce snow and ice ablation in Alpine glacier ski resorts. Cold Regions Science and Technology 52 (3): 371-384.

Patzelt, G. (1978) Der Österreichische Gletscherkataster. Almanach '78 der Österreichischen Forschung, Vienna: 129-133.

Patzelt, G. (1980) The Austrian glacier inventory: status and first results. IAHS Publ. 126: 181-183.

Patzelt, G. (1985) The period of glacier advances in the Alps, 1965 to 1980. Zeitschrift für Gletscherkunde und Glazialgeologie 21: 403-407.

Paul, F., Kääb, A. \& Haeberli, W. (2007) Recent glacier changes in the Alps observed by satellite: Consequences for future monitoring strategies. Global and Planetary Change 56: 111-122.

Raff, C., Mallaun, M., Mayer, R. \& Erschbamer, B. (2006) Vegetation succession pattern and diversity changes in a glacier valley, Central Alps, Austria. Arctic, Antarctic, and Alpine Research 38 (3): 421-428.

Rentsch, H., Eder, K. \& Geiss, T. (2004) Der Gletscherrückgang in den Ostalpen in der letzten Dekade des 20. Jahrhunderts.
Zeitschrift für Gletscherkunde und Glazialgeologie 39: 65-74.

Richter, E. (1888) Die Gletscher der Ostalpen. Stuttgart, Engelhorn.

Schöner, W. \& Böhm, R. (2007) A statistical mass-balance model for reconstruction of LIA ice mass for glaciers in the European Alps. Annals of Glaciology 46: 161-169.

Seiser, B. (2010) Gletscherinventar 2006 der Stubaier Alpen. Masterarbeit, Universität Innsbruck.

Uppala, S. M., KÅllberg, P. W., Simmons, A. J., Andrae, U., Da Costa, B., Fiorino, M., Gibson, L. K., Haseler, J., Hernandez, A., Kelly, G. A. et al. (2005) The ERA-40 re-analysis. Quarterly Journal of the Royal Meteorological Society 131 (612): 2961-3012.

Walcher, J. (1773) Nachrichten von den Eisbergen in Tyrol. Frankfurt and Leipzig, Kurzböcken.

Würländer, R. \& Eder, K. (1998) Leistungsfähigkeit aktueller photogrammetrischer Auswertemethoden zum Aufbau eines digitalen Gletscherkatasters. Zeitschrift für Gletscherkunde und Glazialgeologie 35: 167-185.

Zemp, M., Paul, F., Hoelzle, M. \& Häberli, W. (2007) Glacier fluctuations in the European Alps 1850-2000: an overview and spatio-temporal analysis of available data. In: The darkening peaks: Glacial retreat in scientific and social context, Orlove B., Wiegandt E. \& Luckmann B. (Hg.) Berkeley, CA, University of California Press, S. 11-167. 
Jakob Abermann

Österreichische Akademie der Wissenschaften

Kommission für Geophysikalische

Forschungen

Dr. Ignaz-Seipel Platz 2, 1010 Wien

Institut für Meteorologie und Geophysik

Universität Innsbruck

Innrain 52, 6020 Innsbruck

Jakob.Abermann@uibk.ac.at

Michael Kuhn

Institut für Meteorologie und Geophysik

Universität Innsbruck

Innrain 52, 6020 Innsbruck

Michael.Kuhn@uibk.ac.at
Astrid Lambrecht

Institut für Meteorologie und Geophysik

Universität Innsbruck

Innrain 52, 6020 Innsbruck

jetzt:

Kommission für Erdmessung und Glaziologie

Bayerische Akademie der Wissenschaften

Alfons-Goppel-Straße 11, 80539 München

Astrid.Lambrecht@keg.badw.de

Lea Hartl

Alpine Forschungsstelle Obergurgl

Universität Innsbruck

Gaisbergweg 3, 6456 Obergurgl

Lea.Hartl@student.uibk.ac.at 


\title{
Kapitel 4 I Zur Geschichte des Vernagtferners - Gletschervorstöße und Seeausbrüiche im vergangenen Jahrtausend
}

\author{
Kurt Nicolussi
}

\section{Zusammenfassung}

Für den Vernagtferner, Ötztaler Alpen, wird der Kenntnisstand zu den Vorstößen und Hochständen im vergangenen Jahrtausend zusammengestellt: Neben einem mittelalterlichen Hochstand (um 1300 AD) sind dies vor allem die vier neuzeitlichen, durch historische Dokumente gut dokumentierten Hochstände um 1600, 1680, 1772 und 1845. Die markanten Vorstöße des Vernagtferners stimmen zeitlich weitgehend mit den an anderen $\mathrm{Al}$ pengletschern nachgewiesenen Vorstößen überein, außergewöhnlich waren sie jedoch hinsichtlich Vorstoßgeschwindigkeiten und Reichweite, aber auch wegen der wiederholten Bildung des Eisstausees und dessen Ausbrüchen.

\section{Abstract}

The state of knowledge on the advances and maximum extents of the glacier Vernagtferner, Ötztal Alps, in the last millennium is compiled: Besides a medieval maximum extent (around AD 1300) these are mainly the four by historic documents well-documented maximum extents of the modern period around $\mathrm{AD} 1600,1680,1772$ and 1845 . The dramatic advances of Vernagtferner were largely synchronous with advances of other Alpine glaciers, though exceptional not only regarding advance speeds and range, but also because of the repeated formation of an ice lake and its outbursts.

\section{Einleitung}

Das vergangene Jahrtausend war im Alpenraum klima- und umweltgeschichtlich in Relation zur gesamten Nacheiszeit weitgehend durch kühle Temperaturen und wiederholte, weitreichende Gletschervorstöße sowie überwiegend große Gletscherstände gekennzeichnet. Dieser Zeitabschnitt wird daher heute als „Kleine Eiszeit“ (Little Ice Age) bezeichnet, deren Hauptphase vom späten 16. bis zur Mitte des 19. Jahrhunderts anzusetzen ist (auch als „neuzeitliche Gletscherhochstands- 
periode" bezeichnet, Patzelt \& Bortenschlager 1973), deren eigentlicher Beginn aber bereits in die zweite Hälfte des 13. Jahrhunderts fällt und einen ersten Höhepunkt bereits im 14. Jahrhundert aufweist (Nicolussi \& Patzelt 2001, Holzhauser et al. 2005, Nussbaumer et al. 2012). Die Rekonstruktion der Gletschervariabilität dieser Periode beruht einerseits auf naturwissenschaftlich orientierten Geländearbeiten, andererseits aber auch auf historischen Schrift- und Bildquellen (Zumbühl 1980, Zumbühl et al. 1983, Nicolussi 1993, Nussbaumer et al. 2007). Solche Dokumente liegen in für den Ostalpenraum einmaliger Detailliertheit für den Vernagtferner, Ötztaler Alpen, vor.

Der Vernagtferner ist zwar bis heute mit einer Fläche von $7,92 \mathrm{~km}^{2}$ (Stand 2010) einer der größten Gletscher Österreichs, der Gletscher bietet aber gegenwärtig keinen sehr einprägsamen Anblick. Gekennzeichnet ist der Vernagtferner heute durch ein relativ flaches, weitgespanntes und durch mehrere Felsrücken geteiltes Einzugsgebiet, wodurch der früher einheitliche Gletscher in mehrere Teilgletscher zerfallen ist, deren Gletscherzungen jeweils über $2800 \mathrm{~m} \mathrm{NN}$ enden. In der Vergangenheit bot dieser Gletscher oftmals ein gänzlich anderes Bild: Während mehrerer Vorstöße rückte der Vernagtferner gemeinsam mit dem benachbarten, zwischenzeitlich in mehrere Teile zerfallenen Guslarferner (insgesamt ca. $2.986 \mathrm{~km}^{2}$, Stand 1969) aus dem Vernagttal jeweils surgeartig, d.h. ausbruchsartig, und damit sehr rasch in das quer vorgelagerte Rofental vor und endete schließlich auf rund 2080 m NN (vgl. u.a. Abb. 8). Aufgrund der bei diesen Vorstößen erreichten hohen Fließgeschwindigkeiten zerriss die Gletscheroberfläche und war durch eine Vielzahl von Eistürmen (auch Séracs genannt) charakterisiert. Dies ist durch Schrift- und Bildquellen des 17. bis 19. Jahrhunderts gut dokumentiert. Die historischen Vorstöße des Vernagtferners erregten insofern die Aufmerksamkeit der Zeitgenossen, da es mit dem Erreichen des Rofentales zum Aufbau eines Eiskörpers zwischen Vernagttal und der gegenüberliegenden „Zwerchwand“ kam. Dieser manchmal hammerförmige Eisdamm hemmte beziehungsweise staute wiederum die Abflüsse aus dem inneren Rofentals, die gespeist wurden durch Niederschläge, Schneeschmelzwasser und auch durch die Gletscherbäche des Hintereisund des Hochjochferners, und führte so zu wiederholten Eisstauseebildungen.

Ausbrüche dieses Gletschersees bewirkten wiederholt Schäden im Ötztal und waren auch noch in Innsbruck durch höhere Wasserstände des Inns spürbar. Erst die Gefährdung durch die Eisstauseebildungen lenkte die Aufmerksamkeit der lokalen Bevölkerung und der Behörden auf den an sich abgelegenen Vernagtferner. Diese Aufmerksamkeit schlug sich auch in der erstmaligen kartographischen Darstellung eines Gletschers in einer TirolKarte nieder: In der Karte des Warmund Ygl, gedruckt 1605, ist der Vernagtferner, bezeichnet als „Groß Verner - Glacies continua et perpetua" (Meixner \& Siegl 2010), eingetragen.

Die Schriftquellen zu den Hochständen des 17. und 18. Jahrhunderts sind, abgesehen von wenigen Ausnahmen (Nicolussi 1993), bereits 
am Ende des 19. Jahrhunderts durch Eduard Richter (1892) publiziert worden, die Veröffentlichung ergänzender Bildquellen erfolgte in den letzten Jahrzehnten (Hoinkes 1969, Nicolussi 1993). Zu den Hochständen des 18. und 19. Jahrhunderts existieren bereits zeitgenössische Publikationen (Walcher 1773, Stotter 1846, Schlagintweit \& Schlagintweit 1850, Sonklar 1860). Ergänzende Kartierungen und Feldbefunde zur Vorstoßgeschichte des Vernagtferners liegen jedoch erst seit kurzem vor (Zanesco et al. 2008, Patzelt 2013). Der vorliegende Artikel stellt den Kenntnisstand zu den Vorstößen des Vernagtferners im vergangenen Jahrtausend auf Basis der erwähnten Arbeiten zusammen. Die Bilddokumentation konzentriert sich dabei auf die Gletscherentwicklung im 19. Jahrhundert.

\section{Ein Gletscherhochstand um 1300}

Die bisher älteste erfasste Vorstoß- und Hochstandsphase des Vernagtferners ist mittels Geländebefund nachgewiesen. Das Gletschervorfeld wird im Rofental auf der orographisch rechten Seite auf $2280 \mathrm{~m} \mathrm{NN}$ von einem als Doppelwall ausgebildeten Ufermoränenkomplex begrenzt. Dieser staut heute ein kleines Moor auf. Nach dem Flechtenbewuchs kann der innere Moränenwall dem Hochstand um 1845, die letzte Überlagerung des äußeren Walles jenem um 1770 zugeschrieben werden. Die Aufgrabung dieser äußeren Moräne erbrachte jedoch eine dreiphasige Ablage- rungssequenz: Unter der Überschüttung im Zuge des Hochstands des Vernagtferners im 18. Jahrhunderts befindet sich eine weitere Ablagerung, die wohl einem Hochstand des 17. Jahrhunderts zuzuweisen ist. Letztere überlagert eine weitere Moränenablagerung, die an der Basis torfiges Material bedeckt (Zanesco et al. 2008, Patzelt 2013).

Die Radiokarbon-Datierung des organischen Basismaterials ergab nach Kalibration ein Alter von 1150-1300 cal AD (kalibrierte Altersangabe mit 95,4 \% Wahrscheinlichkeit; 68,2 \% Wahrscheinlichkeit: 1210-1280 cal $\mathrm{AD}$; unkalibriertes ${ }^{14} \mathrm{C}$-Datum: $790 \pm 50 \mathrm{BP}$ ). Die Ablagerung des untersten Moränenmaterials erfolgte kurz danach, wohl um $1300 \mathrm{AD}$. Mit dem Geländebefund und der Datierung ist ein hochmittelalterlicher Gletscherhochstand des Vernagtferners nachgewiesen (Zanesco et al. 2008, Patzelt 2013).

\section{Die 1600er Hochstandsperiode}

Die erste mit Schrift- und Bildquellen belegte Vorstoßperiode des Vernagtferners datiert in die Jahre um 1600 (Richter 1892, Nicolussi 1993). Außerhalb des Ötztales wurde man wegen eines katastrophalen Ausbruchs des Eisstausees des Vernagtferners am 20. Juli 1600 auf die Gletscheraktivität aufmerksam. Nach den zeitgenössischen Schilderungen hatte der Gletscher bereits 1599 das Rofental erreicht, womit die Bildung des Eisdammes begann; ein Seeausbruch noch im Jahr 
1599 wird nicht erwähnt. Die Vorstoßaktivität hielt zumindest auch im Jahr 1601 noch an. Dies lässt sich nach einer aquarellierten Federzeichnung (Abb. 1) aus diesem Jahr erkennen (Nicolussi 1993). Die Gletscherzunge des Vernagtferners, aufgenommen von der gegenüberliegenden, "Zwerchwand“ genannten Flanke des Rofentales, ist mit einer zerrissenen, in einzelne Eistürme aufgelösten Oberfläche dargestellt. Dieses für sehr schnell fließende Gletscher typische Merkmal in der Zeichnung lässt auch für den Sommer 1601 einen anhaltenden Eisnachschub und damit ein weiteres Vorrücken der Eisfront im Rofental annehmen. Zum Zeitpunkt der Bildaufnahme am 9. Juli 1601 lag das Zungenende des Vernagtferners bereits rund 630-680 m talab der Mündungsstelle des Vernagtbaches in die Rofenache.

Der in Abb. 1 dargestellte See hatte eine Länge von ca. 1700 m, was eine Seespiegelhöhe von ca. $2260 \mathrm{~m}$ bedingt. Der See stieg in den Folgetagen weiter an und begann am 12. Juli, nach Erreichen eines Spiegelniveaus von etwa
2265 m, zwischen Zwerchwand und Eisdamm überzulaufen. Im Anschluss daran kam es zu keiner neuerlichen Eisstauseebildung, jedenfalls fehlen entsprechende historische Berichte. Offensichtlich waren der Eisnachschub und damit der Druck des Gletschers nicht mehr intensiv genug, um die beim letzten Ausbruch gebildeten Durchlässe im Eisdamm wieder zu verschließen. Das Ende des Vorrückens der Eisfront ist nicht bekannt, allerdings kann es in Analogie zu den besser dokumentierten späteren Hochständen für das Jahr 1602 angenommen werden. Auch die maximale Vorstoßreichweite ist nicht genau bestimmbar, da direkte Zeugen wie Moränen nicht erhalten sind, und sie kann nur abgeschätzt werden: Das Maximum lag wohl ca. 670-710 m talabwärts der Mündungsstelle des Vernagtbaches (Nicolussi 1993).

Während dieses ersten neuzeitlichen Vorstoßes reichte der Eisdamm an der Zwerchwand bis auf 2275-2285 m NN (Nicolussi 1993). Damit blieb der Gletscher unter dem in den 1770er Jahren erreichten Maximum von 2295

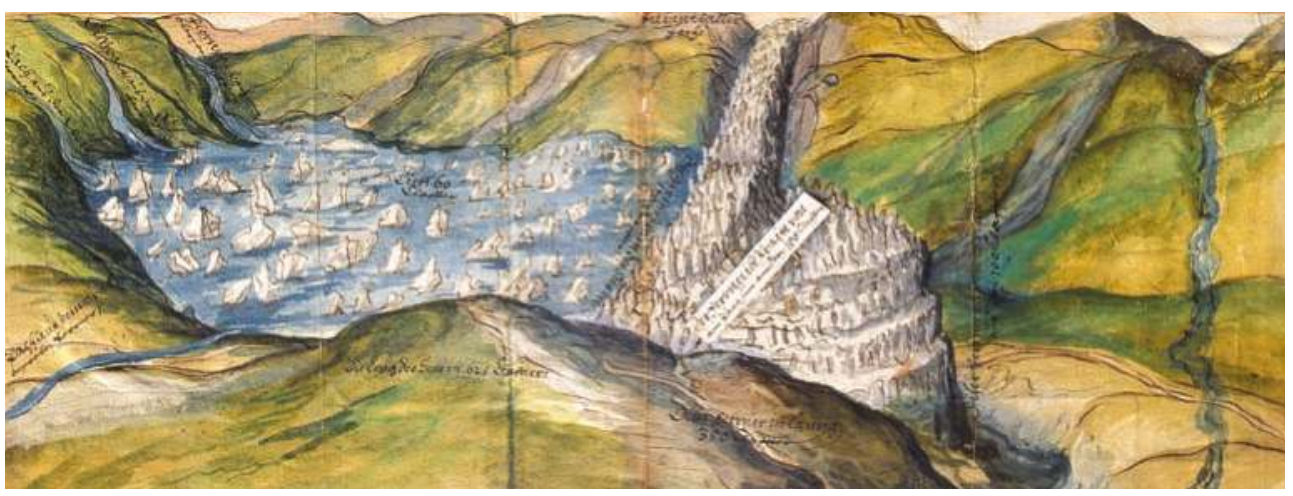

Abb. 1: Der Vernagtferner und der Eisstausee, 9. Juli 1601, nach Abraham Jäger. Aquarellierte Federzeichnung, $220 \times 525$ mm (Tiroler Landesmuseum Ferdinandeum). Diese Darstellung ist bis heute die älteste bekannte Ansicht eines Gletschers weltweit (Nicolussi 1993) 
$\mathrm{m} N \mathrm{~N}$, übertraf hingegen die maximale Eishöhe des Hochstandes in den 1840er Jahren von 2272-2275 m NN (Finsterwalder 1897, Patzelt 2013).

\section{Die 1680er Hochstandsperiode}

Die zweite mit historischen Quellen dokumentierte Hochstandsperiode des Vernagtferners datiert in die Jahre um 1680 (Richter 1892). Erste Nachrichten über ein Vorrücken des Gletschers stammen aus dem Jahr 1676, im November 1677 erreichte der Gletscher schließlich die Zwerchwand (Nicolussi 1993). Eine Darstellung aus dem Jahr 1678 zeigt den Vernagtferner wiederum mit der typischen, in viele Eistürme aufgelösten Oberfläche (Hoinkes 1969, Nicolussi 1993). Ein erster Seeaufstau geschah nach historischen Nachrichten ab Mai 1678 und bereits am 24. Mai desselben Jahres erfolgte ein erster Ausbruch, der ohne nennenswerte Schäden im Ötztal ablief (Richter 1892). Der Eisdamm im Rofental war Ende Juni 1678 bereits rund $665 \mathrm{~m}$, am 6. Juli schließlich ca. $675 \mathrm{~m}$ lang und reichte an der Zwerchwand bis in eine Höhe von ca. 2240 m NN (Nicolussi 1993). Das Gletscherende lag Mitte 1678 bereits rund 320-380 m talabwärts der Mündung des Vernagtbaches in die Rofenache, woraus sich für den Zeitraum von Ende 1677 bis Jahresmitte 1678 eine mittlere Vorstoßgeschwindigkeit von rund $50 \mathrm{~m} /$ Monat ableiten lässt.
Nach dem Ausbruch am 24. Mai 1678 bildete sich der Eisstausee neu und erreichte am 27. Juni 1678 schon eine Länge von rund $600 \mathrm{~m}$ sowie am 6. Juli eine von ca. 1100 $\mathrm{m}$. Der See vergrößerte sich auch in den folgenden Tagen weiter, so stieg der Wasserstand bis zum 12. Juli um ca. $11 \mathrm{~m}$ auf ca. $2230 \mathrm{~m} \mathrm{NN}$, bevor ein Ab- beziehungsweise Überlaufen begann, das in der Nacht des 16./17. Juli 1678 in einem für das Ötztal katastrophalen Ausbruch kulminierte (Richter 1892).

Im Jahr 1679 wurde der weitere Vorstoß des Vernagtferners bereits messend beobachtet (Nicolussi 1993) und nach Auswertung der historischen Quellen kann die Position des Gletscherendes für Ende Mai 1679 mit ca. 560-580 m talab der Mündung des Vernagtbaches in die Rofenache bestimmt werden. Nach den Quellen lag der Gletscherstand damals aber noch hinter dem Maximum der Hochstandsperiode von 1600. Seit der Jahresmitte 1678 rückte der Gletscher damit insgesamt etwa 170 bis $230 \mathrm{~m}$ beziehungsweise rund 15-20 m/Monat vor, was eine deutliche Verlangsamung gegenüber $1677 / 78$ bedeutete. Ende Mai 1679 lag die Eisgrenze an der Zwerchwand bereits in einer Höhe von ca. $2290 \mathrm{~m} \mathrm{NN}$ und hatte damit ihr Maximum während dieser Vorstoßperiode wohl erreicht (Nicolussi 1993).

Der Eisstausee wies Ende Mai 1679 eine Länge von rund $1500 \mathrm{~m}$ auf, woraus sich eine Seespiegelhöhe von ca. $2240 \mathrm{~m} \mathrm{NN}$ ableiten lässt. Für Mitte Juni 1679 ist ein Seeausbruch nachweisbar, der ohne Schäden abging (Nicolussi 1993). Im Gegensatz dazu verursachte ein 
weiterer Seeausbruch am 14. Juni 1680 wiederum eine Reihe von Sachschäden im Ötztal. Im Folgejahr 1681 erreichte der Eisstausee eine wohl außergewöhnliche Ausdehnung: Anfang Juli 1681 lag der Seespiegel bei ca. 2280 m NN oder knapp darunter (Abb. 2). Durch Aushacken beziehungsweise Anlegen eines Überlaufkanals an der Zwerchwand kam es zu einem Sinken des Wasserstands auf rund $2170 \mathrm{~m} \mathrm{NN}$ und zu einem schadlosen Abfluss des Sees (Richter 1892, Nicolussi 1993).

Zum Vernagtferner selbst liegen aufschlussreiche Informationen nach 1679 erst wieder für das Jahr 1681 vor. Danach war die Gletscherzunge im Rofental nun „hart und blau“, die ein schnelles Vorrücken anzeigende aufgerissene Oberfläche war also verschwunden.

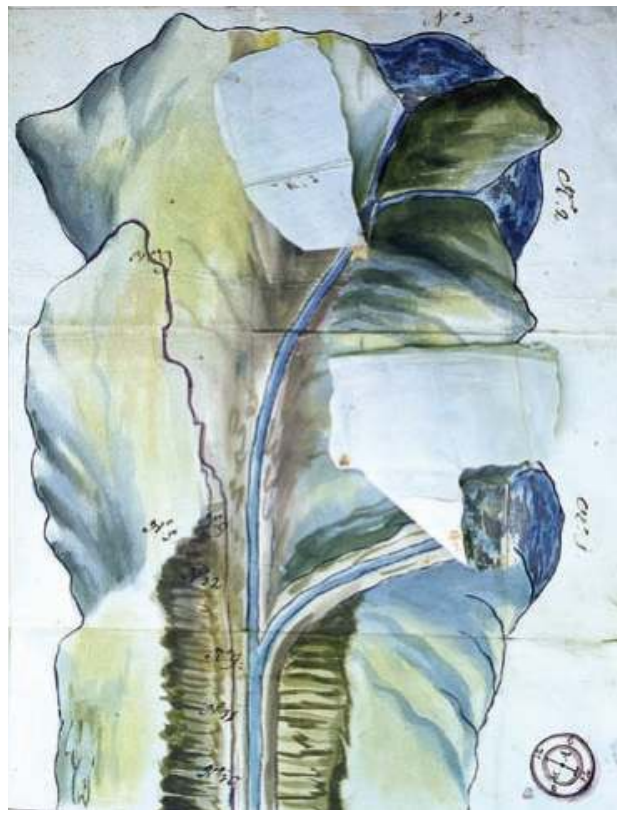

Gleichzeitig soll der Vernagtferner bereits eingesunken gewesen sein, eine Bemerkung, die wohl auf den Zuflussbereich im untersten Vernagttal und den Eisdamm selbst zu beziehen ist. Der Maximalstand dieser Vorstoßperiode kann also für 1681 angenommen werden.

Die Endposition des Vernagtferners während dieser Vorstoßperiode ist nicht exakt bekannt und ist nur eingrenzbar, da entsprechende Geländebelege vom nachfolgenden 1770er Vorstoß, der nach Moränenablagerungen rund 800 m talabwärts des Referenzpunktes Mündung Vernagtbach reichte, überfahren und damit zerstört wurden. Allerdings dürfte kein wesentlicher Größenunterschied zwischen 1680er und 1770er Hochstand anzunehmen sein, da nach zeitgenössischen Nachrichten

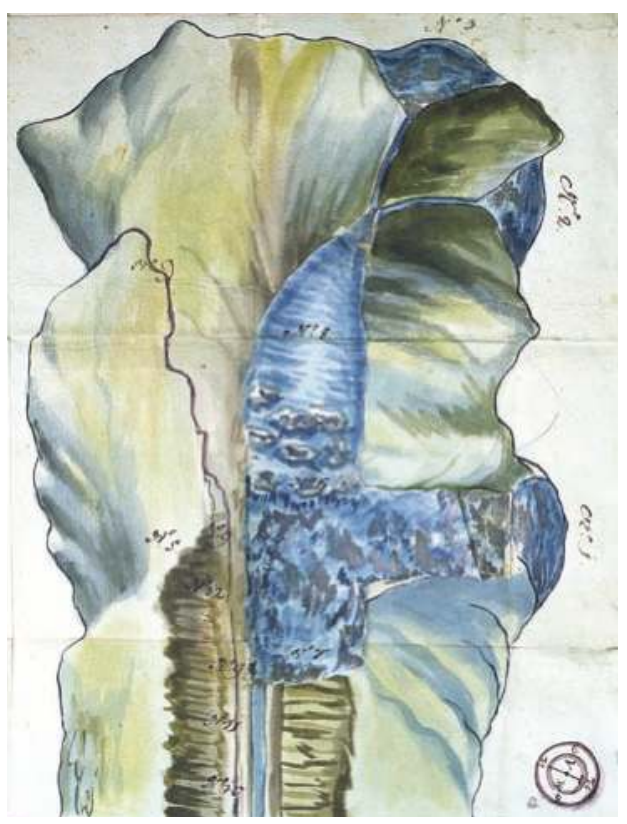

Abb. 2: Ausschnitt aus dem Plan des Rofentals mit der Situation des Flussnetzes und der Gletscherausdehnung 1677 (links) und 1681 (rechts), dat. 15. Juli 1681. Aquarellierte Federzeichnung, insgesamt 480 x 360 mm, Bildteil 390 x 360 mm (Tiroler Landesmuseum Ferdinandeum) 
die Gletscherzunge des Vernagtferners erst am Ende des Vorstoßes in den 1770er Jahren die frühere Ausdehnung erreichte beziehungsweise überschritt. Entsprechend lässt sich der Maximalstand für das Jahr 1681 bei rund 780-800 m talab der Vernagtbach-Mündung ableiten.

Auch zur maximalen Seegröße der 1680er Vorstoßperiode gibt es Angaben aus dem 18. Jahrhundert: Danach soll der Eissee eine Länge von bis zu ca. $2340 \mathrm{~m}$ gehabt haben, was einer Seespiegelhöhe von etwa 2290 m NN und damit in etwa der maximalen Eishöhe an der Zwerchwand entsprechen würde. Unklar ist allerdings, worauf diese Nachrichten aus den Jahren um 1770 beruhen. Denkbar sind Angaben in heute unbekannten Quellen oder zeitgenössische Beobachtungen im Gelände (Nicolussi 1993).

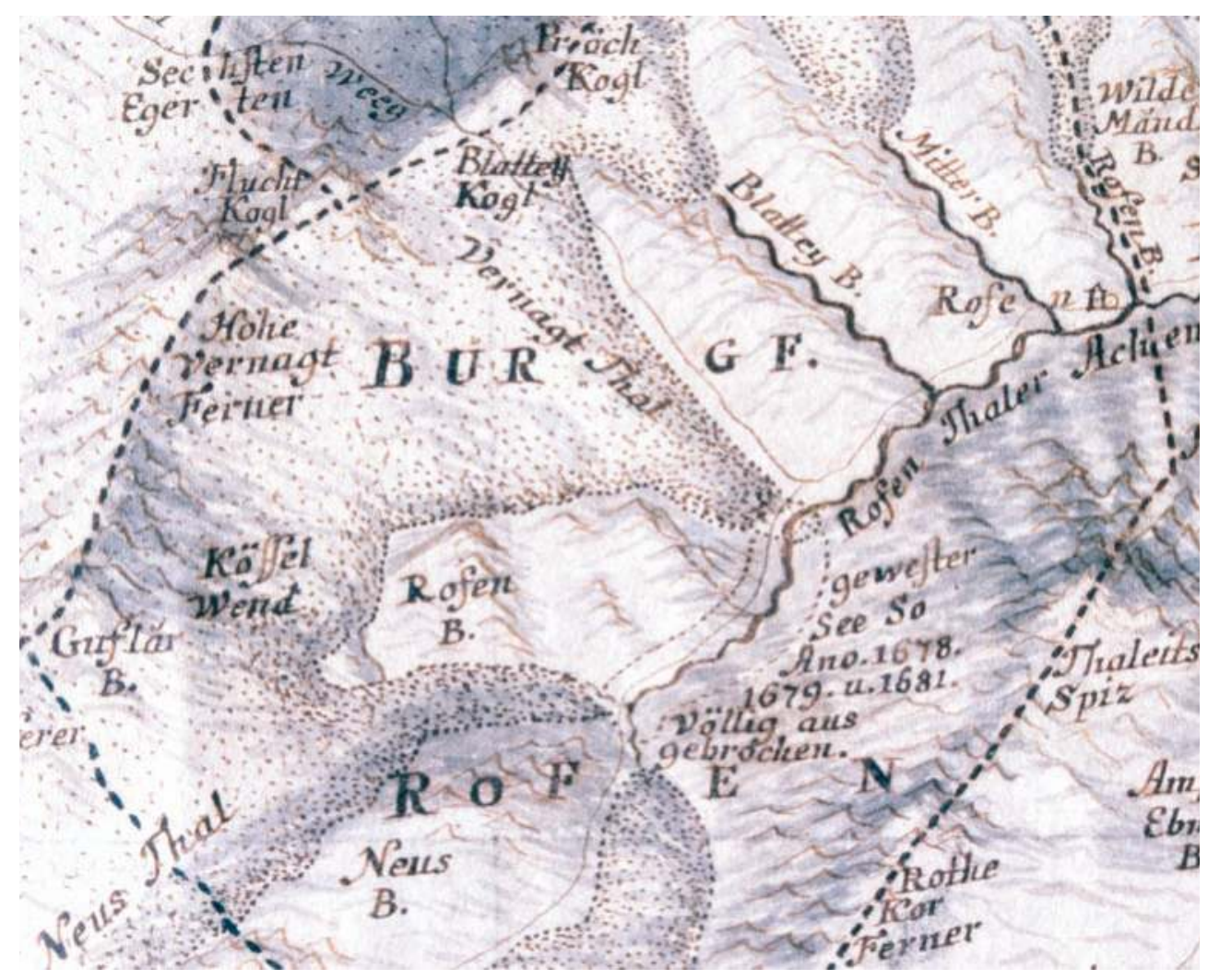

Abb. 3: Das innere Rofental im Atlas Tyrolensis. Ausschnitt aus der Originalzeichnung der verkleinerten, ungedruckten Karte von Peter Anich, Maßstab ca. 1:138.000, gez. 1764. Federzeichnung (Tiroler Landesmuseum Ferdinandeum) 


\section{Die 1770er Hochstandsperiode}

Der Beginn der Hochstandsperiode des Vernagtferners ca. 1770/75 wurde in der 1774 gedruckten Karte von Tirol (Atlas Tyrolensis, ca. 1:103.800, Kinzl 1976) kartographisch und textlich festgehalten. Bei diesen Karteneintragungen handelt es sich um Ergänzungen der früher durchgeführten Aufnahme: Die Kartierungen für den Atlas Tyrolensis wurden im Tiroler Oberland bereits in den Jahren 1760/63 durchgeführt (Hye 1976), eine 1764 von Peter Anich erstellte, handgezeichnete Version des Atlas Tyrolensis (Hye 1976) zeigt den Vernagtferner entsprechend noch vor Beginn der 1770er Vorstoßperiode (Abb. 3): Nach dieser Originalzeichnung hatte der Gletscher 1760/63 eine relativ große Ausdehnung und das Zungenende lag gerade 250-500 m oberhalb des Rofentales.

Nachrichten über ein Vorrücken des Vernagtferners liegen ab Juni 1771 vor: Am 27. Juni war das Gletscherende noch etwa 500 (400600) $\mathrm{m}$ von der Rofenache entfernt (Richter 1892). Im August desselben Jahres rückte der Vernagtferner bis zur Zwerchwand vor und Ende des Monats bildete der Vernagtferner bereits einen rund $250 \mathrm{~m}$ langen und an der Zwerchwand knapp $40 \mathrm{~m}$ hinaufreichenden Eisdamm. Die mittlere Vorstoßgeschwindigkeit von Ende Juni bis Ende August 1771 kann damit auf rund $10 \mathrm{~m} /$ Tag geschätzt werden. Ähnliche Vorstoßbeträge wurden auch 1845 unmittelbar vor Erreichen der Rofenache beobachtet. Mit dem schnellen Anwachsen des Eisdammes begann auch wieder die
Eisstauseebildung. Der See hatte Ende Oktober 1771 bereits eine Länge von knapp $400 \mathrm{~m}$ und am 16. November eine von rund $750 \mathrm{~m}$. Der Vorstoß und damit das Anwachsen des Eisdamms im Rofental setzte sich im Winter 1771/72 mit durchschnittlich rund $16 \mathrm{~m}$ pro Woche fort, um den 24. April 1772 war der Eisdamm bereits 760 bis $870 \mathrm{~m}$ lang. In weiterer Folge, von Mitte April bis Anfang Juni, rückte das Gletscherende noch mit etwa $12 \mathrm{~m} /$ Woche talauswärts vor (Richter 1892) und dieses befand sich Anfang Juni 1772 etwa 450-500 m nördlich der Vernagtbach-Mündung. Bemerkenswert sind die Vermerke in den Berichten von Juni und Juli 1772, dass der Eisdamm die Höhe des Eises von „1680“ bereits erreicht habe (Richter 1892). Im Lauf des Sommers 1772 verlangsamte sich die Vorstoßgeschwindigkeit weiter und lag in der zweiten Augusthälfte beziehungsweise Anfang September talabwärts bei ca. $9 \mathrm{~m}$ pro Woche (Walcher 1773).

Bereits früh im Jahr 1772, und zwar Ende April, soll der Eissee bereits rund $1700 \mathrm{~m}$ (Seespiegelhöhe ca. $2250 \mathrm{~m} \mathrm{NN}$ ) lang gewesen sein. Die folgenden Nachrichten berichten ein weiteres Ansteigen des Seespiegels (Richter 1892). Für den 16. August 1772 wird die Länge des Eissees (Abb. 4) allerdings mit rund 1300 m (Seespiegelhöhe ca. 2240 m NN) angegeben (Walcher 1773), ohne dass für die Monate davor ein markantes Abflussereignis oder eine Erhöhung der Wasserführung in der Rofenache in den Quellen vermerkt ist.

Relativ wenige Nachrichten sind zur Entwicklung des Eisstausees im Jahr 1773 verfügbar: Danach war das Spiegelniveau zu Sommerbe- 


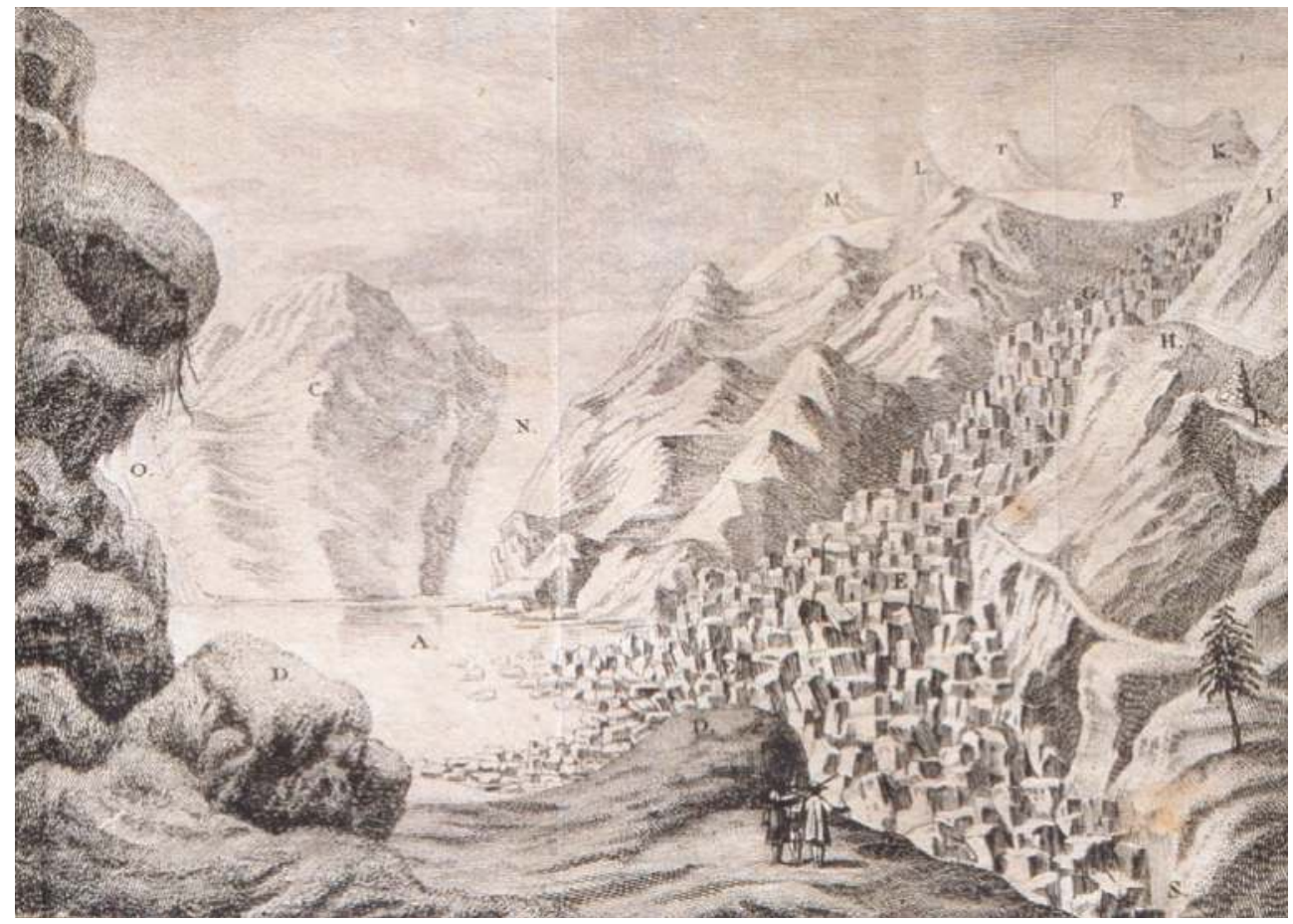

Abb. 4: „Der Rofener Eissee am 16. August Jahr 1772“. Kupferstich, 101x218 mm (Walcher 1773)

ginn bereits einige Meter höher als jenes von 1772. Berichtet wird auch von zwei Hochwasserereignissen, um den 11. Juli und am 23. Juli 1773, die allerdings ohne Schadensfolgen blieben (Richter 1892).

Der Gletschervorstoß hielt 1773 und auch im folgenden Winter 1773/74 an. Schließlich wird vermerkt, dass der Vernagtferner an vielen Stellen nun seine frühere Ausdehnung erreicht beziehungsweise übertroffen habe (Richter 1892). Mit 1774 versiegen die Berichte, die Situation wurde ab diesem Sommer als ungefährlich eingestuft. Entsprechend ist anzunehmen, dass auch der Gletschervorstoß im Jahr 1774 zu Ende ging. Erhaltene Moränenablagerungen belegen, dass der Vernagt- ferner damals ca. $800 \mathrm{~m}$ über die Mündungsstelle des Vernagtbaches die Rofenache hinaus reichte. Diese Moränen dokumentieren, dass der Vernagtferner während der Vorstoßperiode in den 1770er Jahren seine maximale neuzeitliche Ausdehnung erreichte.

Im Jahr 1774 blieb der Seeauslauf ab Neujahr verschlossen, der Wasserspiegel stieg an und der Eisstausee erreichte den Hintereisferner, was eine Mindesthöhe des Seespiegels von ca. $2230 \mathrm{~m}$ erfordert. Vom 12. bis 22. Juni stieg der Wasserstand um rund $10 \mathrm{~m}$ an und reichte damit bis auf wenige Meter an die Oberkante des Eisdammes heran (Richter 1892). Damals dürfte die Spiegelhöhe des Eisstausees bei ca. 2270-2280 m NN gelegen haben. Ab dem 


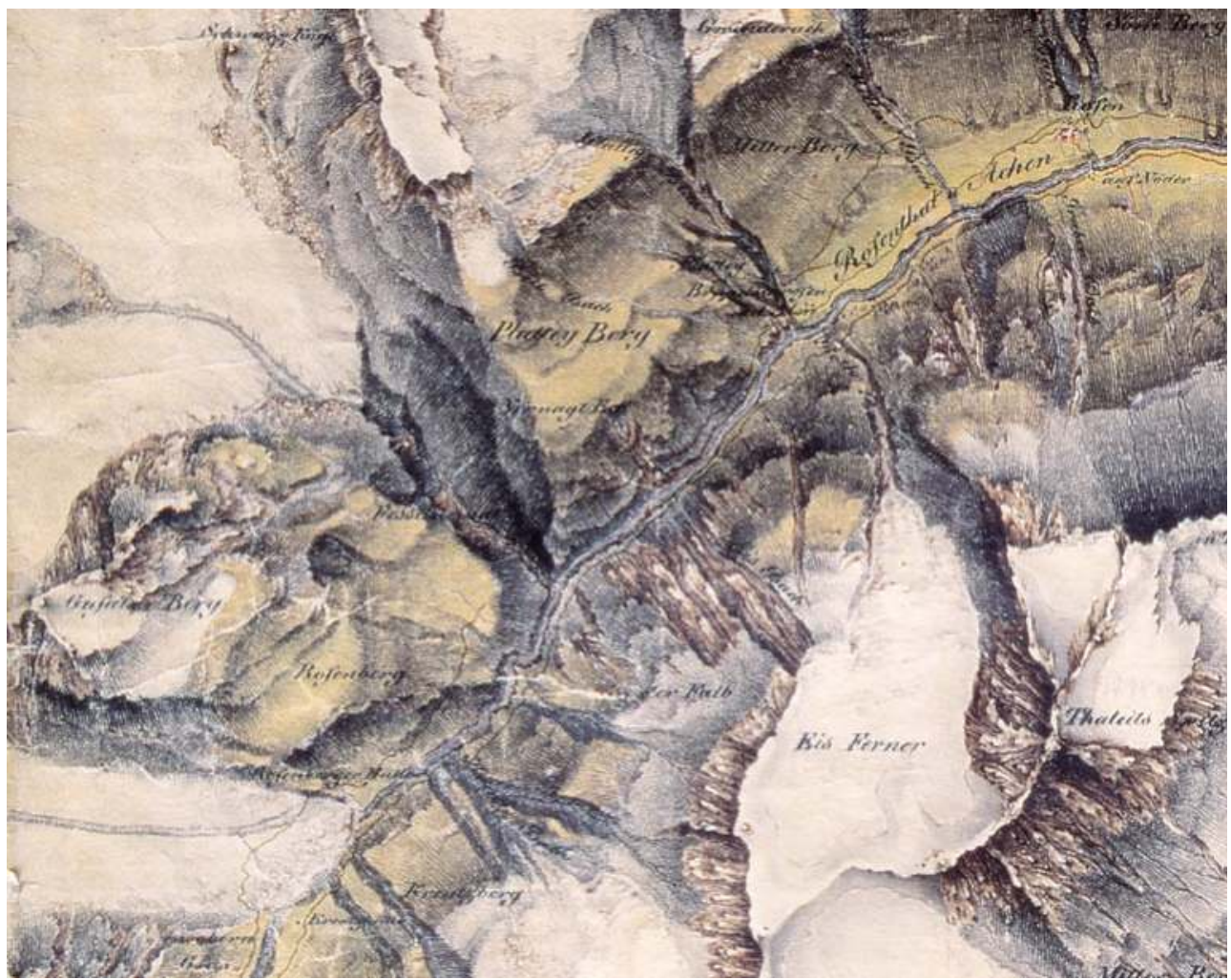

Abb. 5: Das Rofental mit den Gletscherzungen von Vernagt- und Hintereisferner. Ausschnitt aus der kolorierten Handzeichnung der Zweiten oder Franziszeischen Landesaufnahme, Section 68, Originalmaßstab 1:28.800, aufgenommen 1817, 71 x $46 \mathrm{~cm}$ (Kriegsarchiv Wien)

26. Juni 1774 begann der See abzulaufen und der Seespiegel sank, zuerst um etwa 10-20 m. Am 4. Juli beschleunigte sich der Vorgang und der Großteil des Eissees floss innerhalb von 12 Stunden ab (Richter 1892). Eine Chronik aus Längenfeld, verfasst von einem Anton Schöpf (Bote für Tirol 1867), verzeichnet auch für die Folgejahre bis 1780 weitere Eisstauseebildungen und Abflüsse ohne jedoch Angaben zu den jeweiligen Seedimensionen zu machen.

\section{Der 1820er Vorstoß}

Die Gletscherentwicklung im frühen 19. Jahrhundert ist wiederum durch eine Kartenaufnahme sowie zeitgenössische Berichte dokumentiert. Das Kartenblatt der Franziszeischen Landesaufnahme (Aufnahmemaßstab 1:28.800) stellt für das angeführte Aufnahmejahr 1817 den Vernagtferner mit einem Gletscherende dar, das rund $1400 \mathrm{~m}$ vom Rofental entfernt lag (Abb. 5). Sowohl 
die schmale Mittelmoräne zwischen Guslarund eigentlichem Vernagtferner als auch die vergleichsweise breit gezeichnete Gletscherzunge deuten auf eine bereits eingesetzte erhöhte Fließdynamik hin. Folgt man den Schriftquellen begann der Vorstoß allerdings erst 1820 (Stotter 1846, Finsterwalder 1897) und dauerte bis 1822. Daran war allerdings diesmal nicht der Guslarferner, sondern nur der eigentliche Vernagtferner beteiligt. Die Gletscherstirn rückte 1820-22 bis nahe an die Rofenache vor, überschritt diese jedoch nicht. Noch im Jahr 1822 begann bereits das Abschmelzen (Stotter 1846), das wohl rasch erfolgte, da die Gletscherzunge in der Schlucht des Vernagtbaches nur schmal ausgebildet war.

\section{Die 1850er Hochstandsperiode}

Diese Hochstandsperiode ist durch vergleichsweise viele Schrift- und Bildquellen dokumentiert. Erste Beobachtungen einer erhöhten Fließdynamik beziehen sich auf den unteren Abschnitt des Guslarferners und datieren in das Jahr 1840. Das gemeinsame Gletscherende von Guslar- und Vernagtferner war damals stark schuttbedeckt und zeigte noch keine Vorstoßaktivitäten. 1842 wurden auch eine „Zerspaltung“ des Vernagtferners und damit ein Anstieg von dessen Fließgeschwindigkeit bemerkt. Das Vorrücken des gemeinsamen Gletscherendes begann schließlich im Herbst 1843 (Stotter 1846), am 13. November war die Zunge noch ca. $1330 \mathrm{~m}$ von der Zwerchwand entfernt. Der Vorstoß setzte sich im Folgejahr beschleunigend fort, dessen Geschwindigkeit stieg von rund $0,5 \mathrm{~m} / \mathrm{Tag}$ im April auf etwas über $1 \mathrm{~m} / \mathrm{Tag}$ im Spätsommer/ Frühherbst 1844 (Abb. 6). Ein Aquarell von Thomas Ender hält diese Phase in beeindruckender Manier fest (Abb. 7). Die Vorstoßdynamik wird durch den auch seitlich hochgewölbten, zerspaltenen Eiskörper deutlich.

Die Distanz zwischen Gletscherende und Zwerchwand betrug am 18. Oktober 1844 noch rund $760 \mathrm{~m}$. Ein weiterer Anstieg der Vorstoßgeschwindigkeit ist auch bis zum 1. Juni 1845, dem Zeitpunkt des Erreichens des Rofentals beziehungsweise der Zwerchwand, dokumentiert: In den vorhergehenden etwa zwei Wochen rückte das Gletscherende im Mittel rund 11,5 m/Tag vor (Stotter 1846). Eine Darstellung der Vereinigung (Konfluenz) von Guslar- und Vernagtferner belegt, dass die größere Eismasse aus dem Nährgebiet des Vernagtferners und weniger vom Guslarferner kam (Abb. 7).

Mit Erreichen des Rofentales setzte die Bildung des Eisdammes ein, der am 14. Juni 1845 bereits eine Erstreckung von etwa 320 $\mathrm{m}$ hatte (Abb. 8, Stotter 1846). Die Vorstoßgeschwindigkeit des Vernagtferners war somit in den ersten beiden Juni-Wochen ähnlich hoch geblieben wie kurz vor Erreichen des Rofentales. Zur ersten Eisstauseebildung während dieser Hochstandsphase kam es unmittelbar nach Beginn des Eisdammaufbaus. Der erste Ausbruch ist für den 14. Juni 1845 belegt (Stotter 1846). Der See hatte zu diesem Zeitpunkt eine Länge von rund $850 \mathrm{~m}$, der 


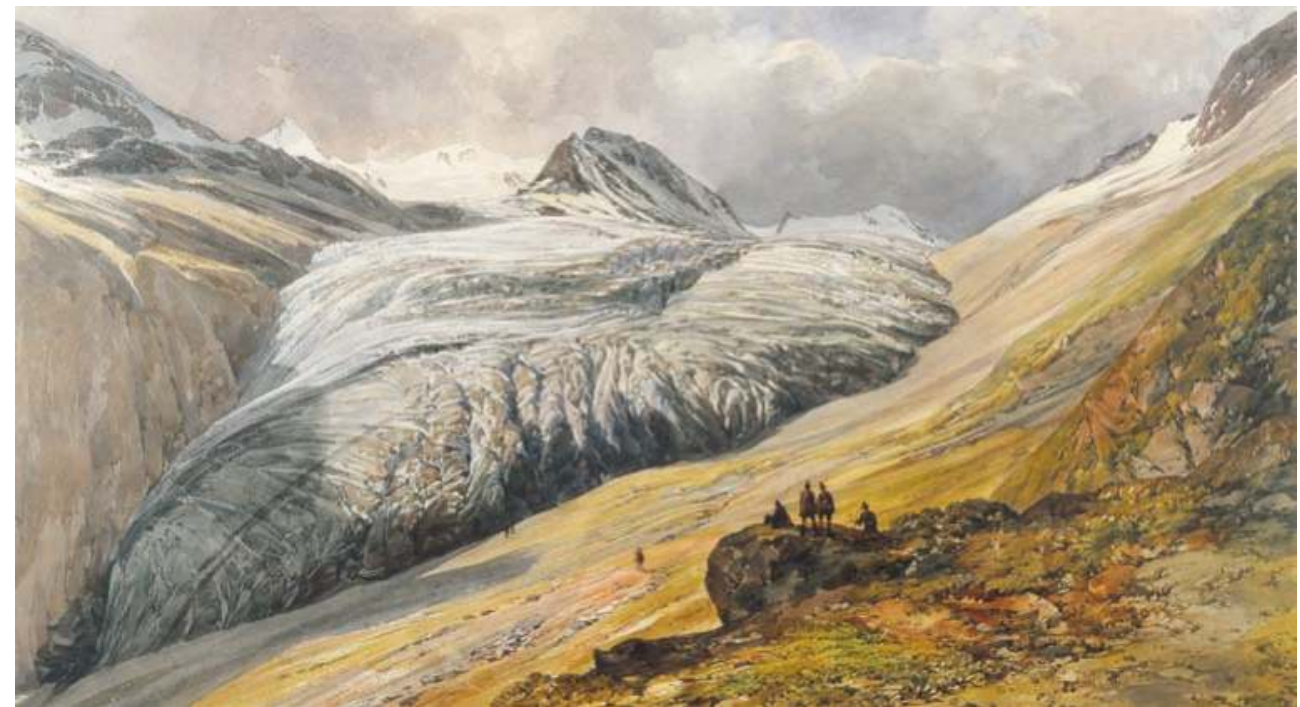

Abb. 6: „Der Fernak-Ferner bei Fend, im Hintergrunde des Ötzthales“, von Thomas Ender, 1844. Aquarell, $302 \times 533$ mm (Österr. Privatbesitz)

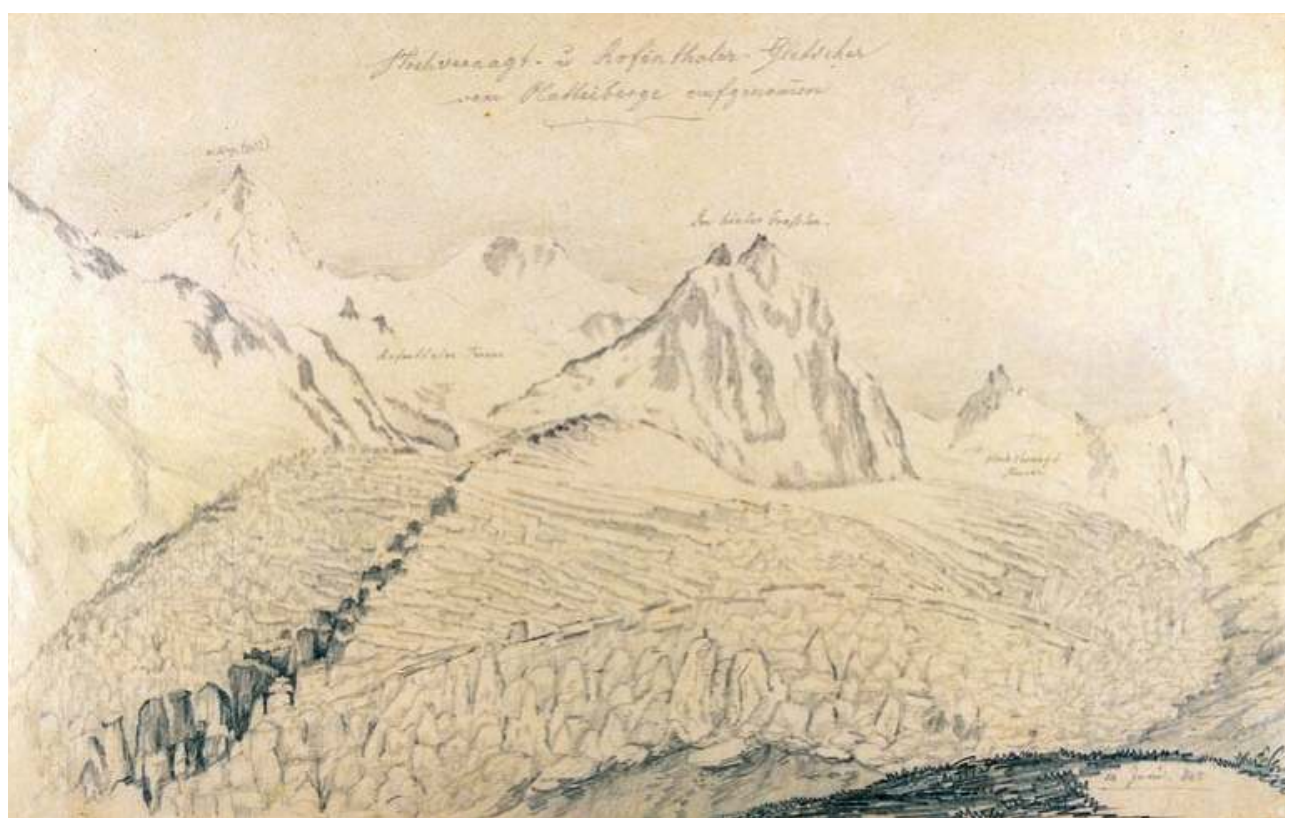

Abb. 7: „Vernagt Gletscher von der Höhe des Plattei-Berges aufgenom[m]en“, von Leonhard von Liebener, 13. Juni 1845. Bleistiftzeichnung, 209 x 272 mm (Österr. Privatbesitz). Liebener inspizierte zusammen mit Michael Stotter den vorstoßenden Vernagt- bzw. Guslarferner, hier als Hoch-Vernagt-Ferner bzw. Rofenthaler Ferner bezeichnet (Hohenauer 1969) 


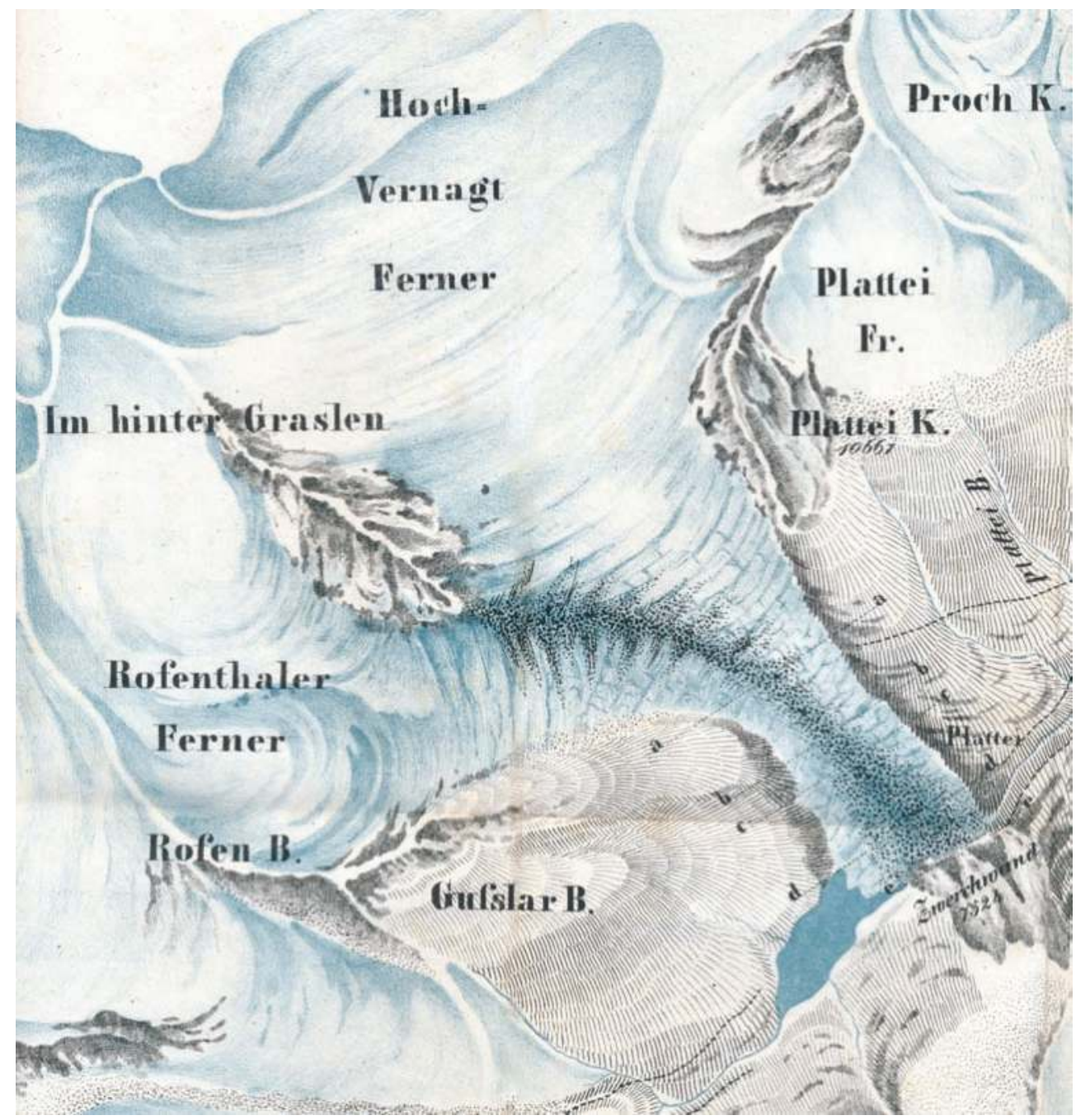

Abb. 8: Ausschnitt aus der „Karte des Rofenthales“. Die Darstellung zeigt die Situation des Vernagtferners und Eisstausees im Sommer 1845. Die Karte wurde in der zeitgenössischen Publikation von Stotter (1846) veröffentlicht. Die Linien a bis e geben die Position der Zungenspitze am 13. November 1843 (a), 18. Juni 1844 (b) sowie am 3. Jänner (c), 19. Mai (d) und 1. Juni 1845 (e) wieder. Farblithographie, 38,8 x 51,4 cm

Seespiegel lag entsprechend bei ca. 2190 m NN (Abb. 8). Das Anwachsen des Eisdammes ging auch in der Folgezeit weiter: Bis September 1845 wurde eine Verbreiterung um etwa $60 \mathrm{~m}$ beobachtet (Richter 1888).
Relativ wenige Nachrichten dokumentieren die Entwicklung im Jahr 1846. Der Vernagtferner erreichte in diesem Jahr bezüglich der Höhe des Eisdammes bereits nahezu das Maximum der Vorstoßperiode. Dies lässt sich 
den Angaben in einer Bilddarstellung (Abb. 9) von Franz Arnold, damals Kurat in Vent, entnehmen (Zwiedineck-Südenhorst 1903). Dabei wird nach den erhaltenen Spuren die maximale Breite des Eisdammes um 1770 mit rund $444 \mathrm{~m}$ angegeben, was gut mit der Vorfeldkartierung von Patzelt (2013) übereinstimmt. Im Sommer 1846 war der Eisdamm danach noch rund $29 \mathrm{~m}$ „kleiner" als beim vorangegangenen Hochstand (Abb. 9), nach der Kartierung der maximalen Eishöhe von 1845/48 an der Zwerchwand lag diese letztendlich 20 bis 23 Höhenmeter unter jener von 1770/75 (Patzelt 2013). Der Eissee bildete sich 1846 immer wieder neu, die sechs berichteten Entleerungen verliefen jeweils weitgehend schadlos, da sie langsam vor sich gingen (Sonklar 1860, Finsterwalder 1897).

Das Vorrücken des Gletscherendes hielt auch im Jahr 1847 an, der Eisdamm im Rofental erreichte in diesem Sommer eine Längserstreckung von knapp 1000 m. Für das Jahr 1847 ist auch ein stärkerer Seeausbruch dokumentiert, unmittelbar davor, am 28. Mai 1847, erreichte der Eisstausee eine Längserstreckung von 1210 m (Schlagintweit \& Schlagintweit 1850), was ein Spiegelniveau von ca. $2230 \mathrm{~m}$ NN erfordert. Für das Folgejahr 1848 ist ein noch höherer Seespiegel nachweisbar, dieser lag damals bei bis zu ca. $2240 \mathrm{~m} \mathrm{NN}$ (Hess 1918, Patzelt 2013), bevor der Eissee am 13. Juni mit Schadensfolgen ausbrach. Im An-

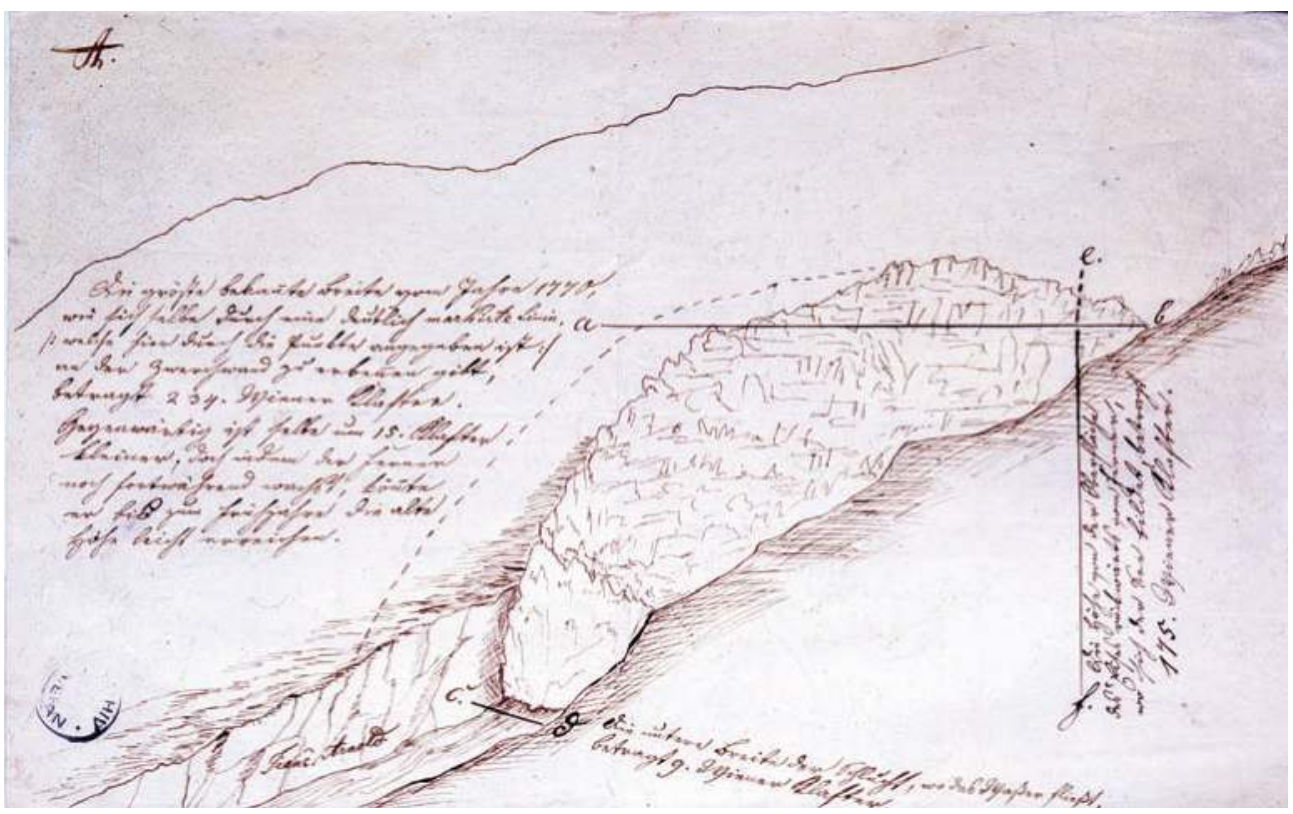

Abb. 9: Der Eisdamm des Vernagtferners im Rofental im Sommer 1846, von Franz Arnold. Federzeichung, Bleistift, 343 x 215 mm (Archiv Meran, Steiermärkisches Landesarchiv, Graz). Während die Angaben zu den Eisdammdimensionen der Vorstoßperioden 1770/75 (234 W. Klafter, ca. 444 m) und 1845/48 (15 W. Klafter kleiner, ca. 29 m) gut nachvollziehbar sind, ist die angeführte Angabe zur Höhe des Eisdammes 1846 (175 W. Klafter, ca. $332 \mathrm{~m}$ ) deutlich zu groß 
schluss an dieses Abflussereignis sind keine weiteren Eisstauseebildungen dokumentiert.

Das Ende des Vorstoßes des Vernagtferners wurde im Sommer 1848 erreicht, die Längenzunahme gegenüber 1847 war jedoch unbedeutend (Schlagintweit \& Schlagintweit 1850). Noch im Jahr 1848 begann das Rückschmelzen des Gletscherendes. Eine vergleichsweise unscheinbare Moräne dokumentiert, dass der Vernagtferner bei seinem Maximum 1848 etwa $610 \mathrm{~m}$ unterhalb der Mündung des Vernagtbaches in die Rofenache endete (vgl. Patzelt 2013). Damit blieb die maximale Gletscherlänge von 1848 rund
$190 \mathrm{~m}$ hinter jener des 1770er Hochstandes zurück.

Ab 1848 kam es zu einem vorerst langsamen Rückschmelzen des Gletschers (Sonklar 1860). Die Zeichnung von Friedrich Simony aus dem Jahr 1852 (Abb. 10, Nicolussi 1995) zeigt noch einen mächtigen, im Gegensatz zur Vorstoßphase nun durch eine vergleichsweise glatte Oberfläche charakterisierten Eiskörper, dessen Ende steil in der Rofenschlucht hängt. Zu diesem Zeitpunkt war die Gletscheroberfläche im untersten Bereich des Vernagttales jedoch bereits um rund $85 \mathrm{~m}$ gegenüber den Ufermoränen eingesunken (Simony 1863).

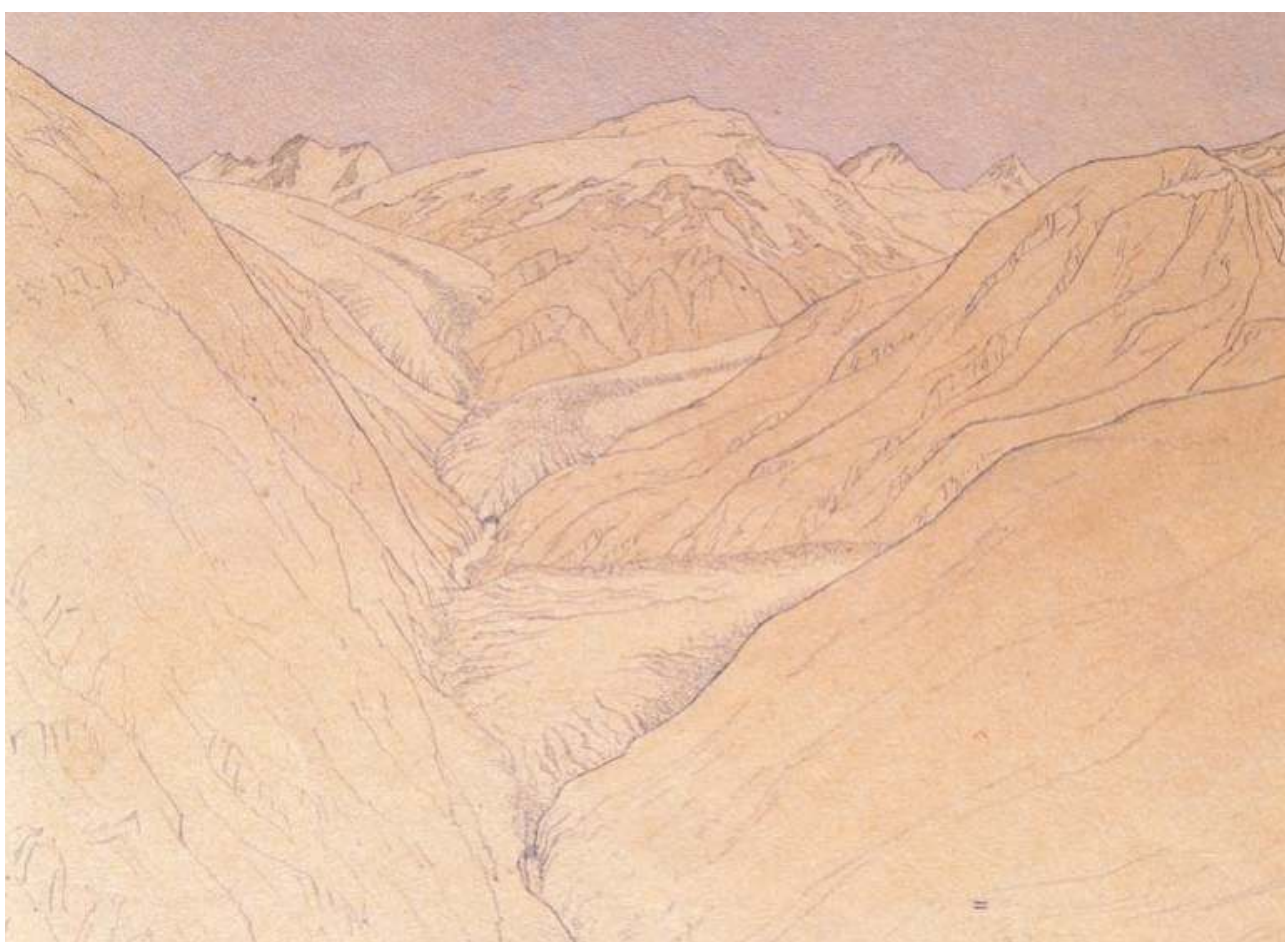

Abb. 10: Das innere Rofental mit dem Eisdamm des Vernagtferners und dem Hintereisferner (Bildmitte) und Hochjochferner (links hinten) im Sommer 1852. Ausschnitt aus dem Panorama „Mittlere Gruppe der Oetzthaler Alpen vom Venter Berg aus aufgenommen“, von Friedrich Simony, aufgen. 28.-30.8.1852. Bleistift mit Farben, 28 x 108 cm (Simony-Nachlass, Naturhistorisches Museum Wien) 
Dieser Dickenverlust ging aufgrund des fehlenden Eisnachschubes aus den höher gelegenen Gletscherbereichen rasch weiter, 1862 war schließlich die Verbindung des Vernagtferners zum Eiskörper im Rofental unterbrochen (Richter 1888).

\section{Der Vorstoß in den 1860er Jahren}

In späteren Publikationen zum Vernagtferner weitgehend unbeachtet blieben Notizen über einen Vorstoß des Gletschers in den 1860er Jahren. Erste Anzeichen einer gesteigerten Gletscheraktivität, und zwar zuerst des Guslarferner, wurden von Nikodem Klotz - dem bereits bei der Beobachtung der 1850er Vorstoßperiode aktiven Rofenhof-Bauern - schon im Herbst 1865 und um die folgende Jahreswende beobachtet (Tiroler Stimmen 1866, Patzelt 2013). Damals waren die beiden Gletscherzungen von Vernagt- und Guslarferner vereint, nach den Angaben rückte die Zunge des Guslarferners im Jänner 1866 um rund 6 $m$ vor (Senn 1867). Die Zungenposition ist nicht beschrieben. Nach Trientl (1868) hatte der Vernagtferner im Oktober 1866 noch das Aussehen eines abschmelzenden Gletschers, das Vorrücken des eigentlichen Gletscherendes erfolgte somit wohl erst 1867. Die Nachrichten zu den Vorstoßaktivitäten verstummen allerdings 1868 bereits wieder, woraus geschlossen werden kann, dass der Vorstoß schnell zu Ende gegangen sein dürfte. Nach der Kartierung von Eisrandspuren durch Patzelt (2013) ist dieser Vorstoß mit einem Maximum ca. 1867 auch über Moränenspuren fassbar, das Zungenende im Vernagttal lag auf $2415 \mathrm{~m} \mathrm{NN}$ und damit etwa $1270 \mathrm{~m}$ von der Rofenache entfernt. Der Vernagtund Guslarferner im Jahr 1869, und damit unmittelbar nach dem 1867er Vorstoß, sind in einem Panorama von der Kreuzspitze von Carl Jordan und Georg Engelhardt dargestellt. Dieses erfasst auch die Gletscherzunge, allerdings ohne deren Ende (Abb. 11). Auffallend sind der verhältnismäßig große Anteil des Guslarferner-Zuflusses an der gemeinsamen Zunge sowie die für einen Zeitpunkt unmittelbar nach einem Vorstoß breit und mächtig erscheinende Mittelmoräne. Insgesamt ist anzunehmen, dass das Vorrücken der Gletscherzunge des Vernagtferners trotz der berichteten Zerspaltung und Verdickung im mittleren Zungenbereich (Trientl 1868) während dieses Vorstoßes wohl gering war.

\section{Die Entwicklung nach 1870}

Nach dem Ende des 1867er Vorstoßes bis zum folgenden Wiedervorstoß um 1900 (Hess 1904) dürfte der Gletscherrückgang ohne Unterbrechungen erfolgt sein, auch wenn die Dokumentation Lücken aufweist. Die Originalzeichnung der im Gebiet des Vernagtferners 1871/72 aufgenommenen 3. 


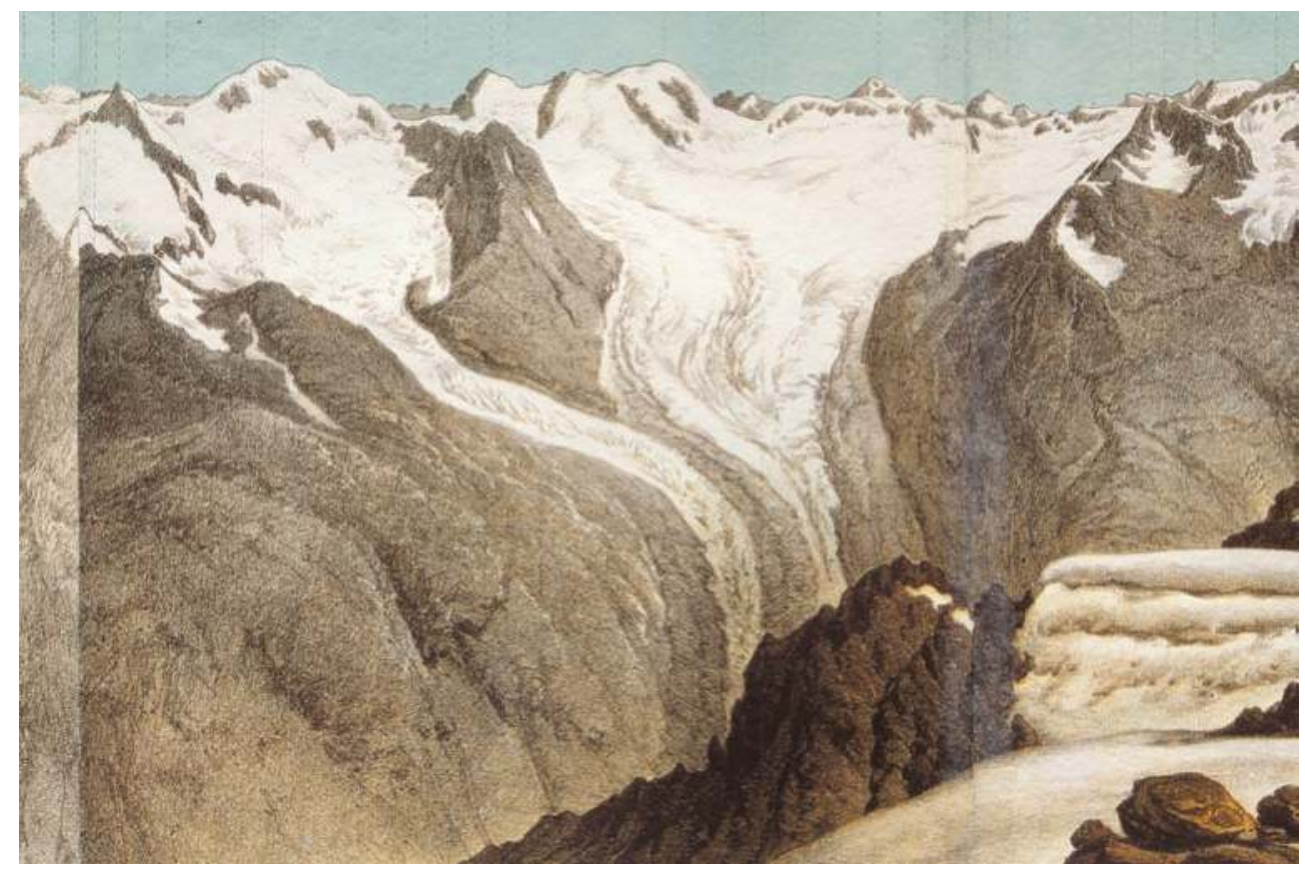

Abb. 11: Ausschnitt aus dem „Panorama von der Kreutzspitze bei Vent im Oetzthale. Aufgenommen von Carl Jordan und Georg Engelhardt“. 1869, erschienen im Verlag Franz Senn. Die Bilddarstellung zeigt Guslar- und Vernagtferner (im Bild links bzw. rechts) mit einer vereinigten, nur teilweise von einer Mittelmoräne bedeckten Gletscherzunge. Farblithographie, Gesamtgröße 112,2 x 33,7 cm (ULB Tirol)

Landesaufnahme (Abb. 12) zeigt den unteren Zungenabschnitt des Vernagtferners bereits gänzlich schuttbedeckt. Allerdings ist die in der Karte (Abb. 12) eingezeichnete Position als nicht verlässlich anzusehen, müsste sich doch der Gletscher zwischen 1867/68 und 1871/72 um nahezu $400 \mathrm{~m}$ zurückgezogen haben und der Eiskörper an der Position $1871 / 72$ um rund $70 \mathrm{~m}$ eingesunken sein, was in einer so kurzen Zeit nicht möglich ist. Der Toteiskörper des ehemaligen Eisdammes war 1871/72 noch mehrere hundert Meter lang, schmolz aber im darauf folgenden Jahrzehnt gänzlich ab: 1883 fand Richter (1888) im Rofental keine eindeutig identifizierbaren Eisreste mehr vor.

Eine im August 1884 auf Veranlassung von Richter (1885) von Gustav Jägermayer aufgenommene Photographie (Abb. 13) ist noch immer das älteste bekannte Bilddokument dieser Art des Vernagt- und Guslarferners. Sie zeigt die vereinigte Gletscherzunge weiterhin stark schuttbedeckt und dadurch typischerweise mit einer steilen Gletscherstirn endend. Eine ähnliche Situation ist schließlich durch die 1888/89 erfolgte Kartenaufnahme des Vernagtferners im Maßstab 1:10.000 durch Finsterwalder (1897) dokumentiert. Diese 


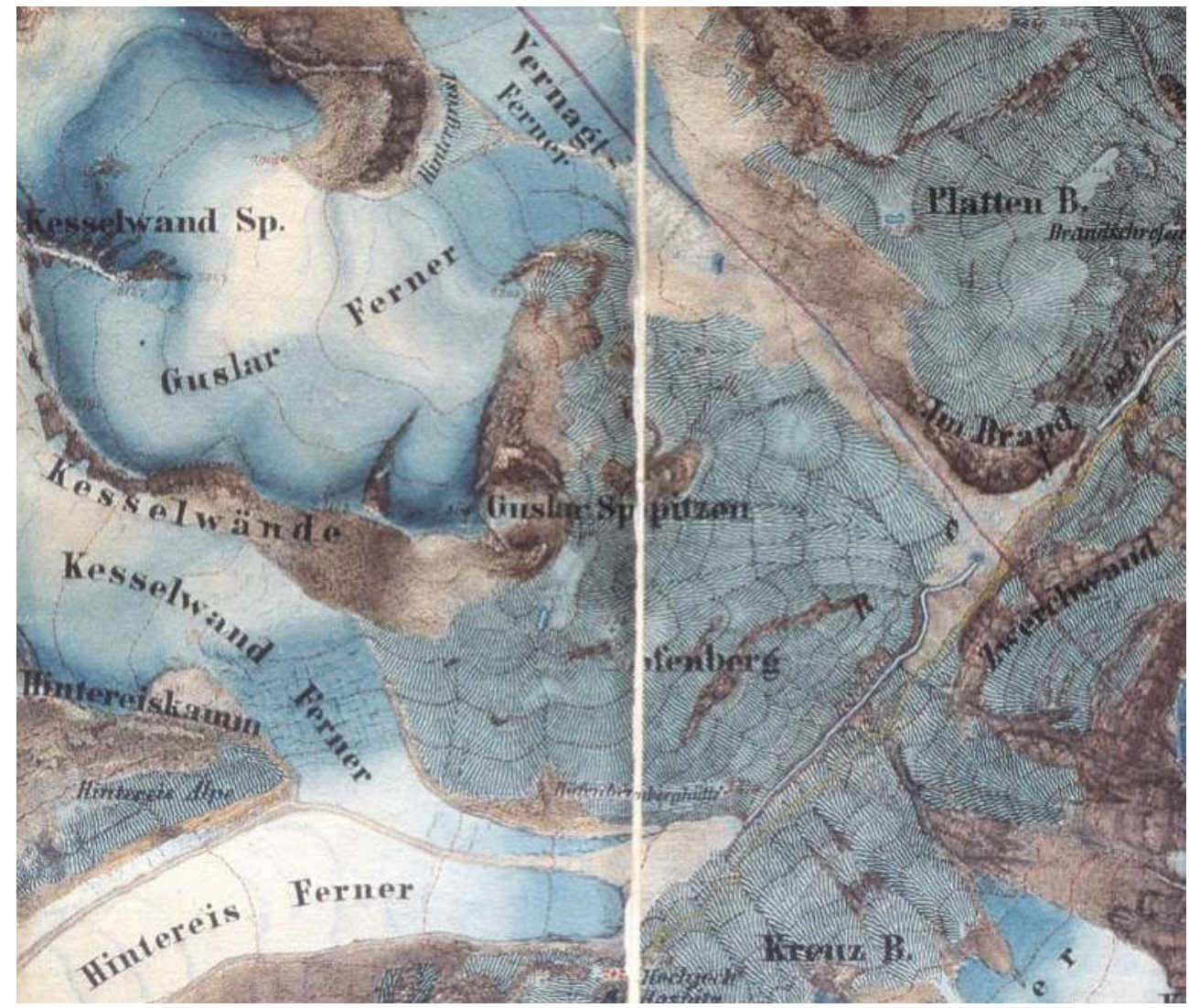

Abb. 12: Das innere Rofental mit dem Gletschervorfeld des Vernagtferners. Ausschnitt aus der kolorierten Handzeichnung der Dritten oder Francisco-Josephischen Landesaufnahme der Österreichischen Monarchie, Zone 18, Colonne III (Section S.O.) bzw. Colonne IV (Section S.W.), Originalmaßstab 1:25.000, aufgenommen 1871/72, 85,5 x $61 \mathrm{~cm}$ (Archiv des Bundesamtes für Eich- und Vermessungswesen, Wien)

Kartenaufnahme markiert den Beginn der bis heute fortdauernden wissenschaftlichen Forschung am Vernagtferner.

Die vergangenen 125 Jahre sind durch ein generelles, auch im Vergleich zu anderen Alpengletschern markantes, rasches Rückschmelzen des Vernagtferners geprägt. Unterbrochen wurde dieser Rückzug nur von zwei kurzen Wiedervorstößen, um 1900 und 1980 (Abb. 17). Während letzterer bezüglich Eisdynamik und Vorstoßbetrag wenig auffällig war, zeichnete sich ersterer durch eine rapide, aber nur wenige Jahre andauernde Erhöhung der Fließdynamik im Zungenbereich des Vernagtferners aus: Eine deutliche Zunahme der Fließgeschwindigkeit wurde ab 1894 beobachtet, 1898 hatte die Eiswelle das Gletscherende nahezu erreicht (Abb. 14), das damals ca. $470 \mathrm{~m}$ hinter dem Gletscherstand von 1889 lag (Finsterwalder 1897, Hess 1904). Als Re- 
aktion auf den erhöhten Eisnachschub rückte der Vernagtferner mit einer hochgewölbten Eisfront in wenigen Jahren insgesamt rund $320 \mathrm{~m}$ vor (Abb. 15). Insgesamt war der Vorstoßbetrag trotz der hohen Fließdynamik vergleichsweise gering (Hess 1904, Finsterwalder \& Hess 1926), die Vorstoßtendenz ließ ab 1902 rasch nach und endete 1904 (Abb. 16).

\section{Diskussion}

Nach Schrift- und Bildquellen sowie zeitgenössischen Publikationen stieß der Vernagtferner während der Neuzeit fünfmal, um 1600, $1680,1770 / 75,1820$ und um 1845 , bis in das Rofental vor und bildete, mit Ausnahme des Vorstoßes von 1820, dort jeweils einen Eisdamm. Die Ausbildung dieses mehr- oder weniger hammerförmigen Eiskörpers verursachte die gefürchteten Eisstauseebildungen. Ein weiterer Hochstand des Vernagtferners im vergangenen Jahrtausend, um 1300, ist nach Feldbefunden belegt (Zanesco et al. 2008, Patzelt 2013). Die Vorstöße geschahen dabei jeweils surgeartig (Hoinkes 1969), mit für Alpengletscher außergewöhnlich hohen Geschwindigkeiten: In der zweiten Maihälfte 1845, unmittelbar vor Erreichen des Rofentales, wurde ein tägliches Vorrücken von durchschnittlich 11,5 m beobachtet. Entsprechend dieser Fließdynamik war die Gletscheroberfläche aufgerissen und zeigte die so charakteristischen, immer wieder zusammenstürzenden Eistürme. Die Vorstoßaktivität hielt jeweils nur relativ kurz an: Immer rund drei Jahre nach Erreichen des Rofentales war der Maximalstand erreicht; die Gletscheroberfläche wurde wiederum vergleichsweise glatt und auch wieder begehbar.

Den größten Stand in der Neuzeit erreichte der Vernagtferner 1774 und somit während der dritten historischen Hochstandsperiode (Abb. 17). Dies ist durch eine Moräne dokumentiert, die rund $800 \mathrm{~m}$ talab der Einmündung des Vernagtbaches in die Rofenache liegt. Nach den historischen Berichten war im Verhältnis dazu die Gletscherausdehnung um 1680 (mit einem Maximalstand 1681) nur wenig kleiner, der Endstand kann mit rund 780-800 m talabwärts der VernagtbachEinmündung angenommen werden. Demgegenüber blieben die Hochstände von ca. 1602 und 1848 - die Ausdehnung des 1845/48 Vorstoßes ist wiederum aufgrund von Moränenablagerungen kartierbar - mit Endpositionen von ca. 670-710 und ca. $610 \mathrm{~m}$ außerhalb der Vernagtbach-Mündung vergleichsweise kleiner. Deutlich weniger weit reichte noch der Vorstoß um 1820, dieser endete 1822 wenige Zehnermeter vor der Rofenache und damit über $800 \mathrm{~m}$ hinter dem 1774 erreichten Stand. Unklar verbleibt die Eisausdehnung des Vorstoßes um 1300, nach der relativen Lage der datierten Ufermoränen kann aber ein den neuzeitlichen Maximalständen entsprechender Hochstand angenommen werden.

Für den Zeitraum der letzten etwa 150 Jahre ist ein genereller Rückgang des Vernagtferners, unterbrochen von drei jeweils kurz andauernden Wiedervorstößen um 1867, 1900 und 1980, dokumentiert. 


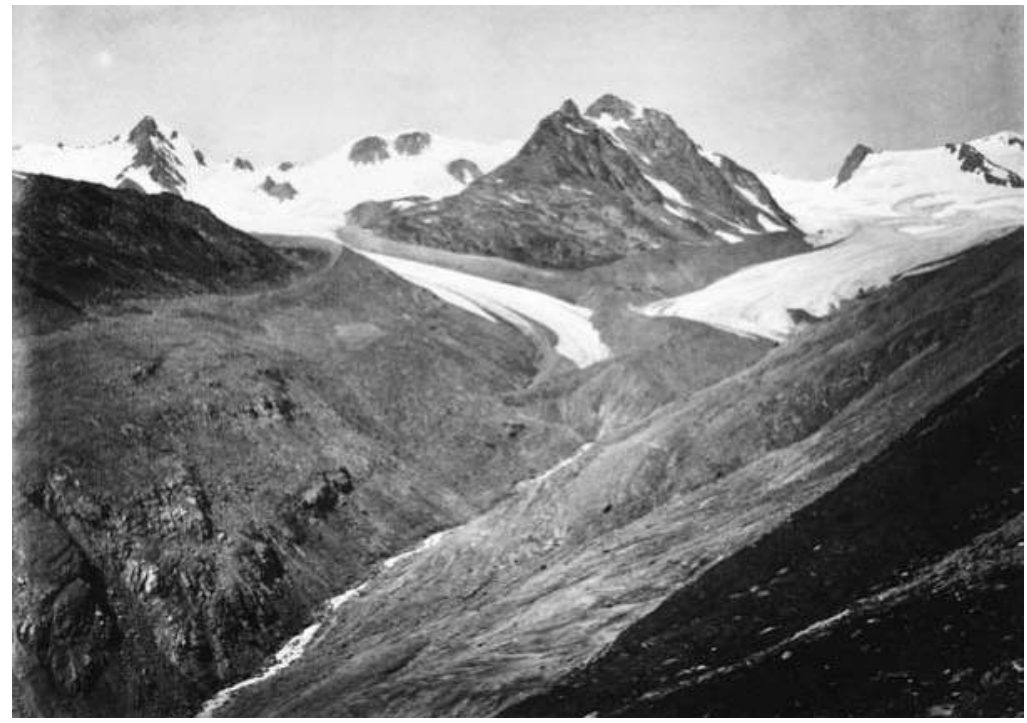

Abb. 13: „Kesselwandspitze \& Hochvernagt v. Plattei. 1725. Photographie und Verlag Würthle und Spinnhirn in Salzburg“. Aufgenommen von Gustav Jägermayer im August 1884 (Richter 1885). Die Abbildung ist die älteste bekannte Photographie des Vernagtferners (Tiroler Landesmuseum Ferdinandeum)

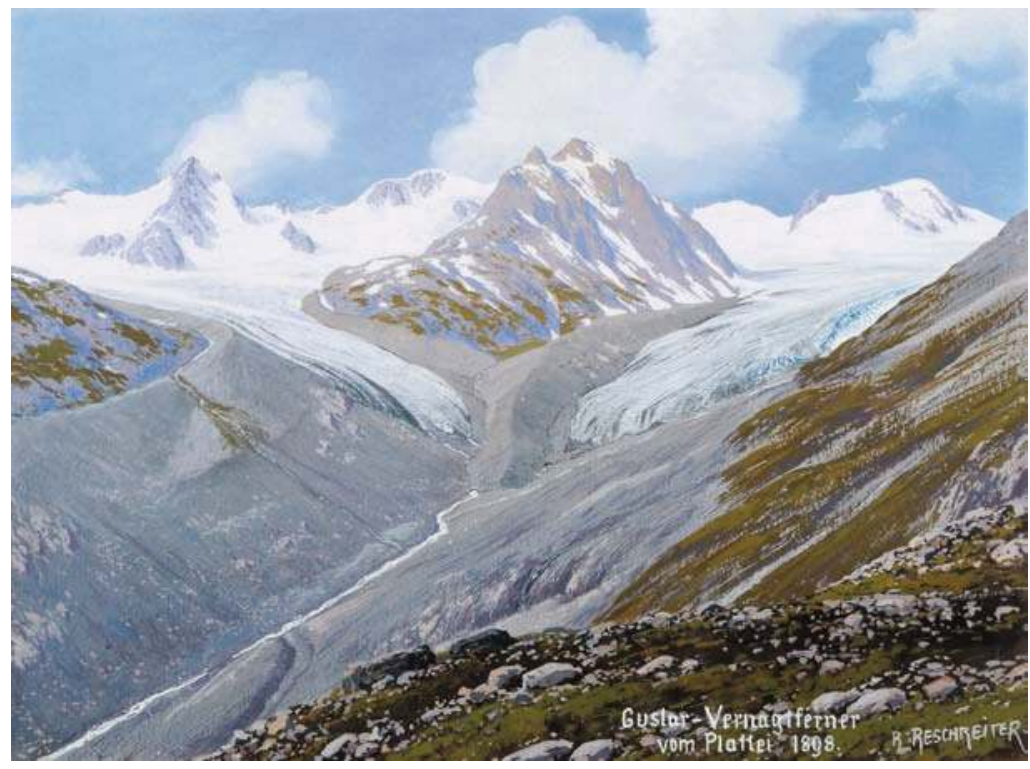

Abb. 14: „Guslar-Vernagtferner vom Plattei 1898.“, von Rudolf Reschreiter. Die Bildserie (siehe auch Abb. 15 und 16), von Reschreiter nach Fotografien gemalt, dokumentiert den 1900er Vorstoß des Vernagtferners. Der aktive Zungenteil des Gletschers (im Bild rechts) ist aufgewölbt und zeigt die erhöhte Eisfließdynamik an. Aquarell, 230 x 308 mm (Alpenvereinsmuseum Innsbruck) 


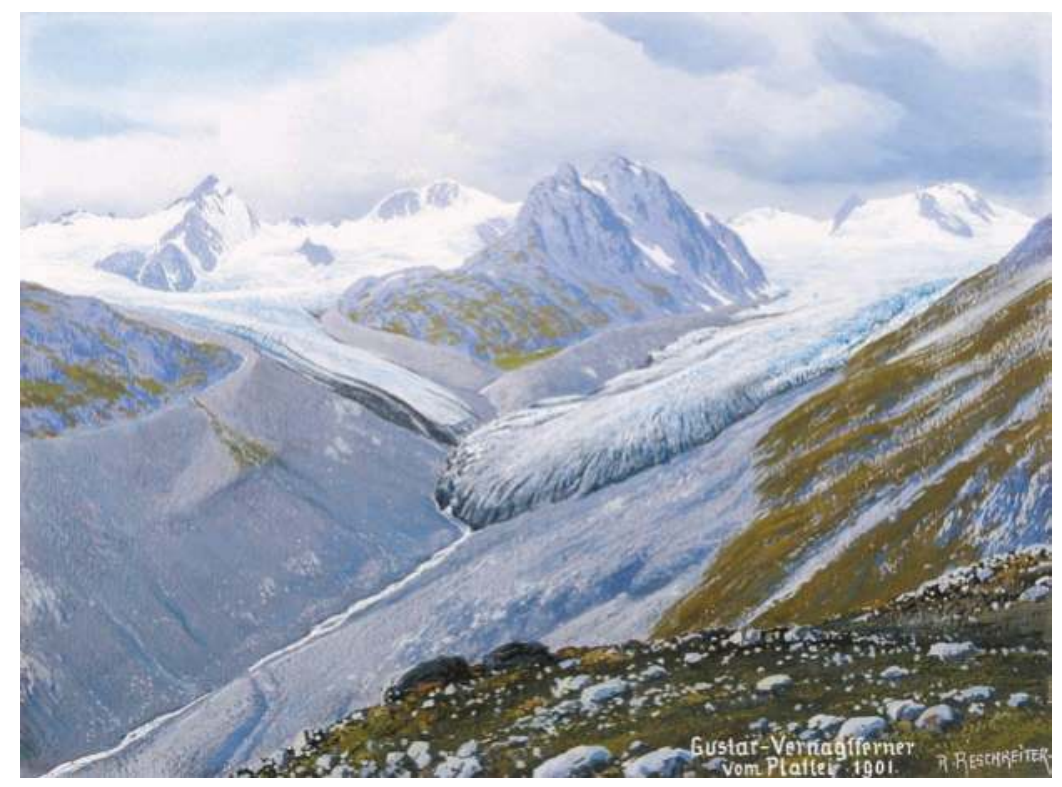

Abb. 15: „Guslar-Vernagtferner vom Plattei 1901.“, von Rudolf Reschreiter. Der Vernagtferner hatte in wenigen Jahren das schuttbedeckte Gletscherende (Abb. 14) überfahren, die Vorstoßaktivität ließ im Jahr 1901 bereits nach. Aquarell, 230 × 308 mm (Alpenvereinsmuseum Innsbruck)

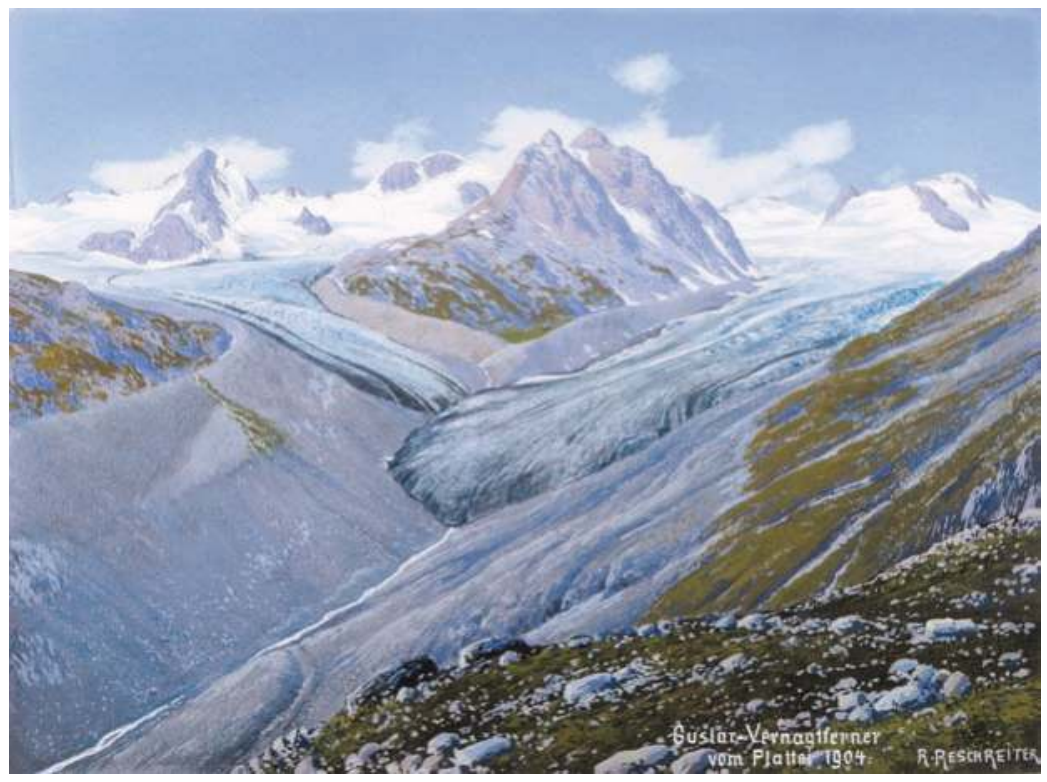

Abb. 16: „Guslar-Vernagtferner vom Plattei 1904.“, von Rudolf Reschreiter. Im Jahr 1904 ging der Vorstoß des Vernagtferners zu Ende, das Vorrücken nach 1901 (Abb. 15) war nur noch gering. Aquarell, 230 x 308 $\mathrm{mm}$ (Alpenvereinsmuseum Innsbruck) 
Während der Hochstandsphasen erreichte der Vernagtferner nie eine Situation, in der das Gletscherende durch kontinuierlichen Eisnachschub stabilisiert worden wäre. Vielmehr wurde jeweils mit hoher Dynamik Eismasse in das Rofental vorgeschoben und anschließend ließ der Eisnachschub immer sehr rasch nach. Die Verbindung zwischen dem inaktiven, langsam abschmelzenden Eisdamm zum übrigen Ablationsgebiet und weiter hinauf ins Akkumulationsgebiet blieb jeweils noch für rund zwei Jahrzehnte bestehen, dann erfolgte eine Unterbrechung der Eisverbindung im unteren Vernagttal. Als Folge verlagerte sich damit das aktive Gletscherende „sprunghaft“ zurück. Die surgeartigen Vorstöße und die dann immer wieder abrupten Zurück- verlagerungen der Gletscherzunge bedingen eine für einen Alpengletscher außergewöhnliche Variabilität der Gletschererstreckung (Längenänderungskurve in Abb. 17). Bis zum gänzlichen Verschwinden des Eisdammes im Rofental dauerte es aufgrund der ursprünglich hohen Mächtigkeit des Eiskörpers (sichtbar in Abb. 10) und der im Zuge der Abschmelzung zunehmenden Schuttbedeckung (Abb. 12), die die Eisablation wiederum stark hemmte, jeweils drei bis vier Jahrzehnte.

Ein Vergleich der Vorstoßdynamik des Vernagtferners während der letzten vier Jahrhunderte mit anderen, gut dokumentierten Alpengletschern (Aletschgletscher, Unterer Grindelwaldgletscher, Mer de Glace) bezüglich Verlauf und Dimension zeigt sowohl

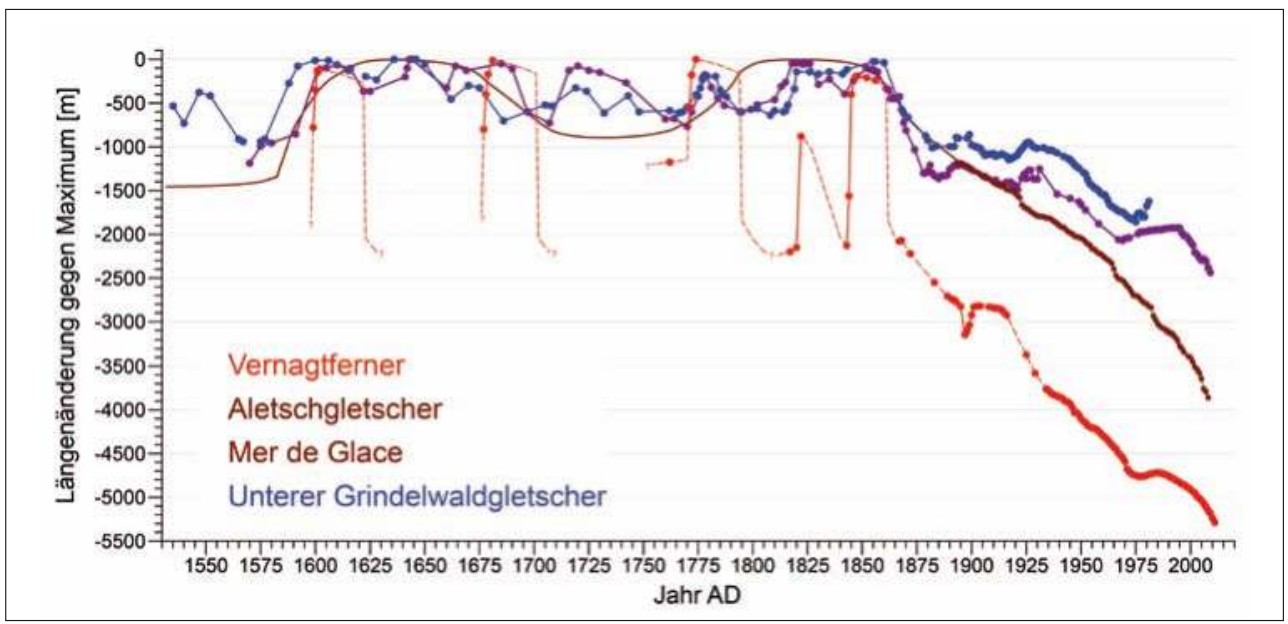

Abb. 17: Längenänderungen des Vernagtferners (rot) im Vergleich mit jenen des Aletschgletschers (braun), Mer de Glace (violett) und Unteren Grindelwaldgletschers (blau) während der letzten knapp fünf Jahrhunderte. Die Längenangaben beziehen sich auf den während der Kleinen Eiszeit erreichten Maximalstand des jeweiligen Gletschers. Die Rekonstruktion der Zungenposition des Vernagtferners beruht auf der Auswertung von Schriftquellen, Bilddarstellungen, Karten und Gletscherlängenänderungsmessungen (jeweils Datenpunkte und durchgezogene Linie; geschätzte Änderungen: dünne, strichlierte Linie). Vergleichsreihen: Aletschgletscher: Holzhauser et al. 2005, Gletscherberichte 1881-2002; Mer de Glace: Nussbaumer et al. 2007; Unterer Grindelwaldgletscher: Zumbühl et al. 1983 
deutliche Unterschiede als auch Übereinstimmungen auf: So weicht einerseits der Vernagtferner jeweils bezüglich Vorstoß- und Rückzugsbeträgen deutlich ab, die Hochstände des Vernagtferners stimmen andererseits zeitlich mit Vorstößen beziehungsweise Hochständen der anderen Gletscher weitgehend überein. Die Maxima während der jeweiligen Vorstoßphasen werden allerdings teilweise mit mehreren Jahren Differenz erreicht. Auch sind für den Vernagtferner nicht alle der an den Vergleichsgletschern nachgewiesenen Vorstoßphasen, z.B. um 1640 beziehungsweise 1725, dokumentiert. Die Übereinstimmungen belegen jedoch, dass die Hochstände des Vernagtferners im vergangenen Jahrtausend durchwegs klimatisch und nicht nur eisdynamisch bedingt waren und damit entsprechend klimageschichtlich interpretierbar sind. Auch die Wiedervorstöße um 1900 und 1980 fallen mit vergleichsweise gletscherfreundlichen Phasen zusammen und sind hier kein Widerspruch, einzig das kurzfristige Vorrücken um 1867 ist eine Ausnahme, da dieses in eine allgemeine Gletscherrückzugsperiode fällt.

Während die vier neuzeitlichen, die Hauptphase der Kleinen Eiszeit markierenden Hochstände des Vernagtferners schon lange bekannt sind, ist mit einem Geländebefund zwischenzeitlich auch für den ersten Abschnitt der Kleinen Eiszeit, um 1300, ein Gletscherhochstand des Vernagtferners belegt. Dieser steht wiederum in Übereinstimmung mit nachgewiesenen Vorstößen und Hochständen ähnlicher Zeitstellung am Gepatsch- sowie Gurgler Ferner, ebenso mit entsprechenden Nachweisen für Mer de Glace (Coutterrand
\& Le Roy 2012), Unterer Grindelwald- und Aletschgletscher (Holzhauser et al. 2005).

\section{Literatur}

Anich, P. \& Hueber, B. (1774) Atlas Tyrolensis. Faksimiledruck, Kinzl, H. (Hg.), Wagner (1974), Innsbruck, 23 Blätter.

Bote für Tirol (1867) Aufschreibung des Ferners von 1771 (Anton Schöpf Chronik). 136: 5-6.

Coutterrand, S. \& Le Roy, M. (2012) L'empreinte des glaciations. In: Mer de Glace, art \& science, Nussbaumer, S., Deline, P. Vincent, C. \& Zumbühl, H.J. (Hg.), Editions Esope, Chamonix: 6079.

Finsterwalder, S. (1897) Der Vernagtferner - seine Geschichte und seine Vermessung in den Jahren 1888 und 1889. Wissenschaftliche Ergänzungshefte zur Zeitschrift des Deutschen und Österreichischen Alpenvereins, Band 1, Heft 1, Verlag des DuÖAV, Graz, 112 S., 2 Karten.

Finsterwalder, S. \& Hess, H. (1926) Über den Vernagtferner. In: Festschrift zum fünfzigjährigen Bestehen der Sektion Würzburg des Deutschen und Österreichischen Alpenvereins (Deutscher und Österreichischer Alpenverein, Sektion, Würzburg, Hrsg.), Würzburg, S. 30-41. Gletscherberichte (1881-2002) Die Gletscher der Schweizer Alpen. Jahrbücher der 
Glaziologischen Kommission der Akademie der Naturwissenschaften Schweiz (SCNAT), hrsg. seit 1964 durch die Versuchsanstalt für Wasserbau, Hydrologie und Glaziologie (VAW) der ETH Zürich, No. 1-122, (http://glaziology.ethz. ch/swiss-glaciers).

Hess, H. (1904) Die Gletscher. Vieweg, Braunschweig, $426 \mathrm{~S}$.

Hess, H. (1918) Der Stausee des Vernagtferners im Jahre 1848. Zeitschrift für Gletscherkunde 11: 28-33.

Hohenauer, G. (1969) Gottfried von Liebener, der Tiroler Geologe und Mineraloge, Straßen- und Brückenbauer. Veröffentlichungen des Tiroler Landesmuseums Ferdinandeum, 49: 79-100.

Hoinkes, H. (1969) Surges of the Vernagtferner in the Ötztal Alps since 1599. Canadian Journal of Earth Sciences, 6: 853-861.

Holzhauser, H., Magny, M. \& Zumbühl, H.J. (2005) Glacier and lake-level variations in west-central Europe over the last 3500 years. The Holocene, 15(6): 789-801.

Hye, F.H. (1976) Peter Anich und Blasius Hueber. Die Geschichte des „Atlas Tyrolensis" (1759-1774). In: Peter Anich, Kinzl, H. (Hg.), Tiroler Wirtschaftsstudien 32, Wagner, Innsbruck: 7-50.

Kinzl, H. (1976) Peter Anich. Tiroler Wirtschaftsstudien 32, Wagner, Innsbruck, 344 S.

Meixner, W. \& Siegl, G. (2010) Historisches zum Thema Gletscher, Gletschervorfeld und Obergurgl. In: Glaziale und periglaziale Lebensräume im Raum Obergurgl,
Koch, E.-M. \& Erschbamer, B. (Hg.), innsbruck university press, Innsbruck, S. 13-29.

Nicolussi, K. (1993) Bilddokumente zur Geschichte des Vernagtferners im 17.Jahrhundert. Zeitschrift für Gletscherkunde und Glazialgeologie, 26 (1990): 97-119.

Nicolussi, K. (1995) Jahrringe und Massenbilanz - Dendroklimatologische Rekonstruktion der Massenbilanzreihe des Hintereisferners bis zum Jahr 1400 mittels Pinus cembra-Reihen aus den Ötztaler Alpen, Tirol. Zeitschrift für Gletscherkunde und Glazialgeologie, 30 (1994): $11-52$.

Nicolussi, K. \& Patzelt, G. (2001) Untersuchungen zur holozänen Gletscherentwicklung von Pasterze und Gepatschferner (Ostalpen). Zeitschrift für Gletscherkunde und Glazialgeologie, 36 (2000): 1-87.

Nussbaumer, S. U., Zumbühl H. J. \& Steiner, D. (2007) Fluctuations of the Mer de Glace (Mont Blanc area, France) AD 1500-2050. Part I: The history of the Mer de Glace AD 1570-2003 according to pictorial and written documents. Zeitschrift für Gletscherkunde und Glazialgeologie 40 (2005/2006): 5-140.

Nussbaumer, S. U., Deline, P., Vincent, C. \& Zumbühl, H.J. (2012). Mer de Glace. Art \& science. Atelier ésope, Chamonix: 192 S.

Patzelt, G. \& Bortenschlager, S. (1973) Die postglazialen Gletscher- und Klimaschwankungen in der Venediger Gruppe (Hohe Tauern, Ostalpen). Zeitschrift für 
Geomorphologie N.F., Suppl. Bd. 16: $25-72$.

Patzelt, G. (2013) Das Vorfeld des Vernagtferners und seine Umgebung. Begleitworte zur Karte 1:10.000. Zeitschrift für Gletscherkunde und Glazialgeologie 45/46 (2011/2012).

Richter, E. (1885) Beobachtungen an Gletschern der Ostalpen. II. Die Gletscher der Oetzthaler Gruppe im Jahre 1883. Zeitschrift des Deutschen und Österreichischen Alpenvereins 16: 54-65.

Richter, E. (1888) Die Gletscher der Ostalpen. Handbücher zur Deutschen Landes- und Volkskunde, 3, J. Engelhorn, Stuttgart: 306 S.

Richter, E. (1892) Urkunden über die Ausbrüche des Vernagt- und Gurglergletschers im 17. und 18. Jahrhundert. In: Forschungen zur deutschen Landes- und Volkskunde, 6, Engelhorn, J. (Hg.), Stuttgart, S. 345-440.

Schlagintweit, H. \& Schlagintweit, A. (1850) Untersuchungen über die Physikalische Geographie der Alpen. Barth, Leipzig, $600 \mathrm{~S}$.

Senn, F. (1867). Der Vernagtferner im Venterthale. Wagner, Innsbruck, $23 \mathrm{~S}$.

Simony, F. (1863) Beitrag zur Kunde der Oetzthaler Alpen (mit Panoramen). Mitteilungen des Österreichischen Alpenvereins, 1: 1-24.

Sonklar, K. (1860) Die Oetzthaler Gebirgsgruppe. J. Perthes, Gohta, 292 S.

Stotter, M. (1846) Die Gletscher des Vernagtthales in Tirol und ihre Geschichte. Wagner, Innsbruck, $75 \mathrm{~S}$.
Tiroler Stimmen (1866) Drohende Gletscher. Tiroler Stimmen 1866: 22-23.

Trientl, A. (1866) Der Vernagtferner im Oetzthal. Bote für Tirol 1866, 1007/1008, 1010/1011, 1016, 1019.

Trientl, A. (1868) Bericht 13. Dez. 1867. Bote für Tirol 1868: 2.

Walcher, J. (1773) Nachrichten von den Eisbergen in Tyrol. Kurzböcken, Wien, 96 S., 5 Bildtafeln.

Zanesco, A., Nicolussi, K. \& Patzelt, G. (2008) Die Überschwemmung der Unterstadt von Hall im Jahr 1275. In: Neues zur Geschichte der Stadt. Zanesco, A. \& Schmitz-Esser, R. (Hg.), Forum Hall in Tirol 2: 40-53.

Zumbühl, H.J. (1980) Die Schwankungen der Grindelwaldgletscher. In: Denkschriften der Schweizerischen Naturforschenden Gesellschaft, 92, Birkhäuser, Basel, 279 S., 3 Beilagen, 1 Karte.

Zumbühl, H.J., Messerli, B. \& Pfister, C. (1983) Die Kleine Eiszeit. Gletschergeschichte im Spiegel der Kunst. Katalog zur Sonderausstellung des Schweizerischen Alpinen Museums Bern und des Gletschergarten-Museums Luzern. 9.6.14.8.1983 Luzern, 24.8.-16.10.1983

Bern.

Zwiedineck-Südenhorst, H.v. (1903) Erzherzog Johanns Reise durch das Ötztal 1846. Zeitschrift des Deutschen und Österreichischen Alpenvereins 34: 7794. 
K. Nicolussi

Verzeichnis des Autors

Kurt Nicolussi

Institut für Geographie

Universität Innsbruck

Innrain 52, 6020 Innsbruck

kurt.nicolussi@uibk.ac.at 


\section{Kapitel 5 I Das Potential historischer Karten zur Rekonstruktion des Gletscherrïckgangs im Gurgler Tal}

André Baumeister

\section{Zusammenfassung}

Gegenstand des Artikels ist das Potential historischer Karten zur Rekonstruktion der zeitlichen Veränderung von Gletscherhöhen und deren Ausdehnung. Im Einzugsgebiet der Gurgler Ache am Pegel Obergurgl (Ötztal/ Tirol) wurden Gletschergrenzen und Höhenlinien mehrerer historischer Kartenblätter aus den Jahren 1952 und früher digitalisiert und miteinander verglichen. Neben der Veränderung der Fläche können über die Höhenlinien Informationen zur Entwicklung der Eismächtigkeit eines Gletschers gewonnen werden. Hierzu werden im Bereich der Gletscherfläche mit Hilfe eines Geoinformationssystems (GIS) digitale Geländemodelle erzeugt, aus denen rechnerisch das Verlustvolumen eines Betrachtungszeitraums ermittelt werden kann.

Darüber hinaus wurden weitere historische Quellen verwendet, um den Rückzug des Gurgler Ferners im Zungenbereich mit einer bestmöglichen zeitlichen Auflösung zu dokumentieren.

Die Ergebnisse dieser Arbeit liefern eine Ergänzung zum bestehenden Österreichischen Gletscherinventar und anderen Forschungs- projekten, die sich mit der Entwicklung der Gletscher im Gurgler Tal beschäftigen.

\section{Abstract}

The article at hand discusses the potential of historical maps to reconstruct the development of glaciers in terms of their expansion and elevation. Glacier boundaries and contour lines of several historical maps of the drainage basin ,Pegel Obergurgl' (Ötztal/Tirol) were digitalized and analyzed to obtain information about changes in ice thickness and extension of the glaciers. By generating digital terrain models of the glaciers surface using GIS, it was possible to determine the amount of ice lost during the observation period. Other historical sources of the ,Gurgler Ferner" could then be used to further increase the temporal and spatial precision of the data in the area of the glacial terminus.

The results of this study provide a complement to the existing Austrian glacier inventory and other research projects that deal with the development of the glaciers in the Gurgler Valley. 


\section{Einleitung}

Der Rückzug der Alpengletscher als Folge des Klimawandels ist ein in Wissenschaft (Abermann et al. 2009) und Medien häufig diskutiertes Thema. Ihr Verhalten ist weltweit ein wichtiger Indikator für klimatische Veränderungen (IPCC 2007). Der Rückzug der Gletscher ist jedoch keinesfalls nur von wissenschaftlichem Interesse. Als wichtigster Süßwasserspeicher beeinflussen die Gletscher die Abflussregime zahlreicher Flüsse in den Alpen und in nahezu allen Fließgewässern, von denen Teileinzugsgebiete im Hochgebirge liegen. Eine Veränderung des Eisvolumens hat Konsequenzen für die Wasserwirtschaft und somit für die Land- und Energiewirtschaft zahlreicher Regionen (Braun \& Weber 2008, Psenner 2007). Darüber hinaus besitzen Gletscher einen hohen Stellenwert für den Tourismus, sowohl für den Gletscherskitourismus, als auch als ästhetisches Landschaftselement für die Wanderer und Bergsteiger in den Sommermonaten.

In wohl keinem Gebirge der Welt ist die Entwicklung der Gletscher so gut dokumentiert wie in den Alpen. In zahlreichen Forschungsprojekten werden Monitoring-Programme für einzelne Gletscher oder ganze Regionen betrieben, während auf nationaler Ebene die Entwicklung der Gletscher in Gletscherinventaren dokumentiert wird (Lambrecht \& Kuhn 2007).
Trotz dieser Fülle an Daten beschränken sich mehrjährige Messreihen auf wenige ausgewählte Gletscher und nationale Inventare bieten nur eine grobe zeitliche Aufösung (Abermann et al. 2009). Historische Orthofotos und Karten bieten eine Möglichkeit, die zeitliche und räumliche Auflösung der bestehenden Inventare zu verbessern. Die Entwicklung der Gletscherfläche kann so einfach und kostengünstig dokumentiert werden. Darüber hinaus ermöglichen Karten, deren Höheninformationen über photogrammetrisch ausgewertete Luftbilder ermittelt wurden, Aussagen über die Veränderung der Eismächtigkeit. Mit Hilfe von Geoinformationssystemen (GIS) kann über Digitale Geländemodelle (DGM) die Entwicklung des Eisvolumens berechnet werden. Die Geländemodelle stammen aus historischen Karten. Hierzu werden die Höheninformationen der Höhenlinien dazu verwendet, mit Hilfe eines Interpolationsverfahrens ein Geländemodell zu erzeugen. Das hier beschriebene geodätische Verfahren wurde unter Verwendung bestehender Höhenmodelle bereits in zahlreichen Untersuchungen angewendet (Gspurning et al. 2004, Lambrecht \& Kuhn 2007, Abermann et al. 2009). Das mögliche Potential aller verfügbaren historischen Karten für die Rekonstruktion der Flächen- und Volumenveränderung der Ötztaler Gletscher wurde bisher nur in Ansätzen untersucht und soll in diesem Artikel für das ausgewählte Einzugsgebiet geprüft werden. 


\section{Stand der Forschung}

Möglichkeiten zur Rekonstruktion und Dokumentation der Entwicklung von Gletschern

Die maximale Ausdehnung der Alpengletscher zum Ende der kleinen Eiszeit 1850 ist in der Regel durch dominante End- und Seitenmoränen gekennzeichnet, die sich durch ihre Lage und Mächtigkeit oft deutlich von Moränen jüngerer Phasen unterscheiden (Veit 2002).

Häufig bieten somit geomorphologische Kartierungen oder aufmerksame Beobachtungen im Gelände erste Anhaltspunkte über die Veränderung der Eisausdehnung (Patzelt 1982). Über die Kenntnis der ursprünglichen Ausdehnung und Mächtigkeit des Eises und die Form des Reliefs können darüber hinaus Aussagen zum ursprünglichen Eisvolumen getroffen werden. Oft dokumentieren alte Fotografien oder Postkarten historische Gletscherstände. Im deutschen Gletscherarchiv der Gesellschaft für ökologische Forschung e.V. in München sind diese Quellen länderübergreifend für zahlreiche Alpengletscher zusammengefasst (www.gletscherarchiv.de). Neben der reinen Dokumentation der Längen- und Flächenveränderung existieren für wenige Gletscher Massenbilanzen variierender zeitlicher Auflösung, welche durch unterschiedliche Verfahren ermittelt werden. Mit der direkten glaziologischen Methode werden mit Hilfe von Schnee- und Ablationspegeln, Schneetiefen- und Schneedichteprofilen genaue jährliche Massenbilanzen ermittelt (Fi- scher 2011). Existiert eine Abflussmessstelle, mit der sich die gesamte Schmelzwassermenge des Gletschers erfassen lässt, können jährliche Massenbilanzen auch über hydrologische Verfahren ermittelt werden. In den Ötztaler Alpen wurden am Vernagtferner seit 1964 jährliche Massenbilanzen erhoben (Braun et al. 2007). Lange Zeitreihen zur Massenbilanz sind in den Alpen eher selten und beschränken sich meist auf einzelne Gletscher (Gspurning et al. 2004, Braun et al. 2007, Fischer 2011). Monitoring-Projekte werden zudem von unterschiedlichen Institutionen betrieben und bedienen sich verschiedener Methoden, so dass eine Vergleichbarkeit der Ergebnisse nur eingeschränkt möglich ist.

Mit Hilfe des österreichischen Gletscherinventars wird zum ersten Mal die Entwicklung aller österreichischen Gletscher erfasst, um Veränderungen flächendeckend dokumentieren zu können. Gletscherinventare existieren für die Jahre 1969, 1997 und 2006 und wurden aus unterschiedlichen Datenquellen erzeugt. Die Grundlage für das Inventar von 1969 sind Luftbilder, die von Groß (1987) photogrammetrisch ausgewertet und später von Lambrecht \& Kuhn (2007) digitalisiert wurden. Das Inventar von 1997 wurde ebenfalls basierend auf photogrammetrisch ausgewerteten Luftbildern erzeugt. Dabei wurden neben der Gletscherfläche mit Hilfe digitaler Höhenmodelle die Gletscherhöhen ausgewertet. Der Fehler der hier verwendeten Höhenmodelle liegt bei $\pm 0,71 \mathrm{~m}$ (Lambrecht $\&$ Kuhn 2007). Die Daten für das Modell von 2006 stammen aus hochauflösenden Laserscann-Befliegungen (Abermann et al. 2009). 
Die hieraus abgeleiteten Höhenmodelle ermöglichen eine Berechnung von Volumenveränderungen über das geodätische Verfahren (Reinhardt \& Rentsch 1986).

Für dieses Verfahren werden mindestens zwei digitale Geländemodelle (DGM) gleicher Auflösung benötigt. Eine Rasterzelle wird in einem DGM über ihre Koordinaten definiert und besitzt zusätzlich einen z-Wert zur Kennzeichnung der Höhe. Verringert ein Gletscher sein Eisvolumen, so schlägt sich diese Veränderung in der Verkleinerung der Fläche und/ oder in einem Verlust der Mächtigkeit nieder. Dieser Höhenverlust kann für jede Rasterzelle mit Hilfe einer Differenzberechnung der zWerte zweier Geländemodelle unterschiedlichen Alters in einem Geoinformationssystem berechnet werden. Da die Größe einer Rasterzelle bekannt ist, kann mit Hilfe der Höhendifferenz auch das Verlustvolumen jeder Zelle ermittelt werden.
Historische Karten als Archiv der Gletscherentwicklung

Bereits durch die Römer wurde eine vollständige Abbildung der Alpen in Karten des römischen Reiches angestrebt. Da das Hochgebirge jedoch in erster Linie ein Hindernis darstellte und das römische Interesse hauptsächlich dem Erhalt der Handelswege über die Pässe und in den großen Alpentälern galt, beschränkte sich die kartographische Beschreibung ausschließlich auf diese Bereiche (Brodersen 1995). Bis ins 17. Jahrhundert ging der Informationsgehalt der Karten nur wenig über die Verortung von Gemeinden und Handelswegen hinaus. Nur selten wurde eine realitätsnahe Darstellung der Topographie angestrebt (Abb. 1). Erstmalig im Atlas Tyrolensis (Anich \& $\mathrm{Hu}-$ eber 1774) wurde 1774 eine Karte veröffentlicht, die eine detailgetreue Darstellung des Reliefs und die Benennung von markanten

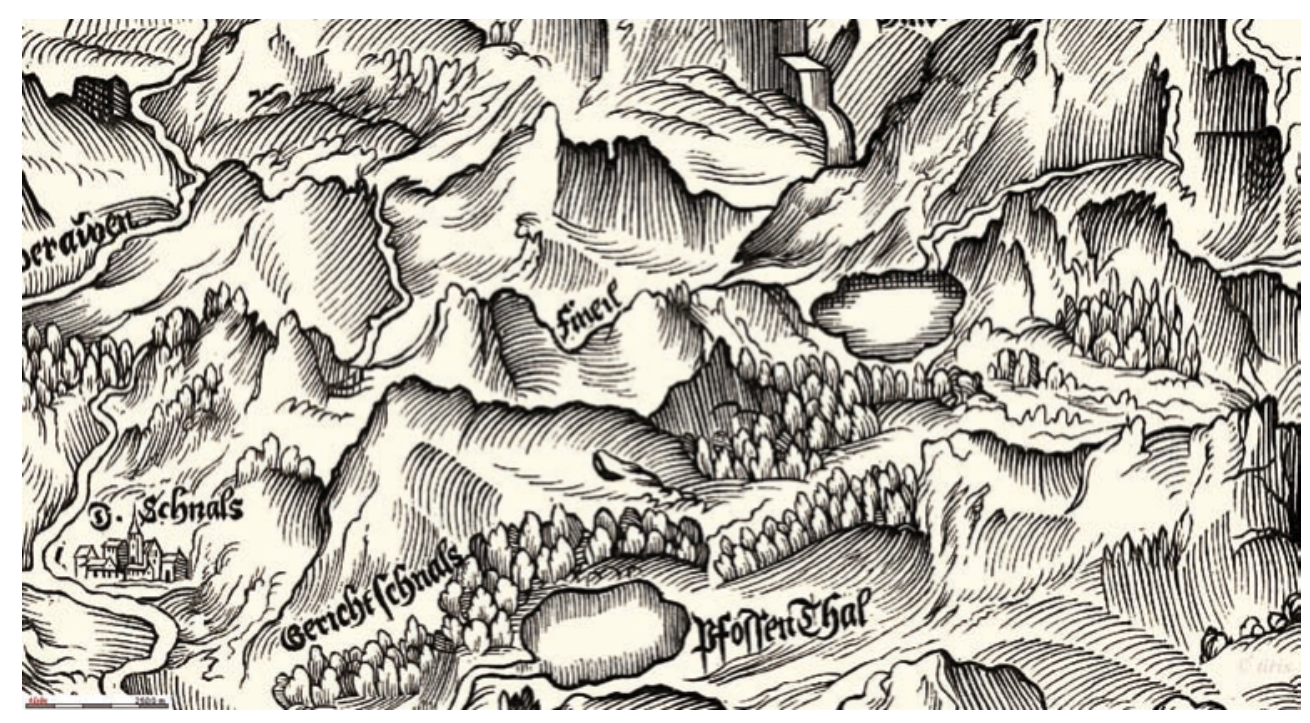

Abb. 1: Tirolische Landtafel von 1611 (Quelle: Tiroler Landesarchiv) 
Berggipfeln und Gletschern zeigt (Abb. 2). Mit der dritten Landesaufnahme im Maßstab 1:25.000 aus den Jahren 1870-1873 wurde über die Darstellung von Höhenlinien die Abbildung der Orographie erneut verbessert (Abb. 3). Eine Optimierung vermessungs-

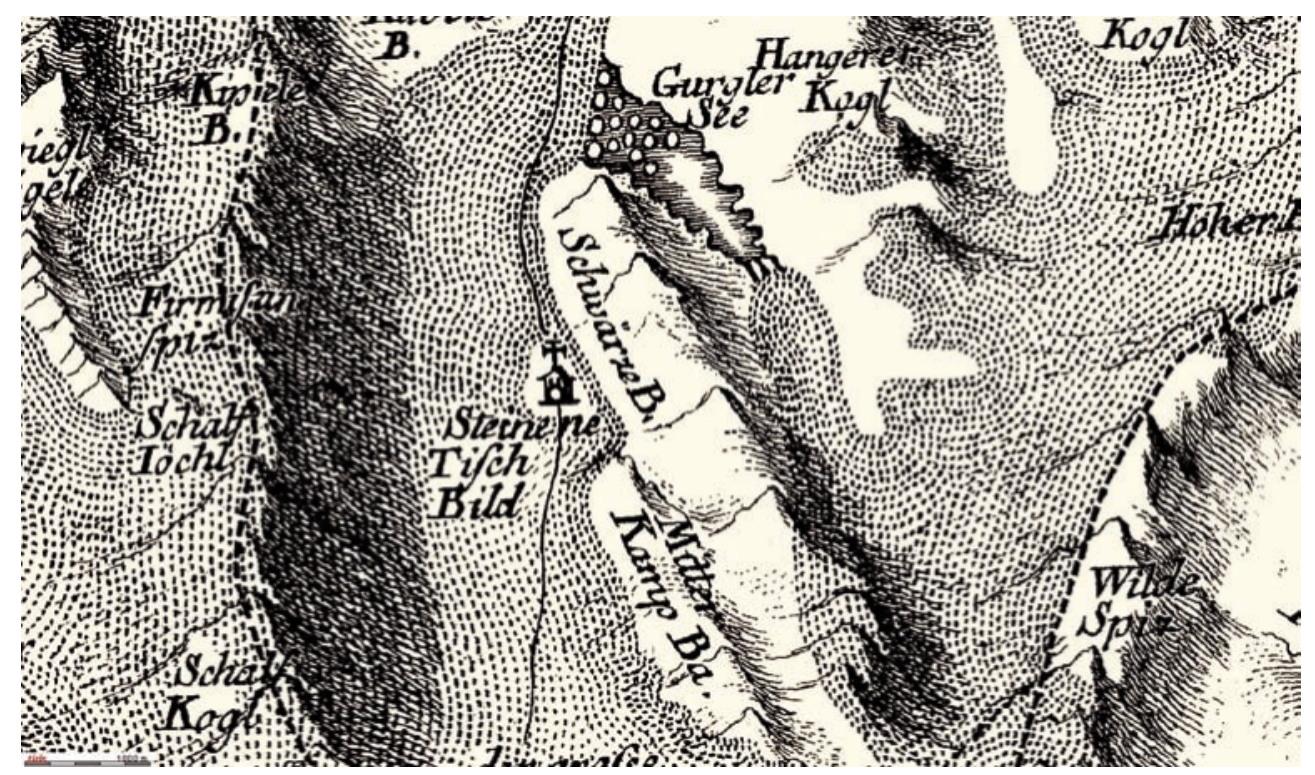

Abb. 2: Atlas Tyrolensis von 1774 (Quelle: Tiroler Landesarchiv)

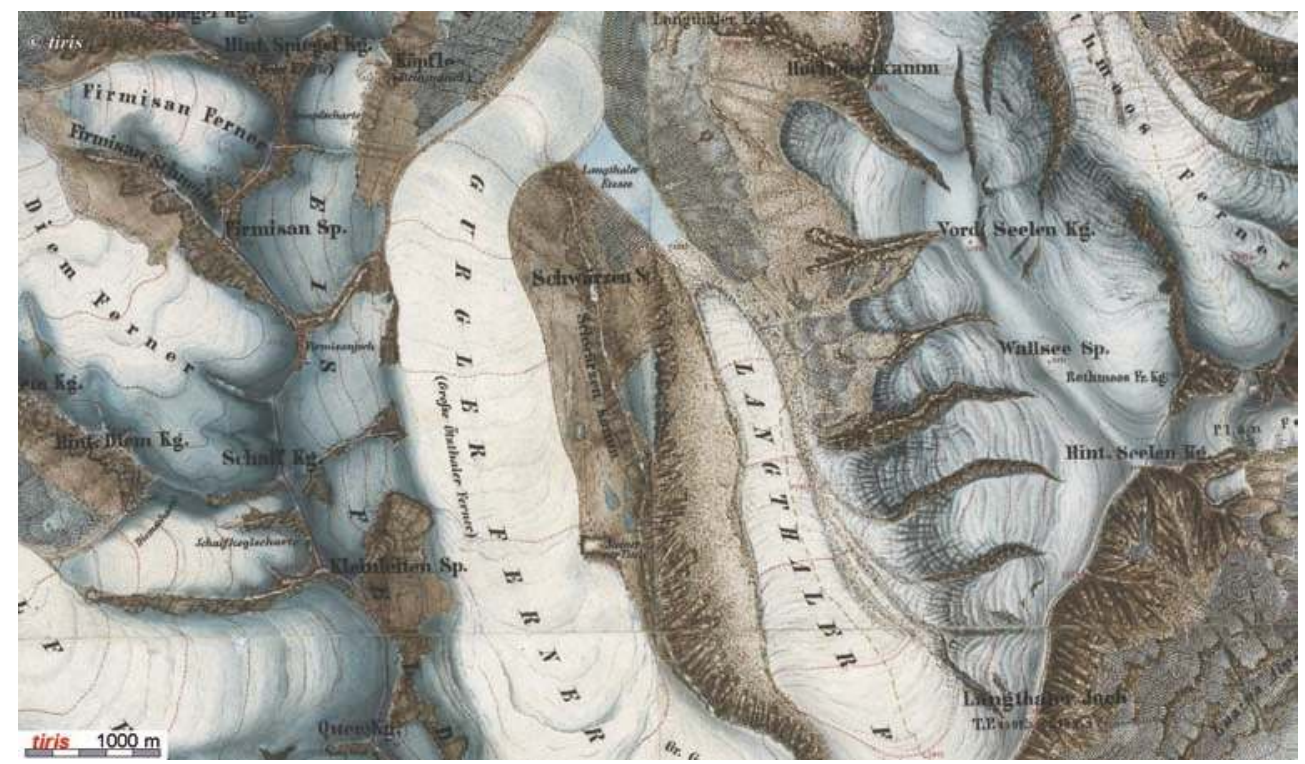

Abb. 3: Dritte Landesaufnahme von 1870-73 (Quelle: Tiroler Landesarchiv) 
technischer Methoden und ihrer Anwendung lag in dieser Zeit maßgeblich im Interesse des Militärs, weshalb die Landesaufnahme unter der Federführung des militärgeographischen Instituts erfolgte (Beimrohr 2012).

Erst mit der Aufnahme von Luftbildern und ihrer photogrammetrischen Auswertung zur Erstellung topographischer Karten wurde Kartenmaterial produziert, welches den Genauigkeitsansprüchen an die Höheninformationen der hier beschriebenen Untersuchung gerecht wird. In den Alpen wurden großflächige Befliegungen erstmalig nach dem zweiten Weltkrieg von den alliierten Streitkräften durchgeführt (Fasching 2000). Das genaue Jahr der Befliegung ist oft nicht mehr nachvollziehbar, so dass meist das Jahr der Kartenveröffentlichung als Anhaltspunkt für die zeitliche Einordnung dient. Für die Ötztaler Alpen liegt ein solches Kartenwerk erstmalig für das Jahr 1952 vor. Aus dem gleichen Zeitraum stammt das Kartenblatt des Deutschen Alpenvereins (DAV) von 1949. Nach Informationen des DAV wurden Karten dieser Zeit mittels terrestrischer Photogrammetrie erstellt. Sie entsprechen den hier geforderten Ansprüchen an Genauigkeit. Das Blatt Obergurgl des DAV liegt dem Verfasser bisher nicht vor und konnte deshalb nicht genauer geprüft werden, so dass in dieser Arbeit für den genannten Zeitraum nur die Karte des US Army Map Service verwendet wurde.

Erst 1974 wurde vom Bundesamt für Eichund Vermessungswesen (BEV) eine Neuaufnahme mittels Aerophotogrammetrie realisiert. Nach Thomas Knoll (persönliche Mitteilungen 2012), Leiter des Kartenarchivs im Bundesamt für Eich- und Vermessungswesen, existierte bis zur Neuaufnahme lediglich ein provisorisches amtliches Kartenblatt in 1:50.000 (ÖK 50) basierend auf einer terrestrischen Geländeaufnahme aus dem Jahre 1888/89. Die hieraus abgeleiteten Höhenlinien sind Ergebnis einer zumeist händischen Interpolation, so dass diese Karte für die eigenen weiteren Auswertungen nicht verwendet wurde. Es bleibt zu prüfen, inwieweit sich eine digitale Verarbeitung der frühen ÖK 50 für die eigene Zielsetzung eignet. Die Grundlage aller weiteren Auswertungen bildeten zunächst nur Karten, die auf photogrammetrisch ausgewerteten Luftbildern beruhen.

\section{Untersuchungsgebiet}

Das im Rahmen dieses Artikels bearbeitete Untersuchungsgebiet beschränkt sich auf das Einzugsgebiet der Gurgler Ache am Pegel Obergurgl in den Ötztaler Alpen/Tirol (Abb. 4). Der Messpegel befindet sich unterhalb der Gemeinde Obergurgl auf einer Höhe von 1878,64 m. Er wurde 1946 errichtet und zunächst nur zur Aufzeichnung von Wasserständen mittels Lattenpegel verwendet ( $\mathrm{Hy}$ drographischer Dienst in Österreich 2009). Seit 1966 stehen tägliche Abflussdaten zur Verfügung, die online abgerufen werden können. Die Gurgler Ache durchfließt auf einer Länge von ca. 16 km das Gurglertal und vereinigt sich in Zwieselstein mit der Venter Ache zur Ötztaler Ache. 


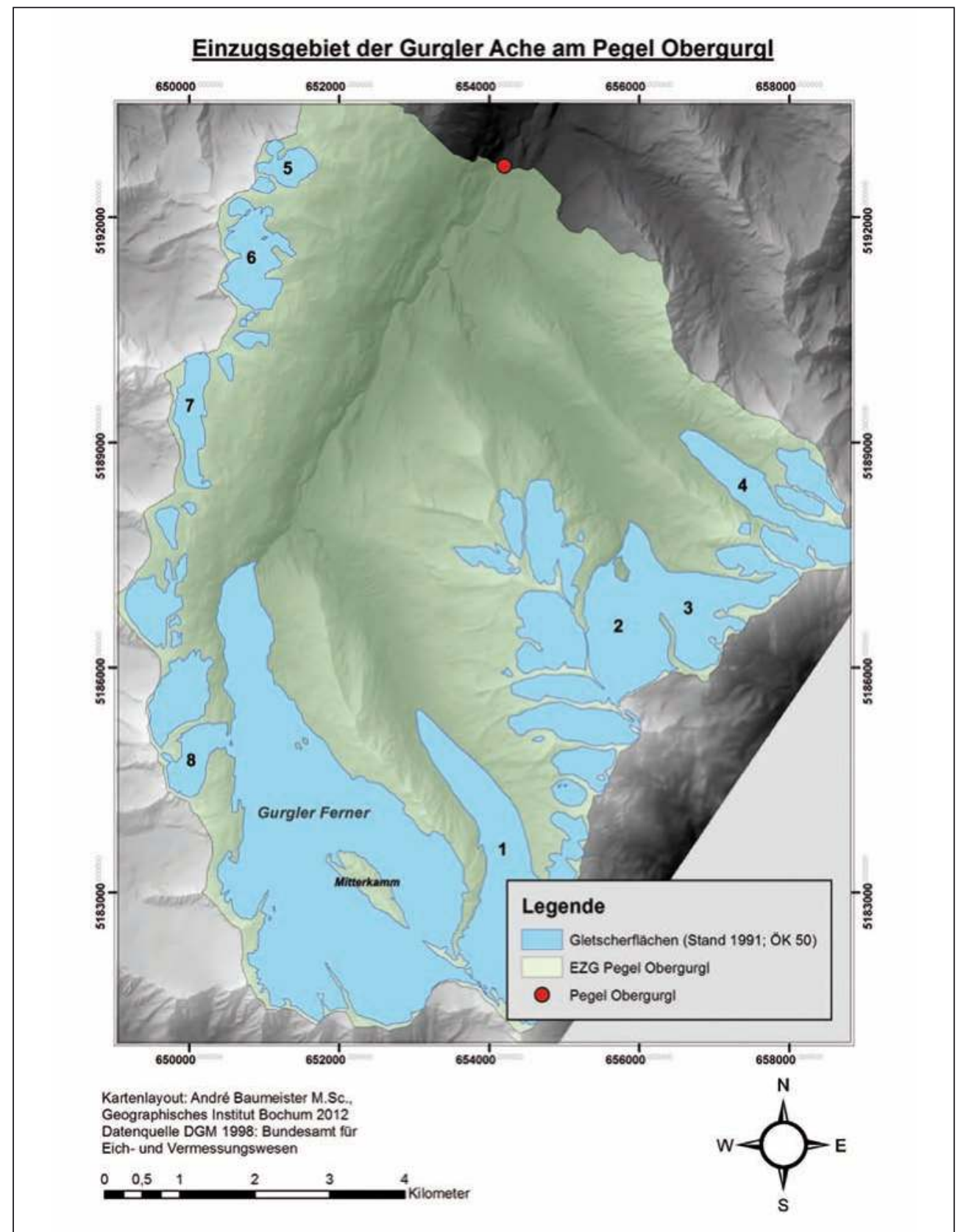

Abb. 4: Untersuchungsgebiet im Einzugsgebiet der Gurgler Ache. Zusätzlich markiert wurden folgende Gletscher: Langtaler Ferner (1), Wasserfallferner (2), Rotmoosferner (3), Gaisbergferner (4), Lehnerferner (5), Manigenbachferner (6), Ramolferner (7) und Kleinleitenferner (8) 
Das Einzugsgebiet oberhalb des Pegels hat eine Größe von $72,5 \mathrm{~km}^{2}$ und ist $\mathrm{zu}$ ca. 30 \% vergletschert. Der größte Gletscher im Untersuchungsgebiet ist der Gurgler Ferner. Mit einer Fläche von ca. $9,5 \mathrm{~km}^{2}$ ist er gleichzeitig der drittgrößte Gletscher des Landes Tirol. Dahinter folgt der östlich benachbarte Langtaler Ferner (Abb. 4, 1) mit einer Fläche von 2,9 $\mathrm{km}^{2}$ (Stand 1997 nach Fischer et al. 2010). Die Beschränkung auf das Einzugsgebiet der Gurgler Ache und die Verfügbarkeit der Abflussdaten ermöglichen vergleichende Betrachtungen von Abflussdaten und Gletscherentwicklung.

\section{Material und Methoden}

\section{Verwendetes Kartenmaterial}

In Tab. 1 sind alle Karten aufgelistet, die hinsichtlich ihrer Eignung für die Untersuchungen dieser Arbeit überprüft wurden. Die für eine Untersuchung der Gletscherflächen- oder volumenveränderungen geeigneten Karten sind unterstrichen. Die letztendlich verwendeten Karten wurden zusätzlich rot markiert. Geeignete Karten wurden über photogravimetrisch ausgewertete Luftbilder erzeugt, deren Aufnahme unmittelbar vor der Erstellung der Karte stattgefunden hat. Nur so entsprechen Ausdehnung und Höheninformationen der Gletscher dem angegebenen Stand der Karte. Während der häufigen Aktualisierungen, die oft aus Geländebegehungen resultierten, wurden die Gletscher nicht neu vermessen. In Einzelfällen wurde zwar der Gletscherrand aktualisiert, die Höheninformationen wurden aber belassen. Aktualisierte Karten sind demnach für das hier vorgestellte Verfahren nicht geeignet. Die Befliegungen der Neuaufnahmen wurden nach Thomas Knoll (persönliche Mitteilung 2012) ein bis maximal zwei Jahre vor der Veröffentlichung durchgeführt.

Ein Ausschnitt der Karte des US Army Map Service von 1952 ist in Abb. 5 dargestellt.

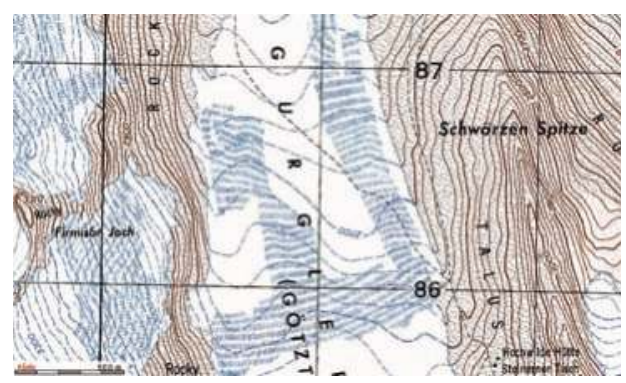

Abb. 5: Karte des US Army Map Service von 1952 (Quelle: Tiroler Landesarchiv)

Die Karte liegt im Maßstab 1:25.000 vor und zeigt Isolinien mit einer Äquidistanz von 20 m. Verwaltet und archiviert werden die Karten vom Tiroler Landesarchiv. Ein Zugriff ist über das Online-Portal tiris des Landes Tirol möglich (tiris Kartendienste 2013). Die weiteren verwendeten Karten aus den Jahren 1974 und 1991 sind jeweils historische Ausgaben der ÖK 50 des Bundesamts für Eichund Vermessungswesen (BEV) im Maßstab 1:50.000 mit einer Äquidistanz der Isolinien von $20 \mathrm{~m}$. Beide Blätter wurden als Scans über das Kartenarchiv des BEV bezogen. Das Ergebnis der Neuaufnahme von 1998 wurde an dieser Stelle nicht verwendet. Die Befliegung 
Tab. 1: Verfügbares Kartenmaterial des Untersuchungsgebietes seit 1888

\begin{tabular}{|c|c|c|c|c|}
\hline $\begin{array}{l}\text { Jahr der Veröf- } \\
\text { fentlichung / } \\
\text { Stand }\end{array}$ & Herausgeber & $\begin{array}{l}\text { Art der Aufnahme / Aktuali- } \\
\text { sierungsgrundlage }\end{array}$ & $\begin{array}{l}\text { Eignung für } \\
\text { Kartierung } \\
\text { Gletscherfläche }\end{array}$ & $\begin{array}{l}\text { Eignung für } \\
\text { gravimetrisches } \\
\text { Verfahren }\end{array}$ \\
\hline$/ 1888$ & $\mathrm{BEV}$ & $\begin{array}{l}\text { terrestrische } \\
\text { Photogrammetrie }\end{array}$ & ja & nein \\
\hline 1949 & Alpenverein & $\begin{array}{l}\text { Neuaufnahme, terrestrische } \\
\text { Photogrammetrie }\end{array}$ & ja & ja \\
\hline$\underline{1952}$ & $\begin{array}{l}\text { US Army Map } \\
\text { Service }\end{array}$ & $\begin{array}{l}\text { Neuaufnahme, Aerophoto- } \\
\text { grammetrie }\end{array}$ & ja & ja \\
\hline 1955 & Alpenverein & nicht spezifizierte Nachträge & nein & nein \\
\hline 1965 & Alpenverein & nicht spezifizierte Nachträge & nein & nein \\
\hline 1968 & Alpenverein & nicht spezifizierte Nachträge & nein & nein \\
\hline 1974 & Alpenverein & nicht spezifizierte Nachträge & nein & nein \\
\hline$\underline{1974}$ & $\mathrm{BEV}$ & $\begin{array}{l}\text { Neuaufnahme, } \\
\text { Aerophotogrammetrie }\end{array}$ & ja & ja \\
\hline 1977 & Alpenverein & $\begin{array}{l}\text { vollständige Neugestaltung } \\
\text { auf BEV-Grundlage }\end{array}$ & nein & nein \\
\hline 1982 & Alpenverein & nicht spezifizierte Nachträge & nein & nein \\
\hline 1982 & $\mathrm{BEV}$ & $\begin{array}{l}\text { geringfügige Anpassungen } \\
\text { an ausgewählten Gletschern }\end{array}$ & nein & nein \\
\hline 1988 & Alpenverein & nicht spezifizierte Nachträge & nein & nein \\
\hline$\underline{1991}$ & $\mathrm{BEV}$ & $\begin{array}{l}\text { Neuauswertung der Glet- } \\
\text { scher, Aerophotogrammetrie }\end{array}$ & ja & ja \\
\hline 1993 & Alpenverein & $\begin{array}{l}\text { nicht spezifizierte Nachträge } \\
\text { nach Geländebegehungen }\end{array}$ & nein & nein \\
\hline$\underline{1998 / 1997}$ & $\mathrm{BEV}$ & $\begin{array}{l}\text { Neuaufnahme, Aerophoto- } \\
\text { grammetrie }\end{array}$ & ja & ja \\
\hline 2000 & Alpenverein & $\begin{array}{l}\text { digitale Nachführung, } \\
\text { Situationsergänzungen } \\
\text { auf BEV-Grundlagen }\end{array}$ & nein & nein \\
\hline$\underline{2004 / 05}$ & $\mathrm{BEV}$ & $\begin{array}{l}\text { Umstellung auf ÖK50- } \\
\text { UTM, Aktualisierung der } \\
\text { Gletscherausdehnung }\end{array}$ & ja & nein \\
\hline$\underline{2008}$ & Alpenverein & $\begin{array}{l}\text { Gletscherrandbereinigung } \\
\text { nach Luftbildern }\end{array}$ & ja & nein \\
\hline
\end{tabular}


für diese Aufnahme aus dem Jahr 1997 ist gleichzeitig Grundlage des zweiten Gletscherinventars und darüber hinaus das aktuellste verfügbare DGM des Untersuchungsgebietes. Das Höhenmodell liegt in einer Rastergröße von $10 \times 10 \mathrm{~m}$ vor und wird vom BEV als digitaler Datensatz zur Verfügung gestellt. Die Berechnungen der Volumenveränderung der Gletscher im Einzugsgebiet wurden auf Grundlage dieses Geländemodells und des jeweils betrachteten historischen Geländemodells durchgeführt.

Auf der Grundlage zusätzlichen Kartenmaterials wurde darüber hinaus der Rückgang der Eisrandlage in höherer zeitlicher Auflösung rekonstruiert. Hierzu zählt u.a. die von Patzelt (1982) veröffentlichte Karte des Gurgler Ferners im Maßstab 1:10.000, auf der Eis- randlagen unterschiedlichen Alters seit 1850 eingetragen sind. Als Kartengrundlage diente eine vom BEV durchgeführte Befliegung aus dem Jahr 1981. Weiters wurden die in den Gletscherinventaren der Jahre 1969 und 1997 erfassten Eisrandlagen berücksichtigt. Die jüngste kartierte Eisrandlage ist einem Luftbild des Jahres 2009 entnommen. Im Luftbildatlas Tirol werden online über die Plattform tiris aktuelle und historische Luftbilder zur Verfügung gestellt. Die aktuellen Luftbilder des DAV aus dem Jahr 2003 sind über die digitalen Kartenwerke erhältlich und dienen hier als Grundlage für die kartographische Darstellung des Gurgler Ferners (Stand 2009). Eine Zusammenfassung aller in dieser Arbeit verwendeten Karten befindet sich in chronologischer Reihenfolge in Tab. 2.

Tab. 2: Verwendetes Kartenmaterial

\begin{tabular}{cccc}
\hline $\begin{array}{c}\text { Jahr der Veröffentlichung / } \\
\text { Stand }\end{array}$ & Quelle & $\begin{array}{c}\text { Verwendung } \\
\text { Fläche } \\
\text { Gurgler Ferner }\end{array}$ & $\begin{array}{c}\text { Verwendung gravime- } \\
\text { trisches Verfahren }\end{array}$ \\
\hline 1952 & US Army Map Service & $\mathrm{x}$ & $\mathrm{x}$ \\
\hline 1969 & Gletscherinventar & $\mathrm{x}$ & $\mathrm{x}$ \\
\hline 1974 & BEV & $\mathrm{x}$ & $\mathrm{x}$ \\
\hline 1981 & BEV / Kartierung Patzelt & $\mathrm{x}$ & $\mathrm{x}$ \\
\hline 1991 & BEV & $\mathrm{x}$ & \\
\hline 1997 & DGM 10 / BEV & $\mathrm{x}$ & \\
\hline $1998 / 1997$ & BEV & $\mathrm{x}$ & \\
\hline 2003 & DAV & $\mathrm{x}$ &
\end{tabular}


Georeferenzierung und Digitalisierung historischer Karten

Alle verwendeten Kartenblätter standen vor ihrer Bearbeitung in nicht georeferenzierter Form als digitaler Scan zur Verfügung, d.h. die Bilddatei verfügten über keinen räumlichen Bezug. Als Grundlage für die Georeferenzierung diente das Gitternetz des österreichischen Bundesmeldenetzes im Gauß-Krüger Format (M28), das den Karten aufgedruckt ist. Um den möglichen Lagefehler klein zu halten, wurden die Referenzierungspunkte gleichmäßig in hoher Dichte über das Kartenblatt verteilt. Die auf diesem Weg georeferenzierten Karten des BEV dienten als Vorlage für die Georeferenzierung von gitternetzlosen Luftbildern und Karten, die auf anderen Bezugssystemen basieren (US Army Map 1952). Hierfür wurden eindeutig identifizierbare Referenzierungspunkte wie Hütten oder Berggipfel gewählt.

Die Digitalisierung des Gletscherrandes erfolgte mit einem GIS. Je nach Eignung der Karte wurden alle Gletscherflächen im Einzugsgebiet der Gurgler Ache vollständig digitalisiert.

\section{Berechnung von Eisvolumenveränderungen mit Hilfe des gravimetrischen Verfahrens}

Um aus den Höheninformationen der Karten Geländemodelle ableiten zu können, mussten zunächst für jede Karte alle Höhenlinien auf den Gletscherflächen digitalisiert werden. Damit eine realitätsnahe Interpolation der Glet- scherhöhen erreicht werden konnte, wurden die Höhenlinien deutlich über den Rand des Gletschers hinaus digitalisiert. Die Interpolation der historischen Geländemodelle erfolgte in ArcGIS mit Hilfe der Methode Topo to Raster, die bereits von Gspurning et al. (2004) und Fischer (2011) verwendet wurde. Nach Esri (2013) zeichnet sich die Methode vor allem durch hydrologisch korrekte Ergebnisse aus. Es handelt sich hierbei um das einzige auf linienhafte Eingabedaten ausgerichtete Interpolationsverfahren. Die Zellengröße des interpolierten Geländemodells muss an die des aktuellen DGMs angepasst werden. In diesem Fall handelt es sich um ein Raster mit einer Auflösung von 10 x 10 m. Mit Hilfe der vorher digitalisierten Polygone der Gletscherflächen wurden die interpolierten Geländemodelle auf die tatsächlichen Gletscherflächen des jeweiligen Jahres reduziert. Die so erzeugten Geländemodelle geben die Höhe der historischen Gletscheroberfläche wieder. Mit Hilfe des in ArcGIS integrierten Raster Calculators können die Höhen des aktuellen Geländemodells (DGM $\mathrm{t}_{2}$ ) von den Höhen des interpolierten, auf Basis der historischen Karten entstandenen Geländemodells (DGM $\mathrm{t}_{1}$ ) subtrahiert werden. Dieser Rechenschritt erzeugt ein Raster, welches die Höhenveränderung der Gletscheroberfläche zwischen dem Zeitpunkt $\mathrm{t}_{1}$ und dem Zeitpunkt $\mathrm{t}_{2}$ darstellt. Da Länge und Breite der Rasterzellen bekannt sind, kann über die Höhendifferenz $\left(t_{1}-t_{2}\right)$ das Volumen für jede Zelle bestimmt werden. Hierzu stehen in ArcGIS die Funktionen Surface Volume und Cut Fill zur Verfügung (Klaus \& Baumeister 2012). 


\section{Ergebnisse}

Gletscherstände des Gurgler Ferners zwischen 1850 und 2009

Wie bereits beschrieben wurden in allen betrachteten Karten zunächst die Gletscherflächen digitalisiert. Da einige Karten und Luftbilder keine oder nur unvollständige Höheninformationen enthalten, konnten aus ihnen keine Höhenmodelle interpoliert werden. Um der Gesamtheit der Karten und Luftbilder Rechnung zu tragen, wurden alle Gletscherstände der untersuchten Quellen für den Zungenbereich des Gurgler Ferners zusammengetragen. Die Ergebnisse aus der Digitalisierung aller verfügbaren Informationen des Gletscherstandes am Gurgler Ferner sind in Abb. 6 dargestellt. Nicht dargestellt wurden in der Karte die Gletscherstände der Jahre 1969 (Gletscherinventar) und 1981 (Digitalisierung der Gletscherfläche aus Patzelt 1982), da zwischen den beiden Jahren kaum Veränderungen zu beobachten waren. Lediglich im Bereich der Zungenspitze ist ein geringer Vorstoß zu erkennen, der zu Beginn der 1980er Jahre bei vielen Gletschern beobachtet werden konnte. In diesem Betrachtungsmaßstab würde eine Darstellung weiterer Eisrandlagen lediglich die Qualität der Darstellung beeinträchtigen.
Die Ergebnisse zeigen deutlich die maximale Ausdehnung des Gurgler Ferners zum Ende der Kleinen Eiszeit 1850. Zu dieser Zeit erstreckte sich der Eiskörper bis über den Taleingang des Langtales hinaus, wodurch das Schmelzwasser des Langtaler Ferners aufgestaut wurde. Hier bildete sich der Gurgler Eisstausee, dessen Ablagerungen am Talboden des Langtales zu finden sind. Die Eisrandlagen nach Patzelt (1982) stützen sich auf geomorphologische Kartierungen. Insgesamt hat sich der Gurgler Ferner zwischen den Jahren 1850 und 2009 um knapp 2,5 km zurückgezogen. Insbesondere im westlichen Bereich der Karte fällt jedoch auf, dass sich die Eisrandlage kaum verändert hat. Hier bestimmt die Geländemorphologie maßgeblich das Verhalten des Gletschers. Im steilen Gelände bedingt eine Abnahme der Mächtigkeit nur eine geringe Verschiebung des Eisrandes. Dies lässt vermuten, dass sich bei negativen Massenbilanzen der Volumenverlust besonders in einer Verringerung der Mächtigkeit und weniger einem Rückzug der Gletscherfront niederschlägt. Im Jahr 2009 trennen sich zum ersten Mal die zwei zuvor miteinander verbundenen Akkumulationsgebiete östlich und westlich des Mitterkamms. Eigene Kartierungen zeigten noch im Vorjahr eine Verbindung zwischen den zwei Gletscherzungen, die bereits 2011 deutlich über $100 \mathrm{~m}$ voneinander getrennt waren. 


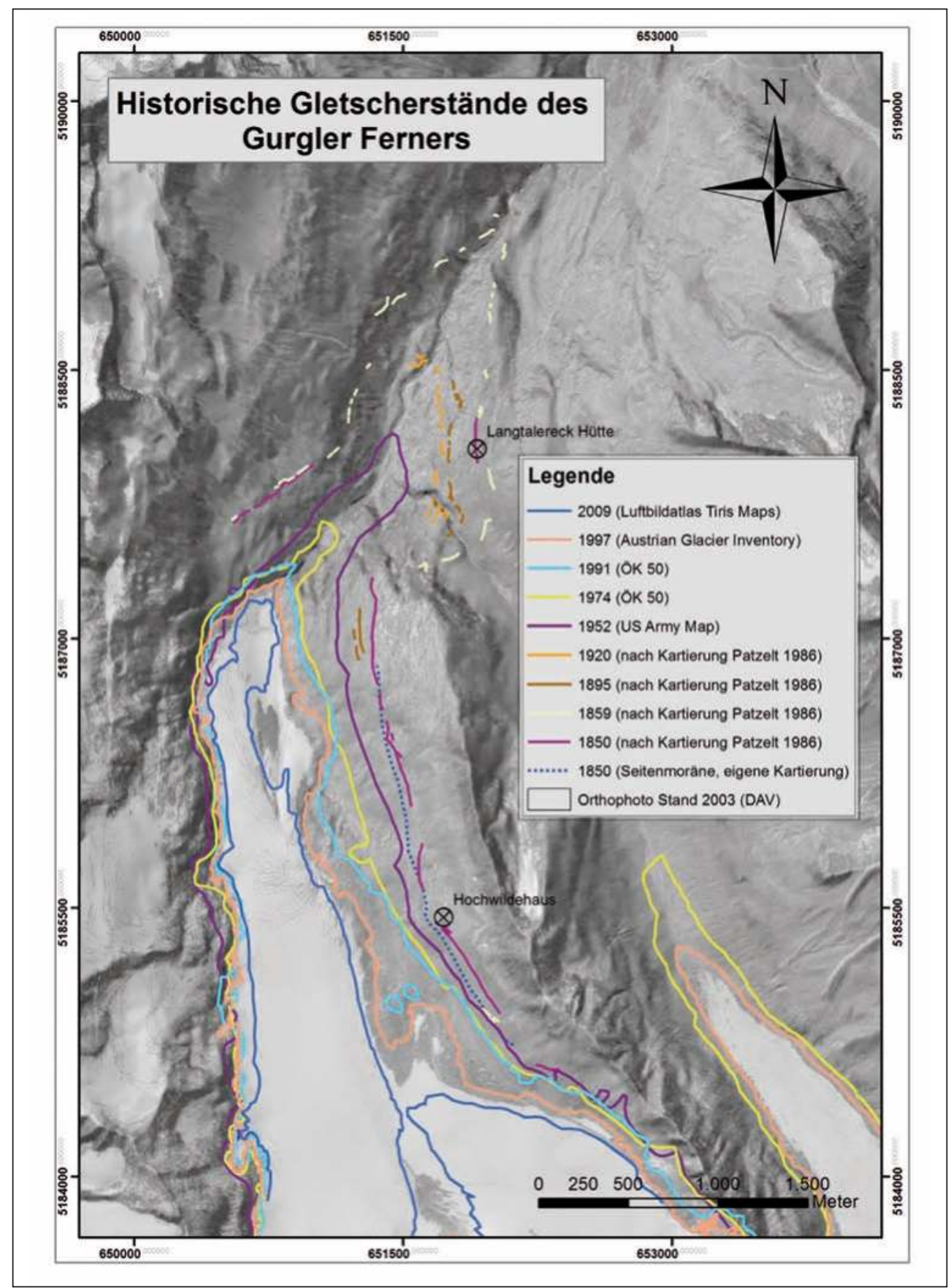

Abb. 6: Entwicklung der Gletscherstände des Gurgler Ferners zwischen 1850 und 2008 
Veränderung der Gletscheroberfläche im Einzugsgebiet der Gurgler Ache zwischen 1952 und 1997

Die Flächenberechnungen der mit Eis bedeckten Flächen im Untersuchungsgebiet (Tab. 3) wurden mittels der durch die Digitalisierung gewonnenen Flächendaten der Jahre 1952, 1974, 1991 und 1997 durchgeführt und mit den Daten des Gletscherinventars des Jahres 1969 ergänzt. Noch 1952 war das Untersuchungsgebiet mit einer Größe von $72,5 \mathrm{~km}^{2}$ auf einer Fläche von $29 \mathrm{~km}^{2}$ mit Eis bedeckt. Bis 1997 reduzierte sich diese Fläche um ca. $25 \%$ auf $23 \mathrm{~km}^{2}$.
Für den Zeitraum 1952-1997 zeigen sich Höhenabnahmen von > $100 \mathrm{~m}$. Wie vermutet befinden sich diese maximalen Mächtigkeitsverluste insbesondere im Bereich der Zunge des Gurgler Ferners, in der sogenannten Gletscherschlucht. Weitere derartig große Höhenverluste treten ebenfalls in den Zungenbereichen der Talgletscher des Langtaler-, Rotmoos- und Gaisbergferners auf. Darüber hinaus zeigen sich große Höhenverluste im Bereich westlich des Hochwildehauses (Abb. 7). Das Relief dieses heute eisfreien Bereichs zeichnet sich durch ein ausgeprägtes Becken aus. Die geringsten Höhenabnahmen zeigen sich in den höher gelegenen Kar- und

Tab. 3: Veränderung der Gletscherfläche im Einzugsgebiet

\begin{tabular}{cccc}
\hline Jahr & Gletscherfläche in $\mathrm{km}^{2}$ & $\begin{array}{c}\text { Abnahme in \% zum } \\
\text { vorherigen Stand }\end{array}$ & $\begin{array}{c}\text { Abnahme in \% zur } \\
\text { Ausgangsfläche }\end{array}$ \\
\hline 1952 & 29,03 & - & - \\
\hline 1969 & 27,57 & 5,29 & 5,29 \\
\hline 1974 & 26,99 & 2,14 & 7,55 \\
\hline 1991 & 25,36 & 6,40 & 14,44 \\
\hline 1997 & 23,13 & 9,65 & 25,49 \\
\hline
\end{tabular}

Veränderung des Eisvolumens im Einzugsgebiet der Gurgler Ache in den Jahren 1952, 1974 und 1991

Die Ergebnisse des in „Material und Methoden" beschriebenen Verfahrens sind in den Abb. 7, 8 und 9 dargestellt. Zu sehen ist jeweils die Höhenveränderung im Bereich des Gletschers zwischen dem Geländemodell des jeweiligen Betrachtungsjahrs und dem aktuellen DGM aus dem Jahr 1997.
Hängegletschern wie dem Wasserfallferner und dem Kleinleiten Ferner. Höhenzunahmen zeigen sich am Lehner Ferner. Für diesen Betrachtungszeitraum scheinen jedoch Mächtigkeitszunahmen dieser Art auf Interpolationsfehler, bedingt durch die Steilheit des Geländes, zurückzuführen zu sein. Das errechnete Verlustvolumen für den hier betrachteten Zeitraum beläuft sich auf 0,657 km³ . 


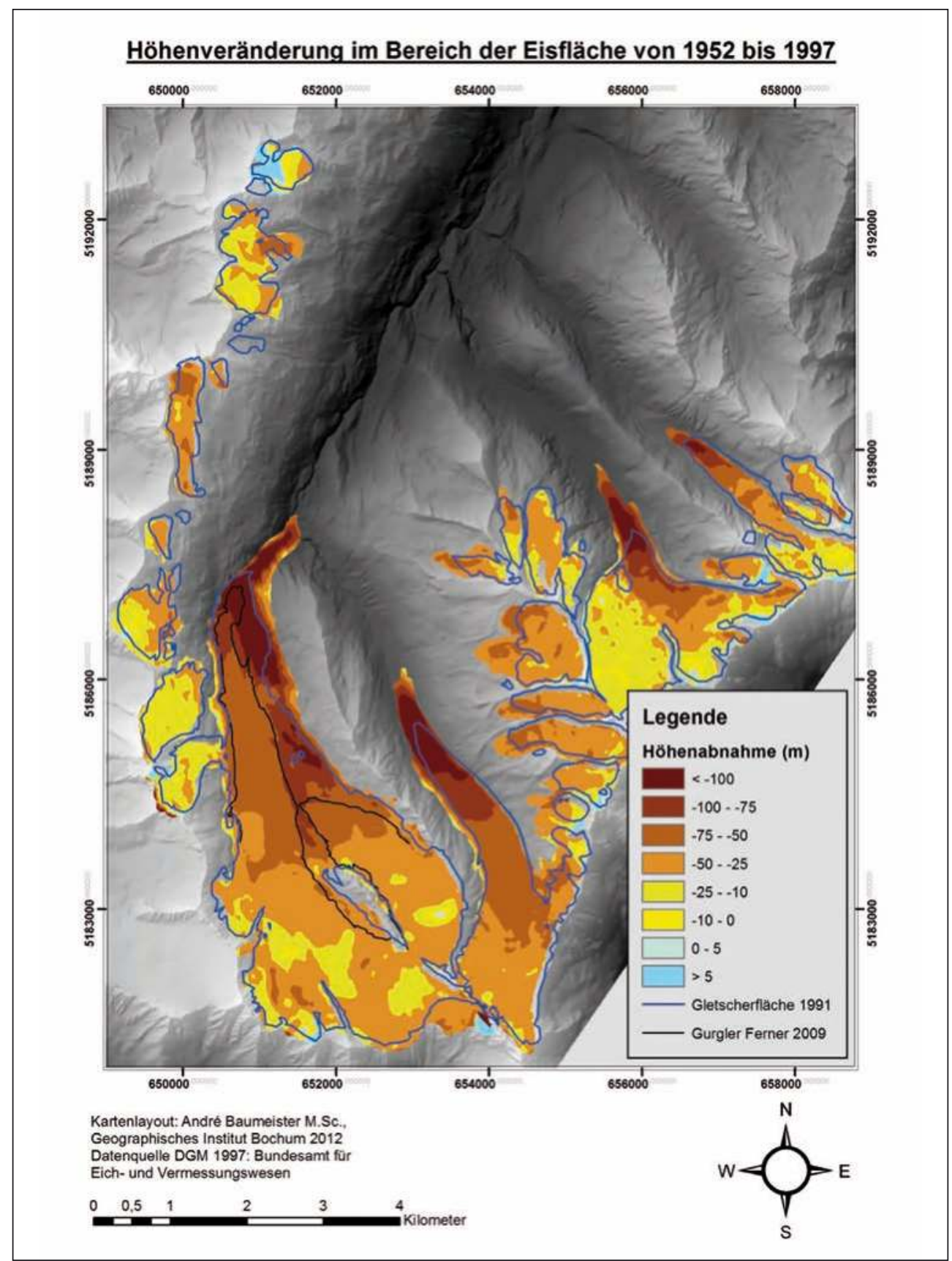

Abb. 7: Höhenabnahme der Gletscher im Einzugsgebiet der Gurgler Ache für den Zeitraum 1952-1997. Berechneter Eisvolumen-Verlust: 0,657 km³ 


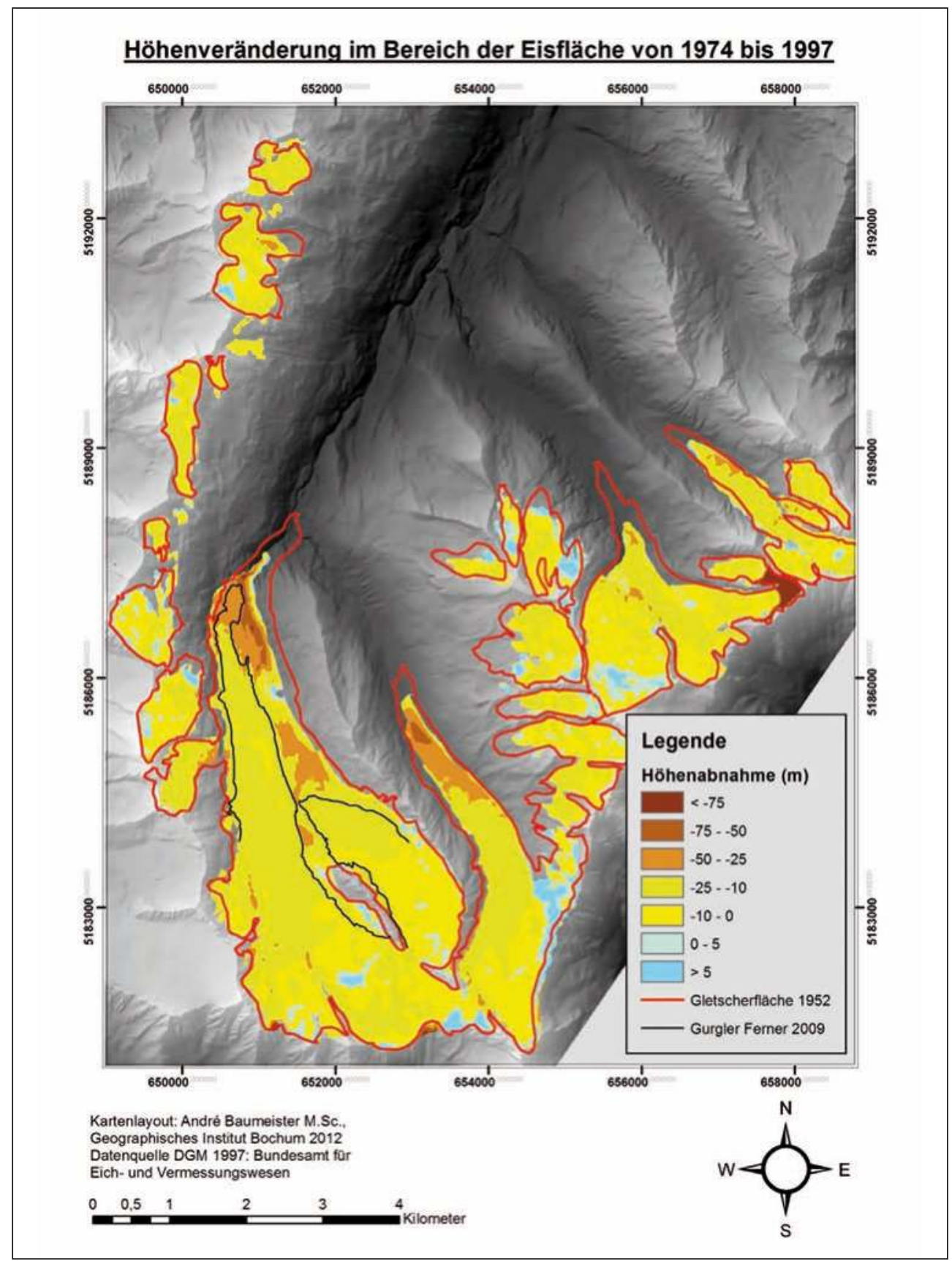

Abb. 8: Höhenabnahme der Gletscher im Einzugsgebiet der Gurgler Ache für den Zeitraum 1974-1997. Berechneter Eisvolumen-Verlust: 0,32 $\mathrm{km}^{3}$ 


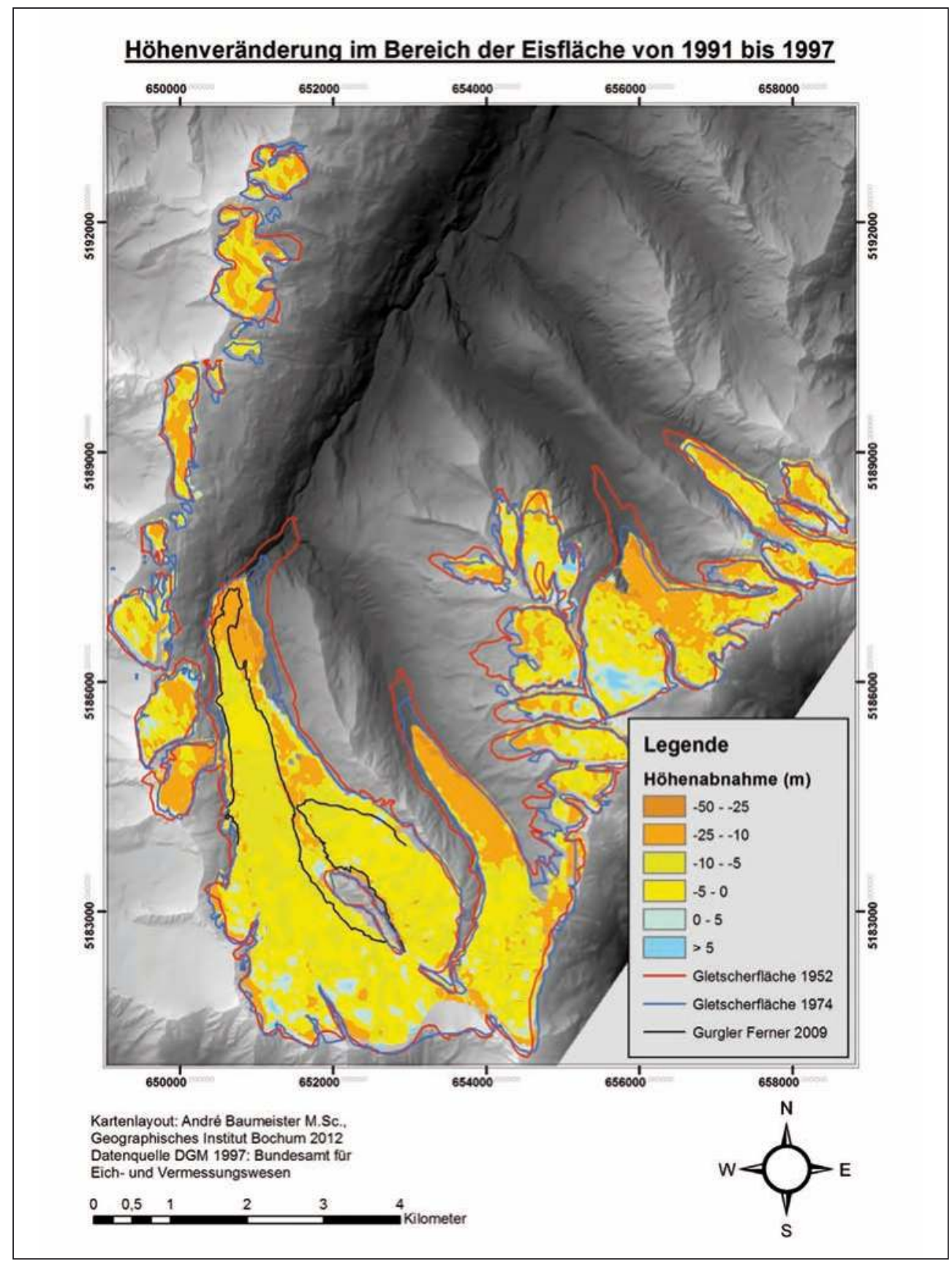

Abb. 9: Höhenabnahme der Gletscher im Einzugsgebiet der Gurgler Ache für den Zeitraum 1991-1997. Berechneter Eisvolumen-Verlust: 0,192 $\mathrm{km}^{3}$ 
Für den Zeitraum 1974-1997 (Abb. 8) zeigt sich ein ähnliches Bild, auch wenn die Höhenabnahmen deutlich geringer sind als für den vorher beschriebenen längeren Zeitraum. Die größten Abnahmen im Bereich zwischen 50 und > $75 \mathrm{~m}$ liegen ebenfalls auf den Gletscherzungen. Auch in dieser Auswertung sind Höhenzunahmen oder stark abweichende Höhenabnahmen, wie im Bereich zwischen Rotmoos- und Gaisbergferner, wahrscheinlich auf Interpolationsfehler zurückzuführen. Zunahmen der Gletscherhöhe, wie beispielsweise im oberen Bereich des Wasserfallferners lassen vielmehr darauf schließen, dass in diesen Bereichen die Mächtigkeit nur gering abgenommen hat. Es ist auffällig, dass sich Höhenzunahmen oft auf sehr steile Geländebereiche beschränken. $\mathrm{Da}$ in steilem Gelände horizontale Abweichungen der Höhenlinien zu großen Fehlern bei der Interpolation führen können, müssen Höhenzunahmen mit Vorsicht interpretiert werden. Zwischen 1974 und 1997 hat die Eismasse im Einzugsgebiet um $0,32 \mathrm{~km}^{3}$ abgenommen.

Trotz des nur kurzen Zeitraums zwischen 1991 und 1997 (Abb. 9) zeigen sich auch hier Mächtigkeitsabnahmen von bis zu $50 \mathrm{~m}$. Neben den Zungenbereichen der großen Talgletscher sind nun auch die hoch gelegenen Gletscher wie Ramolferner und Mannigenbach Ferner betroffen. Berücksichtigt man die Ergebnisse des Zeitraumes 1952-1997, fällt auf, dass ein verhältnismäßig großer Anteil des Verlustes der Eismächtigkeit in den 7 Jahren zwischen 1991 und 1997 stattgefunden hat. Insgesamt hat sich das Eisvolumen im betrachteten Zeitraum um 0,192 km³ verrin- gert. Dies entspricht knapp $30 \%$ der gesamten Volumenabnahme seit 1952, obwohl sich der Betrachtungszeitraum lediglich über 6 der insgesamt 45 Jahre erstreckt.

Auch wenn jährliche Schwankungen in den Betrachtungszeiträumen durchaus unterschiedlich ausfallen können, lässt eine Berechnung des jährlichen Eisverlustes einen besseren Vergleich der Ergebnisse zu. Hiernach belaufen sich die jährlichen Verluste zwischen 1952 und 1974 auf $14,65 \times 10^{6} \mathrm{~m}^{3}$ pro Jahr. Zwischen 1974 und 1991 hat sich das Eisvolumen jährlich um 7,11 x $10^{6} \mathrm{~m}^{3}$ verringert, während von 1991 bis 1997 der jährliche Eisverlust $27,42 \times 10^{6} \mathrm{~m}^{3}$ beträgt.

\section{Diskussion}

Die Ergebnisse zeigen ein eindeutiges und kaum überraschendes Bild. Die Gletscher im Untersuchungsgebiet ziehen sich, mit Ausnahme kurzer Vorstoßphasen, kontinuierlich zurück. Diese Ergebnisse entsprechen einem weltweiten Trend (IPCC 2007), der für den Alpenraum durch zahlreiche Studien bestätigt werden kann (Lambrecht \& Kuhn 2007 , Braun \& Weber 2008). Die Ergebnisse zeigen deutlich, dass sich dieser Trend im letzten Betrachtungszeitraum von 1991-1997 deutlich verstärkt hat. Auch diese Daten entsprechen weltweiten Beobachtungen (IPCC 2007). Im Fokus dieses Artikels stehen deshalb nicht aus den Ergebnissen ableitbare inhaltliche Aussagen über Gletscherstandsschwankungen, 
sondern die einleitende Frage nach dem Potential historischer Karten Gletscherstandsschwankungen zu dokumentieren.

In wohl keinem Gebirge der Welt wurden bestehende Karten so häufig aktualisiert wie in den Alpen. Die gute Dokumentation und Transparenz des Tiroler Landesarchivs, des Alpenvereins und letztendlich des Bundesamtes für Eich- und Vermessungswesen sind die Grundlage für die Auswahl geeigneter Karten. Die Qualität der erzeugten Daten kann nur über ein detailliertes Hintergrundwissen zur Entstehung des jeweiligen Kartenblatts gewährleistet werden. Für eine reine Rekonstruktion der Gletscherfläche genügen Informationen zum Aufnahmejahr. Für die Erstellung von Höhenmodellen ist zudem die Art der Aufnahme von Relevanz. Neuauflagen, in denen lediglich die Gletscherfläche korrigiert wurde, sind für das geodätische Verfahren ungeeignet. Geeignet sind in diesem Fall nur Neuaufnahmen, die aus photogrammetrisch ausgewerteten Luftbildern erzeugt wurden. Trotz dieser strengen Kriterien konnten für diese Arbeit zahlreiche Karten ausgewählt und bearbeitet werden.

Die Lagegenauigkeit amtlicher topographischer Karten wird in Österreich nach Aussage der Herausgeber lediglich durch die Signaturen eingeschränkt. Im Kartographischen Modell 1:50.000 (KM50-R) beträgt die Zeichengenauigkeit $0,1 \mathrm{~mm}$, das entspricht 5 $\mathrm{m}$ in der Natur. Die Lagegenauigkeit in den verwendeten Luftbildern ist von der Qualität der Georeferenzierung abhängig. Hier wurde während der Bearbeitung die geringmöglichste Abweichung angestrebt. Der Höhenfehler des aus Befliegungen abgeleiteten DGM wird nach Aussagen des BEV für Siedlungsgebiete mit $\pm 1 \mathrm{~m}$ und für Gletscher und Ödland mit $\pm 5 \mathrm{~m}$ angegeben. Für Isolinien auf Karten, die aus Luftbildern erzeugt wurden, gilt eine vergleichbare Genauigkeit. Die Genauigkeit von Höhenangaben auf den älteren topographischen Karten wurde im Rahmen dieser Arbeit stichprobenartig geprüft. Die Höheninformationen auf den Isolinien der historischen Karten wurden mit den Höhenangaben des aktuellen DGMs verglichen. Die Abweichungen lagen auf dem gesamten Kartenblatt (mit Ausnahme der Gletscherflächen) in der Regel im Bereich von $\pm 5 \mathrm{~m}$. Der Fehler wird tendenziell mit zunehmender Hangneigung größer, so dass in steileren Felsflanken auch größere Abweichungen festgestellt wurden. Um genauere Aussagen zum möglichen Messfehler des Verfahrens im Untersuchungsgebiet treffen zu können, sind weitere Untersuchungen notwendig. Hierzu muss ein Fehler für jeweils unterschiedliche Hangneigungsklassen berechnet und der Anteil des Untersuchungsgebietes in der entsprechenden Klasse berücksichtigt werden.

Mögliche Ungenauigkeiten im Interpolationsverfahren sind abhängig von der Genauigkeit der Digitalisierung der Höhenlinien und den Ergebnissen des gewählten Interpolations-Algorithmus. Hierzu wurden ebenfalls Testgebiete außerhalb der Gletscherflächen historischer Karten ausgewählt und nach dem beschriebenen Verfahren bearbeitet. Auf diesem Wege konnte die Abweichung interpolierter historischer Höhenmodelle vom DGM 1997 geprüft werden. Wie auch bei der Über- 
prüfung der Isolinien lag die Abweichung im Bereich von $\pm 5 \mathrm{~m}$ und zeigte eine steigende Tendenz in steileren Geländebereichen.

Für Gletscherflächen ergeben sich zusätzliche Ungenauigkeiten in den Bereichen oberhalb der Firngrenzen. Die meist weißen Flächen können auf Luftbildern nur schwer photogrammetrisch ausgewertet werden, weshalb die Abweichung der angegebenen Geländehöhe größer sein kann (Fischer 2011). Gspurning et al. (2004) nennen zusätzlich die Abgrenzung der Gletscherfläche als weitere Fehlerquelle, wobei dieser Fehler im hier betrachteten Untersuchungsgebiet aufgrund der Gesamtgröße der Gletscherfläche zu vernachlässigen ist. Mögliche Fehler bei der geodätischen Methode werden also maßgeblich durch die Qualität des Ausgangsmaterials bestimmt. Hier spielt vor allem auch die Zellgröße der Rasterdaten eine Rolle. Während Gspurning et al. (2004) mit einer Zellgröße von $25 \times 25$ m arbeiten, werden in den meisten Arbeiten Geländemodelle mit einer Auflösung von $\leq 10 \mathrm{~m}$ verwendet. Abermann et al. (2009) geben den Bilanzfehler der geodätischen Methode für Gletscher $>1 \mathrm{~km}^{2}$ mit $\pm 1,5 \%$ und für kleinere Gletscher mit $\pm 5 \%$ an. Fischer (2011) vergleicht in ihrer Arbeit die geodätische mit der direkten glaziologischen Methode und stellt ebenfalls heraus, dass die Beschaffenheit des Gletschers maßgeblich die Größe der Abweichung bestimmt. Die Anwendung der geodätischen Methode unter Verwendung historischer Karten wird in keinem der genannten Artikel in Frage gestellt.

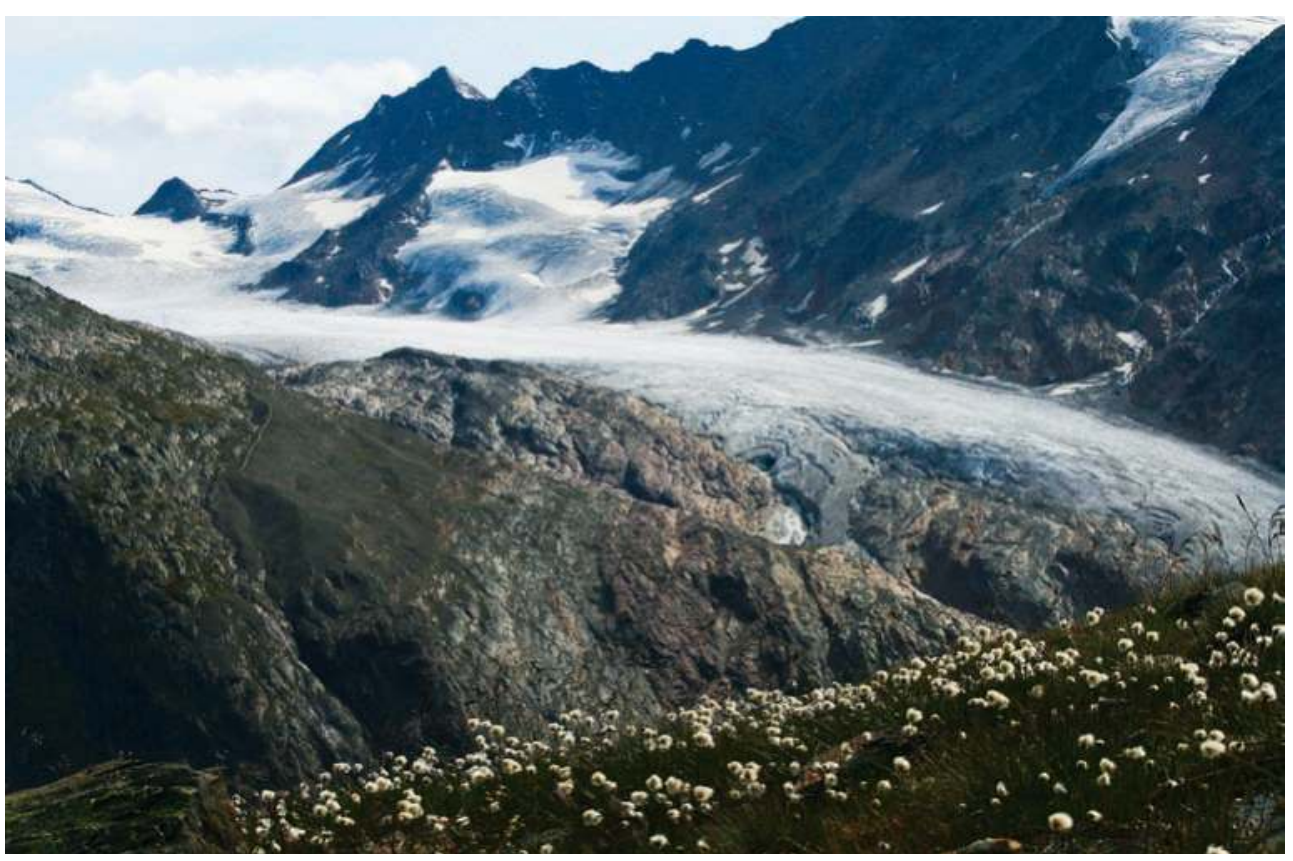

Abb. 10: Der Gurgler Ferner im Jahr 2008 (Foto: André Baumeister) 
Eine zusätzliche Sicherheit über die Plausibilität der Ergebnisse liefert der Vergleich mit den Daten der Arbeit von Kuhn et al. (2009). Hier wurde über das geodätische Verfahren die Höhenveränderung des Gurgler Ferners zwischen 1969 und 1997 berechnet. Die Ergebnisse sind mit den in dieser Arbeit gewonnenen Daten vergleichbar. Auch die in den Ergebnissen beschriebenen Prozesse am Gurgler Ferner finden sich in dieser Arbeit wieder. Abb. 10 zeigt ein Foto vom vorderen Bereich des Gurgler Ferners. Gut zu erkennen sind die Seitenmoräne von 1850 und der ausgeprägte Gletscherschliff. Die hierdurch erkennbare ehemalige Ausdehnung des Gletschers und die Morphologie der Gletscherschlucht bestätigen die berechneten großen Höhenabnahmen im Bereich der Gletscherzunge.

Abb. 11 zeigt den Trend der Niederschlagsund Abflussdaten im Untersuchungsgebiet. Der Trend der Abflusshöhe ist deutlich stärker ausgeprägt als der Trend des jährlichen Nie- derschlags, was auf den zusätzlichen Schmelzwassereintrag durch die negativen Massenbilanzen der Gletscher zurückzuführen ist. Für den Zeitraum zwischen 1976 bis 1997 wurde hieraus ein zusätzlicher Schmelzwassereintrag von ca. $0,3 \mathrm{~km}^{3}$ geschätzt. Für den gleichen Zeitraum wurde über das geodätische Verfahren eine Abnahme des Eisvolumens von 0,32 $\mathrm{km}^{3}$ berechnet. Berücksichtigt man die geringere Dichte des Eises mit einem Faktor von 0,85 (Fischer 2011), ergibt dies einen zusätzlichen Schmelzwassereintrag von $0,27 \mathrm{~km}^{3}$.

\section{Schlussfolgerung}

Historische Karten bieten eine kostengünstige und durchaus geeignete Möglichkeit die Entwicklung von Gletschern in Hinblick auf Fläche und Volumen zu rekonstruieren. Die

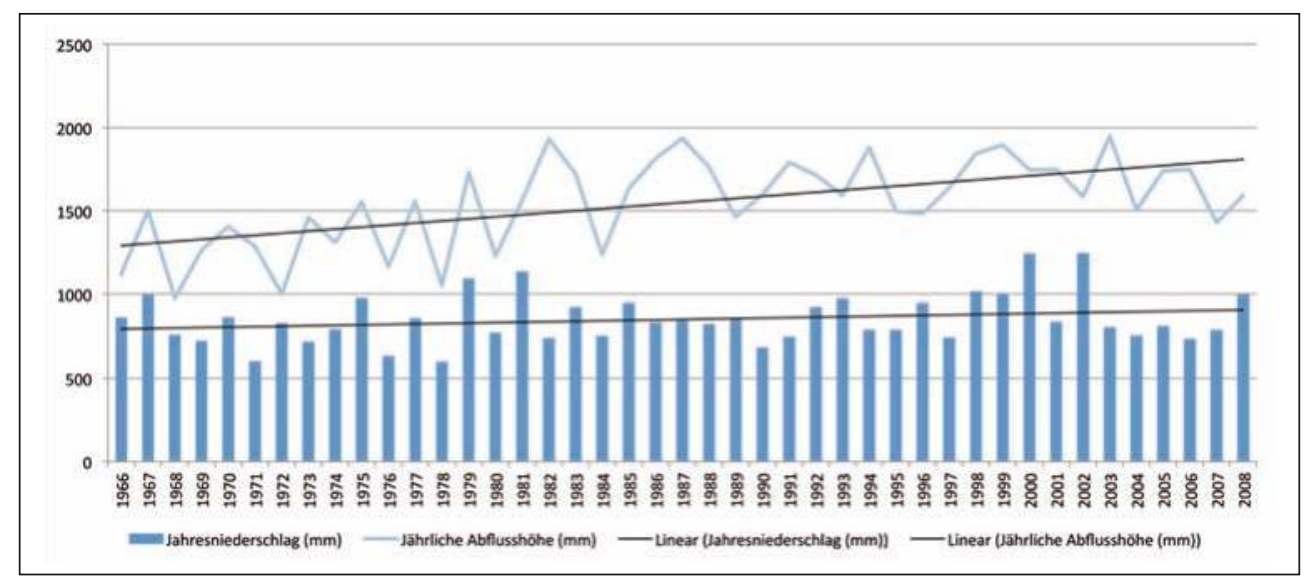

Abb. 11: Darstellung des jährlichen Niederschlags und der jährlichen Abflusshöhe in Obergurgl von 1966 bis 2008 (Datenquelle: Niederschlag - Hydrographischer Dienst Österreich, Abflussdaten - www.lebensministerium.at) 
zeitliche Auflösung von bestehenden Inventaren kann so deutlich verbessert werden. Die Plausibilität der in dieser Arbeit gewonnenen Daten und die Anwendung der geodätischen Methode unter Verwendung historischen Kartenmaterials bestätigen diese Aussage. Die Möglichkeiten hierzu werden in erster Linie durch die Qualität des Kartenmaterials vorgegeben. Unerlässlich sind Informationen über Aufnahmejahr, Art der Aufnahme und Aktualisierung. Das Fehlerpotential in der weiteren Bearbeitung der Eingangsdaten (Georeferenzierung, Digitalisierung, Interpolation) ist bei gründlicher Bearbeitung verhältnismäßig gering. Im Untersuchungsgebiet eignen sich hierzu in erster Linie die aerophotogrammetrisch ausgewerteten Luftbilder seit ca. 1950. Zur Dokumentation der flächenhaften Veränderung eignen sich zudem auch terrestrisch aufgenommene Karten, die Gletscherstände seit Ende des 19. Jahrhunderts darstellen. Ältere Karten sind für die Fragestellung in dieser Arbeit nicht geeignet.

Während die Ergebnisse der Flächenrekonstruktion nur wenig Diskussionsbedarf liefern, ist das Potential der durch das geodätische Verfahren erzeugten Daten ganz von der Fragestellung abhängig. Die Größe des Gletschers, Inklination und die gewünschte zeitliche Aufösung spielen hierbei eine wichtige Rolle. Die Genauigkeit der Ergebnisse nimmt mit geringerer Gletschergröße, größerer Geländeneigung und kürzerer zeitlicher Auflösung tendenziell ab, während die Rekonstruktion großer Gletscherflächen in ganzen Einzugsgebieten über längere Zeiträume sehr plausible Daten liefert.

\section{Literatur}

Deutscher Alpenverein (2009) Alpenvereinskarten Digital. München.

Abermann, J., Lambrecht, A., Fischer, A. \& Kuhn, M. (2009) Quantifying changes and trends in glacier area and volume in the Austrian Ötztal Alps (1969-19972006). The Cryosphere. 3: 205-215.

Anich, P. \& Hueber, B. (1774) Atlas Tyrolensis. Wien.

Beimrohr, W. (2012) Die Erste und die Zweite Landesaufnahme von Tirol. URL: http://www.tirol.gv.at/fileadmin/www. tirol.gv.at/themen/kultur/landesarchiv/ downloads/Erste_Zweite_Landesaufnahme-Tirol.pdf.

Braun, L. N., Escher-Vetter, H., Siebers, M. \& Weber, M. (2007) Water Balance of the highly Glaciated Vernagt Basin, Ötztal Alps. In: The water balance of the alps: What do we need to protect the water resources of the Alps? Proceedings of the conference held at Innsbruck university, 28-29 September 2006, Psenner, R. (Hg.) Innsbruck University Press, Innsbruck, S. 33-42.

Braun, L. \& Weber, M. (2008) Gletscher Wasserkreislauf und Wasserspende. In: Klimawandel in den Alpen: Fakten Folgen - Anpassung, BMU-Bundesministerium für Umwelt, Naturschutz und Reaktorsicherheit, Berlin, S. 48-55.

Brodersen, K. (1995) Terra cognita. Studien zur römischen Raumerfassung. G. Olms Verlag, Hildesheim/New York 
Esri (2013) ArcGIS Resource Center. URL: http://help.arcgis.com/de/arc gisdesktop /10.0/help/index.html\#/na/00r9000 0001n000000/.

Fasching, G. L. (2000) Die Österreichischen Militärkartenwerke. Planungen, Entwicklungen und Realisierungen seit 1955. In: PER ASPERA AD ASTRA, Gartner, G. \& Lechthaler, M. (Hg.), Eigenverlag des Instituts für Kartographie und Reproduktionstechnik, Wien, S. 175-189.

Fischer, A. (2011) Comparison of direct and geodetic mass balances on a multi-annual time scale. The Cryosphere 5: 107-124.

Groß, G. (1987) Der Flächenverlust der Gletscher in Österreich 1850-1920-1969. Zeitschrift für Gletscherkunde und Glaziologie 23: 131-141.

Gspurning, J., Tintor, W., Tribuser, M. \& Wakonigg, H. (2004) Volumen- und Flächenänderung an der Pasterze von 1981 bis 2000. Carinthia II 114: 463-472.

Hydrographischer Dienst in Österreich (2009) Hydrographisches Jahrbuch von Österreich. Wien.

IPCC (2007) Climate change 2007. The physical science basis: contribution of Working Group I to the Fourth Assessment Report of the Intergovernmental Panel on Climate Change. 1. Aufl. UNEP, New York.

Klaus, R. \& Baumeister, A. (2012) GIS-basierte Verlustvolumenbestimmung von Gletschern anhand historischer Karten. geoLoge (1): 3-13.
Kuhn, M., Lambrecht, A., Abermann, J., Patzelt, G. \& Groß, G. (2009) Projektbericht 10. Die österreichischen Gletscher 1998 und 1969, Flächen- und Volumenveränderungen, Verlag der österreichischen Akademie der Wissenschaften, Wien.

Lambrecht, A. \& Kuhn, M. (2007) Glacier changes in the Austrian Alps during the last three decades, derived from the new Austrian glacier inventory. Annals of Glaciology 46: 177-184.

Patzelt, G. (1982) Gurgler Ferner 1981. Institut für Hochgebirgsforschung. Universität Innsbruck.

Psenner, R. (2007) The water balance of the alps. What do we need to protect the water resources of the Alps? Proceedings of the conference held at Innsbruck university, 28-29 September 2006. Innsbruck University Press, Innsbruck.

Reinhardt, W. \& Rentsch, H. (1986) Determination of changes in volume and elevation of glaciers using Digital Elevation Models für the Vernagtferner, Ötztal Alps, Austria. Annals of Glaciology (8): 151-155.

tiris Kartendienste (2013) URL: http:// mo.tirol.gv.at/scripts/esrimap.dll?Name $=$ anich $\& C \mathrm{md}=$ Start, zuletzt geprüft am: 11.02.2013.

Veit, H. (2002) Die Alpen. Geoökologie und Landschaftsentwicklung. Ulmer, Stuttgart. 
A. Baumeister

\section{Verzeichnis des Autors}

André Baumeister

Angewandte Physische Geographie

Universität Bochum

Universitätsstraße 150, D-44780 Bochum

andre.baumeister@rub.de 


\section{Kapitel 6 I Die Ötztaler Ache}

Wolfgang Gattermayr

Das hydrographische Regime der Ötztaler Ache

Seite 121 bis 156

Daniel Erhart

Die Lebewelt der Ötztaler Ache

Seite 157 bis 164 


\title{
Das hydrographische Regime der Ötztaler Ache
}

\author{
Wolfgang Gattermayr
}

\section{Zusammenfassung}

Die Ötztaler Ache ist einer der größten $\mathrm{Zu}$ bringer des Inn in Tirol. Seit der Gründung des Hydrographischen Dienstes in Österreich 1893/94 wird das Gewässer hydrographisch erforscht. Die ältesten Messstellen wurden 1897 eingerichtet, nur wenige davon gibt es heute noch. Die Erfassung des hydrographischen Regimes erfolgt an Pegelanlagen. Die Messungen betreffen Wasserstand, Durchfluss, Wassertemperatur, Schwebstoff und Geschiebe. Ziel ist die Schaffung langer Messreihen, damit auf Basis dieser Datenreihen stete Veränderungen dokumentiert werden, Aussagen zum Klimawandel und extremwertstatistische Aussagen für Langzeitprojekte wie Flussverbauungen gemacht werden können. Die Daten bilden Grundlagen für wasserwirtschaftliche Planungen aller Art, u.a. auch für Kraftwerksplanungen. Mit der Automatisierung des Messnetzes können die Messwerte online abgefragt werden und zum Zwecke der Hochwasserwarnung in NiederschlagAbfluss-Modelle Eingang finden.

\section{Abstract}

The Ötztaler Ache (catchment area $894 \mathrm{~km}^{2}$ ) is one of the largest tributaries of the Inn River in Tyrol. The hydrological regime is since the foundation of the Hydrographical Service in Austria (1893/94) under observation. In 1897 the first water gauge has been installed. Only few of the historical gauges are working until today. The monitoring includes parameters as water level, discharge, water temperature, suspended load and bed load transport. The aim of the measurements is the generation of longterm series to identify trends or variation in the different parameters of alpine catchment areas, e.g. caused by climate change. Measurement data are also needed for statistical analysis, for planning of watershed management and especially for flood forecasting by applying rainfall-runoff-models. 
W. Gattermayr

\section{Hintergrund}

Die Erhebung von hydrographischen Grundlagendaten erfolgt durch den Hydrographischen Dienst in Erfüllung eines gesetzlichen Auftrages, wie er im Wasserrechtsgesetz 1959 i.d.g.F., $\$ 59$ c, e und $\mathrm{f}$ festgelegt ist. Der Bundesminister für Land- und Forstwirtschaft, Umwelt und Wasserwirtschaft hat durch Verordnung Art, Umfang und örtlichen Bereich der durchzuführenden Beobachtungen und Messungen zu bestimmen. Im Rahmen der Erhebung und Überwachung hat der Landeshauptmann u.a. auch für die Verbreitung von hydrographischen Nachrichten insoweit zu sorgen, als dies für den Betrieb der Schifffahrt, der Wassernutzung, die Erfüllung internationaler Verpflichtungen und die Abwehr von Gefahren für Leben und Eigentum notwendig wird. Die geprüften Messergebnisse werden im Hydrographischen Jahrbuch von Österreich, Abteilung VII/3-Wasserhaushalt im Bundesministerium für Land- und Forstwirtschaft, Umwelt und Wasserwirtschaft, veröffentlicht.

\section{Einleitung}

3000 v. Chr. (und davor) erfolgten bereits gewässerkundliche Beobachtungen als Grundlage für Wasserbauten im Vorderen Orient, in Mesopotamien, Ägypten, Ceylon, Indien,
Altchina, Java und in den Inka-Staaten Südamerikas (HZB 1996).

1893/94 wurde im österreichischen Teil der Monarchie das Hydrographische Zentralbüro gegründet. Das war der Auftakt für den Beginn von regelmäßigen Beobachtungen und die schrittweise Einrichtung von hydrographischen Messnetzen.

Anfangs standen Augenbeobachtungen im Vordergrund. Der darauf abgestimmte Messrhythmus ist teilweise heute noch Taktgeber im Beobachtungswesen. Der technische Fortschritt ab den 1980er Jahren hat schließlich das Messwesen revolutioniert. Dienten in der 2. Hälfte des 20. Jahrhunderts zunächst analoge Schreibgeräte und Messgeber der kontinuierlichen Datenerfassung, so hat sich in der letzten Dekade des 20. Jahrhunderts die digitale Mess- und Registriertechnik durchgesetzt. Die Weiterentwicklung der Sensoren bis zur berührungslosen Messung von Niederschlag, Schneehöhen und vor allem Wasserstand erlaubt nun auch bei „schwerem Wetter“ z.B. Hochwasserabflüsse zu erfassen, ohne dass die Messpegel ein Opfer der Naturgewalten werden. Somit ist es auch möglich, in Wildbächen und Talflüssen, die bei Hochwasser wildbachähnlichen Charakter annehmen, Hochwasserganglinien aufzuzeichnen, auch wenn Schlamm und Geröll durch die Gewässerprofile geschleust werden. So ist auch zu erklären, dass die hydrographischen Beobachtungsreihen im Einzugsgebiet der Ötztaler Ache trotz des frühen Beginns im Jahre 1897 erst ab der 2. Hälfte des letzten Jahrhunderts verlässliche Abflussangaben erwarten lassen. 


\section{Vom Ursprung der Ötztaler Ache}

Die Ötztaler Ache entwässert ein 894 km² großes Einzugsgebiet (HZB 1984) zwischen dem Alpenhauptkamm und dem Inntal. Sie ist nach dem Ziller (Tiroler Unterland) der größte Zubringer des Inn zwischen Finstermünz und Kufstein und zugleich der Talfluss des Ötztales. 2,1 km² des Einzugsgebietes entfallen auf Italien.

Im Oberlauf wird die Ötztaler Ache Rofenache und $a b$ Vent, nach Einmündung des Niedertalbaches, Venter Ache genannt. Es gibt keine Quelle, aus der die Ötztaler Ache entspringt. Ihr Wasser entstammt vielmehr dem Entwässerungssystem des Hintereisferners, der als Quellbach der Rofenache angesehen werden kann. Erst an seiner Gletscherzunge kommt der Bach zum Vorschein und wird durch die Abflüsse der unterliegenden und meist vergletscherten Teileinzugsgebiete genährt. In Zwieselstein vereinigt sich die Venter Ache mit der Gurgler Ache, einem rechtsufrigen Zubringer. Ab dem Zusammenfluss dieser beiden Achen findet man in diversen Kartenwerken die Bezeichnung Ötztaler Ache, die an der Gemeindegrenze Roppen/ Haiming in den Inn mündet.

Vom Oberlauf bis zur Mündung durchquert die Ötztaler Ache ständig wechselnde Talformen und überwindet einen Höhenunterschied von mehr als $1800 \mathrm{~m}$. Die Ache durchquert Talbecken und überwindet Geländestufen, zwängt ihre Wasser durch Engen und durchströmt Weitungen im Längs- und
Querprofil des Tales. So kommt es zum ständigen Wechsel von Strömen und Schießen der Welle, es wechseln Erosionsstrecken mit Bereichen vermehrter Ablagerung. Bei sommerlicher Wasserführung ist in den Umlagerungsstrecken des Gewässers daher die Sohle laufenden Veränderungen unterworfen.

Das Einzugsgebiet und seine Umgrenzung

Das Einzugsgebiet eines Oberflächengewässers wird in der Regel durch den Verlauf der Kammlinie umgrenzt. Kämme, Rücken und Grate bilden die oberirdischen Wasserscheiden, an welchen sich für einen Wassertropfen entscheidet, welchem Vorfluter er - der Schwerkraft folgend - zustrebt. Fläche und Form eines Einzugsgebietes werden auf Basis der orographischen Verhältnisse bestimmt. Das orographische Einzugsgebiet kann jedoch vom hydrographischen Einzugsgebiet abweichen. Spalten, Klüfte und Höhlensysteme, letztere eine typische Karsterscheinung, können Niederschlag und Schmelzwasser von der Oberfläche ableiten und es unterirdisch über die orographisch festgelegte Wasserscheide hinweg dem jenseitigen Vorfluter als Berg-, Hang- oder Quellwasser zuführen. Im Großen und Ganzen beschreiben die orographisch bestimmten Grenzen ein Flusseinzugsgebiet mit ausreichender Genauigkeit. Für Detailfragen dürfen jedoch hydrogeologische 


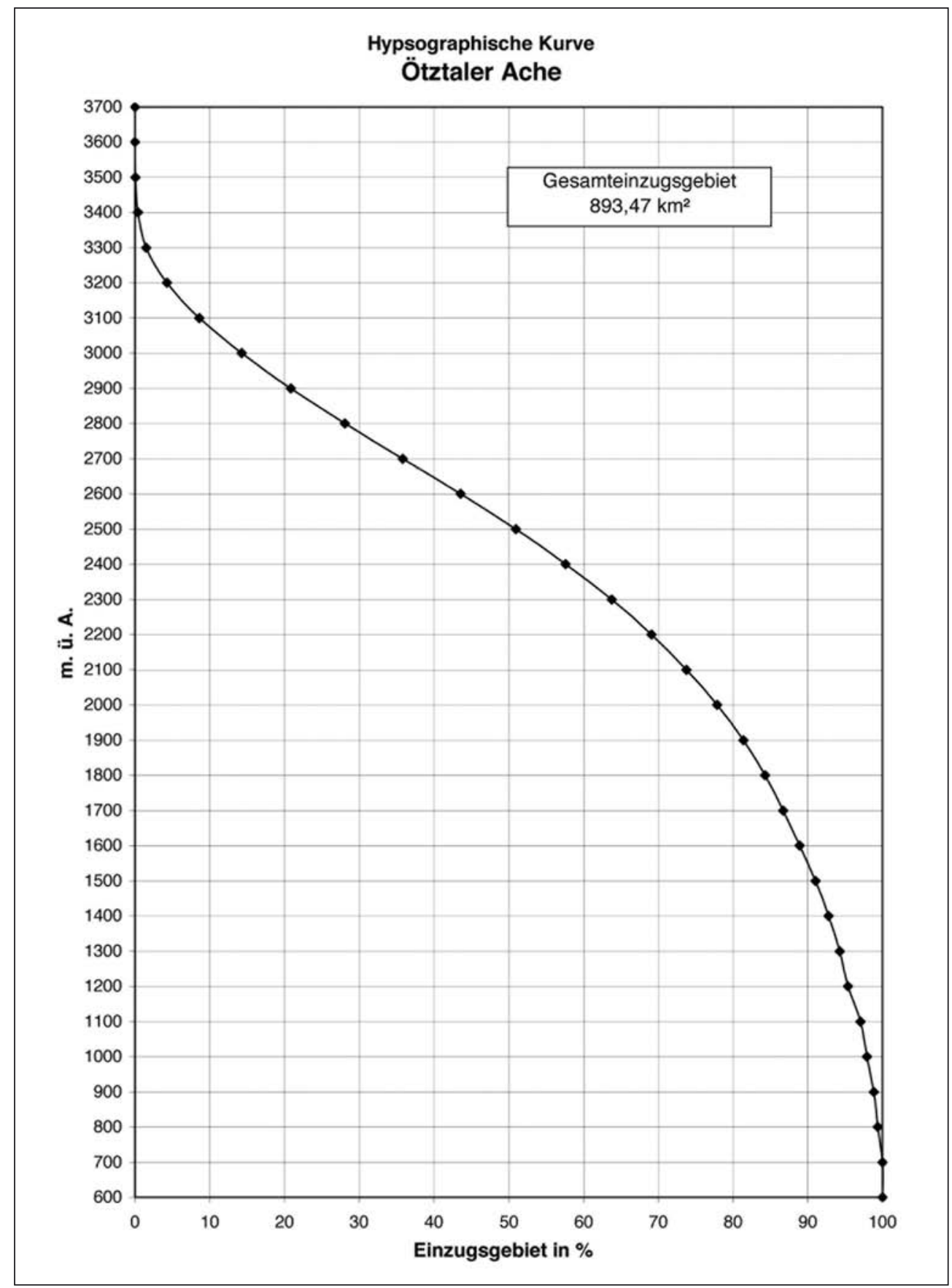

Abb. 1: Hypsographische Kurve des Einzugsgebietes der Ötztaler Ache (tiris 2006) 
Aspekte nicht außer Acht gelassen werden. Im Folgenden basieren sämtliche Flächenangaben auf orographisch bestimmten Grenzverläufen.

\section{Zur Höhenerstreckung des Einzugsge- bietes}

Die höchste Erhebung im Einzugsgebiet der Ötztaler Ache bildet die Wildspitze (3768 m ü.A.), der tiefste Punkt im Einzugsgebiet befindet sich an der Mündung in den Inn auf 675 m ü.A. In Abb. 1 lässt die hypsographische Kurve des Einzugsgebietes der Ötztaler Ache mit der Flächenverteilung über alle Höhenstufen (tiris 2006) den hochalpinen Charakter dieses Einzugsgebietes deutlich erkennen. Rund $20 \%$ des Einzugsgebietes liegen über 2900 m ü.A. Die Halbwertshöhe liegt bei $2500 \mathrm{~m}$, d.h. die Hälfte des Einzugsgebietes befindet sich unter dieser Höhenstufe, die andere Hälfte darüber.

Mithilfe der hypsographischen Kurve lässt sich z.B. die Abflusswirksamkeit von sommerlichen Starkregenereignissen im Einzugsgebiet besser abschätzen. Liegt etwa die Schneefallgrenze bei $4000 \mathrm{~m}$ Seehöhe, dann gibt es auch im Hochgebirge keine Niederschlagsretention durch Neuschnee. Sinkt hingegen im Laufe eines Niederschlagsereignisses die Schneefallgrenze gegen $2000 \mathrm{~m}$ ab, dann nimmt der abflusswirksame Flächenanteil auf gut $20 \%$ ab. In der Folge wird die Abflussentwicklung rückläufig.
Die Ötztaler Ache und ihre größeren Zubringer

Vom Gesamteinzugsgebiet der Ötztaler Ache entfallen auf den Oberlauf bis Zwieselstein (Venter Ache und Gurgler Ache) rund $41 \%$ der Fläche. Die Teileinzugsgebiete der Ötztaler Ache zeigen eine deutliche Asymmetrie in Bezug auf den Talfluss (Abb. 2, tiris 2013). Wie in Tab. 1 ersichtlich, sind die linksufrigen Zubringer kürzer und steiler und weisen kleinere Einzugsgebietsflächen auf. Die orographisch rechten Zubringer sind länger, ausgeglichener im Längsgefälle und flächenmäßig viel größer (Österreichischer Wasserkraft-Kataster, 1948).

Die Angaben zur Vergletscherung in Tab. 1 entsprechen den Auswertungen aus der 2. österreichweiten Gletscherbefliegung um das Jahr 1999.

Hydrographische Erhebungen im Einzugsgebiet der Ötztaler Ache

Mit der Gründung des Hydrographischen Dienstes in Österreich setzte auch in Tirol die systematische Erhebung des Wasserkreislaufes ein. Dazu gehörte u.a. die Errichtung von Messstellen an Oberflächengewässern zur Erfassung von Wasserstand und Abfluss. An der Ötztaler Ache entstanden um das Jahr 1900 die ersten Pegelstellen (Abb. 3), die 


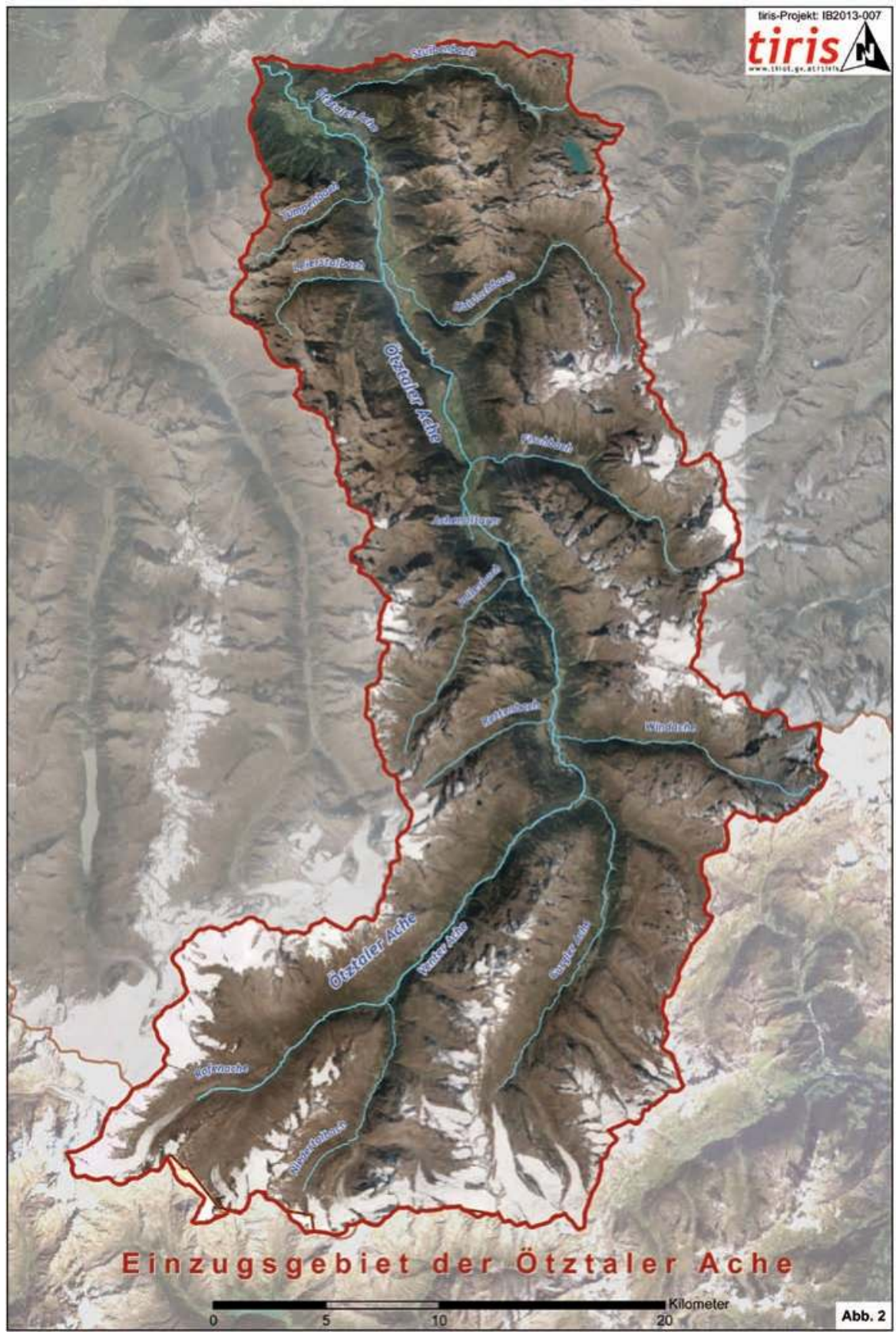

Abb. 2: Das Einzugsgebiet der Ötztaler Ache mit dem Hauptfluss und den bedeutenderen Zubringern (tiris 2013) 
Tab. 1: Bedeutende Zuflüsse der Ötztaler Ache mit Einzugsgebiet und Vergletscherung

\begin{tabular}{lrrrr}
\hline & Natürliches Einzugsgebiet & \multicolumn{2}{c}{ Gletscher } \\
\hline rechtsufrig & gesamt $\left[\mathbf{k m}^{\mathbf{2}}\right]$ & vergletschert [\%] & Anzahl & Fläche $\left[\mathbf{k m}^{\mathbf{2}}\right]$ \\
\hline Niedertalbach & 66,5 & 32 & 19 & 21,18 \\
Gurgler Ache & 131,5 & 18 & 37 & 24,03 \\
Windache & 47,9 & 13 & 15 & 5,99 \\
Fischbach & 81,3 & 14 & 24 & 11,54 \\
Hairlachbach & 66,2 & 3 & 5 & 1,83 \\
Stuibenbach & 52,0 & 1 & 3 & 0,29 \\
Zwischensumme & 445,4 & 15 & 103 & 64,86 \\
\hline linksufrig & & & 4 & 1,92 \\
\hline Rettenbach & 16,2 & 12 & 14 & 2,64 \\
Pollesbach & 30,0 & 9 & 1 & 0,38 \\
Achenaltarm & 19,9 & 2 & 3 & 0,30 \\
Leierstalbach & 30,5 & 1 & 0 & 0 \\
Tumpenbach & 10,0 & 0 & 22 & 5,24 \\
Zwischensumme & 106,6 & 5 & 13 & 114,86 \\
Ötztaler Ache einschließlich Klein- & 894 & & & \\
und Zwischeneinzugsgebiete & & & \\
\hline
\end{tabular}

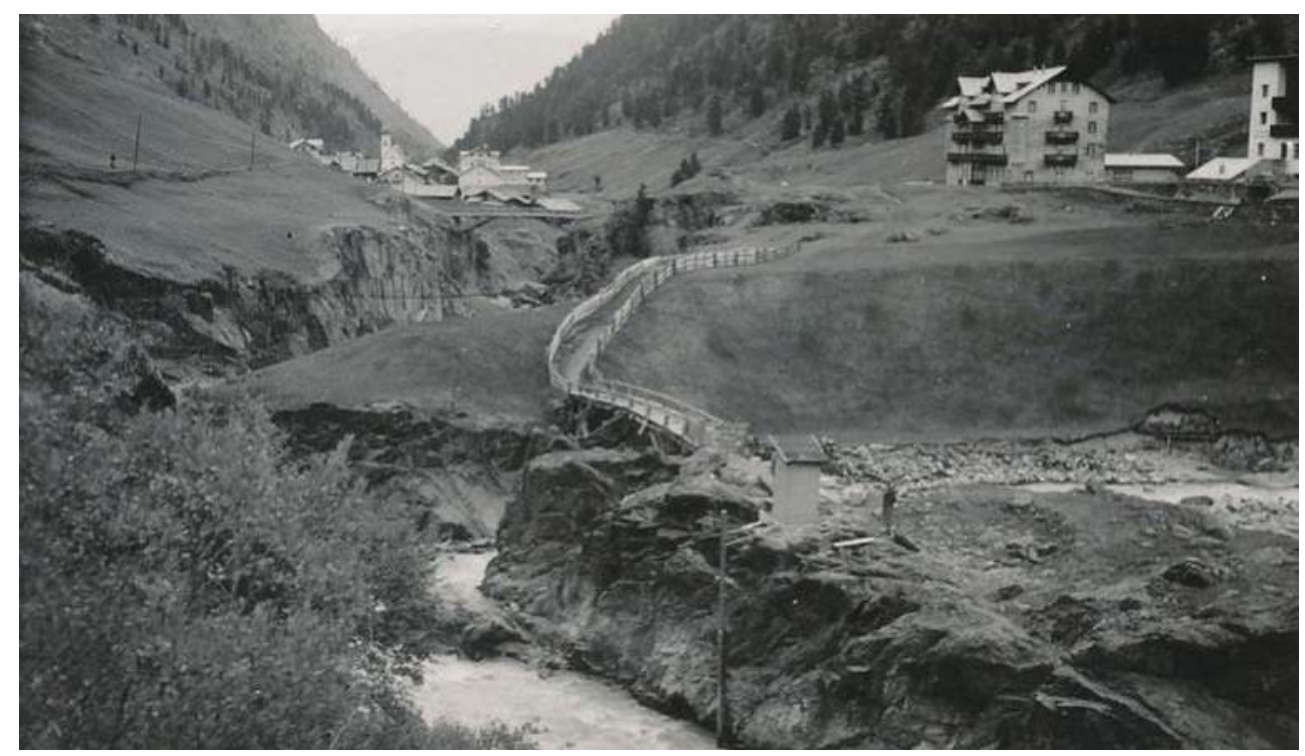

Abb. 3: Der Pegel Vent/Rofenache (vor 1936) auf dem Felssporn zwischen der Rofenache und der Spiegelache, auch Niedertalbach genannt. Pegelausstattung: Lattenpegel, Registrierpegel nach Schwimmerprinzip, begehbares Häuschen (Foto: Hydrographischer Dienst Tirol) 
W. Gattermayr

Tab. 2: Übersicht der historischen Pegelstellen im Einzugsgebiet der Ötztaler Ache

\begin{tabular}{|c|c|c|c|}
\hline Pegel/Gewässer & Beginn & Ende & Betreiber \\
\hline Vent/Rofenache (Abb. 3, 4) & 1936 & offen & Hydrographischer Dienst Tirol \\
\hline Vent/Venter Ache & $\begin{array}{l}1902 \\
1976\end{array}$ & $\begin{array}{l}1975 \\
\text { offen }\end{array}$ & $\begin{array}{l}\text { Hydrographischer Dienst Tirol } \\
\text { TIWAG }\end{array}$ \\
\hline Sölden/Ötztaler Ache & $\begin{array}{l}1903 \\
1954 \\
1973\end{array}$ & $\begin{array}{l}1936 \\
1972 \\
\text { offen }\end{array}$ & $\begin{array}{l}\text { Hydrographischer Dienst Tirol } \\
\text { Westtiroler Kraftwerke AG } \\
\text { TIWAG }\end{array}$ \\
\hline Huben/Ötztaler Ache & 1902 & offen & Hydrographischer Dienst Tirol \\
\hline Gries i.S./Fischbach & $\begin{array}{l}1961 \\
2006\end{array}$ & $\begin{array}{l}1970 \\
\text { offen }\end{array}$ & $\begin{array}{l}\text { TIWAG } \\
\text { TIWAG }\end{array}$ \\
\hline Oberried/Ötztaler Ache & $\begin{array}{l}1927 \\
1941\end{array}$ & $\begin{array}{l}1928 \\
2003\end{array}$ & $\begin{array}{l}\text { Hydrographischer Dienst Tirol } \\
\text { Hydrographischer Dienst Tirol }\end{array}$ \\
\hline Pegel Niederthai/Hairlachbach & $\begin{array}{l}1955 \\
1981\end{array}$ & $\begin{array}{l}1980 \\
\text { offen }\end{array}$ & $\begin{array}{l}\text { TIWAG } \\
\text { TIWAG/Restwasserpegel }\end{array}$ \\
\hline Tumpen/Ötztaler Ache & $\begin{array}{l}1920 \\
1933\end{array}$ & $\begin{array}{l}1931 \\
\text { offen }\end{array}$ & $\begin{array}{l}\text { Hydrographischer Dienst Tirol } \\
\text { Hydrographischer Dienst Tirol }\end{array}$ \\
\hline Habichen/Ötztaler Ache & 1903 & 1918 & Hydrographischer Dienst Tirol \\
\hline Ötzbruck/Ötztaler Ache & 1897 & 1923 & Hydrographischer Dienst Tirol \\
\hline $\begin{array}{l}\text { Zwieselstein/Ötztaler Ache } \\
\text { Lochwaldele/Ötztaler Ache } \\
\text { Nösslach/Ötztaler Ache }\end{array}$ & \multicolumn{3}{|c|}{$\begin{array}{l}\text { vorübergehender Betrieb von Schreibpegeln durch die Westtiroler } \\
\text { Kraftwerke AG (Österreichischer Wasserwirtschaft-Kataster 1948) }\end{array}$} \\
\hline
\end{tabular}

zunächst mit wechselndem Erfolg betrieben wurden (Tab. 2).

Hochwasser, Mureneinstöße und Sohlauflandungen, aber auch massive örtliche Sohleintiefungen oder anhaltende Eisbildung im Winter setzten dem Pegel-Messwesen gehörig zu und zwangen des Öfteren zu Pegelauflassungen, zur Verlegung von Pegelstellen und längeren Messunterbrechungen.

\section{Das aktuelle Pegelmessnetz im Ein- zugsgebiet der Ötztaler Ache}

Nach vieljährigem Pegelbetrieb haben sich folgende Pegelstandorte (Abb. 4) als brauchbar erwiesen und für die laufende hydrographische Beobachtung und Auswertung durchgesetzt:

Die Angaben zur Vergletscherung in Tab. 3 beziehen sich auf die Auswertungen aus der 2 . österreichweiten Gletscherbefliegung um das Jahr 1999. 


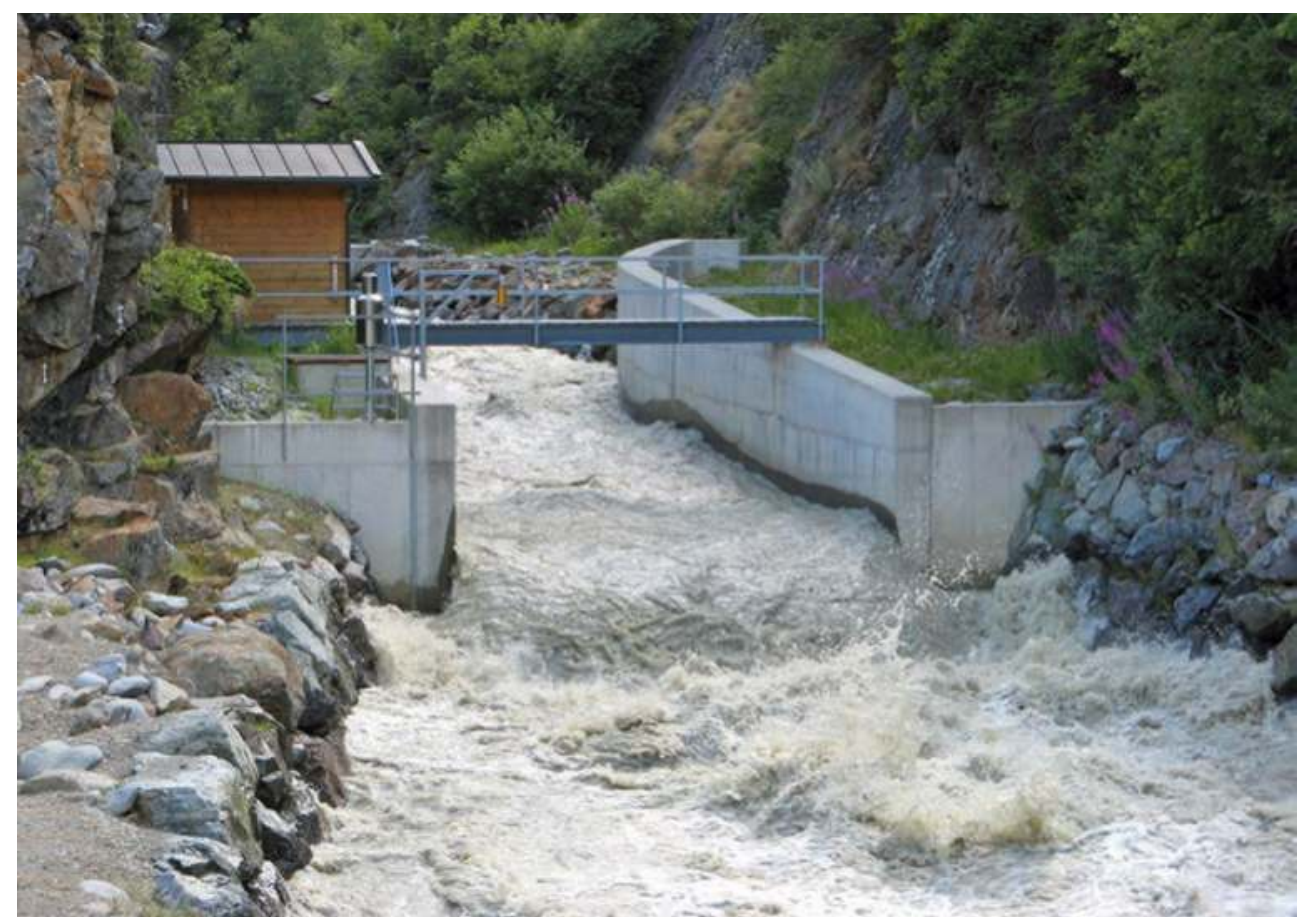

Abb. 4: Die Pegelanlage Vent/Rofenache im Jahre 2005 mit begehbarem Pegelhäuschen, Messsteg und betoniertem Gerinne mit Einlauftrompete im Oberwasser. Gemessen werden: Wasserstand (RADAR und Drucksonde), Oberflächengeschwindigkeit des Wassers (RADAR), Wassertemperatur, Schwebstoff (Trübungssonde), Geschiebe (Geophone in der Gewässersohle). Sämtliche Parameter werden kontinuierlich gemessen, vor Ort digital aufgezeichnet und mittels GPRS fernübertragen (Foto: Hydrographischer Dienst Tirol)

\section{Das hydrographische Regime der Ötztaler} Ache

Das Abflussregime der Ötztaler Ache ist von seiner Nähe zum Alpenhauptkamm geprägt. Eingebettet zwischen Ötztaler Alpen im Süden, den Stubaier Alpen im Osten und dem Geigenkamm im Westen markieren ihre höchsten Erhebungen wie Wildspitze (3768 $\mathrm{m}$ ü.A.) und Weißkugel (3738 $\mathrm{m}$ ü.A.) im Süden, Zuckerhütl (3507 m ü.A.) im Osten und Hohe Geige (3393 m ü.A.) im Westen die Eckpfeiler des Einzugsgebietes. Auch die mittlere Seehöhe mit rund 2500 m deutet da- rauf hin, dass die „Kinderstube“ der Ötztaler Ache im Hochgebirge gelegen ist. Dementsprechend fällt der jahreszeitliche Verlauf der Abflussganglinie aus (Abb. 5).

Auf Basis langjähriger Pegelmessungen und daraus folgender Durchflussermittlungen lassen sich für die einzelnen Pegelstellen charakteristische Abflussangaben erstellen, die für die Pegel Vent/Rofenache, Obergurgl/Gurgler Ache und Tumpen/Ötztaler Ache in den Tab. 4, 5, 6 sowie in den Abb. 6, 7, 8 enthalten sind. 


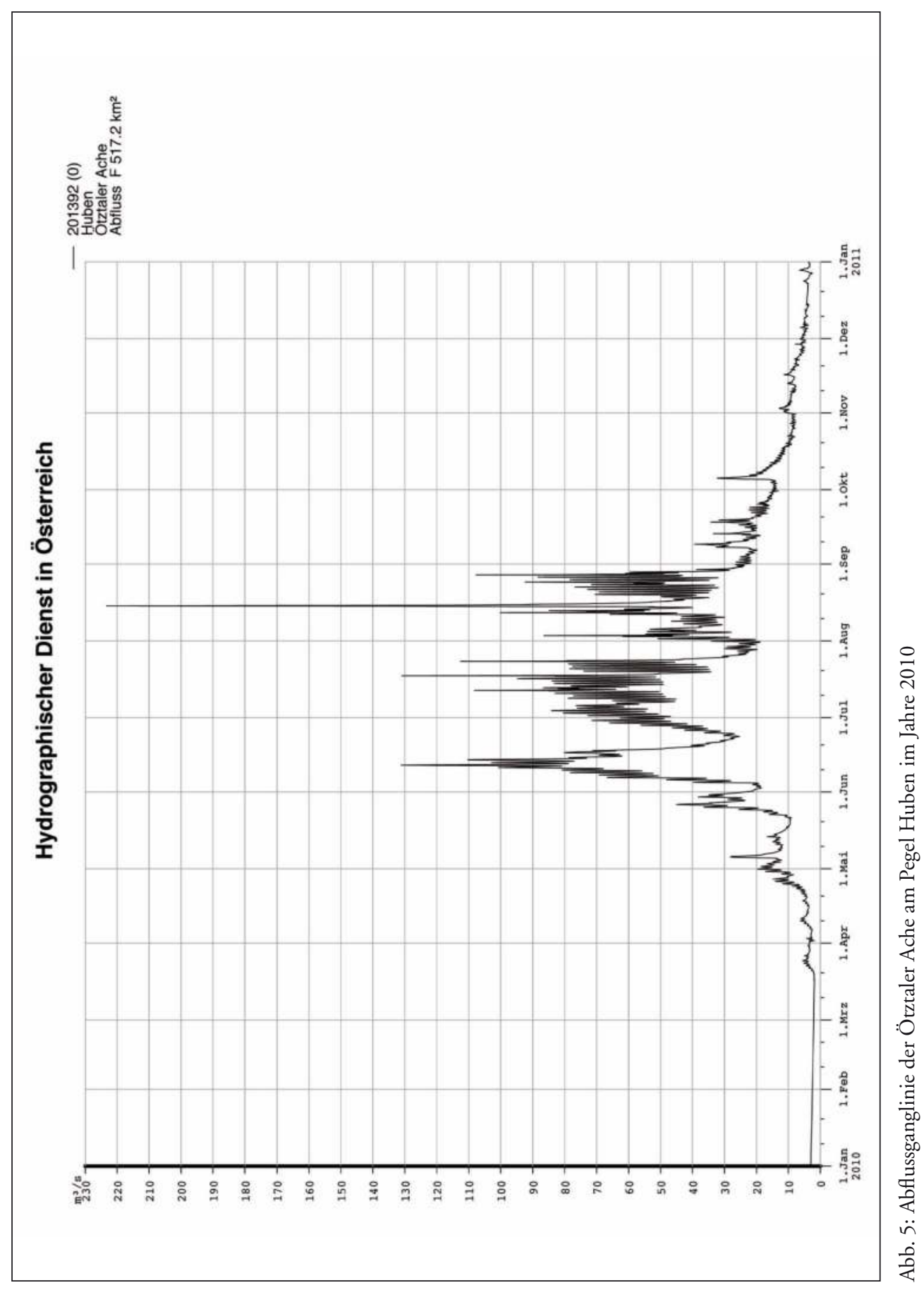


Tab. 3: Übersicht des aktuellen Pegelmessnetzes mit weitgehend natürlichem Einzugsgebiet

\begin{tabular}{|c|c|c|c|c|}
\hline Pegel/Gewässer & $\begin{array}{l}\mathrm{EZG}_{\text {nat }} \\
{\left[\mathrm{km}^{2}\right]}\end{array}$ & $\begin{array}{l}\text { Vergletscherung } \\
\text { des } \mathrm{EZG}_{\text {nat }}\end{array}$ & Mess-Parameter & Betreiber \\
\hline Vernagt/Vernagtbach & 11,44 & $78 \%$ & W, WT, Q & BAdW \\
\hline Vent/Rofenache & 98,1 & $38 \%$ & W, WT, Q, Q, Q & HD-Tirol \\
\hline Vent/Venter Ache & 164,7 & $36 \%$ & W, WT, Q, Q & TIWAG \\
\hline Obergurgl/Gurgler Ache & 72,5 & $32 \%$ & W, Q, Q & TIWAG \\
\hline Sölden/Ötztaler Ache & 448,7 & $21 \%$ & $\mathrm{~W}, \mathrm{WT}, \mathrm{Q}, \mathrm{Q}_{\mathrm{s}}, \mathrm{Q}_{\mathrm{g}}$ & TIWAG \\
\hline Huben/Ötztaler Ache & 517,2 & $19 \%$ & W, WT, Q & HD-Tirol \\
\hline Gries i.S./Fischbach & 70,9 & $16 \%$ & $\mathrm{~W}, \mathrm{Q}, \mathrm{Q}_{\mathrm{s}}, \mathrm{Q}_{\mathrm{g}}$ & TIWAG \\
\hline Fundusalm/Fundusbach & 13,1 & $2 \%$ & W, Q & TIWAG \\
\hline Tumpen/Ötztaler Ache & 785,5 & $15 \%$ & W, WT, Q, Q & HD-Tirol \\
\hline Kühtai/Längentalbach & 9,2 & $0,7 \%$ & W, WT, Q & TIWAG \\
\hline Brunau/Ötztaler Ache & 890,0 & $13 \%$ & W, WT, Q & TIWAG \\
\hline \multicolumn{5}{|c|}{ Abkürzungen und Hinweise: } \\
\hline \multicolumn{2}{|c|}{ natürliches Einzugsgebiet $\left[\mathrm{km}^{2}\right]$} & $Q_{s}$ & \multicolumn{2}{|l|}{ Schwebstofffluss $[\mathrm{kg} / \mathrm{s}]$} \\
\hline \multicolumn{2}{|c|}{ wirksames Einzugsgebiet $\left[\mathrm{km}^{2}\right]$} & $Q_{\mathrm{g}}:$ & \multicolumn{2}{|c|}{ Geschiebefluss $[\mathrm{kg} / \mathrm{s}]$} \\
\hline \multicolumn{2}{|c|}{$\begin{array}{l}\text { Wasserstand [cm über Pegelnullpunkt } \\
\text { (PNP)] }\end{array}$} & BÂdW: & \multicolumn{2}{|c|}{$\begin{array}{l}\text { Bayerische Akademie der Wissenschaften, } \\
\text { Kommission für Glaziologie }\end{array}$} \\
\hline \multicolumn{2}{|c|}{ WT: $\quad$ Wassertemperatur $\left[{ }^{\circ} \mathrm{C}\right]$} & HD-Tirol: & \multicolumn{2}{|c|}{ Hydrographischer Dienst Tirol } \\
\hline \multicolumn{2}{|c|}{ Durchfluss $\left[\mathrm{m}^{3} / \mathrm{s}\right]$} & TIWAG: & \multicolumn{2}{|c|}{ Tiroler Wasserkraft AG } \\
\hline
\end{tabular}

Tab. 4: Mittlere und extreme Wasserführung am Pegel Vent/Rofenache $\left(\mathrm{EZG}_{\mathrm{nat}}=98,1 \mathrm{~km}^{2}\right)$ für die Monate I bis XII aus dem Beobachtungszeitraum 1971 bis 2012

\begin{tabular}{|c|c|c|c|c|c|c|c|c|c|c|c|c|}
\hline Monat & I & II & III & IV & $\mathbf{V}$ & VI & VII & VIII & IX & $\mathbf{X}$ & XI & XII \\
\hline $\mathrm{NQ}\left[\mathrm{m}^{3} / \mathrm{s}\right]$ & 0,310 & 0,096 & 0,092 & 0,101 & 0,209 & 1,37 & 2,14 & 2,23 & 1,33 & 0,885 & 0,162 & 0,380 \\
\hline $\mathrm{MQ}\left[\mathrm{m}^{3} / \mathrm{s}\right]$ & 0,552 & 0,468 & 0,497 & 0,827 & 3,20 & 9,38 & 15,4 & 14,8 & 6,52 & 2,39 & 1,12 & 0,722 \\
\hline $\mathrm{HQ}\left[\mathrm{m}^{3} / \mathrm{s}\right]$ & 1,18 & 0,880 & 4,83 & 6,15 & 28,3 & 63,6 & 75,2 & 109 & 58,6 & 25,3 & 10,0 & 1,49 \\
\hline NNQ & & & & & \multicolumn{8}{|c|}{$0,092 \mathrm{~m}^{3} / \mathrm{s}$ am 21.03 .1992} \\
\hline HHQ & & & & & \multicolumn{8}{|c|}{$109 \mathrm{~m}^{3} / \mathrm{s}$ am 25.08 .1987} \\
\hline NQ & \multicolumn{5}{|c|}{ kleinster Abfluss im Beobachtungszeitraum $\left[\mathrm{m}^{3} / \mathrm{s}\right]$} & NNQ & \multicolumn{5}{|c|}{ kleinster bekannter Abfluss $\left[\mathrm{m}^{3} / \mathrm{s}\right]$} & \\
\hline MQ & \multicolumn{5}{|c|}{ mittlerer Abfluss im Beobachtungszeitraum $\left[\mathrm{m}^{3} / \mathrm{s}\right]$} & HHQ & \multicolumn{5}{|c|}{ größer bekannter Abfluss [m³/s] } & \\
\hline HQ & \multicolumn{5}{|c|}{ größter Abfluss im Beobachtungszeitraum [m³/s] } & $\mathrm{EZG}_{\text {nat }}$ & \multicolumn{5}{|c|}{ natürliches Einzugsgebiet $\left[\mathrm{km}^{2}\right]$} & \\
\hline
\end{tabular}


Tab. 5: Mittlere und extreme Wasserführung am Pegel Obergurgl/Gurgler Ache $\left(\mathrm{EZG}_{\mathrm{nat}}=72,5 \mathrm{~km}^{2}\right)$ für die Monate I bis XII aus dem Beobachtungszeitraum 1966 bis 2011

\begin{tabular}{|c|c|c|c|c|c|c|c|c|c|c|c|c|}
\hline Monat & I & II & III & IV & V & VI & VII & VIII & IX & $\mathbf{X}$ & XI & XII \\
\hline NQ $\left[\mathrm{m}^{3} / \mathrm{s}\right]$ & 0,171 & 0,052 & 0,100 & 0,093 & 0,190 & 0,73 & 1,64 & 1,66 & 0,64 & 0,262 & 0,221 & 0,195 \\
\hline $\operatorname{MQ}\left[\mathrm{m}^{3} / \mathrm{s}\right]$ & 0,265 & 0,215 & 0,219 & 0,479 & 3,42 & 8,54 & 11,7 & 10,1 & 4,82 & 1,72 & 0,647 & 0,372 \\
\hline $\mathrm{HQ}\left[\mathrm{m}^{3} / \mathrm{s}\right]$ & 0,532 & 0,343 & 1,28 & 7,84 & 24,4 & 63,7 & 57,6 & 87,4 & 109 & 26,7 & 15,7 & 1,26 \\
\hline NNQ & & & & & \multicolumn{8}{|c|}{$0,052 \mathrm{~m}^{3} / \mathrm{s}$ am 15.02 .1990} \\
\hline HHQ & & & & & \multicolumn{8}{|c|}{$109 \mathrm{~m}^{3} / \mathrm{s}$ am 20.09 .1999} \\
\hline
\end{tabular}

Tab. 6: Mittlere und extreme Wasserführung am Pegel Tumpen/Ötztaler Ache $\left(\mathrm{EZG}_{\mathrm{nat}}=785,5 \mathrm{~km}^{2}\right.$, ${E Z G_{\text {wirk }}}=759,7 \mathrm{~km}^{2}$ ) für die Monate I bis XII aus dem Beobachtungszeitraum 1951 bis 2012

\begin{tabular}{|c|c|c|c|c|c|c|c|c|c|c|c|c|}
\hline Monat & I & II & III & IV & V & VI & VII & VIII & IX & $\mathbf{X}$ & XI & XII \\
\hline $\mathrm{NQ}\left[\mathrm{m}^{3} / \mathrm{s}\right]$ & 2,36 & 1,96 & 1,80 & 2,54 & 4,52 & 12,80 & 21,30 & 17,40 & 9,30 & 5,03 & 4,06 & 3,16 \\
\hline $\mathrm{MQ}\left[\mathrm{m}^{3} / \mathrm{s}\right]$ & 4,44 & 3,84 & 4,50 & 8,25 & 29,2 & 64,4 & 75,8 & 62,4 & 33,3 & 15,1 & 8,50 & 5,73 \\
\hline $\mathrm{HQ}\left[\mathrm{m}^{3} / \mathrm{s}\right]$ & 11,8 & 21,2 & 45,1 & 49,3 & 220 & 278 & 263 & 410 & 380 & 154 & 96,8 & 33,2 \\
\hline NNQ & & & & & \multicolumn{8}{|c|}{$1,80 \mathrm{~m}^{3} / \mathrm{s}$ am 03.03 .1963} \\
\hline HHQ & & & & & \multicolumn{8}{|c|}{$410 \mathrm{~m}^{3} / \mathrm{s}$ am 25.08 .1987} \\
\hline
\end{tabular}

Ein Vergleich der monatlichen Abflusswerte zeigt die Gemeinsamkeit der Pegelstellen:

- geringe Wasserführung ab Oktober/November bis April

- hohe Wasserführung ab Mai bis Oktober

- größte Abflüsse von Juni bis September

- die hochgelegenen Pegelstellen weisen bei Hochwasser aufgrund ihrer Nähe zum Alpenhauptkamm höhere spezifi- sche Abflüsse [1/s.km²] auf als Pegelstellen im Unterlauf

- aufgrund der stärkeren Vergletscherung sind auch bei hochsommerlichen Schönwetterlagen die spezifischen Tagesmaxima der höher gelegenen Pegelstellen wie Vent und Obergurgl extremer als im Mittellauf der Ötztaler Ache. 


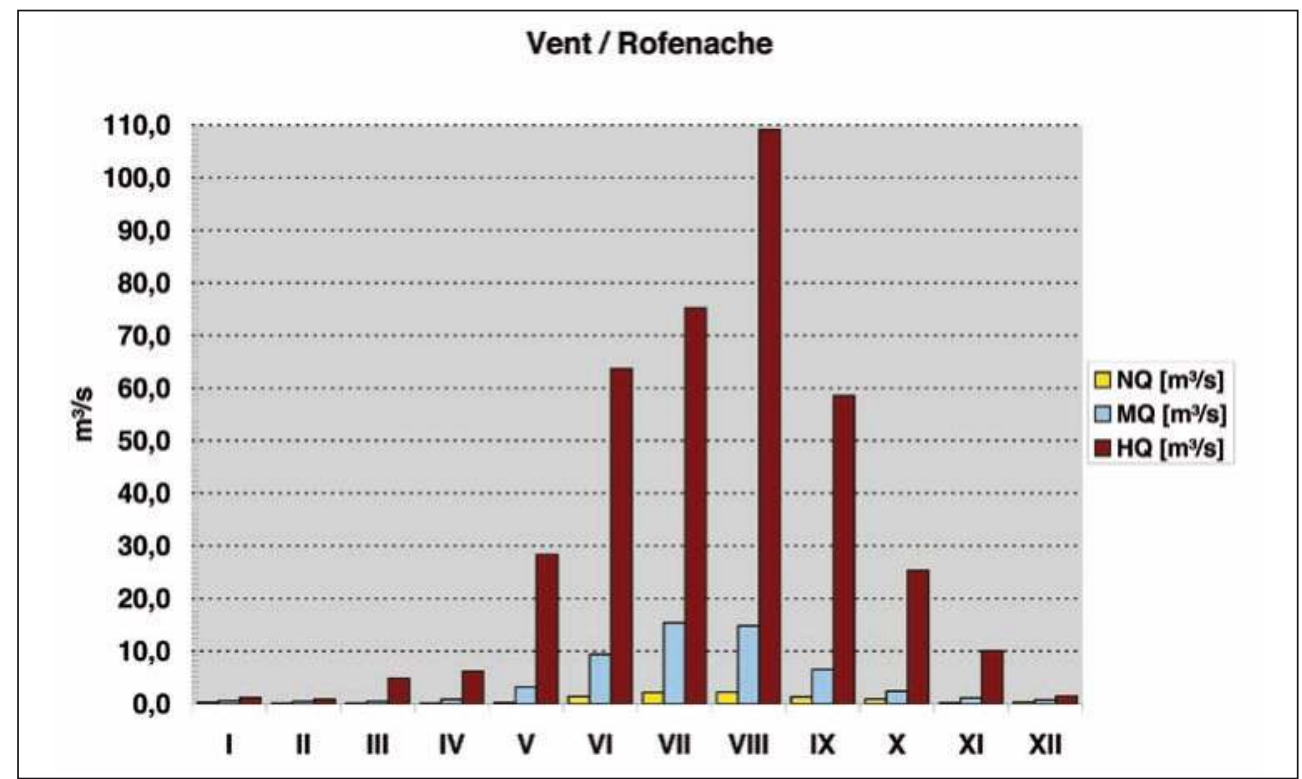

Abb. 6: Mittlere (MQ) und extreme Wasserführung (NQ, HQ) der Rofenache im Beobachtungszeitraum 1971 bis 2012

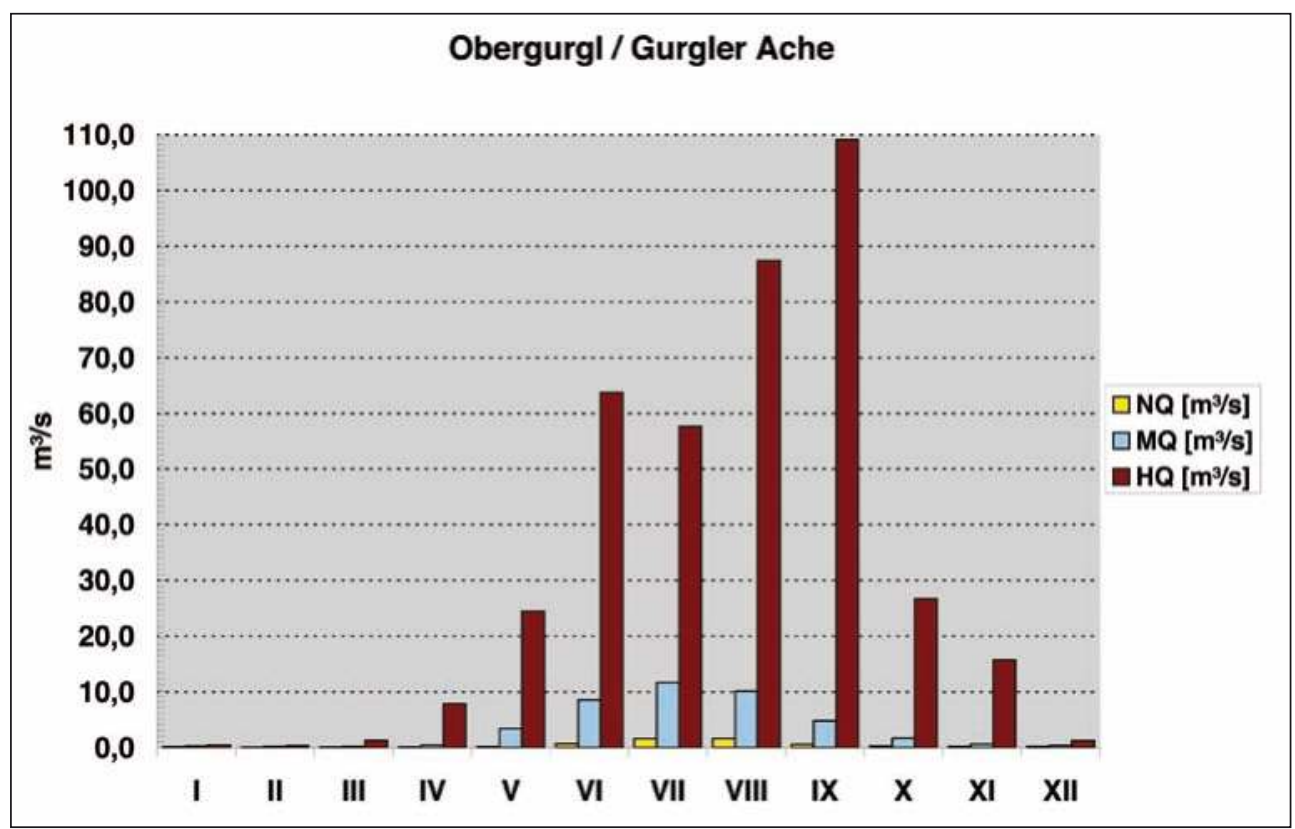

Abb. 7: Mittlere (MQ) und extreme Wasserführung (NQ, HQ) am Pegel Obergurgl/Gurgler Ache im Beobachtungszeitraum 1966 bis 2011 


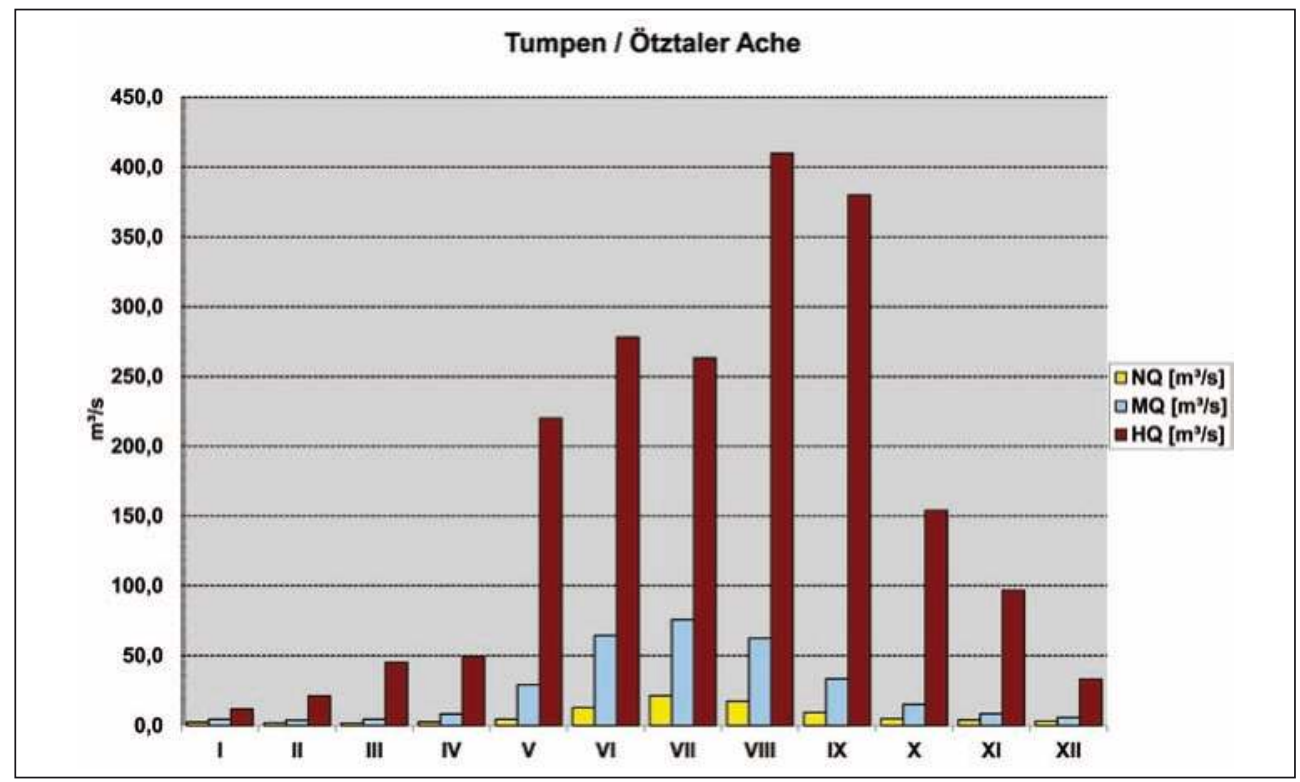

Abb. 8: Mittlere (MQ) und extreme Wasserführung (NQ, HQ) am Pegel Tumpen/Ötztaler Ache im Beobachtungszeitraum 1951 bis 2012

Hochwasser im Einzugsgebiet der Ötztaler Ache

Aus den an einem Pegel aufgezeichneten Wasserständen lassen sich anhand einer Schlüsselkurve (Wasserstand-Durchfluss-Beziehung) die entsprechenden Durchflüsse ableiten. Neben dem Scheitelabfluss kann auch die Hochwasserfracht zur Charakterisierung einer Hochwasserwelle von Interesse sein. Hochwasserschäden werden jedoch meist durch hohe Scheitelabflüsse infolge hoher Wasserstände verursacht.

$\mathrm{Da}$ ein Hochwasserscheitelwert für ein bestimmtes Gewässerprofil zunächst keine Einschätzung erlaubt, ob er ein seltenes oder häufig zu erwartendes Ereignis darstellt, erfolgt die Bewertung von Spitzenabflüssen durch Abschätzung der theoretischen Wiederkehrzeit. Voraussetzung hierfür ist jedoch eine langjährige Beobachtungsreihe mit entsprechend vielen Jahreshochwasserwerten.

Hochwasserschutzmaßnahmen werden in Österreich in der Regel derart ausgelegt, dass eine 100-jährliche Hochwasserspitze (= $\left.\mathrm{HQ}_{100}\right)$ schadlos abgeführt werden kann. Für ein Hochwasser einer bestimmten Jährlichkeit (Wiederkehrzeit) müssen entlang eines Gewässerabschnittes die Durchflüsse für jedes einzelne Gewässerprofil in Abhängigkeit von der Einzugsgebietsfläche ermittelt werden. 


\section{Zu den Hochwasserkollektiven}

Die Abb. 9, 10 und 11 zeigen die jährlich größten Hochwasserscheitelabflüsse an den Pegelstellen Vent/Rofenache, Obergurgl/ Gurgler Ache und Tumpen/Ötztaler Ache mit verschieden langen Beobachtungsreihen nach Erhebungen des Hydrographischen Dienstes Tirol und der TIWAG.

An der Ötztaler Ache konzentrieren sich die größten Abflussspitzen eines Jahres auf die Monate Mai/Juni bis September (Tab. 7). Ein Jahreshöchstabfluss im Oktober stellt die große Ausnahme dar.

\section{Hochwasser und seine Ursachen}

Die oben dargestellten Hochwasserkollektive entstammen den regelmäßigen Wasserstands- und Durchflusserhebungen im Rahmen des Hydrographischen Dienstes Tirol und der Tiroler Wasserkraft AG bzw. Westtiroler Kraftwerke AG. Das ausgewählte Datenmaterial von langjährigen (quasi-)kontinuierlichen Wasserstandsbeobachtungen oder Schreibpegelaufzeichnungen spiegelt die Auswirkungen des Wasserkreislaufes auf die Parameter Wasserstand/Durchfluss wider.

Das Abflussgeschehen wird hauptsächlich gesteuert durch das Niederschlagsgeschehen sowie von der Temperatur und dem Strahlungsangebot in Verbindung mit den Schneeund Eisrücklagen. Die in den Abb. 9, 10 und 11 dargestellten Hochwasserkollektive zeigen große Unterschiede in den einzelnen jährlichen Spitzenabflüssen. Am Pegel Tumpen/ Ötztaler Ache ist die seit 1951 größte beobachtete Hochwasserspitze $\left(410 \mathrm{~m}^{3} / \mathrm{s}\right.$ am 25.8.1987) etwa viermal höher als das kleinste bekannte Jahreshochwasser $\left(97 \mathrm{~m}^{3} / \mathrm{s}\right.$ am 19.6.1952). Ähnliche Verhältniszahlen ergeben sich auch bei den Hochwasserkollektiven

Tab. 7: Verteilung der Jahreshochwasser auf die Kalendermonate am Beispiel der Pegel in Vent, Obergurgl und Tumpen

\begin{tabular}{lccc}
\hline Monat & $\begin{array}{c}\text { Vent (1967-2012) } \\
\text { Rofenache }\end{array}$ & $\begin{array}{c}\text { Obergurgl (1966-2011) } \\
\text { Gurgler Ache }\end{array}$ & $\begin{array}{c}\text { Tumpen (1951-2012) } \\
\text { Ötztaler Ache }\end{array}$ \\
\hline Mai & 0 & 0 & 2 \\
Juni & 3 & 5 & 15 \\
Juli & 14 & 19 & 20 \\
August & 26 & 18 & 18 \\
September & 3 & 3 & 7 \\
Oktober & 0 & 1 & 0 \\
Summe Messjahre & 46 & 46 & 62 \\
\hline
\end{tabular}




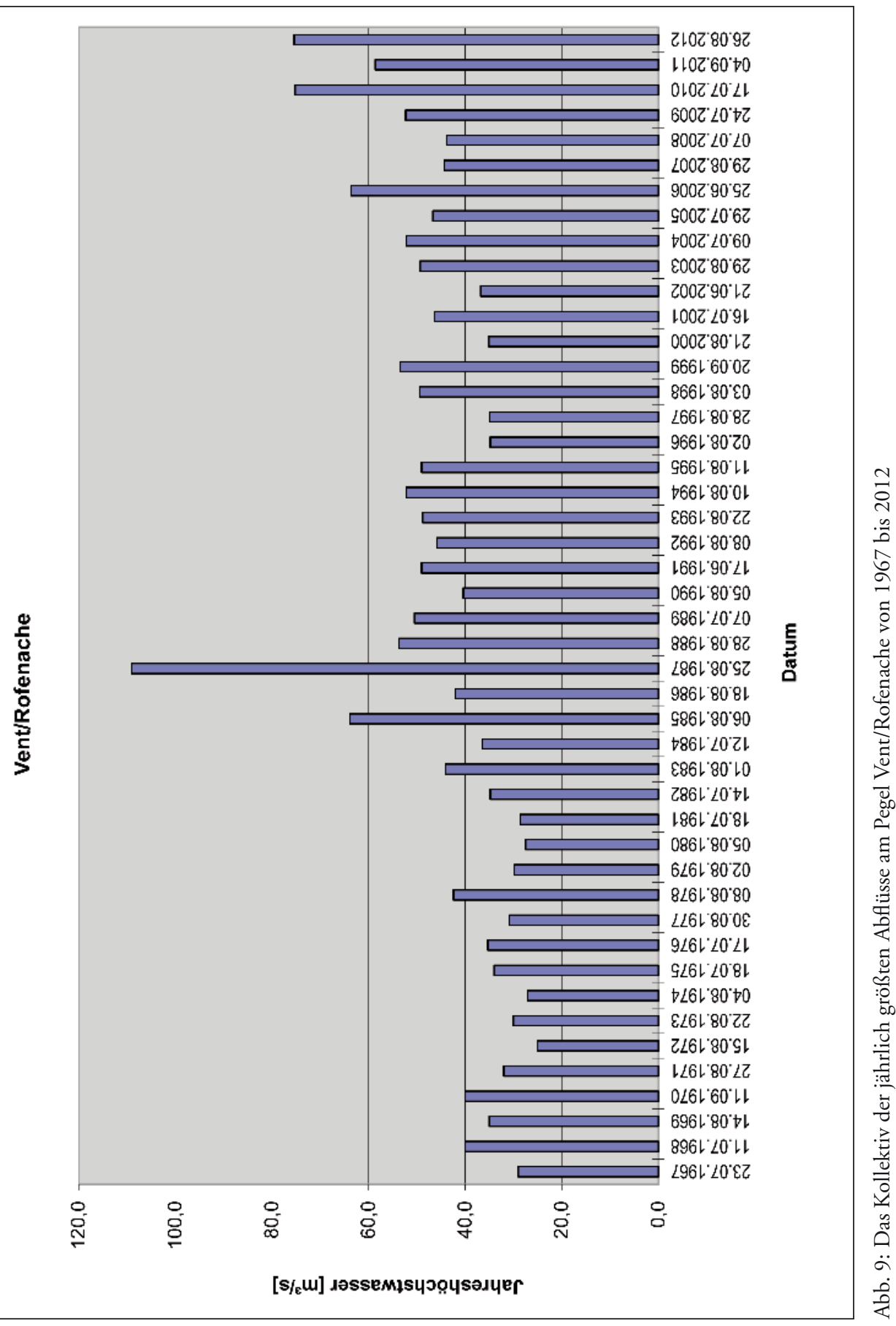


Kapitel 6 I Die Ötztaler Ache

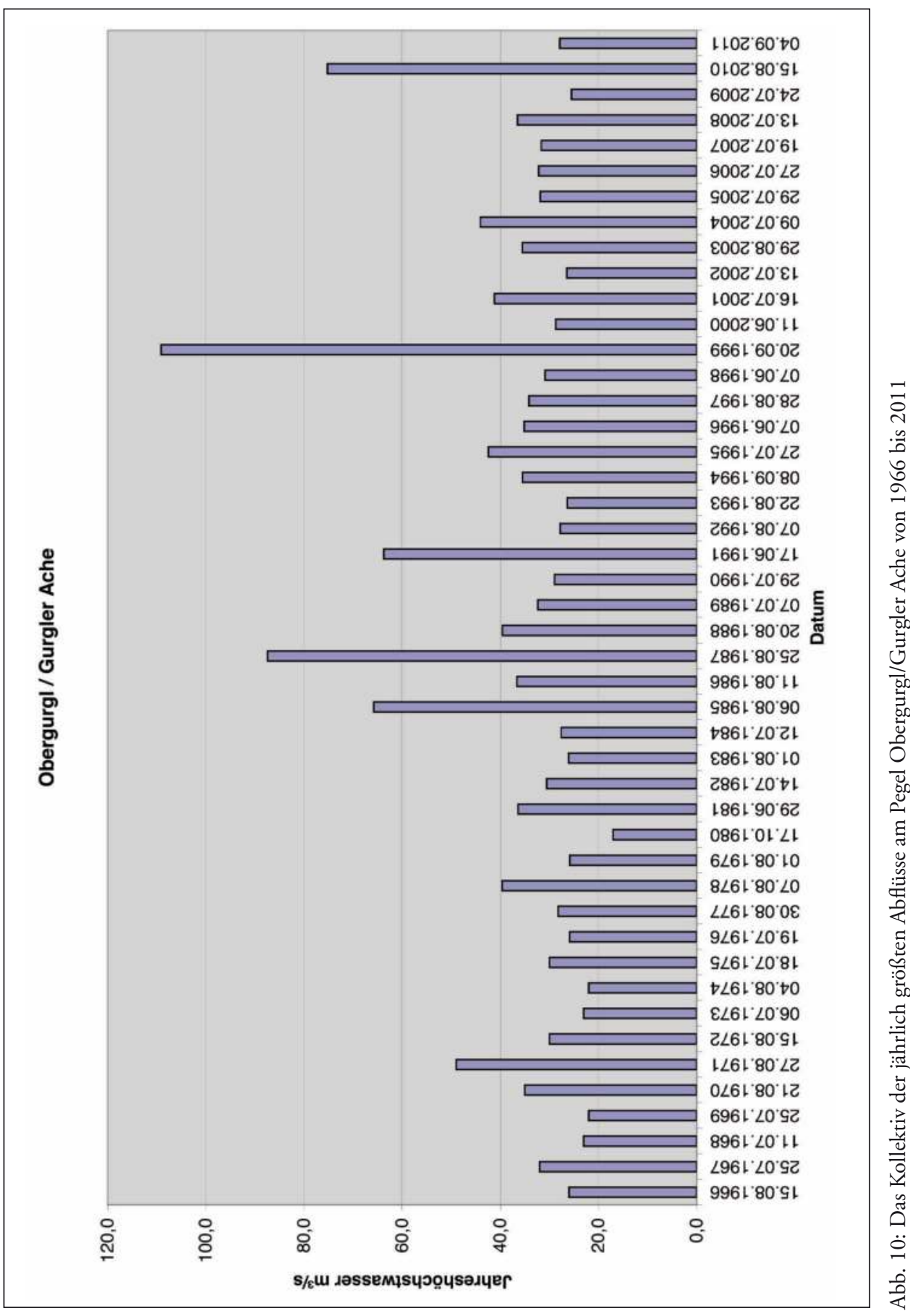




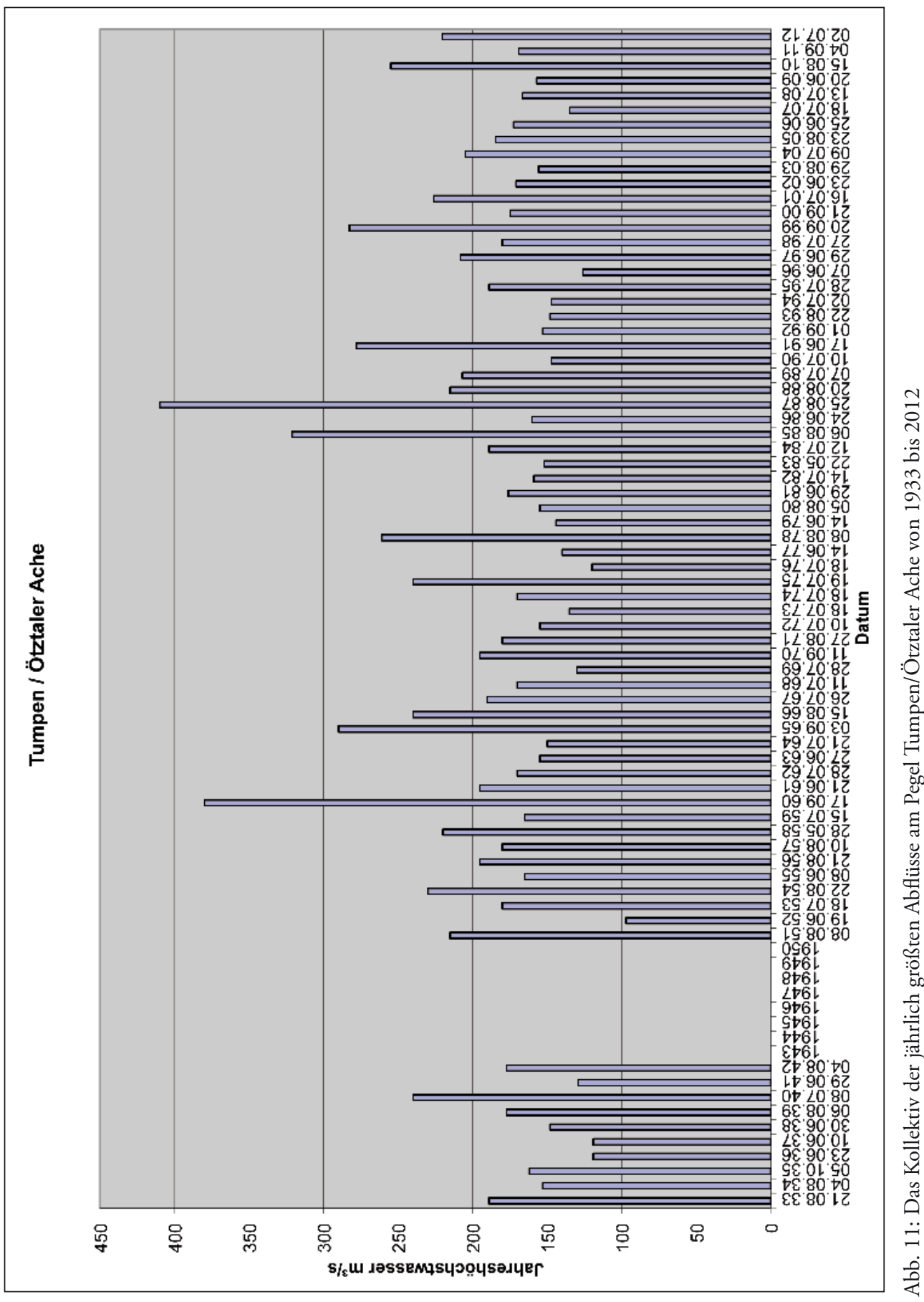


im Oberlauf (Vent/Rofenache und Obergurgl/Gurgler Ache).

Die Ursache für die starke Schwankung bei den Jahreshochwassern liegt in den unterschiedlichen Auslösemechanismen:

- Jahreshochwasser infolge Schneeschmelze (ohne Niederschlag) treten im alpinen Raum nur mit bescheidenen Hochwasserspitzen in Erscheinung.

- Wenn die Gletscherschmelze im Hochsommer so richtig in Gang kommt, werden am Pegel Vent/Rofenache etwa ein- bis fünfjährliche Hochwasserspitzen infolge der relativ starken Vergletscherung erreicht. Talauswärts flachen diese Schmelzhochwasserwellen rasch $\mathrm{ab}$, da die Vergletscherung prozentuell abnimmt.

- Konvektive Niederschläge (SchauerNiederschläge) in den Nachmittagsstunden eines Strahlungstages können die Schmelzhochwasserspitzen deutlich anheben und an den Pegeln im Oberlauf die Jährlichkeit markant ansteigen lassen. Aus einer $\mathrm{HQ}_{3}$-Schmelzhochwasserspitze kann eine aus dem Niederschlag aufgesetzte Abflussspitze ein $\mathrm{HQ}_{10}$ und mehr generieren. Aufgrund der örtlichen und zeitlichen Begrenztheit von Regenschauern verlieren diese Hochwasserspitzen talauswärts meist an Bedeutung, vor allem für die Ötztaler Ache.

- Die größten Hochwasserereignisse, die das Hochwasserkollektiv der Ötztaler Ache z.B. in Tumpen (1960, 1965, 1985, 1987, 1991, 1999) aufweist, die aber auch im Oberlauf zu markanten Spitzenabflüssen geführt haben, fallen mit jenen Wetterlagen zusammen, wie sie Steinacker (1988) beschreibt:

„Wenn kalte Luft über Frankreich ins westliche Mittelmeer vordringt, bildet sich im Golf von Genua meist ein Tief, an dessen Vorderseite eine Südströmung gegen die Alpen auflebt. Bei dieser Situation bildet sich in der Höhe - bedingt durch die Temperaturverteilung - ein Trog westlich der Alpen. Diese Konfiguration ist deshalb „günstig“ für starke Niederschläge im Alpenraum, weil dabei feuchte Mittelmeerluft gegen die Alpen geführt wird, die Hebung dieser feuchtwarmen Luft durch Stau am Alpensüdrand verstärkt wird und weiters im Sommer die $0^{\circ}$-Grenze bzw. Schneefallgrenze meist in Gipfelhöhe des Alpenhauptkamms liegt. Besonders günstig für ergiebige Niederschläge sind solche Zirkulationssysteme, wenn sie sich nur sehr langsam nach Osten bewegen, wie etwa die sog. Vb-Wetterlage (Mittelmeertief wandert von der Adria über den Alpenostrand bis nach Polen) oder quasistationäre Höhentiefdruckgebiete ..."

Bei einer solchen Wetterlage können große Flächen über 20 bis 30 Stunden einem Dauerregen ausgesetzt sein, wobei die Niederschlagsintensitäten meist unter $15 \mathrm{~mm} / \mathrm{h}$ liegen.

- Durch eine stark verzögerte Schneeschmelze, wie 1987, können die Gerinne im Sommer eine beträchtliche Vorfüllung aufweisen und sind daher nicht 
mehr voll aufnahmefähig für den niederschlagsbedingten Abfluss.

- Weitgehend ausgeaperte Gletscher im Spätsommer können die Situation verschärfen, weswegen die höchsten beobachteten Hochwasserabflüsse auf die Monate August und September fallen.

Der rückhaltlose Hochwasserabfluss aus dem Einzugsgebiet der Ötztaler Ache hat natürlich auch Auswirkungen auf den Inn, dessen Hochwassergeschehen häufig von den inneralpinen Einzugsgebieten mitbestimmt wird. In den vorliegenden Hochwasserkollektiven fehlen jedoch jene Hochwasserspitzen, wie sie von einem anderen Typ der Hochwasserentstehung verursacht wurden. Durch den wiederholten Ausbruch des Rofener und des Gurgler Eissees in den vergangenen Jahrhunderten entstanden gewaltige Flutwellen, die durch die Talschluchten auf die Ötztaler Ache zugerast sind (Nicolussi, Kapitel 4 in diesem Band). In der Folge kam es zu argen Verheerungen und Verwüstungen im Siedlungsraum des Ötztales bis in das Inntal. Die Hochwasserspitzen dieser Flutwellen dürften zumindest im Oberlauf um eine ganze Größenordnung höher gewesen sein als die niederschlagsbedingten Abflussspitzen.

Die folgende Zeittafel gibt eine Übersicht zu den Ausbrüchen dieser beiden Eisseen (Leys \& Reinwarth 1975):
Verheerungen durch Ausbrüche des Rofener Eissees:

1599 Bildung des Rofener Eissees oberhalb Vent im Ötztal durch Vorstoß des Vernagtferners, dessen Zunge die Rofener Ache aufstaute.

1600 (25. Juli): Erster Ausbruch des Eissees; große Hochwasserschäden im Ötztal mit Verwüstung von Feldern und Straßen. Das Längenfelder Becken wurde in einen See verwandelt. Sogar die Bewohner von Innsbruck wurden durch plötzlich steigenden Wasserstand in Schrecken versetzt.

1678 (17. Juli): Zweiter verheerender Ausbruch mit großen Verwüstungen im Ötztal bis in das Inntal. Zur gleichen Zeit erfolgte wegen rascher Gletscherschneeschmelze im Sulztal ein Ausbruch des Fischbaches in Längenfeld mit großen Verheerungen in Oberlängenfeld.

1679 Ausbruch mit unbedeutenden Schäden.

1680 (15. Juni): Dritter verheerender Ausbruch mit neuerlichen Verwüstungen durch das ganze Ötztal; Eisblöcke sollen bis zur Donau geschwommen sein.

1771 Vierter Ausbruch ohne größeren Schaden im Ötztal.

1845 (14. Juni): Fünfter verheerender Ausbruch; infolge neuerlichen Vorstoßes des Vernagtferners Ausbruch mit furchtbaren Verheerungen im Ötztal (der Inhalt des Rofener Eissees wurde 
auf $1,320.000 \mathrm{~m}^{3}$ angeschätzt, der $\mathrm{Ab}$ fluss erfolgte in einer Stunde, Flutwellenhöhe in Vent nach Augenzeugen ca. $10 \mathrm{~m})$.

1846 (8.-11. Februar, 7. Juli, 10. Oktober): Ausbrüche mit Schäden im Ötztal.

1847 (25. Mai): Ausbruch mit Schäden im inneren Ötztal.

1848 (13. Juni): neuerlicher Ausbruch.

1868 (27. Juli): Letzter verheerender Ausbruch mit Vernichtung des Weilers Huben bei Längenfeld. Dies war der letzte Ausbruch des Rofener Eissees. Durch den Rückzug des Vernagtferners bildete sich dieser See nicht mehr.

\section{Ausbruch des Gurgler Eissees:}

1716 Der Gurgler Eissee bildete sich durch Vorstoß des Gurgler Gletschers mit Absperrung des Längentales (Länge 1700 Schritte, Breite 650 Schritte, Tiefe 100 Klafter, wobei 1 Klafter ca. $1,9 \mathrm{~m}$ beträgt).

1717 (30. Juni): Ausbrüche mit langsamen Entleerungen; dadurch geringe Schäden im Ötztal.

1718 (2. Juni): Ausbrüche mit langsamen Entleerungen; dadurch geringe Schäden im Ötztal.

1724 (10. Juni): Ausbrüche mit langsamen Entleerungen; dadurch geringe Schäden im Ötztal.

1770 Ausbrüche mit langsamen Entleerungen; dadurch geringe Schäden im Ötztal.
1817 Neubildung des Gurgler Eissees infolge Vorstöße des Gurgler Ferners, langsame Entleerung ohne Schaden.

1834 Ausbruch mit großen Schäden im Ötztal.

1847 Aufstau des Sees mit Abfluss ohne Schäden.

1867 Ausbruch mit Schäden im inneren Ötztal. Durch den Rückzug des Gurgler Ferners bildete sich auch der See ab diesem Zeitpunkt nicht mehr.

\section{Verschiedene Wasserverheerungen durch Gletscher:}

1725 (18. Juni): Murgang im Wütenbach bei Sölden vermutlich infolge plötzlicher Entleerung eines kleinen Eissees. Die Ache wurde zu einem See gestaut, welcher nach Durchbruch große Verheerungen im Ötztal anrichtete. Am gleichen Tag brach auch der Fischbach in Längenfeld infolge großer Wasserführung durch rasche Schneeschmelze (in den Gletschern) des Sulztales aus. In Innsbruck wurden zufolge der starken Wasserführung der Ötztaler Ache Teile der Stadt unter Wasser gesetzt.

In Abb. 12 ist das Hochwasserkollektiv vom Pegel Vent/Rofenache mit den Ausbrüchen des Rofener Eissees der Jahre 1600, 1678, 1679, 1680, 1771, 1845, 1846, 1847, 1848, 1868 erweitert dargestellt. 

Ergebnisse der Wassertemperaturmessung

Die Erfassung der Wassertemperatur ist nicht ganz einfach zu bewerkstelligen. Stark schwankende Wasserstände im Sommerhalbjahr und Eisbildung im Gewässer im Winterhalbjahr können die kontinuierliche Erfassung der Wassertemperatur erheblich erschweren. Die Eis-Erscheinungen sind nicht nur von der Höhenlage der Pegelstelle abhängig. Talaufweitungen, wie sie an der Ötztaler Ache z.B. am Pegel Huben im mittleren Ötztal gegeben sind, begünstigen bereits im Oktober die Eisbildung. Ein starker Rückgang der Wasserführung, die Verlangsamung der Fließgeschwindigkeit und geringe Wassertiefen führen be- sonders nach Neuschnee in Strahlungsnächten zu starker Abkühlung der Gewässer.

An der Pegelstelle Vent/Rofenache ist bereits im September mit Wassertemperaturen von $0{ }^{\circ} \mathrm{C}$ zu rechnen, die auch den gesamten Monat Mai betreffen können (Tab. 8, Abb. 13). Im Regelfall bildet sich im Pegelgerinne von Vent/Rofenache eine geschlossene Eisdecke im Laufe des Herbstes, die erst im März/April wieder aufbricht. Der gesamte Messbetrieb kann dadurch erheblich erschwert werden. Die höchsten gemessenen Wassertemperaturen liegen in den Monaten Mai bis August um $10{ }^{\circ} \mathrm{C}$. Der absolute Höchstwert von $11,1^{\circ} \mathrm{C}$ im Mai ist für diese Jahreszeit außergewöhnlich, er kann aber in der Temperaturganglinie nicht als Ausreißer abqualifiziert werden.

Tab. 8: Mittlere und extreme Wassertemperaturen am Pegel Vent/Rofenache für die Monate I bis XII aus dem Beobachtungszeitraum 2000 bis 2012

\begin{tabular}{lcccccccccccc}
\hline Monat & I & II & III & IV & V & VI & VII & VIII & IX & X & XI & XII \\
NT $\left[{ }^{\circ} \mathbf{C}\right]$ & 0,0 & $-0,1$ & 0,0 & $-0,3$ & 0,0 & 0,1 & 0,7 & 0,6 & 0,0 & $-0,1$ & $-0,1$ & 0,1 \\
MT $\left[{ }^{\circ} \mathbf{C}\right]$ & 0,2 & 0,3 & 0,5 & 1,4 & 3,1 & 4,2 & 4,6 & 4,6 & 3,9 & 2,5 & 0,6 & 0,2 \\
HT $\left[{ }^{\circ} \mathbf{C}\right]$ & 1,5 & 1,4 & 2,9 & 7,8 & 11,1 & 9,8 & 10,2 & 9,3 & 9,2 & 8,3 & 5,1 & 2,0 \\
\hline
\end{tabular}

NT niedrigste Wassertemperatur im Beobachtungszeit-

raum (kleinster 15 -Minuten-Mittelwert) $\left[{ }^{\circ} \mathrm{C}\right]$

MT Monatsmitteltemperatur des Wassers $\left[{ }^{\circ} \mathrm{C}\right]$

HT höchste Wassertemperatur im Beobachtungszeitraum (höchster 15-Minuten-Mittelwert) $\left[{ }^{\circ} \mathrm{C}\right]$

Tab. 9: Mittlere und extreme Wassertemperaturen am Pegel Tumpen/Ötztaler Ache für die Monate I bis XII aus dem Beobachtungszeitraum 1992 bis 2012

\begin{tabular}{lcccccccccccc}
\hline Monat & I & II & III & IV & V & VI & VII & VIII & IX & X & XI & XII \\
\hline NT $\left[{ }^{\circ} \mathbf{C}\right]$ & $-0,2$ & $-0,1$ & $-0,1$ & 0,0 & 2,1 & 3,1 & 4,3 & 4,8 & 2,3 & 0,0 & $-0,1$ & $-0,2$ \\
MT $\left[{ }^{\circ} \mathbf{C}\right]$ & 0,4 & 0,9 & 3,1 & 5,7 & 7,1 & 7,9 & 8,8 & 8,9 & 7,8 & 5,7 & 2,6 & 0,9 \\
HT $\left[{ }^{\circ} \mathbf{C}\right]$ & 4,6 & 5,3 & 9,3 & 12,0 & 12,7 & 13,3 & 13,8 & 13,1 & 12,1 & 10,6 & 8,7 & 5,1 \\
\hline
\end{tabular}


W. Gattermayr

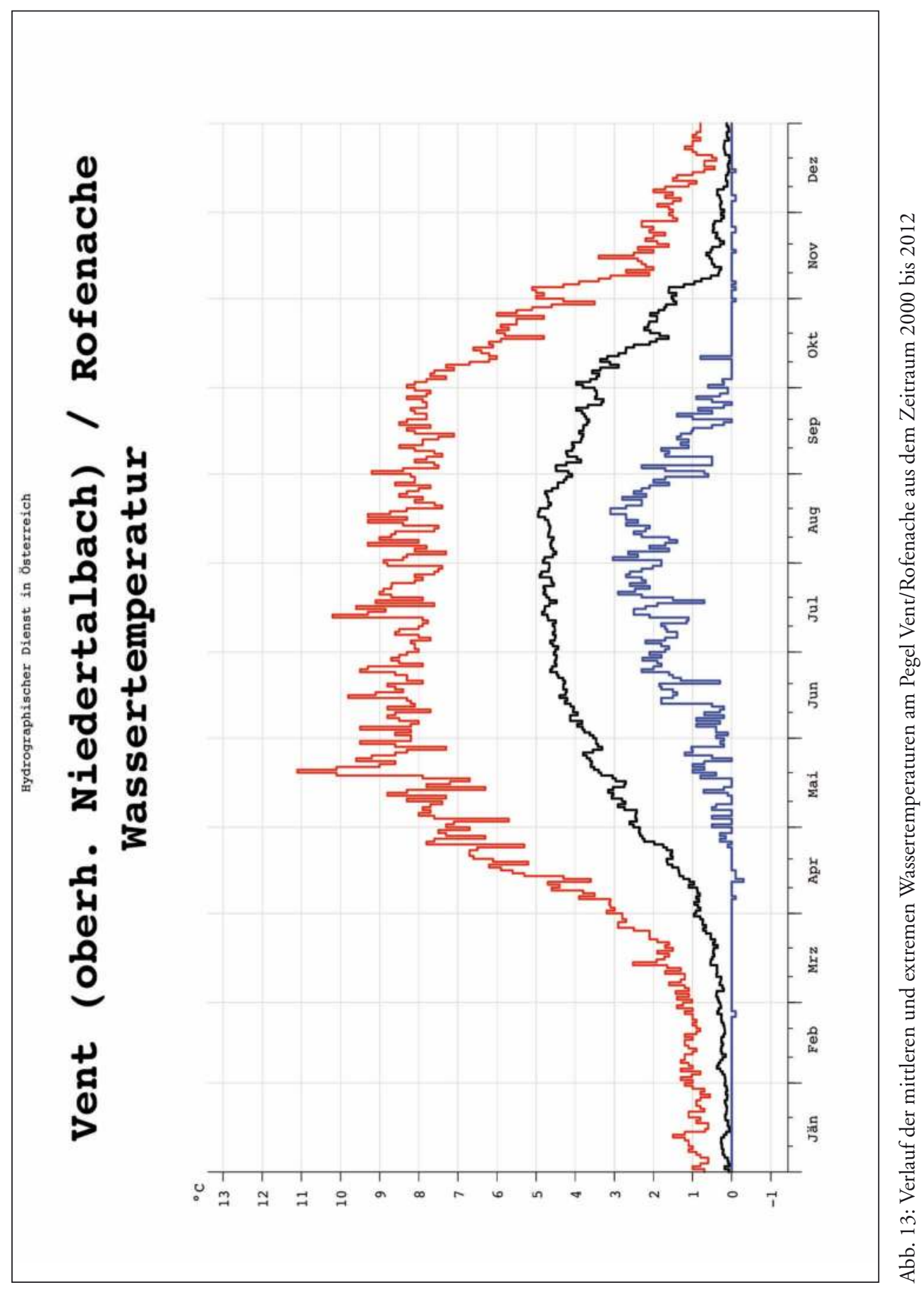


Kapitel 6 I Die Ötztaler Ache

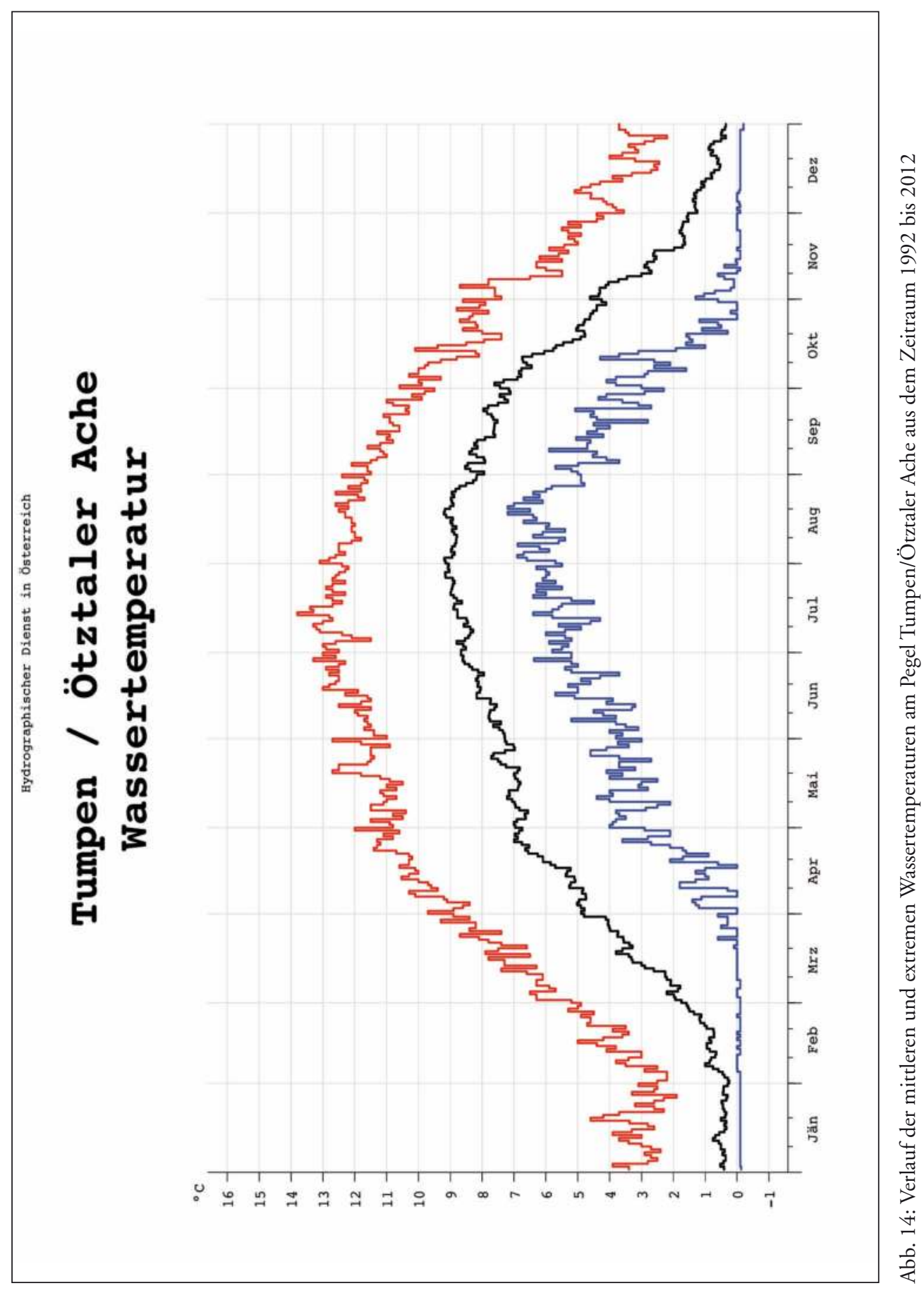


Am tiefer gelegenen Pegel Tumpen/Ötztaler Ache sind Wassertemperaturen um $0{ }^{\circ} \mathrm{C}$ von Oktober bis April bekannt (Tab. 9, Abb. 14). Die höchsten gemessenen Wassertemperaturen liegen knapp unter $14^{\circ} \mathrm{C}$ und beschränken sich auf den Zeitraum Juni bis August. Auch die historischen Pegelstandorte in Tumpen waren teilweise von starker und anhaltender Vereisung im Winterhalbjahr betroffen.

\section{Feststoffführung der Ötztaler Ache}

Gemäß ÖNORM B 2400 wird unter Punkt 6 "Durch das Wasser bewegte feste Stoffe" die Gesamtheit von Geschiebe, Schwebstoffen und Schwimmstoffen verstanden.

Im Rahmen der Erhebung des Zustandes von Gewässern (WRG 1959) bezieht sich die Erhebung des Wasserkreislaufes u.a. auch auf die Erhebung der Feststoffe in den Gewässern hinsichtlich Verteilung nach Menge und Dauer. Im Einzugsgebiet der Ötztaler Ache wurden die ersten Feststoffmessstellen des Hydrographischen Dienstes Tirol in Vent/Rofenache (1999: kontinuierliche Geschiebemessung, 2006: kontinuierliche Schwebstoffmessung) und in Tumpen/Ötztaler Ache (2005: kontinuierliche Schwebstoffmessung) im Bereich der jeweiligen Pegel installiert und seither durchgehend betrieben. Die Erfassung der Feststoffe erfolgt mit Hilfe indirekter und direkter Messverfahren.

- Die kontinuierliche Ermittlung der Schwebstoffführung wird mit einer am
Ufer installierten Trübungssonde und fallweisen Kalibriermessungen mittels Flaschenproben durchgeführt.

- Die Geschiebemessung erfolgt mit Hilfe von Geophonen, welche kontinuierlich die Impulse der darüber bewegten Steine erfassen, und fallweisen Fangkorbmessungen.

Mit den Kalibriermessungen wird eine Beziehung zwischen der Gewässertrübung und den Schwebstoffen hergestellt bei bekannter Wasserführung am Pegel. Für die Ermittlung des Geschiebeflusses müssen Wertepaare zwischen den registrierten Geophonimpulsen und dem mittels Fangkorb gesammelten Geschiebe pro Zeiteinheit gefunden werden. Diese Kalibriermessungen sind bei unterschiedlichen Durchflüssen am Pegel durchzuführen, damit die Wertepaare möglichst den gesamten Messbereich zwischen Niedrigwasser und Hochwasser abdecken.

Der gleichzeitig am Pegel ermittelte Durchfluss erlaubt in vielen Fällen auch eine Korrelation zwischen der Wasserführung und dem Feststofftransport. Der Schwebstofftransport setzt wesentlich früher ein als der Geschiebetransport. Die Menge des transportierten Schwebstoffes ist ein Vielfaches von der Menge des durchdriftenden Geschiebes. Besonders in vergletscherten Einzugsgebieten wie dem hinteren Ötztal färbt der Schwebstoff das Bachwasser milchig weiß, weshalb die von der Gletscherschmelze beaufschlagten Fluten gemeinhin als Gletschermilch bezeichnet werden. 
Kapitel 6 | Die Ötztaler Ache

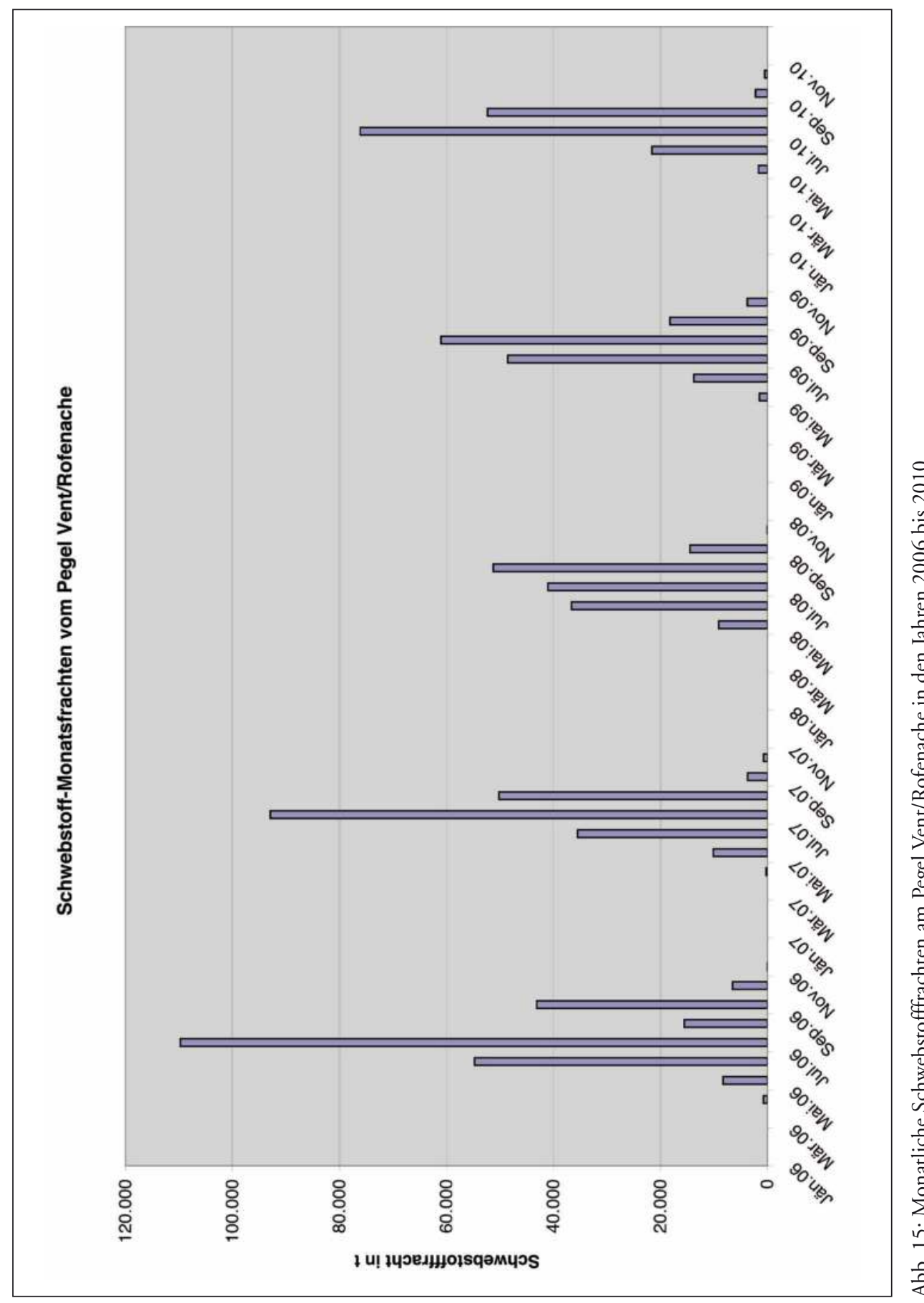


W. Gattermayr

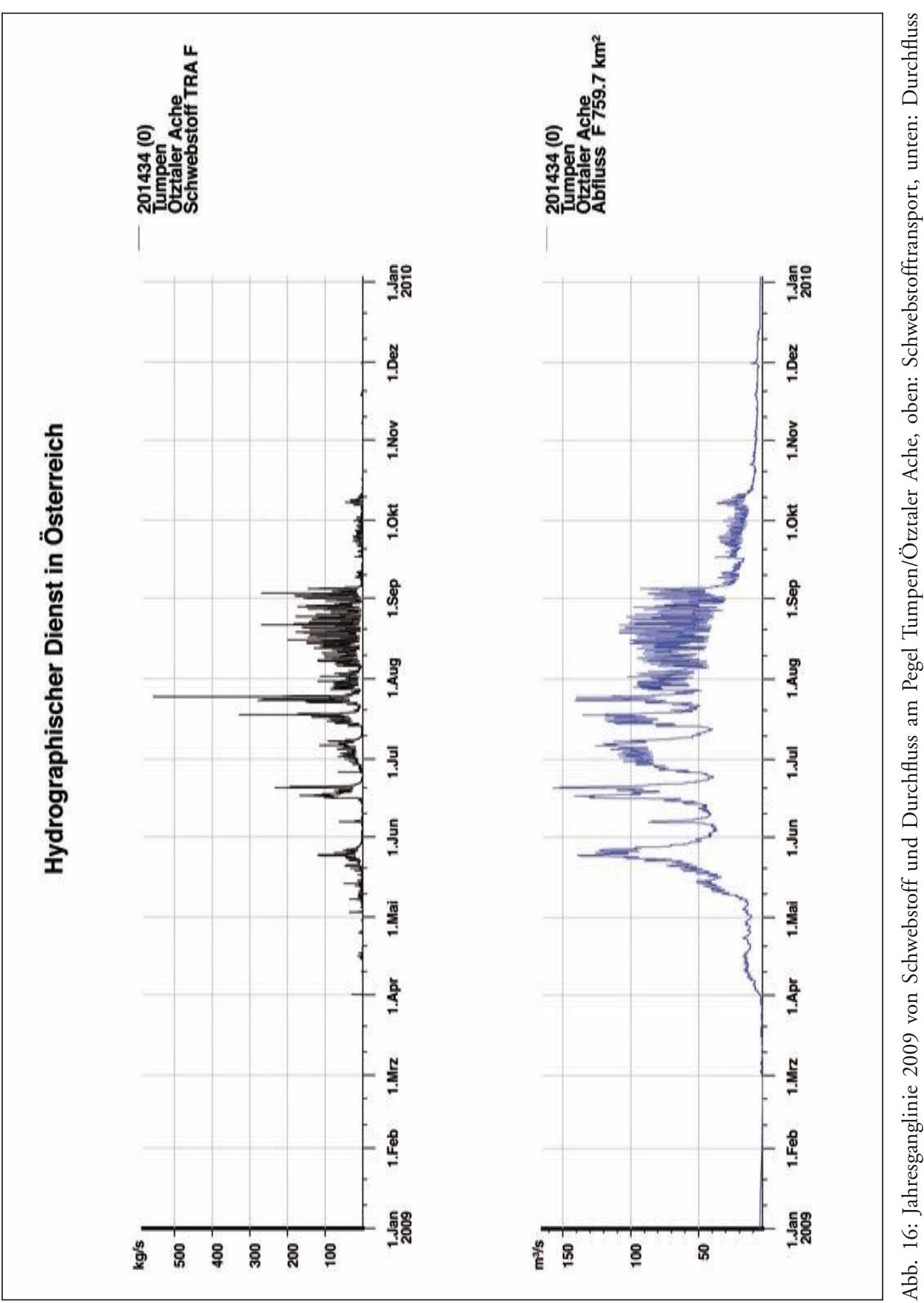


Der Geschiebetransport hängt von der Schleppkraft der fließenden Welle (Durchfluss im Gerinne) und vom bereitgestellten Geschiebepotential ab. Neben den transportierten Geschiebemengen (Geschiebefracht) interessiert auch, ab welcher Strömungsgeschwindigkeit der Geschiebetrieb einsetzt.

Der Nachschub von Feststoffen in den Talfluss erfolgt meist durch Starkregen und davon ausgelösten Oberflächenabfluss oder Murgängen bzw. Rutschungen. Auch die ansteigende Permafrostgrenze begünstigt die Freisetzung von Lockermaterial, welches besonders bei Starkregen und Hochwasser in Bewegung gerät. Geschiebe, das vom Bach/Fluss nicht mehr transportiert wird, lagert sich auf der Gewässersohle $\mathrm{ab}$ und führt zu deren Anhebung. Solche Auflandungen können dazu führen, dass das dadurch verkleinerte Gewässerprofil
u.U. größere Hochwasser nicht mehr ohne Ausuferung abführen kann.

Der Feststofftransport in der Ötztaler Ache weist einen ausgeprägten Jahresgang auf (Abb. 15). Wie in Abb. 16 ersichtlich, unterliegt auch der Abfluss einem Jahresgang, der aber wegen anderer Einflussfaktoren - wie oben erwähnt - nur bedingt mit dem Feststofftransport korreliert. Im Beobachtungszeitraum 2006 bis 2010 schwanken die jährlichen Schwebstofffrachten am Pegel Vent/Rofenache zwischen 150.000 und 240.000 Tonnen (Abb. 17). Für den Unterlauf der Ötztaler Ache sind vom Pegel Tumpen in Abb. 18 die monatlichen Schwebstofffrachten der Jahre 2006 bis 2010 dargestellt. In diesem Zeitraum schwankten die jährlichen Schwebstofffrachten zwischen 340.000 und 720.000 Tonnen (Abb. 19).

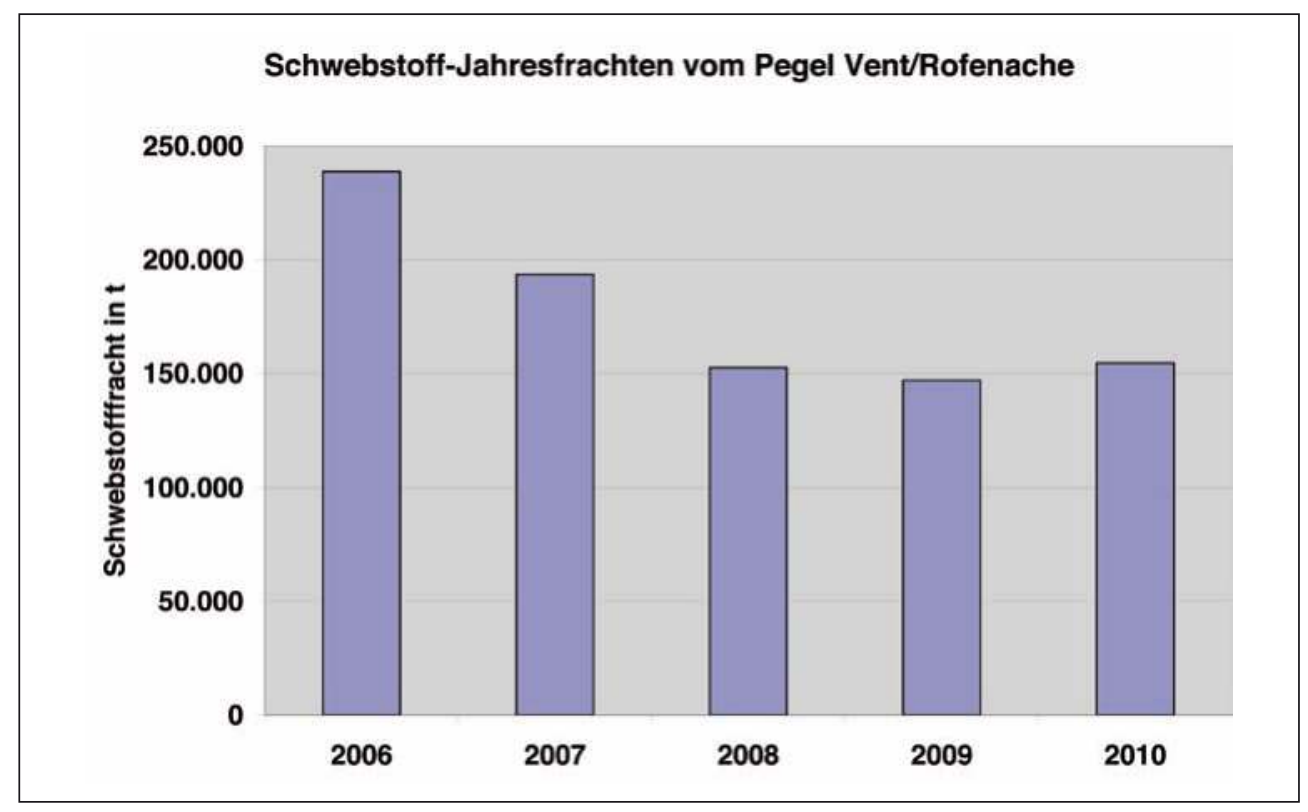

Abb. 17: Schwebstoff-Jahresfrachten am Pegel Vent/Rofenache von 2006 bis 2010 
W. Gattermayr

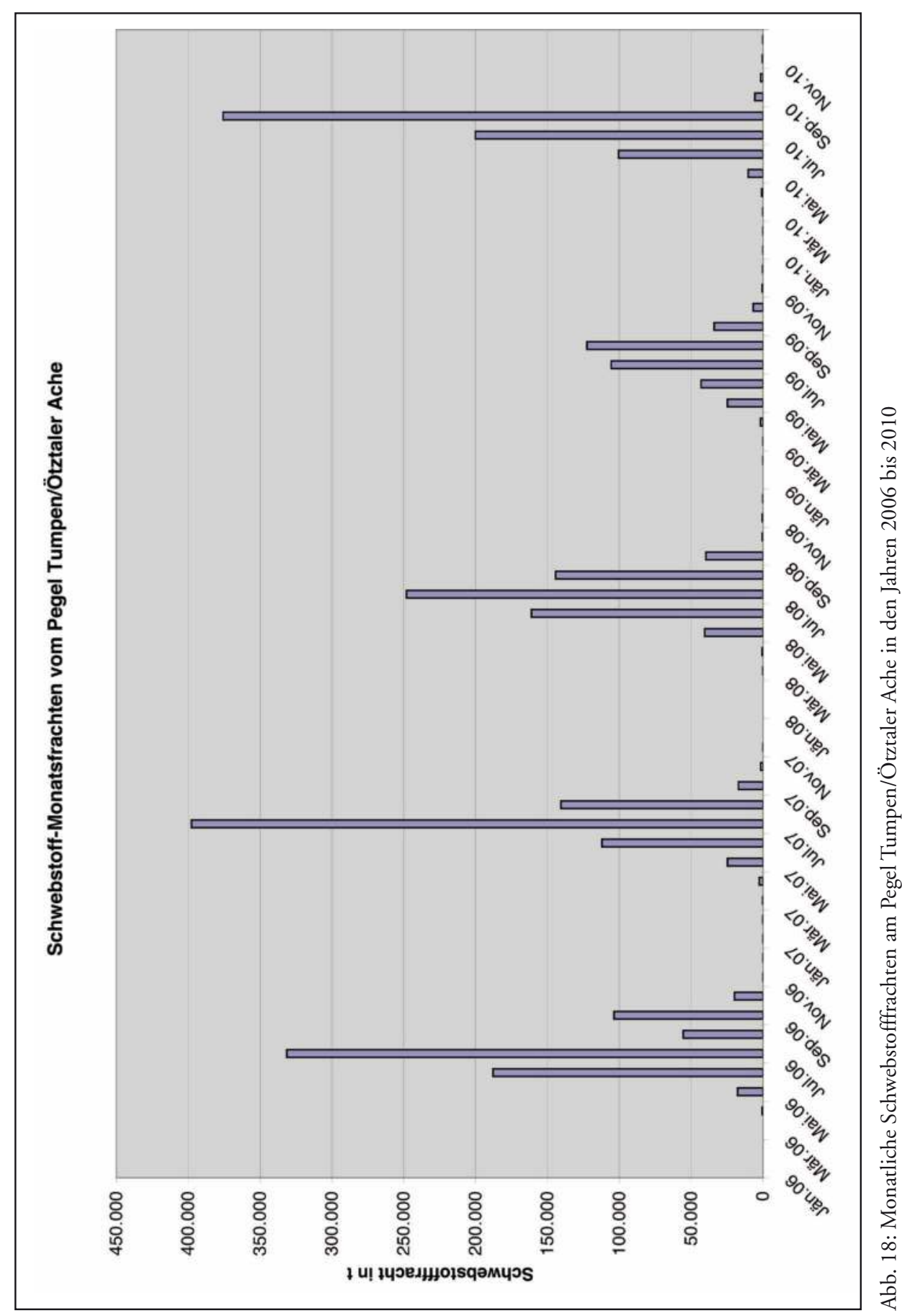




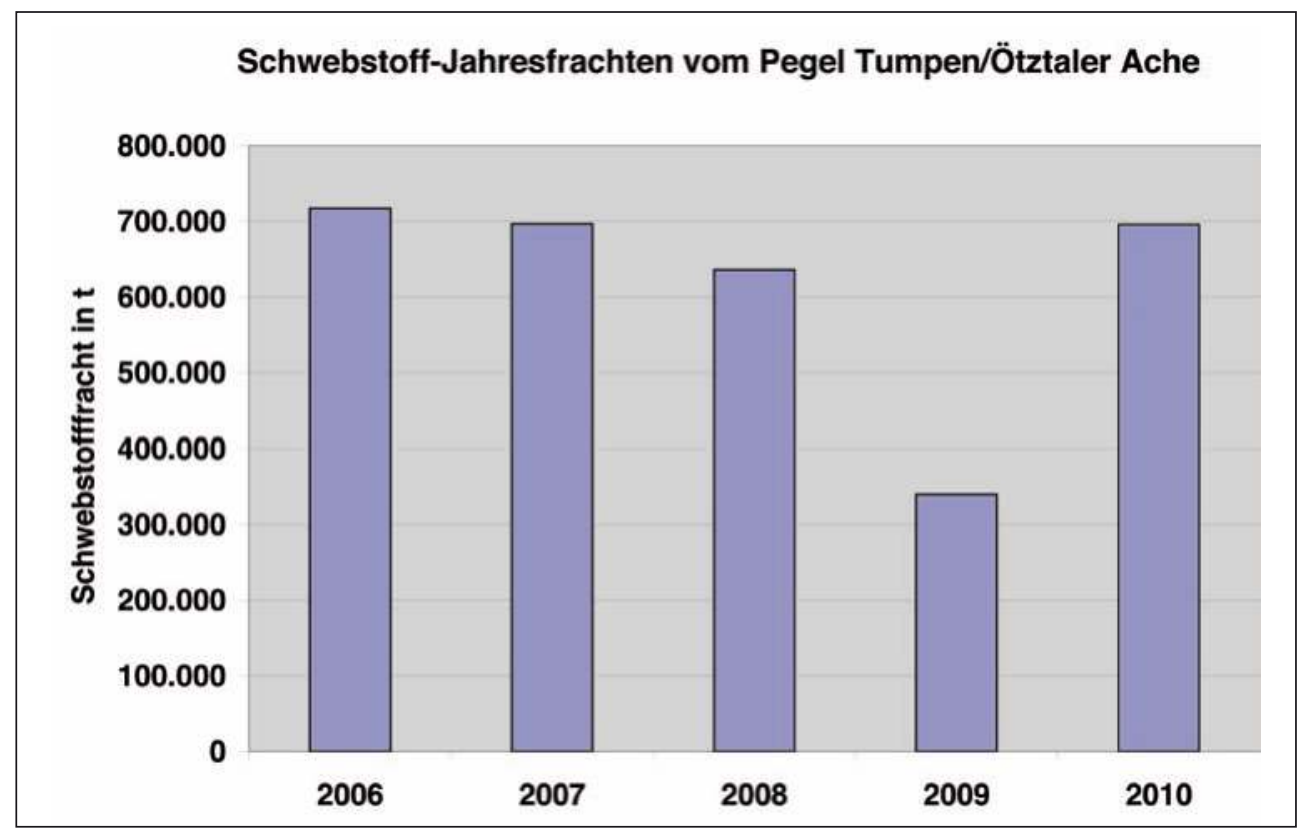

Abb. 19: Schwebstoff-Jahresfrachten am Pegel Tumpen/Ötztaler Ache von 2006 bis 2010

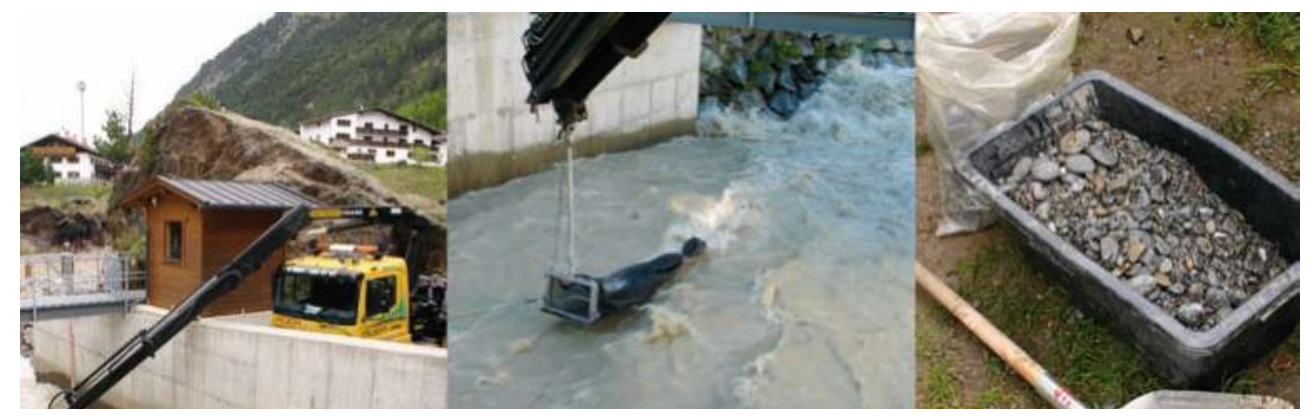

Abb. 20: Geschiebemessung mit einem mobilen Geschiebefänger ( $a, b)$ und die erschrotete Geschiebeprobe (c) am Pegel Vent/Rofenache (Fotos: Hugo Seitz, Institut für Wasserwirtschaft, Hydrologie und Konstruktiven Wasserbau, IWHW, an der BOKU/Wien)

Wie aufwändig die Gewinnung von Geschiebeproben ist, zeigt Abb. 20. Bei höherer Wasserführung muss der Geschiebefänger mittels LKW-Kran bündig in der Gerinnesohle aufgesetzt werden. Der Sammelzeitraum wird sekundengenau protokolliert, damit der Geschiebetransport ermittelt werden kann.
Wie die aufgezeichneten Geophonimpulse erkennen lassen, rollt kein gleichmäßiges Geschiebeband durch das Pegelgerinne (Abb. 21). Obwohl die Abflusskurve einen gleichmäßigen glockenförmigen Verlauf im Tagesgang aufweist, driftet das Geschiebe eher schubweise durch. Die Geschiebefronten 


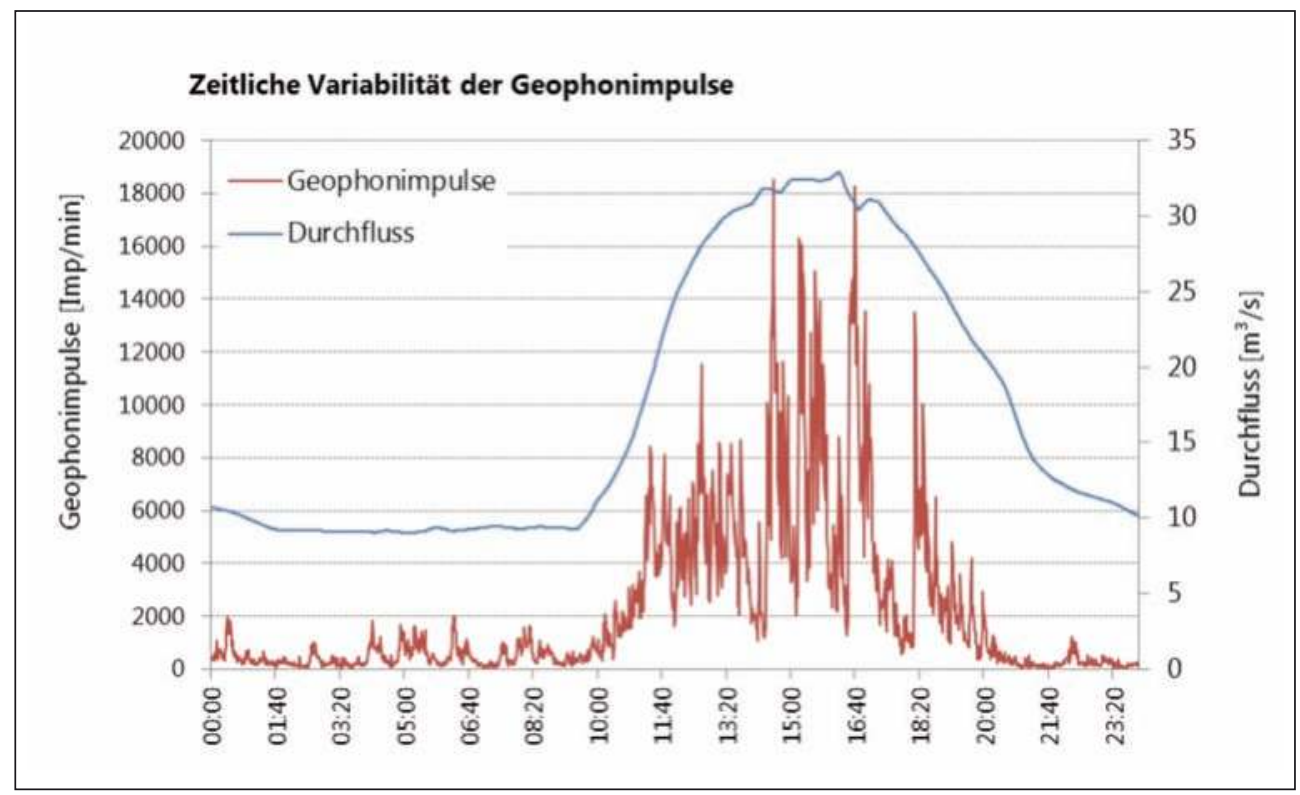

Abb. 21: Variabilität der Geophonimpulse bei bekannter Abflusskurve nach Aufzeichnungen des Hydrographischen Dienstes Tirol und Auswertungen des Institutes für Wasserwirtschaft, Hydrologie und Konstruktiven Wasserbau, IWHW, an der BOKU/Wien

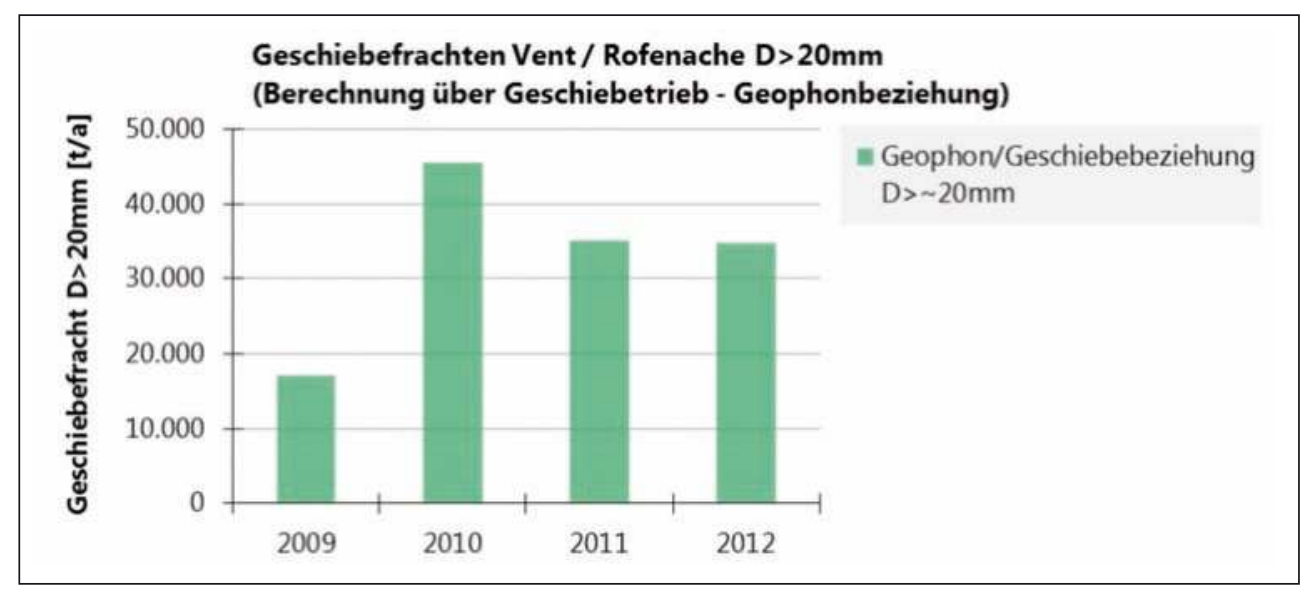

Abb. 22: Übersicht der angeschätzten Geschiebefrachten am Pegel Vent/Rofenache für die Jahre 2009 bis 2012 für Korndurchmesser über 20 mm (Auswertung: Institut für Wasserwirtschaft, Hydrologie und Konstruktiven Wasserbau, IWHW, an der BOKU/Wien im Auftrag des Hydrographischen Dienstes Tirol) 


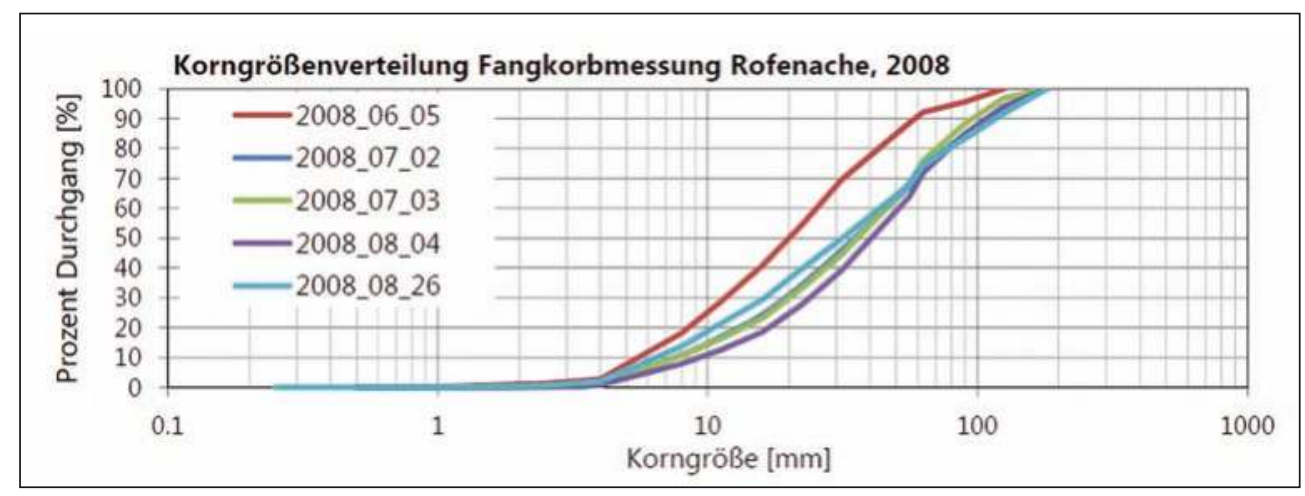

Abb. 23: Die Korngrößenverteilung aus Fangkorbmessungen an fünf Tagen im Jahr 2008 am Pegel Vent/ Rofenache

wandern wie Dünen durch das Pegelgerinne und werden von den sohlgleich eingebauten Geophonen detektiert. Nach aufwändigen Auswertearbeiten liegen für die Messjahre 2009 bis 2012 vorläufige Jahresfrachten des Geschiebes mit einem Korndurchmesser $\geq$ $20 \mathrm{~mm}$ vor, welches durch das Pegelgerinne in Vent/Rofenache gedriftet ist (Abb. 22). In diesem Zeitraum schwankten die jährlichen Geschiebefrachten am Pegel Vent/Rofenache zwischen 18.000 und 46.000 Tonnen.

Im Zuge der Fangkorbmessungen wurde auch die Textur des gesammelten Materials ermittelt. Im Jahre 2008 wurden an fünf Messtagen Geschiebeproben aus der Rofenache gezogen. Die Korngrößenverteilungen an diesen Tagen sind in Abb. 23 dargestellt. Die Kalibriermessungen und die Datenbearbeitung erfolgte durch das Institut für Wasserwirtschaft, Hydrologie und Konstruktiven Wasserbau, IWHW, an der Universität für Bodenkultur Wien (BOKU) im Auftrag des Hydrographischen Dienstes Tirol.

\section{Diskussion}

Die systematische Erfassung des Wasserkreislaufes hat nach der Gründung des Hydrographischen Zentralbüros eingesetzt. Aufgrund der fehlenden technischen Hilfsmittel kam in den ersten Jahrzehnten der hydrographischen Messtätigkeit den Augenbeobachtungen eine große Bedeutung zu. Notgedrungen war der Stichprobenumfang der Messparameter damals stark eingeschränkt. Starkregen im Kurzzeitbereich konnten ohne Registriergeräte ebenso wenig ermittelt werden wie Tagesgänge des Wasserstandes oder der Wassertemperatur. Augenbeobachtungen konnten die Form einer Hochwasserspitze sicherlich nur ansatzweise beschreiben; wie weit der wahre Hochwasserscheitel erfasst wurde, war von der Einsatzbereitschaft eines vor Ort tätigen Beobachters abhängig. Erst mit der Entwicklung von entsprechenden Registriergeräten war es möglich, Vorgänge und Abläufe im 
Wasserkreislauf kontinuierlich zu erfassen. Mit dieser schrittweisen technischen Weiterentwicklung war parallel dazu eine stetige Verbesserung der Datenqualität verbunden. Aber auch Messstellenverlegungen oder anthropogene Beeinflussungen von Pegelstellen z.B. durch Kraftwerksbauten sind bei der Herstellung eines homogenen Datenmaterials eine Herausforderung. Hinzu kommen die natürlichen Schwankungen der Wasserkreislaufkomponenten, an denen auch der Klimawandel beteiligt sein kann. Die Häufung von niederschlagsarmen Jahren oder von größeren Hochwasserereignissen prägen Datenkollektive, die als Grundlage für extremwertstatistische Auswertungen herangezogen werden müssen. Für wasserbauliche Maßnahmen müssen gelegentlich Hochwassersicherheiten ermittelt werden, die vom $\mathrm{HQ}_{100}$ (100-jährliches Hochwasser) bis zum $\mathrm{HQ}_{5000}$ reichen. In vielen Fällen umfassen die Datenkollektive jedoch kaum 50 Jahre und nur selten 100 Jahre. Damit wird klar, dass die Fortsetzung der hydrographischen Messungen und Erhebungen unabdingbar ist.

Die Natur hat sicherlich noch einige Überraschungen in Form von neuen, unerwarteten, noch größeren Ereignissen im Köcher, die bis jetzt in den Datengrundlagen nicht enthalten sind.

Das geflügelte Wort „Nach dem Hochwasser ist vor dem Hochwasser" hat sich immer noch bewahrheitet. Daher sollten wir uns nicht zu sicher fühlen und die Messausrüstung nicht in die Ecke stellen.

\section{Literaturverzeichnis}

HZB (1984) Flächenverzeichnis der österreichischen Flussgebiete Inn bis zur Salzach. Hydrographisches Zentralbüro/ Bundesministerium für Land- und Forstwirtschaft, Wien, 1984.

HZB (1996) Lebendiges Wasser - Vom Kreislauf des Wassers. Mitteilungen des Hydrographischen Zentralbüros $\mathrm{Nr}$. 68, Bundesministerium für Land- und Forstwirtschaft, Wien, 1996.

Leys, E. \& Reinwarth, O. (1975) Auswirkungen der Gletscher und der Gletscherabflüsse auf die Wildbach- und Lawinengefahr und ihre Berücksichtigung in den Gefahrenzonenplänen. http:// www.interpraevent.at/palm-cms/upload_files/Publikationen/Tagungsbeitraege/1975_1_345.pdf

ÖNORM B 2400 (2003) Hydrologie Hydrographische Fachausdrücke und Zeichen. Wien, 2003.

Österreichischer Wasserkraft-Kataster (1948) Ötztaler Ache. Bundesministerium für Handel und Wiederaufbau, Wien, 1948.

Steinacker, R. (1988) Die alpinen Hochwasserereignisse des Sommers 1987 und ihre meteorologischen Rahmenbedingungen. ÖWW 40 (1988), H5/6: 129-134.

tiris (2006) Land Tirol, Abteilung Geoinformation, 2006.

tiris (2013) Land Tirol, Abteilung Geoinformation, 2013. 
WRG 1959 i.d.g.F. Wasserrechtsgesetz 1959

- WRG 1959 in der Fassung BGBl.

I Nr. 14/2011, Siebenter Abschnitt, Erhebung des Zustandes von Gewässern - Wasserkreislauf und Wassergüte (Hydrographie), \$59c Grundsätze der Überwachung und Erhebung, Abs. 3, Land Tirol, 2011.

\section{Verzeichnis des Autors}

\section{Wolfgang Gattermayr}

Sachgebiet Hydrographie und Hydrologie

Abteilung Wasserwirtschaft

Amt der Tiroler Landesregierung

Herrengasse 1-3, 6020 Innsbruck

wolfgang.gattermayr@tirol.gv.at 


\title{
Die Lebewelt der Ötztaler Ache
}

\author{
Daniel Erhart
}

\section{Zusammenfassung}

Die Ötztaler Ache ist einer der wenigen hydrologisch unbeeinflussten Gletscher- bzw. Gebirgsbäche Tirols. Ihre Wasserqualität ist nahezu unbeeinträchtigt. In der Ötztaler Ache findet sich eine an die Gebirgssituation angepasste Lebewelt. Diese setzt sich sowohl aus pflanzlichen Vertretern wie Algen, als auch aus tierischen Vertretern wie jene unter dem Begriff Makrozoobenthos zusammengefassten, verschiedenen Kleinlebewesen des Gewässergrundes und den Fischen zusammen.

\section{Abstract}

The Ötztaler Ache is one of the last hydrological intact glacial and mountain streams in Tyrol. The water quality is nearly untainted. The existing hydrological regime and the glacial influence lead to a specific biotic environment. The Ötztaler Ache is mainly colonised by organisms which are adapted to the special conditions of mountain streams. Examples are several species of algae as well as faunistic elements such as the macrozoobenthos or the fishes.

\section{Einleitung}

Im oberen Einzugsgebiet der Ötztaler Ache befindet sich knapp ein Drittel der Gletscher Tirols. Diese haben einen beträchtlichen Einfluss auf die Hydrologie und die Lebewelt der Ötztaler Ache. Allein das mächtige Einzugsgebiet des hinteren Ötztales und die starke Zuspeisung aus den Zubringern der Venter- und der Gurgler Ache weisen die Ötztaler Ache im Sommer als wasserreichen Gebirgsbach aus. Von Windache, Pollesbach, Fischbach und vielen weiteren rechts- und linksseitigen Zubringern aufgespeist, bahnt sie sich ihren Weg durch das wildromantische Ötztal.

Aufgrund der beachtlichen Strömungsenergien, welche im Frühsommer mit dem Anschwellen der Abflüsse einhergehen sowie des glazialen Einflusses entwickelte sich eine an diese Faktoren angepasste Lebensgemeinschaft. 


\section{Abiotische Gewässerbeschreibung}

Die Ötztaler Ache zeigt aufgrund des alpinen Charakters und des glazial geprägten Einzugsgebietes ein stark rhithrales Abflussgeschehen mit hoher Geschiebeführung und ganzjährig tiefen Wassertemperaturen (im Mittel der wärmsten Monate $<9{ }^{\circ} \mathrm{C}$ ). Die Sauerstoffsättigung des Wassers der Ötztaler Ache ist hoch und die Energiewirkung auf Flussbett und Lebewelt ist als beträchtlich zu kommentieren. Die Ötztaler Ache ist somit einer der wenigen großen hydrologisch intakten Gletscherbäche Tirols. Aufgrund der vorherrschenden Bedingungen ist sie als Lebensraum für Arten, welche auf das Leben im Gebirgsbach spezialisiert sind, zu beschreiben. Die starken früh- bis hochsommerlichen Abflüsse, gefolgt von tiefen Temperaturen im Winter und der starke Anteil von Trübung aufgrund des mitgeführten Gletscherschliffes (der Gletschermilch) erlauben nur selten das Aufkommen von wirklich hohen Biomassen. Der Gletscherschliff ist auch für die charakteristische anfänglich weiß-grünliche Färbung der Ötztaler Ache und die grünliche Färbung des Inn verantwortlich.

\section{Gewässerbeschreibung und Zonierung}

In Anwendung limnologischer Fachbegriffe ist dieser Gebirgsbach auf seinem überwiegen- den Teil dem Epirhithral (der oberen Forellenregion) zuzuordnen. Das Krenal (die Quellregion) der hinteren und seitlichen Zubringer ist sehr oft am Gletschertor der großen Eismassen zu finden. Seit dem letzten Jahrhundert wandert diese Quellregion, durch Abschmelzprozesse bedingt, zunehmend bergwärts. Die Enge des Ötztales bietet der Ache kaum Platz, um ihre Linienführung frei zu gestalten. Daher fließt die Ache in gestreckt-bogigem Verlauf dem nördlich gelegenen Inntal zu. Lotische (schnell fließende) und lenitische (langsam fließende) Abflussbereiche wechseln einander, den Talstufen des Ötztales folgend, ab. Die Uferbereiche sind abwechselnd von schluchtförmigen Steilwänden, landwirtschaftlich genutzten Wiesen und Fichtenwäldern sowie von Galeriewäldern aus Erlen und Weiden geprägt. Immer wieder finden sich grobe Gesteinsblöcke und anstehender Fels an den Uferseiten. Die Sohle der Ötztaler Ache ist sehr variant. Sie zeigt sowohl megalithale Gesteinsblöcke (Durchmesser $>40 \mathrm{~cm}$ ) als auch deutlich kleinere Gesteinsfraktionen. Geprägt wird die Sohle im gesamten Verlauf durch mesolithales $(6-20 \mathrm{~cm})$ bis makrolithales $(20-40 \mathrm{~cm})$ Gestein. Geschiebe im Bereich des Mesolithals und darunterliegender Korngrößen wird zumindest im Sommerhalbjahr in größeren Mengen transportiert.

Der elektrische Leitwert der Ache liegt selten über $150 \mu \mathrm{S} / \mathrm{cm}$ und spiegelt so auch das silikatische Einzugsgebiet wider. Auch der pHWert um 7,5 steht damit im Zusammenhang und ist als nahezu neutral zu bezeichnen. 


\section{Beschreibung der gewässerbezogenen Lebewelt}

Die Lebewelt der Ache setzt sich vornehmlich aus verschiedenen Vertretern von Algen, Insekten und Fischen zusammen. Aufgrund der Wassergüteerhebungsverordnung (WGEV) und Gewässerzustandsüberwachungsverordnung (GZÜV) stehen umfangreiche Datensätze zum Arteninventar der Ötztaler Ache zur Verfügung (GZÜV, BGBl. 479/2006).

\section{Algen}

In den Wintermonaten zeichnet sich das Wasser der Ötztaler Ache oft durch Temperaturen nahe dem Gefrierpunkt aus. Allerdings liegen zu diesen Zeiten reduzierte Abflussmengen, geringere Strömungsgeschwindigkeiten und -energien sowie ein vernachlässigbar geringer Schwebstoff- und Geschiebetransport vor. Dadurch werden die kaltstenothermen Organismen, also jene Organismen, welche an kalte Umgebungstemperaturen angepasst sind, bevorzugt und können sich während des Winterhalbjahr auch vergleichsweise gut entwickeln.

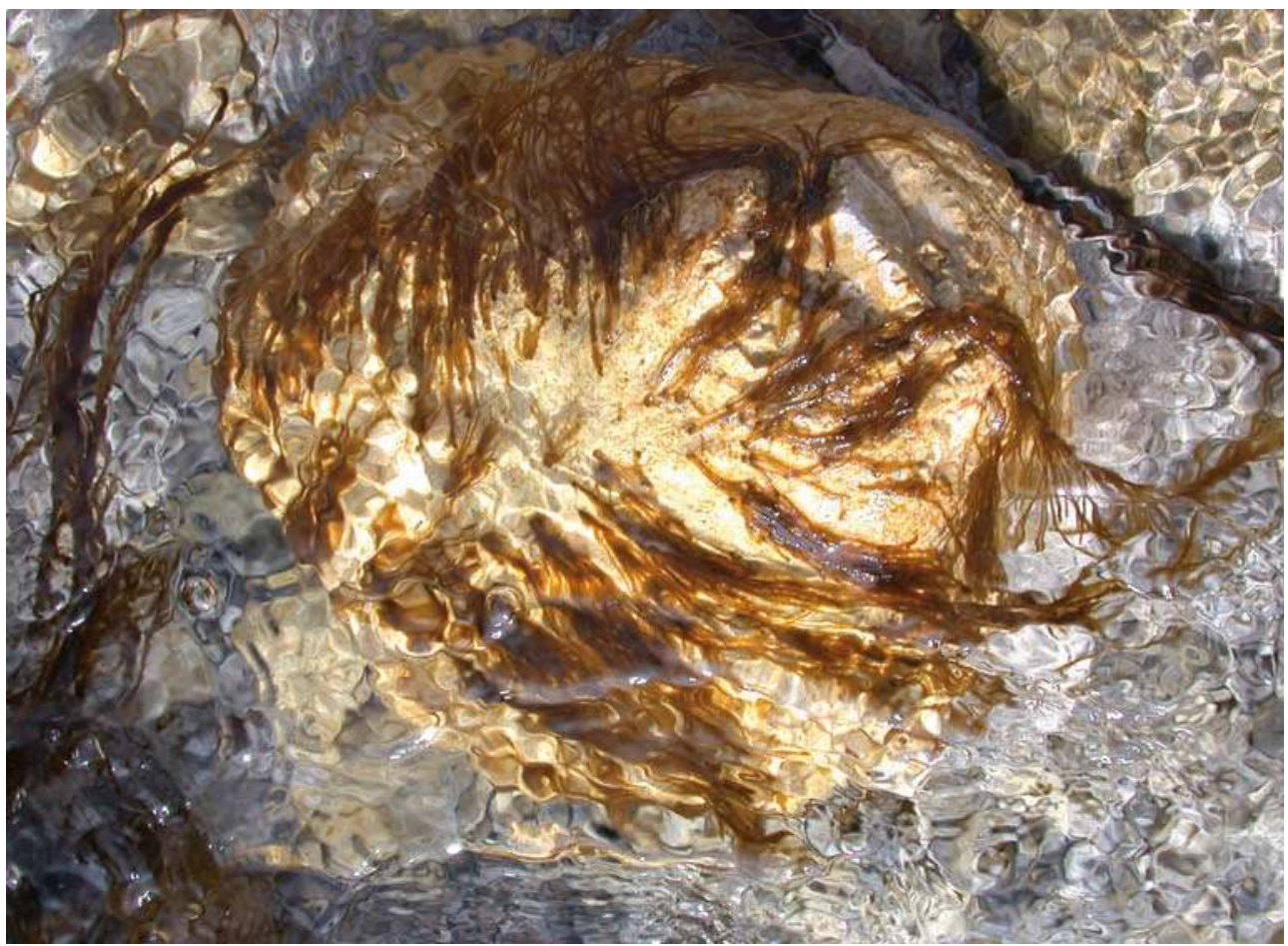

Abb. 1: Die Makroalge Hydrurus foetidus kommt in der Ötztaler Ache vor (Foto: Daniel Erhart) 
Der vor allem im Winter gut zu beobachtende algige Belag, welcher besonders in den geschützten Bereichen der Gewässersohle und am benetzten Ufer zu sehen ist, wird von Kieselalgen (Diatomeen) und einigen wenigen Makroalgen (mit freiem Auge sichtbaren Algenarten) gebildet.

Die Artenzusammensetzung ist mit bisher 35 festgestellten Taxa (Tab. A1 im Anhang) als mäßig artenreich zu beschreiben. Makroskopische Algen leben aufgrund der erodierenden Wirkung der mitgeführten Feststoffe insbesondere im Sommerhalbjahr in einer Kampfzone. Ganzjährig sind in der Ötztaler Ache daher nur wenige Arten vorzufinden, wobei diese ihr Entwicklungshoch jeweils in den Wintermonaten zeigen. In dieser Periode können sie jedoch stellenweise durchaus flächendeckende Ausdehnung erreichen. Unter den Makroalgen in diesem Zusammenhang speziell zu nennen sind die beiden Goldalgenarten Hydrurus foetidus (Abb. 1) und Phaeodermatium rivulare sowie die Blaualge Chamesiphon sp.

\section{Makrozoobenthos}

Unter dem Begriff Makrozoobenthos (Tab. A2 im Anhang) versammeln sich die mit freiem Auge erkennbaren Kleinlebewesen des Gewässergrundes. Dazu gehören die Gruppe

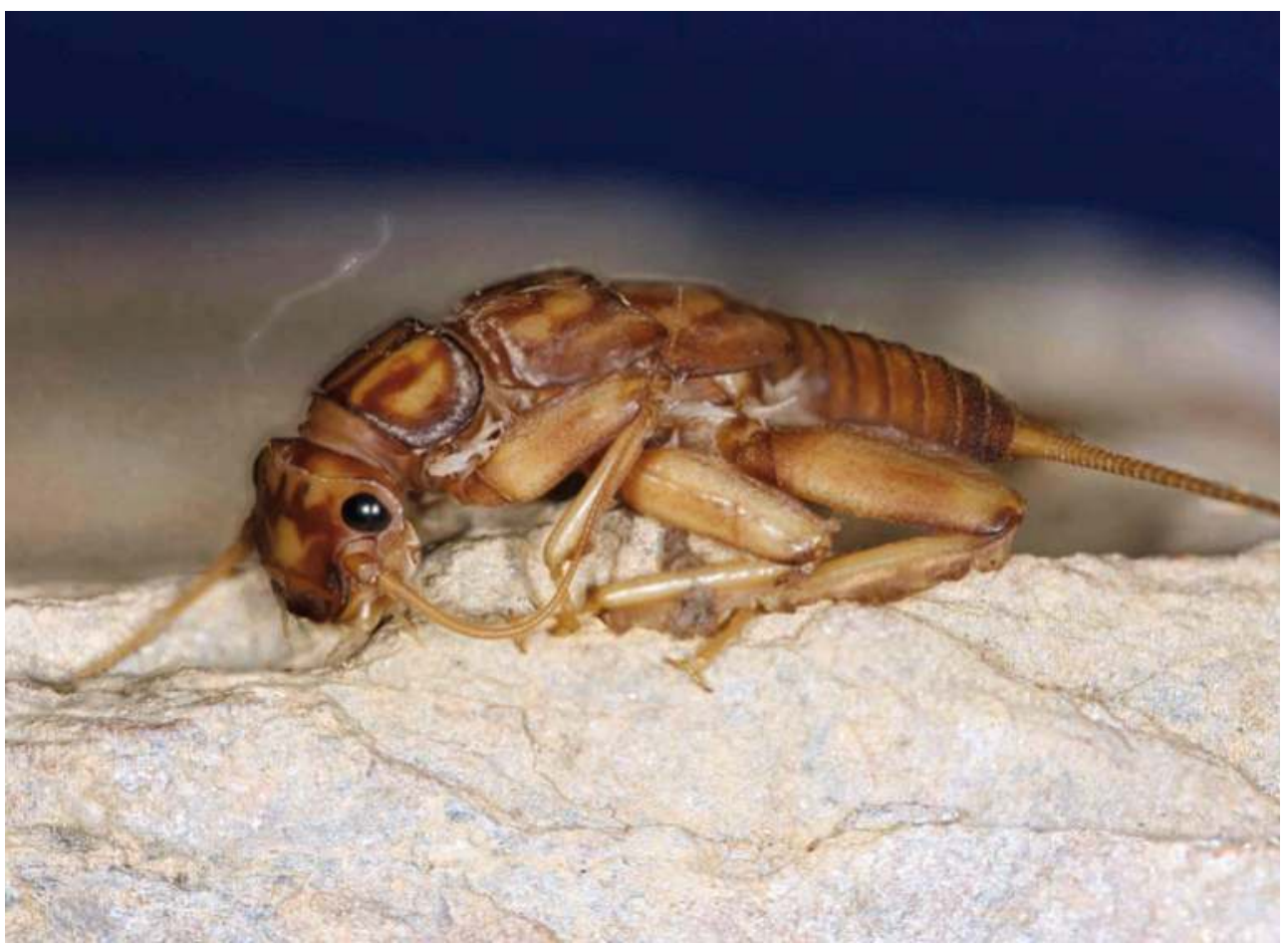

Abb. 2: Steinfliegenlarven der Gattung Perla besiedeln die Ötztaler Ache (Foto: Daniel Erhart) 
der Krebstiere, Muscheln, Schnecken, Strudelwürmer und Egel genauso wie jene der Insekten und Insektenlarven. Manche Insektenarten haben ihre Ei- und Larvalentwicklung auf das nasse Element spezialisiert. Daher finden sich in den Gebirgsbächen häufig die Jugendstadien von verschiedenen Insektengruppen. Manche Insekten haben sich sogar so weit an diesen Lebensraum angepasst, dass sie wie im Fall der Eintagsfliegen nur noch kurze Zeit als Imago (erwachsenes Tier) an Land verbringen.

Aufgrund der rauen Lebensbedingungen überwiegen in der Insektenlebewelt der Ötztaler Ache die Hartsubstratbewohner.

Unter diesen sind vor allem die Steinfliegen (Plecoptera) wie beispielsweise die in Abb. 2 dargestellte Gattung Perla) häufiger vertreten. Mit 7 Arten sind sie die führenden Vertreter der EPT-Taxa (= Ephemeroptera, Eintagsfliegen; Plecoptera, Steinfliegen; Trichoptera, Köcherfliegen). Die Eintagsfliegen sind mit 5 Arten und die Köcherfliegen mit 2 Arten vertreten. Den restlichen Teil der wasserlebenden Insekten bilden vor allem die im Mittel- und Unterlauf häufiger werdenden Mücken- und Fliegenlarven (Diptera). Die Makrozoobenthos-Zönose ist somit je nach Abschnitt der Ache auf 15-25 gleichzeitig vorkommende Arten beschränkt (Daten WGEV 2005). Neuere Auswertungen zeigen für die Ötztaler Ache ein Gesamtartinventar von bis zu 55 Arten. Diese Arten sind teilweise individuenreich vertreten. Es können rund 2.000-4.000, selten bis 10.000 Tiere pro $\mathrm{m}^{2}$ vorgefunden werden. Teilweise sind gletscherbezogene Arten wie z.B. Diamesa steinboecki oder Rhithrogena nivata vorhanden. Ihre Verbreitung konzentriert sich dann aber im Wesentlichen auf die gletschernahen Fließgewässerbereiche.

Bezogen auf die Ernährungstypen dominieren Weidegänger und Detritusfresser vor den räuberischen Arten. Ab dem Mittellauf der Ötztaler Ache kommen auch Filtrierer dazu. Hier muss man jedoch einen Eintrag aus den Seitengewässern der Ache sowie einen passenden Nährstoffeintrag im Nahbereich berücksichtigen.

Die Gewässergüte kann auf Basis der pflanzlichen und tierischen Kleinlebewesen als oligobis mesosaprob (gering belastet) klassifiziert werden (Gewässergüteklasse I-II).

\section{Fische}

Auch die Fische der Ötztaler Ache unterliegen aufgrund der Besonderheit dieses Lebensraumes einem sehr hohen Selektionsdruck. Die Fischlebewelt setzt sich daher vornehmlich aus Bachforellen (Abb. 3), und im Mündungsbereich zum Inn auch aus Äschen und Koppen zusammen. Ergänzt wird diese Fischgesellschaft durch die über Besatz eingebrachten allochthonen (gebietsfremden) Regenbogenforellen und Bachsaiblinge. Zu bemerken ist dabei, dass die Individuendichte der Fische derzeit sehr gering ist. Höhere Biomassen werden meist nur über Besatzmaßnahmen erreicht. Die Bachforelle ist eindeutig der Leitfisch in der Ötztaler Ache und stellt mit über $90 \%$ den größten Anteil am Fischbestand der Ache dar. Die über fischereiliche Bewirtschaftung in die 
Ötztaler Ache eingebrachten Regenbogenforellen und Bachsaiblinge finden zwar als Individuen ihr Auslangen, können jedoch nicht als selbst reproduzierende Fischarten gewertet werden.

Die im Mündungsbereich gelegentlich auftretenden Begleitfische (Äschen und Koppen) sind derzeit weit unterrepräsentiert.

Die eingeschränkte Verbreitung der Koppe könnte auch damit zusammenhängen, dass die Ötztaler Ache bereits nahe der Mündung, beim Weiler Brunau, durch ein künstliches Wanderhindernis vom Inn abgetrennt ist. Im Zuge der Umsetzung der Wasserrahmenrichtlinie ist jedoch damit zu rechnen, dass sich an dieser Situation in naher Zukunft etwas ändern wird. Damit besteht Hoffnung, dass sich der Fischbestand in der Ötztaler Ache auch in den bachaufwärts gelegenen Bereichen wieder verbessert.

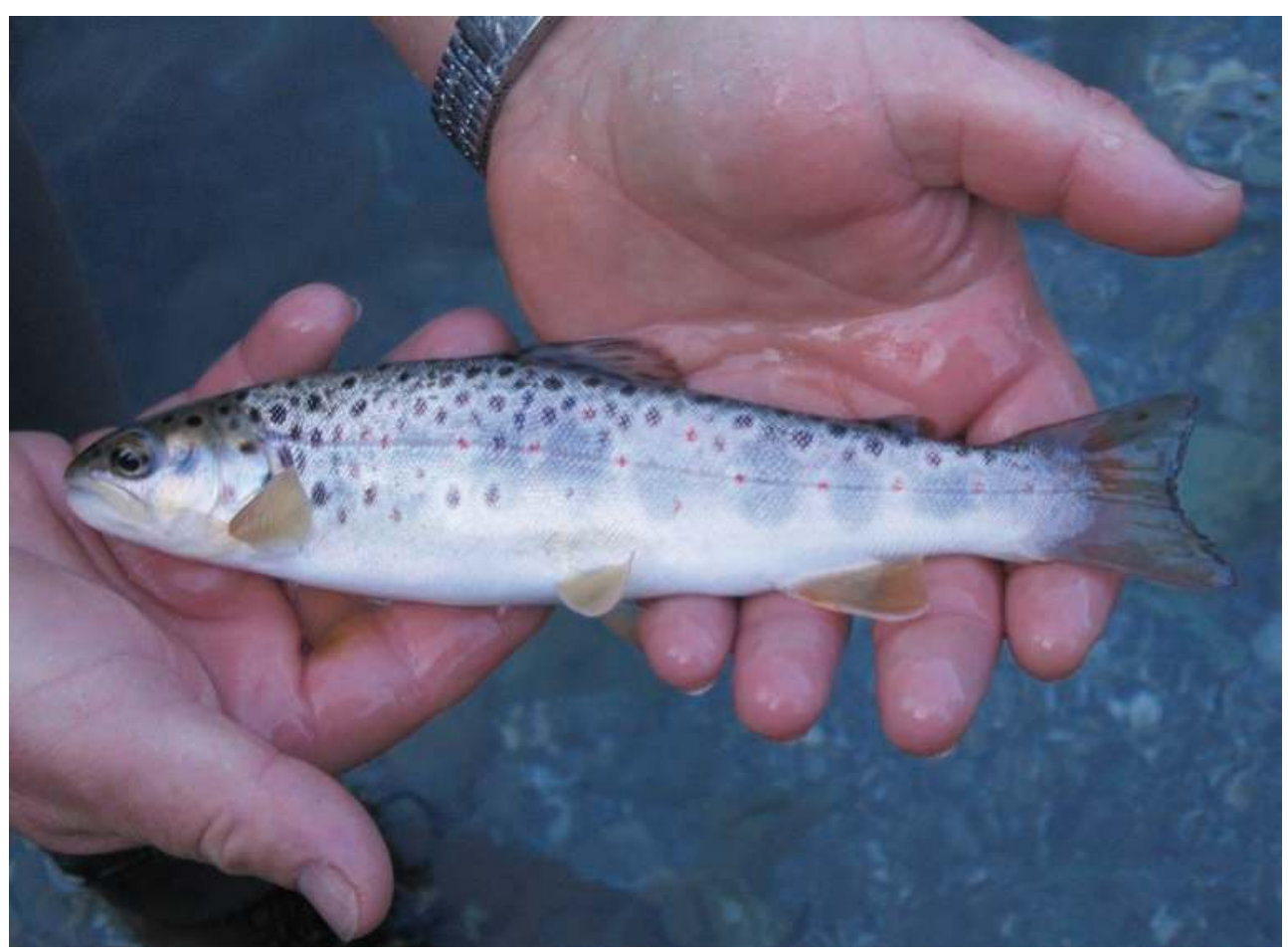

Abb. 3: Ein typischer Bewohner der Ötztaler Ache ist die Bachforelle (Foto: Daniel Erhart) 


\section{Literaturverzeichnis}

GZÜV, BGBl. 479/2006, Bundesministerium für Land- und Forstwirtschaft, Umwelt und Wasserwirtschaft, Sektion VII Abteilung 1/ Nationale Wasserwirtschaft; Amt der Tiroler Landesregierung, Datenquelle: Gewässerzustandsüberwachung in Österreich gemäß GZÜV, BGBl. 479/2006 i.d.g.F.

\section{Verzeichnis des Autors}

Daniel Erhart

Sachgebiet Schutzwasserwirtschaft und

Gewässerökologie

Abteilung Wasserwirtschaft

Amt der Tiroler Landesregierung

Herrengasse 1-3, 6020 Innsbruck

daniel.erhart@tirol.gv.at 


\section{Kapitel 7 I Das Mikroklima waldfreier Standorte in der subalpinen, alpinen und subnivalen Stufe in Obergurgl}

Lea Hartl, Rüdiger Kaufmann, Nikolaus Schallhart, Brigitta Erschbamer

\section{Zusammenfassung}

Im Juli 2000 wurden im Rahmen des ökologischen Langzeit-Messprogramms in Obergurgl neun waldfreie Standorte von der subalpinen (1964 m Meereshöhe) über die alpine bis zur subnivalen Stufe (2793 m Meereshöhe) ausgewählt und mit Datenloggern ausgestattet. Gemessen wurden Lufttemperatur und relative Luftfeuchte in $2 \mathrm{~m}$ Höhe, sowie Bodentemperatur und -feuchte in $10 \mathrm{~cm}$ Tiefe. Das absolute Minimum der Lufttemperatur betrug $-30,0^{\circ} \mathrm{C}$ am höchstgelegenen Standort. Das absolute Minimum der Bodentemperatur wurde im Bereich der Gurgler Heide auf $2255 \mathrm{~m}$ Meereshöhe gemessen $\left(-11,2{ }^{\circ} \mathrm{C}\right)$.

Dieser Standort wies auch die kürzeste Schneedeckendauer auf. Während der 11-jährigen Messperiode wurden die neun Standorte in Obergurgl signifikant früher schneefrei; sie aperten im Schnitt um 1,2 Tage pro Jahr früher aus.

\section{Abstract}

In July 2000, nine treeless monitoring sites were established and equipped with data loggers in the vicinity of Obergurgl from the subalpine zone (1964 m a.s.l.) to the alpine and the subnival zone (2793 $\mathrm{m}$ a.s.l.) as part of the ecological long-term monitoring project. Measured parameters were air temperature and relative air humidity $2 \mathrm{~m}$ above the ground as well as soil temperature and moisture in $10 \mathrm{~cm}$ depth. The absolute minimum of the air temperature amounted to $-30.0{ }^{\circ} \mathrm{C}$ at the highest altitude. The absolute minimum of the soil temperature was monitored at the Gurgler Heide at $2255 \mathrm{~m}$ a.s.l. $\left(-11.2{ }^{\circ} \mathrm{C}\right)$. The lowest number of days with snow cover was also found at this site. During the timeframe of 11 years the snow melt date in spring has significantly shifted forwards by approximately 1.2 days per year. 


\section{Einleitung}

Die Atmosphäre der Erde ist ein hochkomplexes, dynamisches System, in dem unzählige verschiedene Prozesse gleichzeitig stattfinden. Diese Prozesse unterscheiden sich in ihrer räumlichen und zeitlichen Ausdehnung sehr stark, so reicht etwa das Spektrum der atmosphärischen Raumskalen von millimetergroßen Dissipationswirbeln bis hin zu Phänomenen von der Größenordnung des Erdumfangs (Kuttler 2009). Gebräuchlich ist eine Untergliederung in makro-, meso- und mikroskalige Prozesse, wobei sich die Mikro-Skala auf eine räumliche Ausdehnung von wenigen Millimetern bis zu circa 2 Kilometern bezieht (Kraus 2004). In der Ökologie spricht man von „Mikroklima“, wenn es um Messungen von der Bodenoberfläche bis zu einer Höhe von 2 Metern geht (Cernusca 1976). Im Gebirge schwanken die klimatologischen Bedingungen aufgrund topographischer Gegebenheiten kleinräumig oft sehr stark (Fischer 2010, Scherrer \& Körner 2010), daher ist hier ein gutes Verständnis des Mikroklimas für viele Forschungsbereiche von besonders großer Bedeutung. So ist beispielsweise bei Sukzessionsstudien in Gletschervorfeldern und generell bei ökologischen Untersuchungen im Gebirge (Erschbamer 2001, Kaufmann 2001, Koch \& Erschbamer 2010, Erschbamer \& Mayer 2011) eine möglichst genaue Kenntnis der lokal gegebenen klimatologischen Parameter essentiell. Insgesamt bestimmen Exposition, Hangneigung und Horizontabschattung die Lufttemperatur, die Schneeverteilung und damit die Vegetation. Letztere Faktoren wiederum verändern die bodennahen Feuchtigkeitsverhältnisse und die Albedo der Oberfläche. So ergibt sich ein komplexes meteorologisches System mit vielen unterschiedlichen Aspekten.

In Obergurgl betreibt die Zentralanstalt für Meteorologie und Geodynamik (ZAMG) seit 1953 im Bereich des Universitätszentrums Obergurgl eine Klimastation ${ }^{1}$, die eine wertvolle Datenbasis für verschiedene wissenschaftliche Studien liefert. Seit 1999 wird hier ein teilautomatisches Wettererfassungssystem (TAWES) betrieben. Die Daten dieser Station werden im Kapitel 1 von Kuhn et al. in diesem Band vorgestellt.

In den 1950er Jahren führten Aulitzky und Turner im Raum Obergurgl zahlreiche mikroklimatische Untersuchungen durch (Aulitzky 1954, 1955a, 1955b; Turner 1958). Auch im Zuge von glaziologischen Studien wurden Überlegungen zum Kleinklima angestellt (Hoinkes \& Rudolph 1961). Die Bedeutung der Bodentemperatur für das Pflanzenwachstum erkannte bereits Aulitzky (1961). Anhand von Bodentemperaturmessungen über und unter der Waldgrenze zeigte er „kleinstandörtliche“ Unterschiede und die Abhängigkeit von der Schneebedeckung auf (Aulitzky 1961, 1962a, 1962b). Im Rahmen des Man and Biosphere-Projekts (MAB; Moser 1975, Patzelt 1987) wurden in den 1970er Jahren detaillierte Untersuchungen der Energiebilanz auf der Hohen Mut und in

1 Die Klimastation der ZAMG wurde von 1953 bis 2011 von der Alpinen Forschungsstelle Obergurgl betreut. 
einer Wiese bei Obergurgl durchgeführt (Rott 1979, 1987; Staudinger 1987). Dieses Messprogramm endete jedoch mit der Beendigung des MAB-Projekts.

Die Idee eines ökologischen Langzeit-Messprogrammes in Obergurgl wurde ab Mitte der 1990er Jahren vorangetrieben und es entstanden Mikroklimastationen auf der 1923er und 1971er Moräne des RotmoosfernerGletschervorfeldes. Obergurgl wurde als einer der alpinen Standorte für das internationale Long-Term Ecosystem Research Programme (LTER, http://131.130.57.239/LTER_cms/ index.php) nominiert. Das Gebiet zählt heute zur österreichischen LTER/LTSER-Plattform Tyrolean Alps (LTSER = Long-Term Socioeconomic and Ecosystem Research).

Im Jahr 2000 bot das ökologische LangzeitMonitoring-Projekt in Obergurgl (Kaufmann 2005) die Möglichkeit, das Messprogramm auszubauen. Von der subalpinen bis zur subnivalen Stufe wurden repräsentative, baumfreie Pflanzenbestände ausgewählt, in denen Vegetation und Fauna über längere Zeiträume hinweg beobachtet werden sollten. Ziel war es, in den ausgewählten Flächen kurzfristige Fluktuationen, aber auch tiefer greifende ökologische Veränderungen als Folge von Nutzungs- und Klimaänderung aufzudecken (Kaufmann 2005, Mayer et al. 2009). An allen Monitoring-Standorten wurden Datenlogger installiert, um Luft- und Bodentemperaturen sowie Luft- und Bodenfeuchtigkeit zu messen. Damit sollte eine mikroklimatische Charakterisierung der Standorte über die Jahre hinweg möglich werden.
Ziel der vorliegenden Arbeit ist es, die Mikroklima-Daten dieser Messreihen zu präsentieren und Unterschiede zwischen den Standorten aufzuzeigen. Anhand der Bodentemperaturen wurden Einschnei- und Ausaperungsdatum und in der Folge die Anzahl der Tage mit geschlossener Schneedecke an den einzelnen Standorten ermittelt. Auf Grund des Höhengradienten und der unterschiedlichen Vegetation an den einzelnen Standorten wurden große Unterschiede erwartet.

\section{Untersuchungsgebiet}

Das Untersuchungsgebiet mit insgesamt neun Standorten erstreckt sich von 1964 m bis $2793 \mathrm{~m}$ Meereshöhe (Abb. 1, Tab. 1). Die Standorte umfassen die für das innere Ötztal typischen Höhenstufen von der subalpinen zur alpinen und subnivalen Stufe. Die potentielle Waldgrenze ist in Obergurgl bei 2300 $\mathrm{m}$ Meereshöhe anzusetzen, die aktuelle Waldgrenze liegt bei rund $1900-2200 \mathrm{~m}$. Es wurden ausschließlich aktuell waldfreie Flächen ausgewählt. In der subalpinen Stufe wurden drei Standorte eingerichtet, die von einer zwergstrauchreichen Weideausschlussfläche (Standort 1, Wuchshöhe ca. 27 cm; Abb. 2) über eine ca. $15 \mathrm{~cm}$ hohe Zwergstrauchheide (Standort 2, Abb. 2) knapp oberhalb der Ortschaft Obergurgl zu einer niederliegenden, ca. $8 \mathrm{~cm}$ hohen Flechtenheide (Standort 3, Abb. 2) im Bereich der Gurgler Heide reichen. Die Standorte 4a (Abb. 2), 5, 7 und 


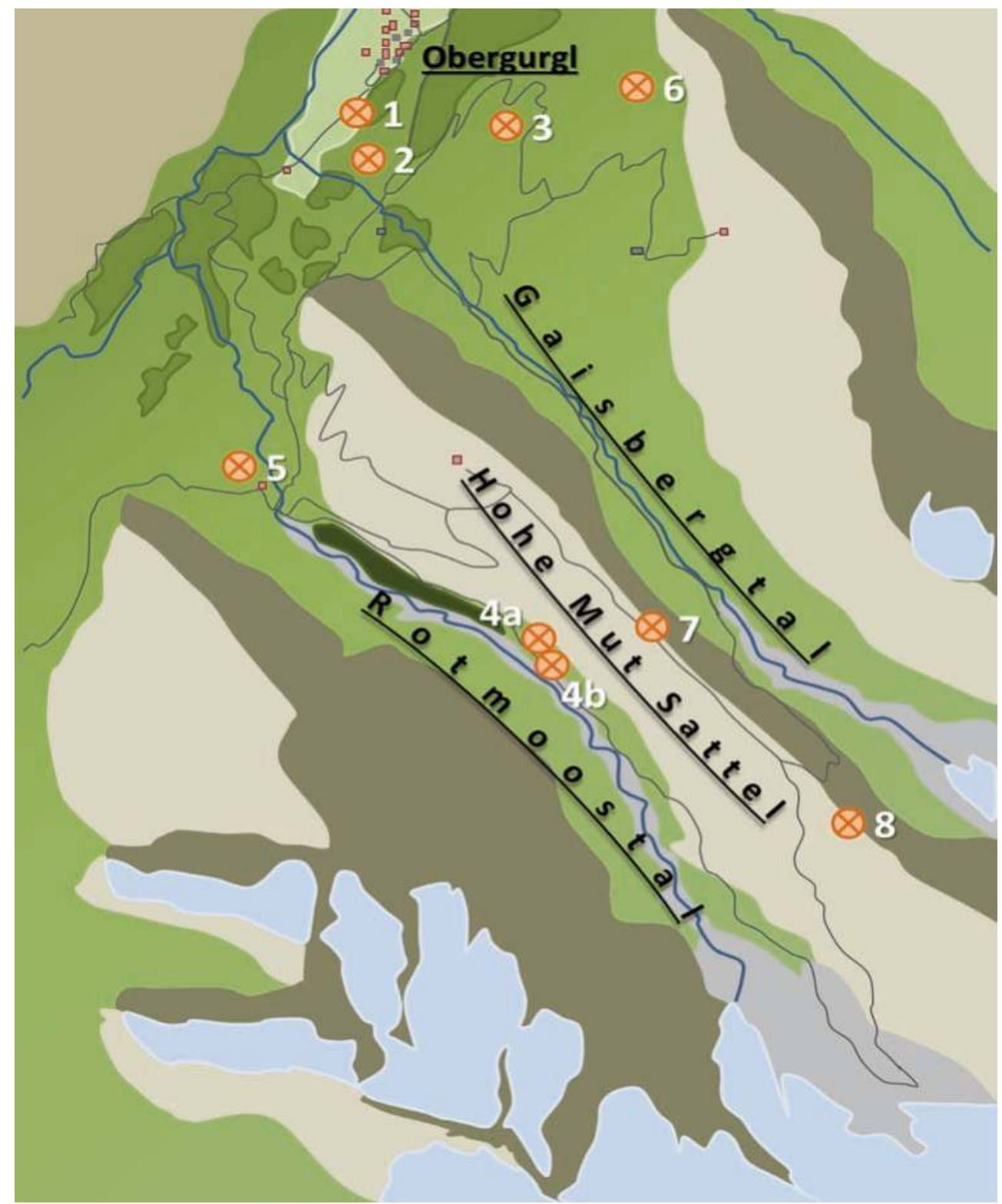

Abb. 1: Schematische Karte des Untersuchungsgebietes und Position der Standorte 1-8 
Tab. 1: Beschreibung der Standorte des ökologischen Monitoring-Projektes in Obergurgl, an denen seit dem Jahr 2000 mikroklimatische Messungen durchgeführt werden (Liste der dominanten Arten: Roland Mayer)

\begin{tabular}{|c|c|c|c|c|c|}
\hline Standort & Lokalität & Meereshöhe & Exposition & Vegetationstyp & Dominante Arten \\
\hline 1 & $\begin{array}{l}\text { Obergurgl } \\
\text { Weideausschluss }\end{array}$ & $1.964 \mathrm{~m}$ & NNW & $\begin{array}{l}\text { zwergstrauch- } \\
\text { reicher Rasen }\end{array}$ & $\begin{array}{l}\text { Agrostis capillaris, Nardus } \\
\text { stricta, Anthoxanthum } \\
\text { alpinum, Mutellina } \\
\text { adonidifolia, Potentilla } \\
\text { aurea }\end{array}$ \\
\hline 2 & $\begin{array}{l}\text { Obergurgl } \\
\text { Rumsoppen }\end{array}$ & $2.039 \mathrm{~m}$ & NW & $\begin{array}{l}\text { Vaccinium- } \\
\text { Zwergstrauch- } \\
\text { heide }\end{array}$ & $\begin{array}{l}\text { Vaccinium vitis- } \\
\text { idaea, V. myrtillus, } V . \\
\text { gaultherioides, Empetrum } \\
\text { hermaphroditum, Calluna } \\
\text { vulgaris }\end{array}$ \\
\hline 3 & Gurgler Heide & $2.255 \mathrm{~m}$ & NW & $\begin{array}{l}\text { Loiseleuria- } \\
\text { Flechtenheide }\end{array}$ & $\begin{array}{l}\text { Loiseleuria procumbens, } \\
\text { Cetraria islandica, Cladonia } \\
\text { arbuscula, Vaccinium } \\
\text { gaultherioides }\end{array}$ \\
\hline $4 a$ & Rotmoostal & $2.295 \mathrm{~m}$ & SW & alpiner Rasen & $\begin{array}{l}\text { Nardus stricta, Carex } \\
\text { sempervirens, Potentilla } \\
\text { aurea, Homogyne alpina, } \\
\text { Deschampsia cespitosa }\end{array}$ \\
\hline $4 \mathrm{~b}$ & $\begin{array}{l}\text { Gletschervorfeld } \\
\text { 1858er Moräne }\end{array}$ & $2.291 \mathrm{~m}$ & SW & Initialrasen & $\begin{array}{l}\text { Kobresia myosuroides, Poa } \\
\text { alpina, Trifolium pallescens, } \\
\text { Anthyllis vulneraria ssp. } \\
\text { alpicola }\end{array}$ \\
\hline 5 & Schönwieskopf & $2.314 \mathrm{~m}$ & $S$ & alpiner Rasen & $\begin{array}{l}\text { Nardus stricta, Mutellina } \\
\text { adonidifolia, Scorzoneroides } \\
\text { helvetica, Geum montanum }\end{array}$ \\
\hline 6 & $\begin{array}{l}\text { Skipiste } \\
\text { Festkogel }\end{array}$ & $2.374 \mathrm{~m}$ & NW & Skipistenrasen & $\begin{array}{l}\text { Festuca rubra agg., Poa } \\
\text { alpina, Polytrichum } \\
\text { juniperinum, Gnaphalium } \\
\text { supinum }\end{array}$ \\
\hline 7 & $\begin{array}{l}\text { Hohe Mut } \\
\text { Bärenhoppet }\end{array}$ & $2.593 \mathrm{~m}$ & SW & alpiner Rasen & $\begin{array}{l}\text { Carex curvula, Avenula } \\
\text { versicolor, Scorzoneroides } \\
\text { helvetica, Phyteuma } \\
\text { hemisphaericum }\end{array}$ \\
\hline 8 & Kirchenkogel & $2.793 \mathrm{~m}$ & SSW & alpiner Rasen & $\begin{array}{l}\text { Festuca pumila, Kobresia } \\
\text { myosuroides, Campanula } \\
\text { scheuchzeri, Oxytropis } \\
\text { lapponica }\end{array}$ \\
\hline
\end{tabular}




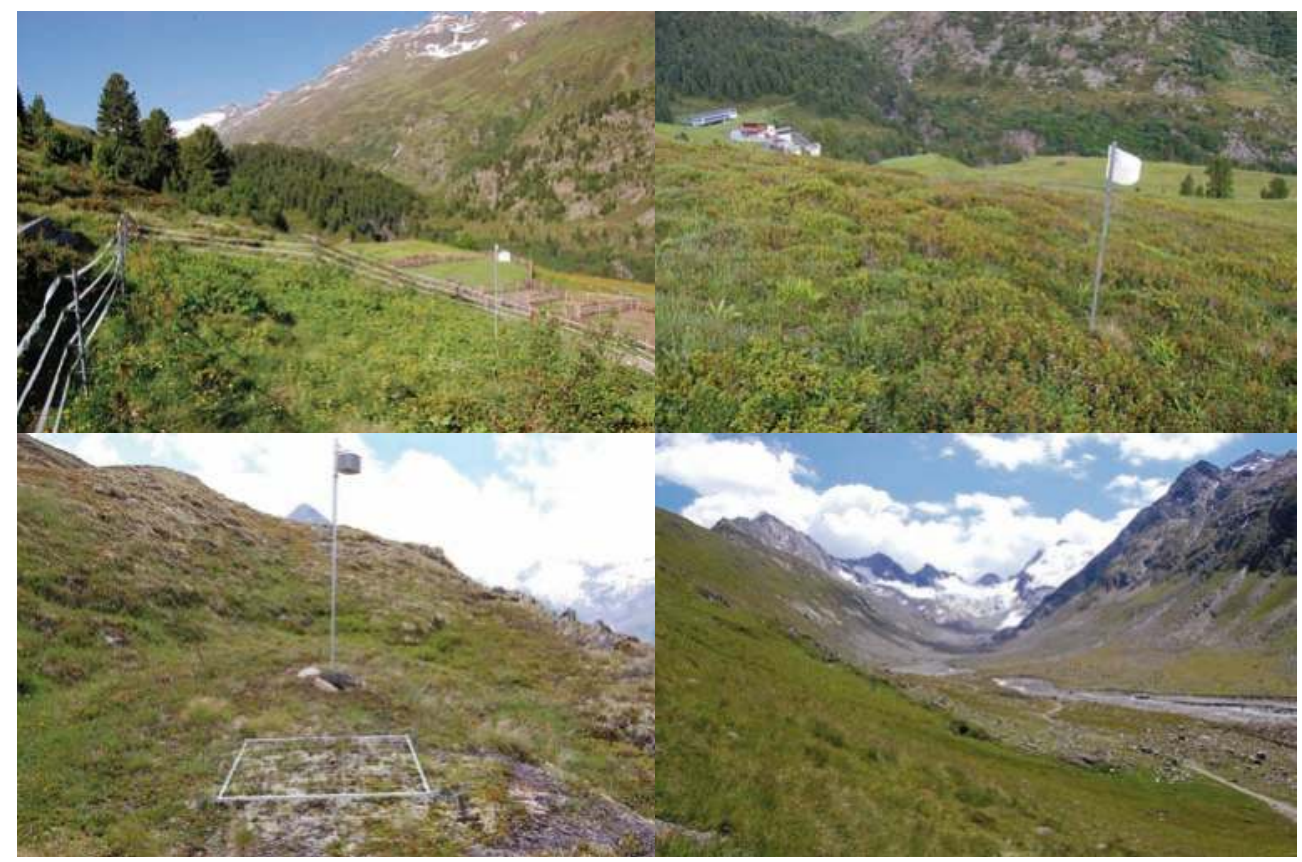

Abb. 2: Fotos der Standorte: Standort 1, zwergstrauchreiche Weidefläche in Obergurgl (oben links); Standort 2, Zwergstrauchheide Rumsoppen (oben rechts); Standort 3, Gurgler Heide (Flechtenheide, unten links); Standort 4a, alpiner Rasen im Rotmoostal (unten rechts) (Fotos: Roland Mayer)

8 (Abb. 3) repräsentieren die alpinen Rasen, wobei die ersten beiden (4a - Rotmoostal, 5 - Schönwieskopf) noch im potentiellen Waldgrenzökoton liegen, aber in historischer Zeit nie bewaldet waren. Standort 7 verdeutlicht den typischen Krummseggenrasen der alpinen Stufe über saurem Ausgangsgestein und Standort 8 die Grenze der geschlossenen alpinen Rasen am Abhang des Kirchenkogels. Die Standorte 4b (1858er Moräne im Rotmoostal, Abb. 3) und 6 (Skipiste Festkogel, Abb. 3) können als Sonderstandorte gewertet werden, da beide noch keine geschlossene Vegetation aufweisen. Standort 4b unterliegt der Primärsukzession und weist bereits einen Initialrasen mit Kobresia myosuroides auf ( $\mathrm{Nagl}$
\& Erschbamer 2010). Standort 6 ist eine kontinuierlich gestörte Skipistenfläche, die durch Pistenpräparierung, aber auch jährliche Ansaat und Düngung beeinflusst wird (Mayer \& Erschbamer 2009).

\section{Methodik}

Zur Messung der Lufttemperatur und -feuchte wurden HOBO Pro Datenlogger (Onset Computer Corporation Inc., Pocasset, MA) mit Strahlungsschutz an $2 \mathrm{~m}$ hohen Masten platziert. Die Messgenauigkeit der Sensoren 


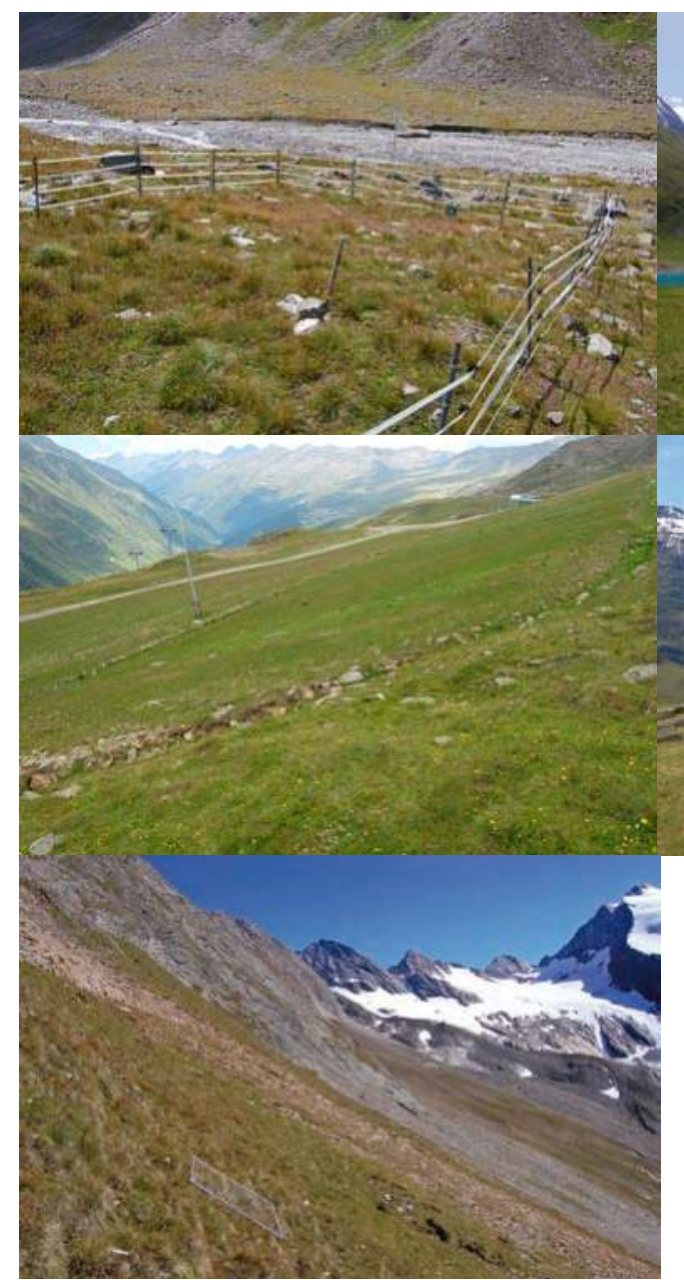

beträgt bei der Temperatur $\pm 0,25^{\circ} \mathrm{C}$, bei der relativen Luftfeuchte $\pm 3 \%$. Eichungen wurden nicht durchgeführt, da die Messgenauigkeit für das ökologische Langzeit-Monitoring als ausreichend betrachtet wurde. Am Standort 6 hängt der Datenlogger an einer Liftstütze, am Standort 7 an der Forscherhütte auf der Kuppe der Hohen Mut (Bärenhoppet). Der Sensor für Bodentemperatur und -feuchtigkeit befindet sich innerhalb des
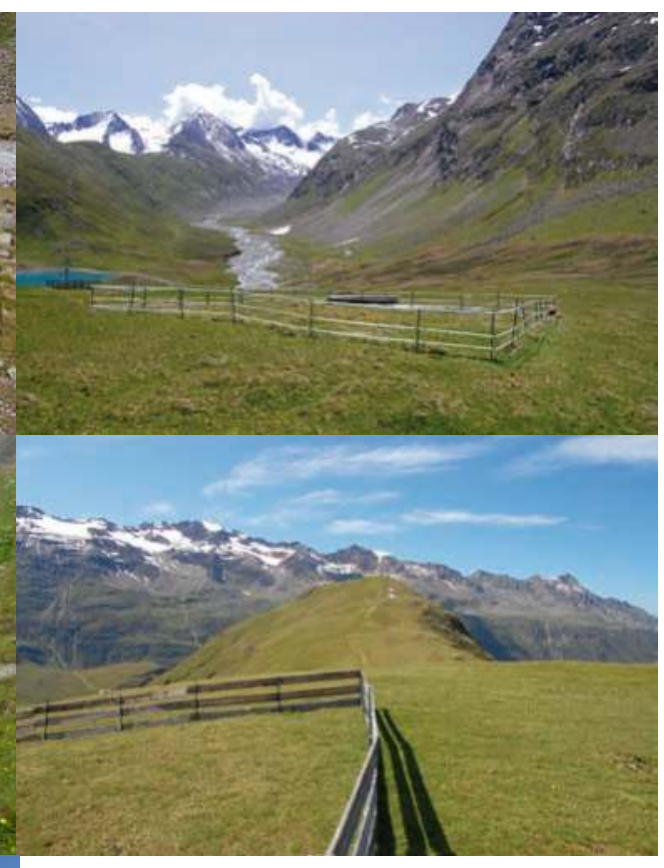

Abb. 3: Fotos der Standorte: Standort 4b, Initialrasen auf der 1858er Moräne im Gletschervorfeld des Rotmoosferners (oben links); Standort 5, alpiner Rasen am Schönwieskopf (oben rechts); Standort 6, Skipiste Festkogel (unten links); Standort 7, Krummseggenrasen auf der Hohen Mut (unten rechts); Standort 8, Rasen am Abhang des Kirchenkogels (ganz unten links) (Fotos: Roland Mayer)

Weidezaunes (Abb. 3). Für den Standort 4a fehlen die Lufttemperatur-Messungen, da der Mast mit dem Datenlogger bereits im ersten Jahr einer Lawine zum Opfer fiel. Für diesen Standort existieren daher nur die Bodentemperaturen. Als Ersatz wurde ab 2001 auf der 1858er Moräne des Rotmoosferner Gletschervorfeldes ein Mast für die Messungen in $2 \mathrm{~m}$ Höhe aufgestellt (Standort 4b, Abb. 3). Hier wurden erst ab 2010 Bodentemperaturen 
gemessen, die auf Grund der geringen Zeitspanne in dieser Arbeit nicht wiedergegeben werden.

Für die Bodentemperatur und -feuchte kamen HOBO Datenlogger mit Temperaturfühlern und kapazitiven Feuchtesensoren (Eigenentwicklung, Cyclobios, Innsbruck) in 10 cm Bodentiefe zum Einsatz. Die Messgenauigkeit des Temperaturfühlers beträgt hier $\pm 0,5^{\circ} \mathrm{C}$. Das Messintervall betrug in der Luft 30 Minuten, im Boden während der ersten Hälfte der Messperiode 2 Stunden, dann 2,5 Stunden. Die Bodenwerte wurden während der Datenaufbereitung durch Spline-Interpolation einheitlich auf ein 2 Stunden-Intervall gebracht. Die Messreihen aller Logger wiesen auf Grund verschiedener technischer Probleme einige Datenlücken auf. Diese wurden im Folgenden nicht interpoliert, sondern von der Auswertung ausgeschlossen. Die Bodenfeuchte-Daten werden hier nicht dargestellt, da es sich um unkalibrierte Sensorsignale in Volt handelt, die zwar die Dynamik der Bodenfeuchte des Messpunktes wiedergeben, aber keinen Vergleich des Wassergehaltes zwischen den Standorten erlauben.

Für die Periode 2000 - 2011 wurden Monatsmittel und Monatsextremwerte der Luft- und Bodentemperatur, Mittelwerte der Luft- und Bodenfeuchte, sowie die durchschnittliche Anzahl frostfreier Tage pro Monat berechnet. Ein Tag wurde als frostfrei gewertet, wenn keine Werte unter $0{ }^{\circ} \mathrm{C}$ gemessen wurden (= Thawing Degree Days, TDD; Molau \& Mølgaard 1996).

Um mögliche standortspezifische Besonderheiten besser sichtbar zu machen, wurden über die gesamte Messperiode gemittelte Tagesgänge der Lufttemperatur, der Luftfeuchte und der Bodentemperatur berechnet. Die Temperaturabnahme mit der Höhe wurde für die Monatsmittelwerte der Lufttemperatur mit Hilfe von einfachen Regressionen im Programm EXCEL berechnet.

Die statistische Auswertung der Daten erfolgte mit den Programmen SPSS 18.0 und STATISTICA 10. Mit Hilfe von Mittelwertvergleichen wurde getestet, ob sich die Standorte hinsichtlich Monatsmittel und Temperaturextreme unterscheiden. Verwendet wurden dazu die Werte für die Vegetationszeiten der Messperiode (Juni bis September).

Ausgehend von der Annahme, dass eine genügend mächtige Schneedecke den Boden so isoliert, dass sich eine weitgehend konstante Bodentemperatur im Bereich $0{ }^{\circ} \mathrm{C}$ bis $-0,5^{\circ} \mathrm{C}$ einstellt, wurde untersucht, an welchen Tagen an den einzelnen Standorten eine Isolation des Bodens durch Schneebedeckung vorliegt. Die Bodentemperatur wurde mit einem gleitenden, zentrierten Mittel über 24 Stunden geglättet. Änderte sich die geglättete Bodentemperatur innerhalb von drei Messintervallen (6 Stunden) nicht, wurde angenommen, dass Schnee den Einfluss der Lufttemperatur dämpfte und dass eine geschlossene Schneedecke vorlag. Um gemeinsame Trends über die Jahre für alle Standorte in den so ermittelten Schneebedeckungsdaten zu untersuchen, wurde eine Kovarianzanalyse für die Variablen Ausaperungsdatum und Schneedeckendauer durchgeführt. Als Kovariable wurden die Jahre (2001-2011) definiert, als zufällige Effekte die Standorte. 


\section{Ergebnisse}

\section{Lufttemperatur}

Das insgesamt wärmste Jahr war 2008 mit einer Jahresmitteltemperatur von $1,2{ }^{\circ} \mathrm{C}$ (Mittel über alle Standorte), gefolgt von 2007 mit $1,1{ }^{\circ} \mathrm{C}$. Am kältesten war es 2010 mit einem Jahresmittel von nur $-0,8{ }^{\circ} \mathrm{C}$. Der kälteste Monat der Messperiode war der Februar 2005 mit $-12,4^{\circ} \mathrm{C}$.

Die Jahresmittel der Lufttemperatur, berechnet über die gesamte Messperiode, variieren zwischen $2,5{ }^{\circ} \mathrm{C}$ (Standort 1) und $-1,9{ }^{\circ} \mathrm{C}$ (Standort 8, Tab. 2). Betrachtet man die Monatsmittel (Abb. 4; Tab. A1 im An- hang), so zeigt sich der Höhengradient mit den höchsten Temperaturen am Standort 1 und den niedrigsten am Standort 8. Regressionen verdeutlichen die Temperaturabnahme mit der Höhe: im Jänner beträgt die Abnahme $0,4{ }^{\circ} \mathrm{C}$ pro 100 Höhenmeter (Abb. 5). Die Monate Oktober bis Dezember sind gleichläufig. Der steilste Gradient ergibt sich für Mai (rund $0,7^{\circ} \mathrm{C}$ pro 100 Höhenmeter, Abb. 5). Mehr als $0,6{ }^{\circ} \mathrm{C}$ pro 100 Höhenmeter sind es auch für die Monate Juni und Juli. In den restlichen Monaten beträgt die Temperaturabnahme $0,5-0,6{ }^{\circ} \mathrm{C}$ pro 100 Höhenmeter.

Vergleicht man die Monatsmittel der Vegetationszeit (Juni-September), sind Standort 1 und Standort 8 signifikant verschieden $(p=0,024)$. Zwischen Standort 2 und Stand-

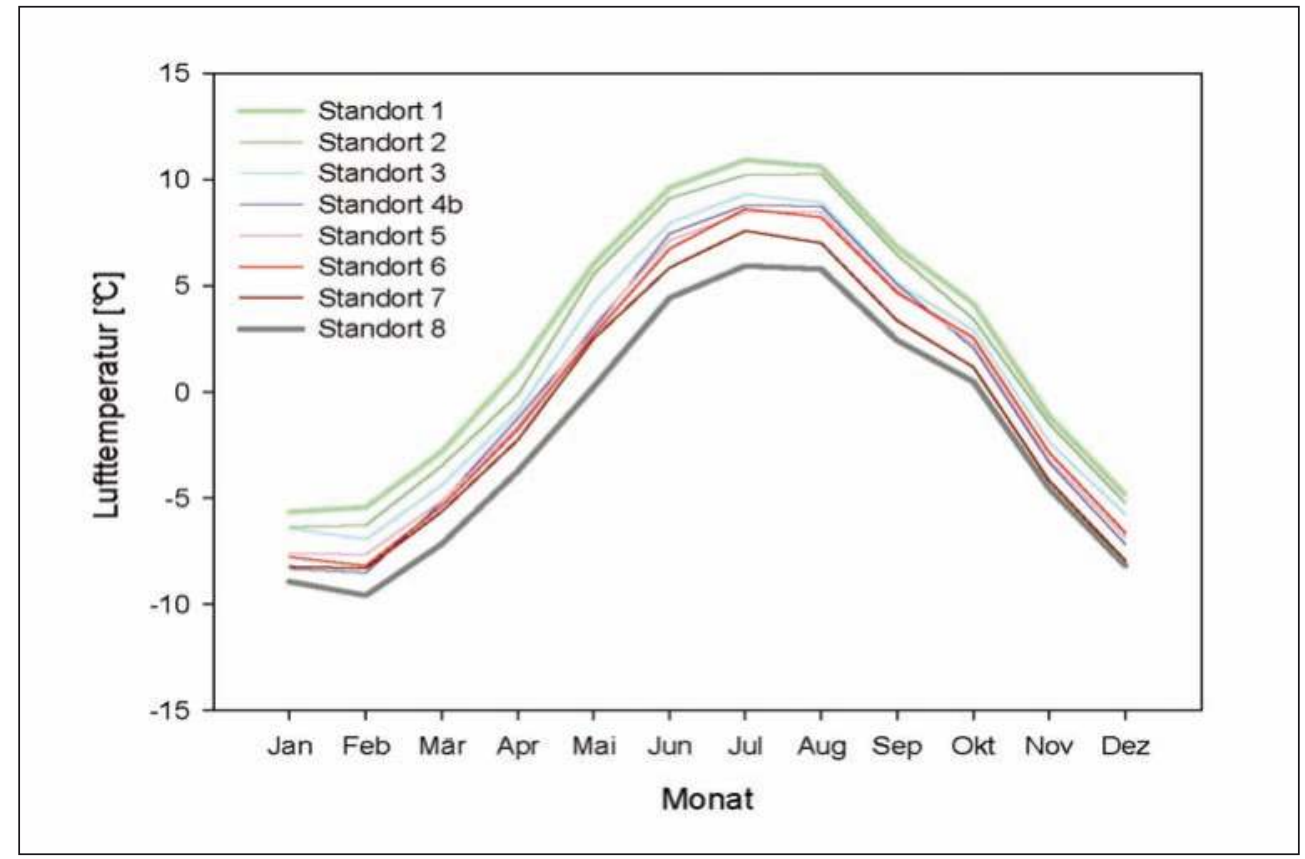

Abb. 4: Monatsmittel der Lufttemperatur, gemittelt über den Untersuchungszeitraum 2000-2011, an den einzelnen Standorten 


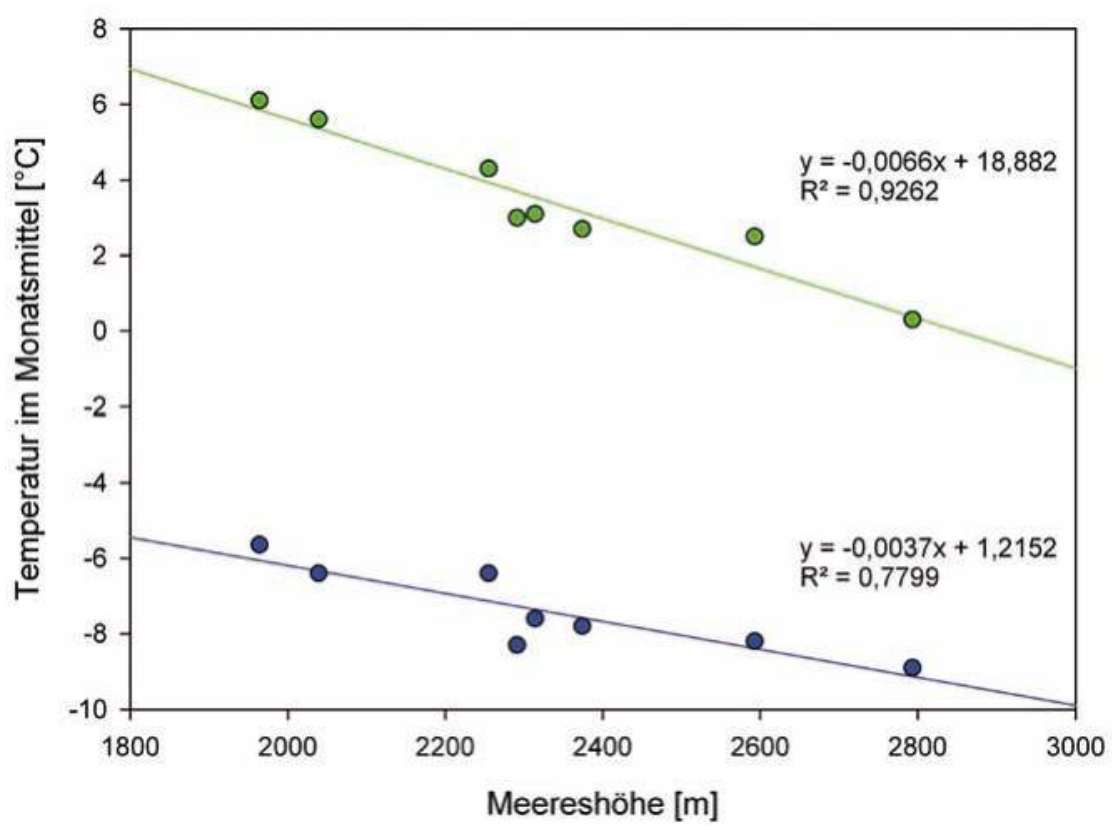

Abb. 5: Regressionen der Lufttemperatur (Monatsmittel) an den einzelnen Standorten für die Monate Mai (grün) und Jänner (blau) und die entsprechenden Regressionslinien

Tab. 2: Jahresmittelwerte der Luft- (a) und Bodentemperatur (b), absolute Maxima und Minima für den Untersuchungszeitraum 2000-2011 an den verschiedenen Standorten und Datum, an dem der jeweilige Extremwert gemessen wurde

\begin{tabular}{lccccc}
\hline $\begin{array}{l}\text { a) Lufttemperatur } \\
\text { Standort }\end{array}$ & Mittelwert & Maximum & Datum Maximum & Minimum & Datum Minimum \\
\hline 1 & 2,5 & 24,6 & 23.07 .09 & $-23,0$ & 28.02 .05 \\
2 & 1,8 & 29,3 & 21.07 .10 & $-23,7$ & 28.02 .05 \\
3 & 1,0 & 24 & 15.07 .05 & $-24,5$ & 28.02 .05 \\
$4 \mathrm{~b}$ & 0,1 & 21,9 & 05.08 .03 & $-29,1$ & 28.02 .05 \\
5 & 0,2 & 23,6 & 25.07 .06 & $-26,0$ & 28.02 .05 \\
6 & 0,1 & 21 & 04.08 .03 & $-25,9$ & 28.02 .05 \\
7 & $-0,7$ & 23,8 & 15.07 .05 & $-25,7$ & 18.12 .09 \\
8 & $-1,9$ & 18,9 & 08.07 .02 & $-30,0$ & 28.02 .05 \\
\hline
\end{tabular}




\begin{tabular}{|c|c|c|c|c|c|}
\hline \multicolumn{6}{|c|}{ b) Bodentemperatur } \\
\hline Standort & Mittelwert & Maximum & Datum Maximum & Minimum & Datum Minimum \\
\hline 1 & 3,8 & 16,2 & 01.08 .01 & $-0,7$ & 24.12 .04 \\
\hline 2 & 3,4 & 14,2 & 05.08 .03 & $-0,7$ & 02.03 .03 \\
\hline 3 & 2,0 & 14,2 & 16.07 .10 & $-11,2$ & 02.01 .08 \\
\hline $4 a$ & 4,1 & 16,3 & 27.07 .06 & $-1,2$ & 23.01 .02 \\
\hline 5 & 4,2 & 18,0 & 01.08 .01 & $-0,7$ & 29.01 .06 \\
\hline 6 & 2,6 & 18,3 & 16.07 .10 & $-4,9$ & 17.01 .02 \\
\hline 7 & 2,4 & 14,5 & 01.08 .01 & $-3,9$ & 15.02 .06 \\
\hline 8 & 2,8 & 17,5 & 05.08 .03 & $-10,1$ & 15.02 .09 \\
\hline
\end{tabular}

ort 8 kann ein schwach signifikanter Unterschied festgestellt werden ( $p=0,057)$. Hinsichtlich der Monatsmaxima (Tab. A1 im Anhang) fällt der Standort 8 eindeutig mit signifikant niedrigeren Werten während der Vegetationszeit auf im Vergleich zu den Standorten $1,2,3$ und 7 ( $\mathrm{p}<0,05)$.

Abb. 6 zeigt den über die Messperiode gemittelten, halbstündlich berechneten Tagesgang der Lufttemperatur an den einzelnen Standorten. Im Mittel beträgt die Tagesamplitude $4{ }^{\circ} \mathrm{C}$; die größte Amplitude hat Standort 1 mit $5,5^{\circ} \mathrm{C}$, die geringste Standort 8 mit nur $2,8{ }^{\circ} \mathrm{C}$. Das Tagesmaximum der Lufttemperatur wurde zwischen 14:00 und 14:30 Uhr (UTC+1) erreicht, lediglich Standort 4b fiel deutlich erkennbar aus diesem Muster heraus. Hier stellte sich das Tagesmaximum bereits um 13:00 Uhr ein.

Die höchste Temperatur der Messperiode wurde mit $29,3^{\circ} \mathrm{C}$ an Standort 2 am 21.7.2010 gemessen (Tab. 2). Das absolute Minimum der Messperiode wurde mit $-30{ }^{\circ} \mathrm{C}$ an Standort 8 am 28.2.2005 gemessen. An diesem Tag wurde, mit Ausnahme von Standort 7, an allen Loggern das Minimum der Messperiode erreicht (Tab. 2).

\section{Luftfeuchte}

Die Monatsmittel der relativen Feuchte, über die Messperiode gemittelt, weisen für alle Standorte ein absolutes Minimum um den Jahreswechsel auf, deutliche sekundäre Minima im Juni und Oktober, sowie ein Maximum zwischen Juli und September und weitere, sekundäre Maxima im späten Frühjahr (April-Mai) und im November (Abb. 7). In den Wintermonaten war Standort 8 mit einigem Abstand der trockenste. Analog zum über die Messperiode gemittelten Tagesgang der Lufttemperatur zeigt Abb. 6 den Tagesgang der relativen Feuchte an den verschiedenen Standorten. Das nächtliche Maximum trat zwischen $22 \mathrm{Uhr}$ (Standort 8) und $0 \mathrm{Uhr}$ (Standorte 1 und 6) ein. 


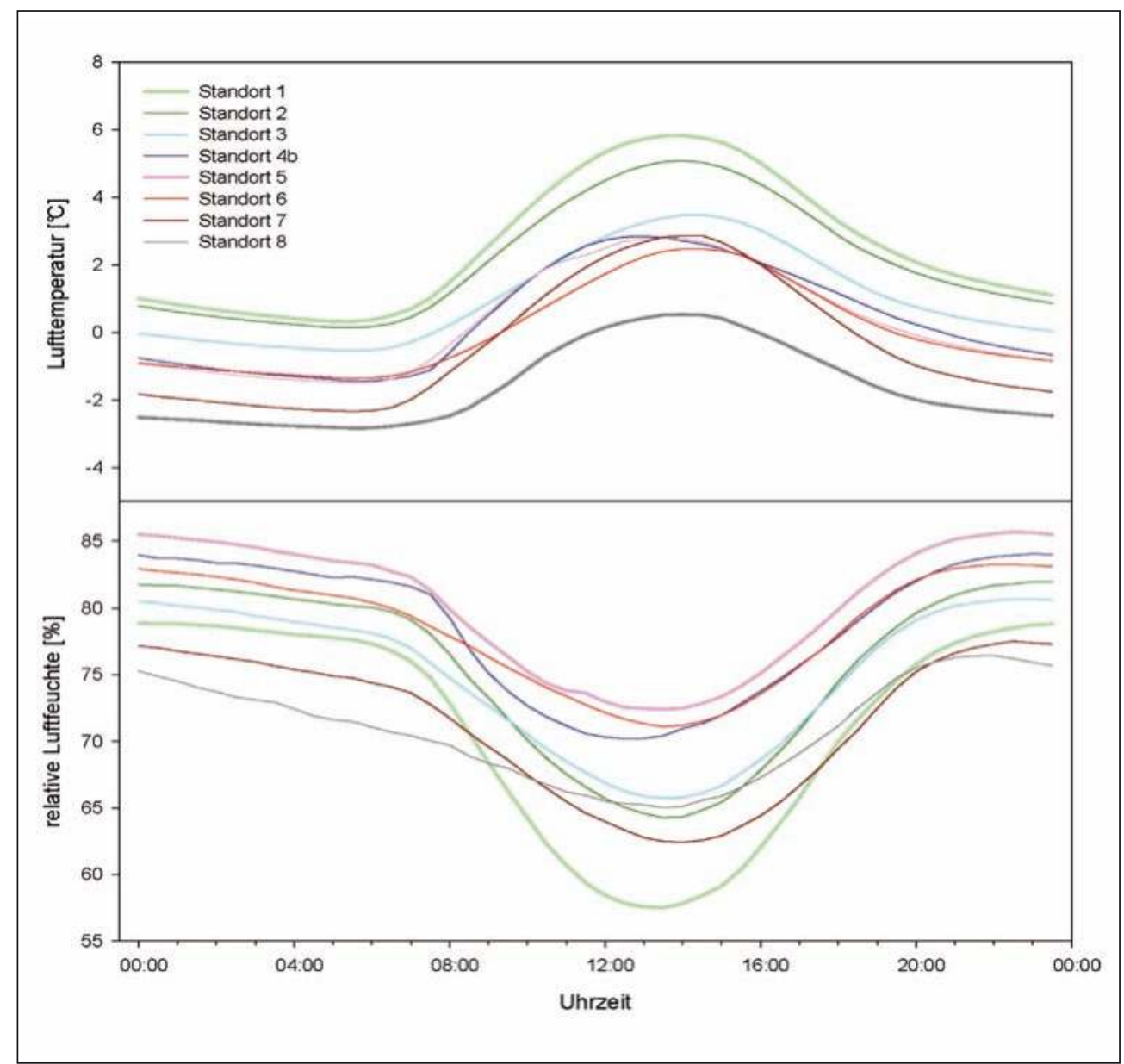

Abb. 6: Oben - Tagesgänge (UTC+1) der Lufttemperatur, gemittelt über den Untersuchungszeitraum 2000-2011, an den einzelnen Standorten. Unten - Tagesgänge (UTC+1) der Luftfeuchtigkeit

\section{Bodentemperatur}

Wie bei der Lufttemperatur wurden auch im Boden im Januar und Februar die kältesten, im Juli und August die wärmsten Temperaturen gemessen (Tab. A1 im Anhang). Das Tagesminimum der Bodentemperatur wurde zwischen 8:00 und 10:00 Uhr erreicht (Abb.
8), d.h. 2,5-4,5 Stunden nach dem Minimum der Lufttemperatur, das Maximum zwischen 18:00 und 20:00 Uhr, d.h. 3,5-5,5 Stunden nach dem Maximum der Lufttemperatur. Standort 8 zeigt mit $2,1^{\circ} \mathrm{C}$ eine wesentlich größere Temperaturamplitude als die übrigen Standorte, die sich zwischen 0,5 und $1,2{ }^{\circ} \mathrm{C}$ täglicher Schwankung bewegen (Abb. 8). 


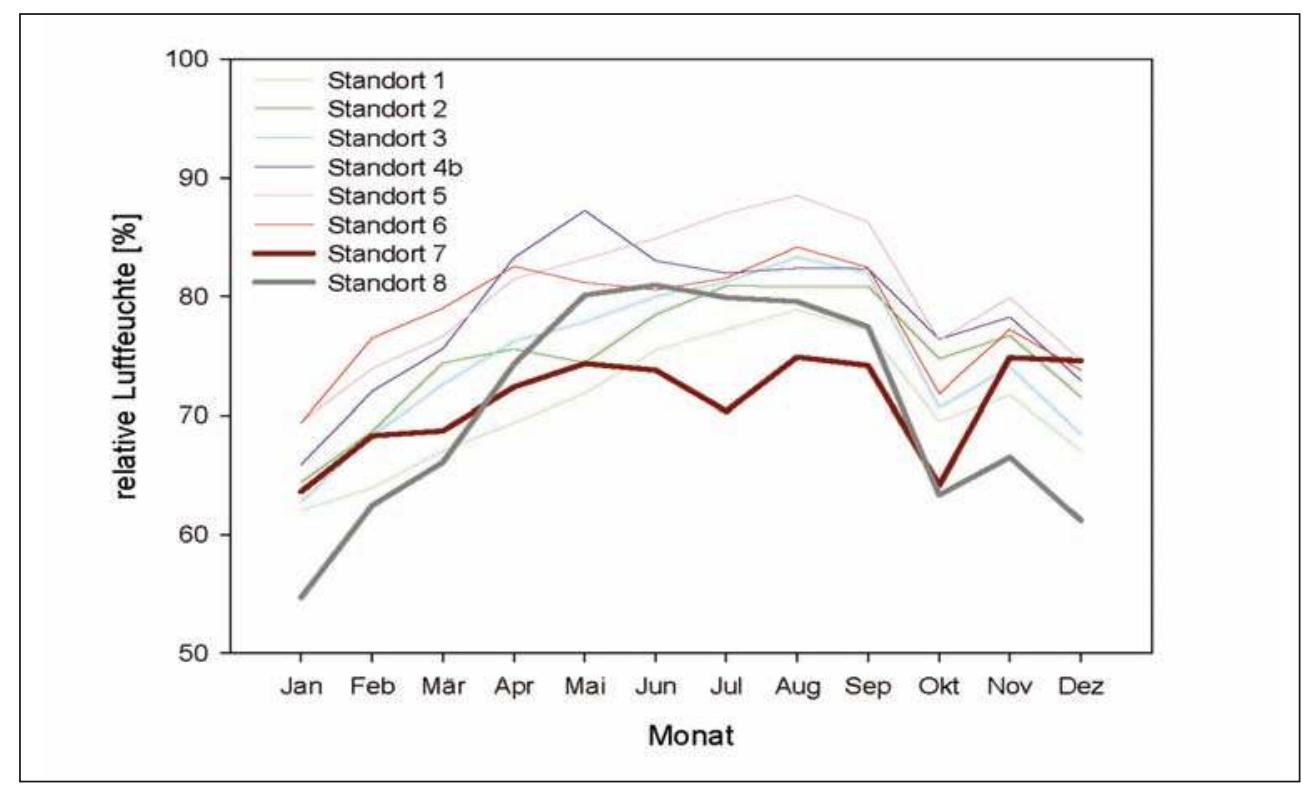

Abb. 7: Monatsmittel der relativen Luftfeuchte, gemittelt über den Untersuchungszeitraum 2000-2011, an den einzelnen Standorten

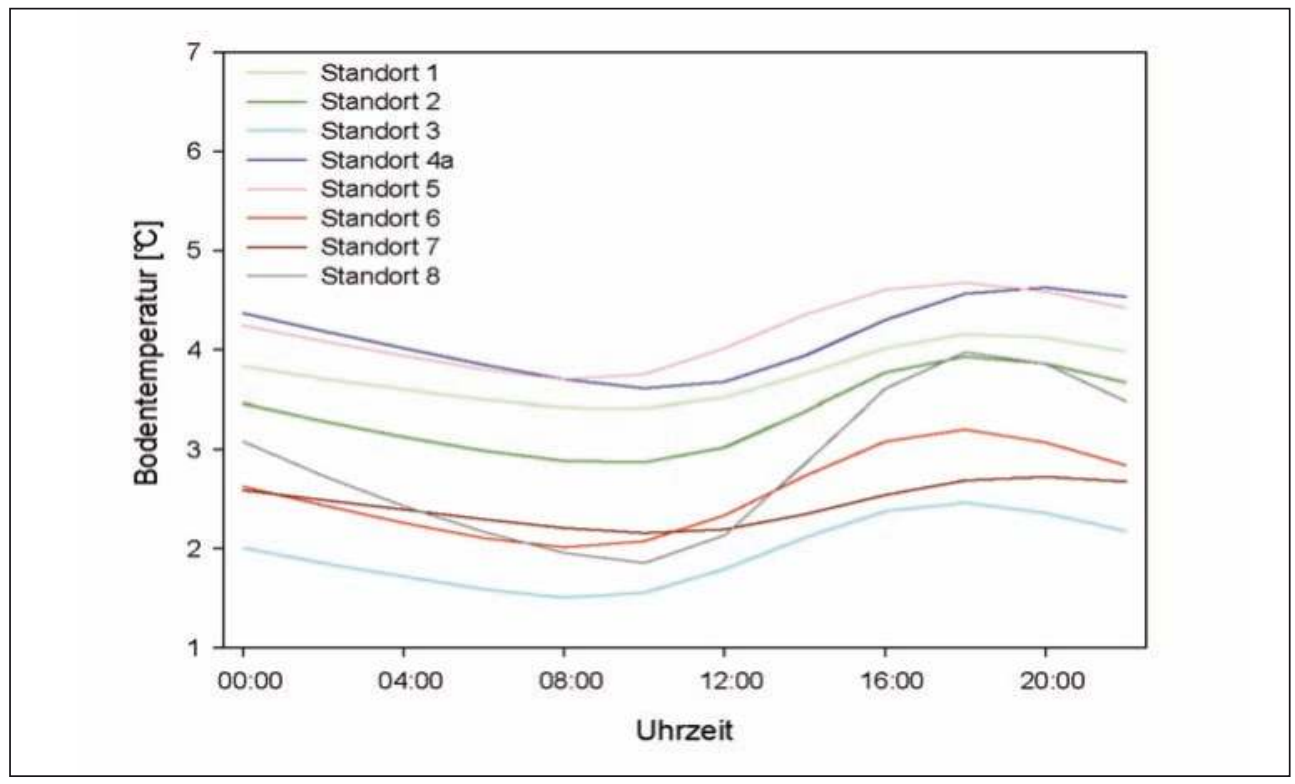

Abb. 8: Durchschnittliche Tagesgänge (UTC+1) der Bodentemperatur an den verschiedenen Standorten, gemittelt über die gesamte Messperiode 
Bodentemperaturunterschiede zwischen den Standorten ergeben sich hinsichtlich der monatlichen Minima: am Standort 3 sinkt die Temperatur am tiefsten ab. Signifikante Unterschiede der Bodentemperaturminima wurden zwischen diesem Standort und den Standorten 1, 2, 4 und 5 festgestellt.

\section{Schneebedeckung}

Abb. 9 zeigt am Beispiel von Standort 1 den Verlauf der Bodentemperatur während der Messperiode, wobei jene Werte markiert sind, bei denen angenommen wird, dass eine Isolation durch Schnee vorliegt. Über alle Jahre und Logger gemittelt liegt nach diesen Krite- rien im Untersuchungsgebiet an ca. $126 \mathrm{Ta}$ gen im Jahr Schnee. Der Winter 2006/2007 war der schneeärmste, 2003/2004 der schneereichste der Messperiode (Tab. 3).

Insgesamt hat sich der Zeitpunkt der ersten Schneebedeckung während der Messperiode nicht erkennbar nach vorn oder hinten verschoben (Tab. 3). Die geringste Schneedeckendauer kann am Standort 3 festgestellt werden. Hier liegt durchschnittlich an 53 Tagen im Jahr Schnee. Es folgt Standort 8, der an durchschnittlich 67 Tagen Schneebedeckung aufweist. Am Standort 7 liegt mit durchschnittlich 166 Tagen am längsten Schnee. Die übrigen Standorte pendeln zwischen 137 (4a), 138 (1), 142 (5), 146 (6) und 151 Tagen (2).

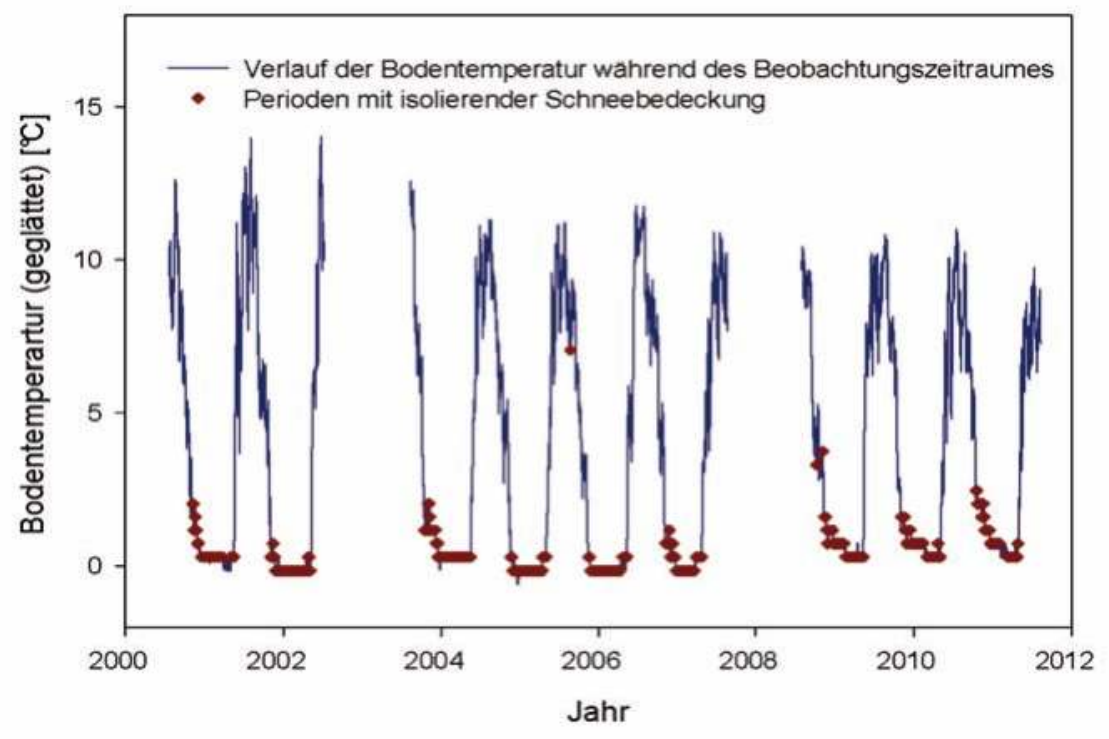

Abb. 9: Geglättete Bodentemperatur (blaue Kurve) an Standort 1 während der gesamten Messperiode. Die roten Symbole markieren jene Perioden, an denen eine absolut konstante Bodentemperatur den Einfluss einer isolierenden Schneedecke anzeigt 
Kapitel 7 I Mikroklimatisches Monitoring in Obergurgl

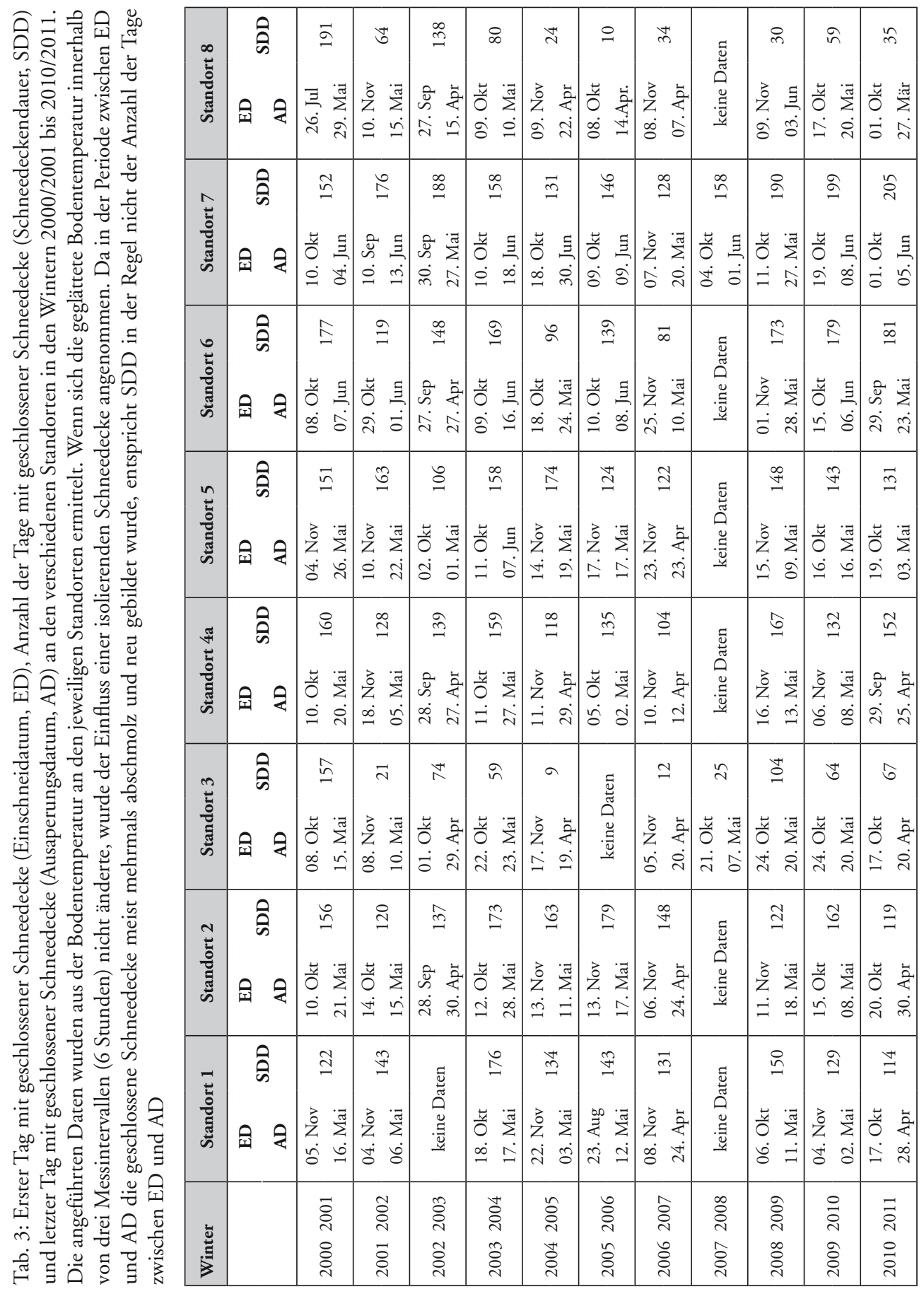


An den einzelnen Standorten war der Ausaperungszeitpunkt sehr unterschiedlich $(\mathrm{p}<0,001)$. Im Schnitt aperte Standort 7 als letzter aus und Standort 8 als erster. Das Datum der Ausaperung verschob sich pro Jahr um 1,2 Tage, d.h. die Flächen aperten mit der Zeit signifikant $(p=0,008)$ früher aus (Kovarianzanalyse: Test der kovariaten Variable Jahr, Standort als zufälliger Faktor). Dieser Trend war bei den Standorten 6 und 7 am wenigsten und bei Standort 8 am stärksten ausgeprägt. Für die Schneedeckendauer ließ sich keine signifikante Veränderung über die Jahre feststellen $(p=0,30)$.

\section{Diskussion}

Es ist allgemein bekannt, dass die mittlere Jahrestemperatur mit der Höhe abnimmt (Körner 2003), wobei in den Zentralalpen eine durchschnittliche Abnahme von $0,6^{\circ} \mathrm{C}$ pro 100 Höhenmeter charakteristisch ist (Nagy \& Grabherr 2009). In unserer Studie zeigte sich, dass diese höhenbedingte Temperaturabnahme im Verlauf des Jahres zwischen 0,4 und $0,7^{\circ} \mathrm{C}$ pro 100 Höhenmeter variiert. Auf die saisonalen Unterschiede hat beispielsweise bereits Rolland (2003) hingewiesen. Seine Metaanalyse über zahlreiche Standorte in Norditalien und Tirol belegte ebenfalls höhere Werte im Sommer. Sowohl Monatsmittel als auch -maxima der Lufttemperatur waren am Abhang des Kirchenkogels (Standort 8) vor allem während der Vegetationsperiode si- gnifikant niedriger als an den meisten anderen Standorten.

Die Grundfrage für ökologische Studien ist allerdings, ob die in $2 \mathrm{~m}$ Höhe zur Charakterisierung der Wetterbedingungen gemessenen Temperaturen genügend Aussagekraft haben für die Dynamik der Vegetation. Mehrere Studien haben in jüngster Zeit immer wieder darauf verwiesen, dass Lufttemperaturen der meteorologischen Standardstationen mit Vorsicht interpretiert werden sollten (Larcher \& Wagner 2009, 2010; Scherrer et al. 2011, Graae et al. 2012) und dass eigentlich das Bioklima gemessen werden müsste. Unter Bioklima versteht man das für die Pflanze relevante Mikroklima von der Oberkante des Pflanzenbestandes bis hinunter zu den Wurzelspitzen (Cernusca 1976). Graae et al. (2012) schlussfolgern, dass für Aussagen zu den Auswirkungen des Klimawandels vor allem Bodenoberflächentemperaturen heranzuziehen sind und nicht die Temperaturen in $2 \mathrm{~m}$ Höhe. In zahlreichen ökologischen Studien werden die Bodentemperaturen in $10 \mathrm{~cm}$ Tiefe bevorzugt, um Strahlungsfehler auszuschließen (Körner et al. 2003).

Die Wuchsform der Pflanzen hat einen entscheidenden Einfluss auf die Temperaturen an der Bodenoberfläche und im Boden. Polsterpflanzen und Spaliersträucher heizen sich im Vergleich zur Lufttemperatur untertags sehr stark auf (Larcher 2012). Dies gilt selbst für schwach bewachsene Flächen wie jene auf der 1971er Moräne des Rotmoosferner-Gletschervorfeldes (Erschbamer, Kapitel 8 in diesem Band). Hochwüchsige Pflanzen, wie beispielsweise Bäume, schatten den Boden naturge- 
mäß stärker ab. In ihrem Wurzelbereich herrschen mitunter niedrigere Temperaturen als in der baumfreien alpinen Rasenstufe (Körner et al. 2003, Körner 2007). Für Obergurgl können dazu keine Aussagen getroffen werden, da im hier vorgestellten Monitoring-Projekt keine Waldstandorte untersucht wurden.

Nachts wirkt die Oberfläche des Bewuchses als wichtigste abstrahlende Fläche, daher verliert der Boden weniger Wärme (Tindall 1999). Standort 1, der die größte tägliche Amplitude der Lufttemperatur zeigt, befindet sich in einer Weideausschlussfläche mit Zwergsträuchern, die durchschnittlich $27 \mathrm{~cm}$ Wuchshöhe erreichen und eine hohe Gesamtdeckung aufweisen (Roland Mayer, unpubl.). Hier wurden dementsprechend geringe Schwankungen der Bodentemperatur festgestellt. An den Standorten 6 (Skipiste Festkogel) und 8 (Kirchenkogel) findet sich dagegen ein sehr niedriger, offener Pflanzenbewuchs, der das Signal der Lufttemperatur nur geringfügig dämpft. Da die Wärmeleitfähigkeit des Bodens vor allem von der Bodenart und dem Wassergehalt des Bodens abhängt (Tindall 1999), wäre eine bodenkundliche Erfassung der Standorte wünschenswert, um die Daten der Bodentemperaturen besser interpretieren zu können. Außerdem sei auf die Energiebilanzmessungen von Rott $(1979,1987)$ und Staudinger (1987) verwiesen, die während des MaB-Projektes (Patzelt 1987) den Krummseggenrasen auf der Hohen Mut mit einer Mähwiese in Obergurgl verglichen hatten. Die Unterschiede wurden ganz klar auf die Vegetation, die Lage der Flächen und auf die Höhendifferenz zurückgeführt.
Neben den topographischen und bodenkundlichen Gegebenheiten wirkt sich vor allem auch die Exposition ausschlaggebend auf die Bodentemperaturen aus (Nagy \& Grabherr 2009): im europäischen GLORIA-Projekt (www.gloria.ac.at) wiesen nordexponierte Gipfelhänge durchwegs kältere Böden auf als jene der übrigen Expositionen. Nachdem die beschriebenen Standorte nicht nach dem Kriterium Exposition ausgewählt wurden und daher nicht alle Expositionen in gleicher Höhenlage vorliegen, können wir hier keine Aussagen treffen.

Hinsichtlich Bodentemperaturminima konnten signifikante Unterschiede je nach Vegetationstyp festgestellt werden. Dabei fällt die Gurgler Heide (Standort 3) im Vergleich zu Standorten mit höherer Zwergstrauchvegetation $(1,2)$ bzw. auch im Vergleich zum alpinen Rasen am Schönwieskopf (5) durch signifikant tiefere Minima auf. Das extreme Milieu der Loiseleuria-Flechtenheide wird damit deutlich. Von Messungen am Patscherkofel wissen wir, dass ein typischer LoiseleuriaBestand im Winter völlig schneefrei geblasen werden kann und daher Bestandestemperaturen von -10 bis $+30{ }^{\circ} \mathrm{C}$ in den Monaten Jänner bis März wechseln können (Cernusca 1976, Körner 2003). Die Gurgler Heide weist unter allen Monitoring-Standorten die geringste Dauer der Schneedecke auf. Die Vaccinien-Zwergstrauchheide (Standort 2) hat im Gegensatz dazu eine dreimal so lange Schneedeckendauer. Die Notwendigkeit eines Schneeschutzes für diesen Pflanzenbestand ist hinlänglich bekannt (Cernusca 1976, Körner 2003, Nagy \& Grabherr 2009, Neuner \& Ha- 
cker 2012), da die dominanten Arten (Vaccinium myrtillus, Rhododendron ferrugineum) als chionophil (Schneeschützlinge) einzustufen sind.

Eine ähnlich kurze Schneedecke wie die Loiseleuria-Flechtenheide auf der Gurgler Heide weist nur noch der alpine Rasen an den Abhängen des Kirchenkogels (Standort 8) auf. Die hier dominierende Kobresia myosuroides ist typisch für windgefegte Standorte mit geringem Schneeschutz (Reisigl \& Keller 1987).

Die Ausaperung erfolgt hier am frühesten: so war der Hang z.B. 2011 bereits Ende März schneefrei. Kantenlagen (Standort 3) oder Steilhänge (Standort 8) sind, unabhängig von der Exposition, jene Bereiche, die am schnellsten ausapern.

Bezüglich der Schneebedeckung ist zu betonen, dass der Datenlogger für die Bodentemperatur auf der Hohen Mut (Standort 7) im Schatten eines Holzzaunes liegt. Hier dürfte vor allem der Zauneffekt für das frühe Einschnei- und späte Ausaperungsdatum und die lange Schneedeckendauer verantwortlich sein. Auf Skipisten wird allgemein angenommen, dass die Schneedeckendauer infolge der Schneekomprimierung durch Pistenpräparierung und -befahrung verlängert wird. Während der Messperiode zeigten sich im Bereich des Standorts 6 (Skipiste Festkogel) allerdings keine großen Abweichungen zu vergleichbaren Standorten der höheren Zwergstrauchheide (Standort 2) oder des alpinen Rasens am Schönwieskopf (Standort 5).

Allgemein ist zu bemerken, dass die Ausaperung im Gegensatz zum Datum der ersten Schneebedeckung kaum durch einzelne Nie- derschlagsereignisse beeinflusst wird und daher allgemeine Trends besser wiedergibt. Das immer frühere Ausaperungsdatum ist für die Pflanzenwelt von großer Bedeutung und auch für den Skitourismus in Obergurgl von einiger Relevanz. Um dieses Ergebnis weiter zu interpretieren, wären Schneehöhenmessungen wünschenswert. Regionale Klimamodelle (Christensen et al. 2007) prognostizieren besonders in den Wintermonaten eine Erwärmung, was die Schneebedeckung weiter reduzieren dürfte. Über die Auswirkungen auf die einzelnen Pflanzenbestände kann derzeit nur spekuliert werden (Erschbamer 2007, Thuiller 2007, Nagy \& Grabherr 2009, Ramming et al. 2010, Gottfried et al. 2012, Pauli et al. 2012). Umso bedeutsamer erscheint es, das ökologische Langzeit-Monitoring-Projekt weiterhin aufrecht zu erhalten, um empirische Daten für künftige Modelle zu generieren.

\section{Literatur}

Aulitzky, H. (1954) Über mikroklimatische Untersuchungen an der oberen Waldgrenze zum Zwecke der Lawinenvorbeugung. Wetter und Leben, 6. Jg, Heft 5-6: 93-98.

Aulitzky, H. (1955a) Die Bedeutung meteorologischer und kleinklimatischer Unterlagen für Aufforstung im Hochgebirge. Wetter und Leben, 7. Jg, Heft 8-11: 241-252. 
Aulitzky, H. (1955b) Über die lokalen Windverhältnisse einer zentralalpinen Hochgebirgs-Hangstation. Arch. Met. Geoph. Biokl. 6 (4): 353-373.

Aulitzky, H. (1961) Die Bodentemperaturverhältnisse einer zentralalpinen Hanglage beiderseits der Waldgrenze; I. Teil. Arch. Met. Geoph. Biokl., Serie B 10: 445-532.

Aulitzky, H. (1962a) Die Bodentemperaturverhältnisse einer zentralalpinen Hanglage beiderseits der Waldgrenze; II. Teil. Arch. Met. Geoph. Biokl., Serie B 11: 301-362.

Aulitzky, H. (1962b) Die Bodentemperaturverhältnisse einer zentralalpinen Hanglage beiderseits der Waldgrenze. III. Teil. Arch. Met. Geoph. Biokl., Serie B 11: 363-376.

Cernusca, A. (1976) Bestandesstruktur, Bioklima und Energiehaushalt von alpinen Zwergstrauchbeständen. OEcol. Plant. 11: 71-102.

Christensen, J.H., Hewitson, B., Busuioc, A., Chen, A., Gao, X., Held, I., Jones, R., Kolli, R.K., Kwon, W.-T., Laprise, R., Magaña Rueda, V., Mearns, L., Menéndez, C.G., Räisänen, J., Rinke, A., Sarr, A. \& Whetton, P. (2007) Regional Climate Projections. In: The Physical Science Basis. Contribution of Working Group I to the Fourth Assessment Report of the Intergovernmental Panel on Climate Change, Solomon, S., Qin, D., Manning, M., Chen, Z., Marquis, M., Averyt, K.B., Tignor, M. \& Miller, H.L. (Hg.) Climate Change 2007, Cambridge
University Press, Cambridge, U.K. and New York, NY, USA, S. 847-940.

Erschbamer, B. (2001) Responses of some Austrian glacier foreland plants to experimentally changed microclimatic conditions. In: Fingerprints of Climate Change, Walther G.-R., Burga C.A. \& Edwards, P.J. (Hg.) Kluwer Academicl Plenum Publishers, New York, S. 263279.

Erschbamer, B. (2007) Winners and losers of climate change in a central alpine glacier foreland. Arctic, Antarctic, and Alpine Research 39: 237-244.

Erschbamer B. \& Mayer R. (2011) Can successional species groups be discriminated based on their life history traits? A study from a glacier foreland in the Central Alps. Plant Ecology \& Diversity 4: 341351.

Fischer, A. (2010) Klima und Gletscher in Obergurgl. In: Glaziale und periglaziale Lebensräume im Raum Obergurgl, Koch E.-M. \& Erschbamer B. (Hg.) Alpine Forschungsstelle Obergurgl 1, innsbruck university press, Innsbruck, S. 53-72.

Gottfried, M., Pauli, H., Futschik, A., Akhaltkatsi, M., Barancok, P., Benito Alonso, J.L., Coldea, G., Dick, J., Erschbamer, B., Fernández Calzado, M.R., Kazakis, G., Krajci, J., Larsson, P., Mallaun, M., Michelsen, O., Moiseev, D., Moiseev, P., Molau, U., Merzouki, A., Nagy, L., Nakhutsrishvili, G., Pedersen, B., Pelino, G., Puscas, M., Rossi, G., Stanisci, A., Theurillat, J.-P., Tomaselli, M., Villar, 
L., Vittoz, P., Vogiatzakis, I. \& Grabherr, G. (2012) Continent-wide response of mountain vegetation to climate change. Nature Climate Change 2/2: 111-115.

Graae, B.J., De Frenne, P., Kolb, A., Brunet, J., Chabrerie, O., Verheyen, K., Pepin, N., Heinken, T., Zobel, M., Shevtsova, A., Nijs, I. \& Milbau, A. (2012) On the use of weather data in ecological studies along altitudinal and latitudinal gradients. Oikos 121: 3-19.

Hoinkes, H. \& Rudolph, R. (1961) Variations in the Mass-Balance of Hintereisferner (Oetztal Alps), 1952-1961, and their Relation to Variations of Climatic Elements. Extract of publication no. 58 of the I.A.S.H. Commission of Snow and Ice, S. 16 - 28.

Kaufmann, R. (2001) Invertebrate succession on an alpine glacier foreland. Ecology 82: 2261-2278.

Kaufmann, R. (2005) Langzeit-Ökosystem Monitoing im Alpinen Raum. Endbericht 2000-2005. Auftraggeber: Land Tirol. Abteilung Umweltschutz, Innsbruck.

Koch, E.-M. \& Erschbamer, B. (2010) Glaziale und periglaziale Lebensräume im Raum Obergurgl. Alpine Forschungsstelle Obergurgl 1, innsbruck university press, Innsbruck.

Körner, Ch. (2003) Alpine Plant Life: Functional Plant Ecology of High Mountain Ecosystems. $2^{\text {nd }}$ ed., Springer, Berlin, Heidelberg.
Körner, Ch. (2007) Climatic treelines: conventions, global patterns, causes. Erdkunde 61, H. 4: 316-324.

Körner, Ch., Paulsen, J. \& Pelaez-Riedl, S. (2003) A bioclimatic characterisation of Europe's alpine areas. In: Alpine Biodiversity in Europe, Nagy L., Grabherr G., Körner Ch. \& Thompson D.B.A. (Hg.), Springer, Berlin, S. 13-28.

Kraus, H. (2004) Die Atmosphäre der Erde. Springer-Verlag, Berlin Heidelberg, S. 10-13.

Kuttler, W. (2009) Klimatologie. Schönigh, Paderborn.

Larcher, W. (2012) Bioclimatic temperatures in the High Alps. In: Plants in Alpine Regions. Cell Physiology of Adaption and Survival Strategies, Lütz, C. (Hg.), Springer, Wien, New York, S. 21-27.

Larcher, W. \& Wagner, J. (2009) High mountain bioclimate: temperatures near the ground recorded from the timberline to the nival zone in the Central Alps. Contrib. Nat. Hist. 12: 857-874.

Larcher, W. \& Wagner, J. (2010) Temperatures in the life zones of the Tyrolean Alps. Österr. Akademie der Wissenschaften, Sitzungsber. Abt. I 213: 31-51.

Mayer, R. \& Erschbamer, B. (2009) Die Vegetation von Schipisten im Vergleich zur angrenzenden Vegetation im inneren Ötztal (Zentralalpen, Nordtirol). Zoolog.-Bot. Ges. Österreich 146: 139157.

Mayer, R., Kaufmann, R., Vorhauser, K. \& Erschbamer, B. (2009) Effects of grazing exclusion on species composition 
in high-altitude grasslands of the Central Alps. Basic and Applied Ecology 10: 447-445.

Molau, U. \& Mølgaard, P. (1996) The ITEX manual. Danish Polar Center, Copenhagen, Denmark.

Moser, W. (1975) Program on Man and the Biosphere, MAB-6 Obergurgl (Austria). Report 1975.

Nagl, F. \& Erschbamer, B. (2010) Vegetation und Besiedlungsstrategien. In: Glaziale und periglaziale Lebensräume im Raum Obergurgl, Koch, E.-M. \& Erschbamer, B. (Hg.), Alpine Forschungsstelle Obergurgl 1, innsbruck university press, Innsbruck, S. 121-143.

Nagy, L. \& Grabherr, G. (2009) The Biology of Alpine Habitats. Oxford Univ. Press, New York.

Neuner, G. \& Hacker, J. (2012) Ice formation and propagation in alpine plants. In: Plants in Alpine Regions. Cell Physiology of Adaption and Survival Strategies, Lütz, C. (Hg.), Springer, Wien, New York, S. 163-174.

Pauli, H., Gottfried, M., Dullinger, S., Abdaladze, O., Akhaltkatsi, M., Benito Alonso, J.L., Coldea, G., Dick, J., Erschbamer, B., Fernández Calzado, R., Ghosn, D., Holten, J., Kanka, R., Kazakis, G., Kollár, J., Larsson, P., Moiseev, D., Moiseev, P., Molau, U., Molero Mesa, J., Nagy, L., Pelino, G., Puscas, M., Rossi, G., Stanisci, A., Syverhuset, A. O., Theurillat, J.-P., Tomaselli, M., Unterluggauer, P., Villar, L., Vittoz, P. \& Grabherr, G. (2012) Recent plant diversity changes on Europe's mountain summits. Science 336/6079: 353-355.

Patzelt, G. (1987) MaB-Projekt Obergurgl. Veröff. Österr. MaB-Progr. Bd. 10, Univ. Verlag Wagner, Innsbruck.

Ramming, A., Jonas, T., Zimmermann, N.E. $\&$ Rixen, C. (2010) Changes in alpine plant growth under future climate conditions. Biogeosciences 7: 2013-2024.

Reisigl, H. \& Keller, R. (1987) Alpenpflanzen im Lebensraum. Alpine Rasen, Schuttund Felsvegetation. Gustav Fischer Verlag, Stuttgart, New York.

Rolland, C. (2003) Spatial and seasonal variations of air temperature lapse rate in alpine regions. Journal of Climate 16: 1032-1046.

Rott, H. (1979) Vergleichende Untersuchungen der Energiebilanz im Hochgebirge. Arch. Met. Geoph. Biokl. Ser. A 28: 211-232.

Rott, H. (1987) Die Energiebilanzmessungen an den Stationen Hohe Mut und Obergurgl-Wiese. In: MaB-Projekt Obergurgl, Patzelt, G. (Hg.), Veröff. Österr. MaB-Progr. Bd. 10, Univ. Verlag Wagner, Innsbruck, S. 147-159.

Scherrer, D. \& Körner, C. (2010) Topographically controlled thermal-habitat differentiation buffers alpine plant diversity against climate warming. Journal of Biogeography 38: 406-416.

Scherrer, D., Schmid, S. \& Körner, C. (2011) Elevational species shifts in a warmer climate are overestimated when based on weather station data. Int. J. Biometeorol. 55: 645-654. 
Staudinger, M. (1987) Verdunstungsbestimmung während der Vegetationsperiode durch Energiebilanzmessungen. In: MaB-Projekt Obergurgl, Patzelt, G. (Hg.), Veröff. Österr. MaB-Progr. Bd. 10, Univ. Verlag Wagner, Innsbruck, S. 161-172.

Thuiller, W., Lavorel, S., Araújo, M.B., Sykes, M.T. \& Prentice, I.C. (2005) Climate change threats to plant diversity in $\mathrm{Eu}$ rope. PNAS 102: 8245-8250.

Tindall J.A. (1999) Unsaturated zone hydrology for scientists and engineers. Prentice-Hall, Englewood Cliffs, New Jersey.

Turner, H. (1958) Über das Licht- und Strahlungsklima einer Hanglage der Ötztaler Alpen bei Obergurgl und seine Auswirkung auf das Mikroklima und auf die Vegetation. Arch. Met. Geoph. Biokl. 8 (3-4): 273-325.
Nikolaus Schallhart

Alpine Forschungsstelle Obergurgl

Universität Innsbruck

Gaisbergweg 3, 6456 Obergurgl

Klaus.Schallhart@uibk.ac.at

Brigitta Erschbamer

Institut für Botanik

Universität Innsbruck

Sternwartestr. 15, 6020 Innsbruck

Brigitta.Erschbamer@uibk.ac.at

\section{Verzeichnis der AutorInnen}

Lea Hartl

Alpine Forschungsstelle Obergurgl

Universität Innsbruck

Gaisbergweg 3, 6456 Obergurgl

Lea.Hartl@student.uibk.ac.at

Rüdiger Kaufmann

Institut für Ökologie

Universität Innsbruck

Technikerstraße 25, 6020 Innsbruck

Ruediger.Kaufmann@uibk.ac.at 


\section{Kapitel 8 | Mikroklima und Biotemperaturen auf der 1971er Moräne des Rotmoosferner- Gletschervorfeldes (Obergurgl, Ötztal)}

Brigitta Erschbamer

\section{Zusammenfassung}

Seit dem Jahr 1996 wird im Gletschervorfeld des Rotmoosferners (Obergurgl, Ötztal) der Jahresverlauf der Bodenoberflächentemperatur auf unbewachsenem Moränenboden des Gletscherstandes 1971 untersucht. Während der Vegetationsperiode wird zusätzlich eine Mikroklimastation betrieben, wobei Luftund Bodentemperaturen, Luftfeuchtigkeit und Temperaturen in Pflanzenpolstern gemessen werden. Der vorliegende Artikel präsentiert die Datenreihen von 1996 bis 2011 (Mikroklimastation) bzw. von 1998 bis 2011 (Bodenoberflächentemperaturen). Die Dauer der Vegetationszeit im Verlauf der Untersuchungsjahre, Temperaturextreme und -mittelwerte werden dargestellt und mögliche Auswirkungen auf die Entwicklungsstadien der Pflanzen diskutiert.

\section{Abstract}

The glacier foreland of the Rotmoosferner is one of the long-term ecological research sites in Obergurgl (Ötztal, Tyrol, Austria). Since
1996, soil surface temperatures are measured the year round on bare ground moraines of the glacier stage 1971. Air and soil temperatures, air humidity and temperatures of plant cushions are recorded during the growing season. Furthermore, the duration of the growing season, temperature extremes and - means are shown and possible effects on plants are discussed. Data from 1996 till 2011 are presented.

\section{Einleitung}

Gletschervorfelder werden als „unwirtliche“ Lebensräume eingestuft, da die abiotischen Bedingungen als ungünstig für die Ansiedelung von Pflanzen erachtet werden. $\mathrm{Zu}$ diesen ungünstigen Bedingungen zählen unter anderen die niedrigen Temperaturen. Kalt muss jedoch nicht gleich kalt für die Pflanze sein (Körner \& Larcher 1988), denn Pflanzentemperaturen weichen oft sehr stark von den meteorologischen Standard-Temperaturmessungen der 
Umgebungsluft ab (Larcher \& Wagner 2009). Entscheidend für die Pflanze sind ihre Wuchsform und -höhe und die Standortparameter, wie z.B. Exposition, Hangneigung, Horizontüberhöhung und damit der Strahlungsgenuss des Wuchsortes. In der Ökologie verwendet man den Begriff „Bioklima“ für den Pflanzenrelevanten Bereich des Mikroklimas, d.h. den Bereich, der von der Bestandsoberfläche bis zu den Wurzeln reicht (Cernusca 1976). In geschlossenen Beständen ist das Bioklima stabiler, wärmer und feuchter (Larcher 2012) als es die Werte der meteorologischen Stationen sind, die in der Regel Standardmessungen in 2 m Höhe durchführen. Die offenen Bestände eines Gletschervorfeldes weisen extremere Verhältnisse auf mit niedrigeren Minima und höheren Maxima (Larcher \& Wagner 2009).

Das Bioklima wurde vor allem in der Zwergstrauchheide des Zentralalpenraumes studiert (Cernusca 1976, Larcher \& Wagner 2004). Körner et al. (2003) verglichen europaweit die Bodentemperaturen in $10 \mathrm{~cm}$ Tiefe vom Waldgrenzbereich mit jenen der alpinen Rasen. Baumbestände wiesen dabei im Vergleich zu alpinen Rasen während der Vegetationszeit eine kühlere Bodentemperatur auf. Larcher \& Wagner (2009, 2010) und Larcher (2012) geben einen Überblick über die Verhältnisse entlang des Höhengradienten von der Waldgrenze zur Gletscherregion. Interessant sind dabei vor allem die bioklimatischen Extremwerte, denn sie erlauben eine Abschätzung der Frost- und Hitzeeffekte, die begrenzend für das Pflanzenleben am Standort sein können (Larcher 2012).
Im Gletschervorfeld können Fröste auch im Sommer auftreten. Die Pflanzen können also jederzeit in ihrer empfindlichsten Phase während des Wachstums geschädigt werden (Taschler et al. 2004, Taschler \& Neuner 2004, Neuner et al. 2013, Wagner et al. 2013). Daneben ist in den spärlich besiedelten Gletschervorfeldflächen an sommerlichen Schönwettertagen aber auch eine beträchtliche Erwärmung der Pflanzenorgane, der Bodenoberfläche und des Bodens zu erwarten (Neuner \& Buchner 2012), sodass sogar Hitzeschäden auftreten können (Buchner \& Neuner 2003). Ziel der vorliegenden Arbeit war es, die Biotemperaturen in jungen Moränen eines Gletschervorfeldes im Ötztal zu erfassen und sie mit der meteorologischen Standardmessung in $2 \mathrm{~m}$ Höhe vor Ort zu vergleichen. Langzeit-Datenreihen sollen mit dieser Arbeit verfügbar gemacht werden. Anhand der Extremwerte wird abgeschätzt, in wie weit Gletschervorfeldpflanzen in ihrer Entwicklung gefährdet sein könnten.

\section{Untersuchungsgebiet}

Die Messstation befindet sich in $2400 \mathrm{~m}$ Meereshöhe auf der orographisch rechten Talseite des Gletschervorfeldes im Rotmoostal, Obergurgl, Ötztal (4649'43,1" N, 11'2'32,54" E), auf der Moräne des Gletscherstandes 1971 (Abb. 1, vgl. auch Abb. 1 in Koch \& Kaufmann 2010). Es handelt sich um eine 


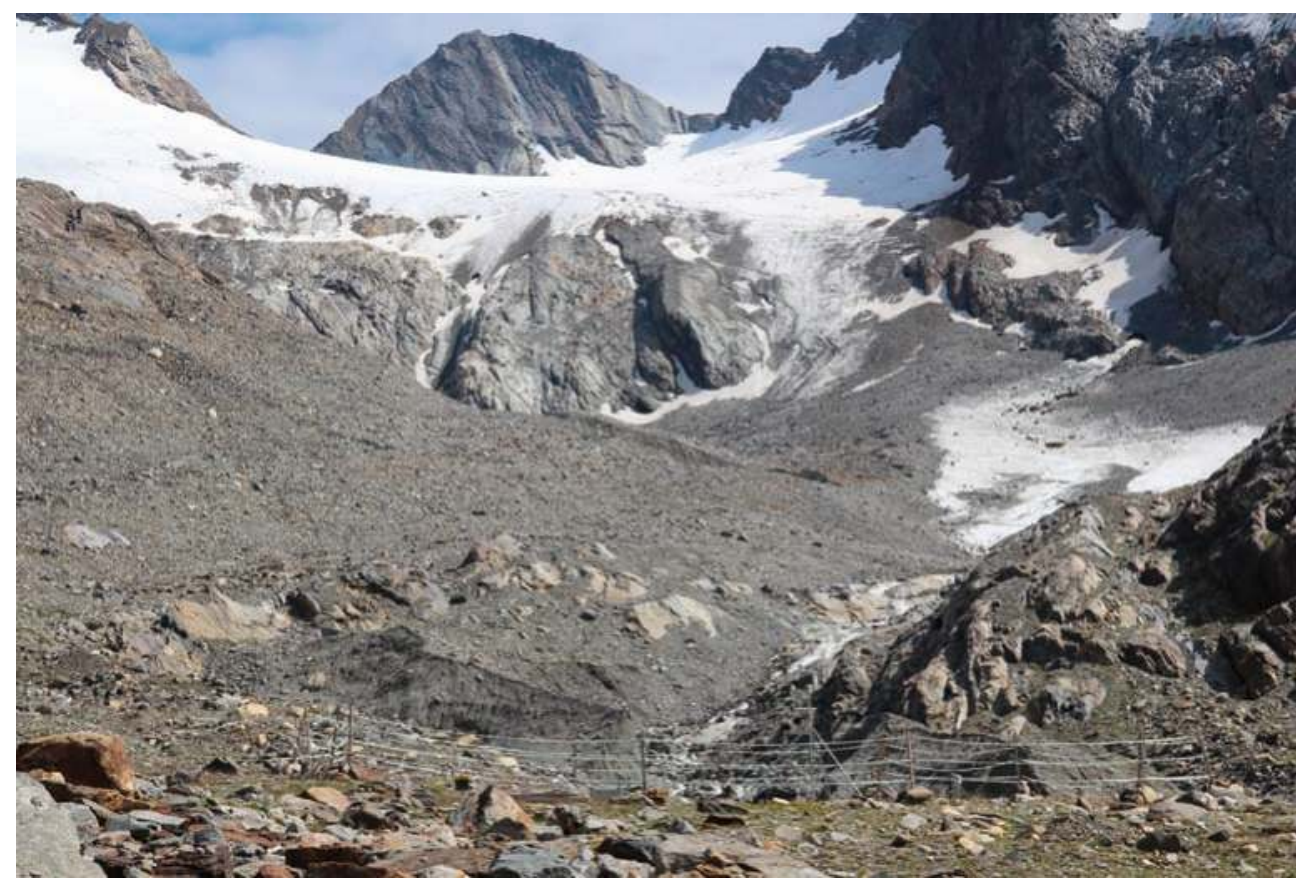

Abb. 1: Untersuchungsgebiet im Gletschervorfeld des Rotmoosferners (Obergurgl, Ötztal, Tirol) auf der Moräne des Gletscherstandes 1971 (Foto: Brigitta Erschbamer 2012)

ebene Fläche, die von einer Pioniervegetation bestimmt wird. Saxifraga aizoides, Saxifraga oppositifolia, Artemisia genipi, Linaria alpina und Poa alpina sind als bedeutendste Arten zu nennen (Raffl et al. 2006, Nagl \& Erschbamer 2010). Die Gesamtdeckung der Vegetation beläuft sich auf weniger als $15 \%$.

Das Untersuchungsgebiet zählt zum Langzeit-Untersuchungsprogramm der Alpinen Forschungstelle Obergurgl und ist damit eine Lokalität der Long-Term Ecosystem Research (LTER) Plattform Tyrolean High Alps.

\section{Methodik}

Im Zuge des Gletschervorfeldprojektes im Rotmoostal (Nagl \& Erschbamer 2010) wurde von der Autorin im Zeitraum von 1996 bis 2011 jeweils in der Vegetationsperiode ein Datenlogger (Grant Squirrel Series 1250, Grant Instruments, Cambridge, England) betrieben, der insgesamt 10 Messkanäle aufwies. Diese Messkanäle umfassten sechs Sensoren für Bodentemperaturen (Pt-Sensoren), zwei für Lufttemperaturen und zwei für Luftfeuchtigkeit. Lufttemperatur und -feuchtigkeit wurden in $2 \mathrm{~m}$ und in $50 \mathrm{~cm}$ Höhe oberhalb 
der Bodenoberfläche gemessen, die Bodentemperaturen in $10 \mathrm{~cm}$ Bodentiefe. Die weiteren Pt-Sensoren wurden in Pflanzenpolstern von Saxifraga aizoides und Saxifraga oppositifolia angebracht, sodass sie komplett durch Sprosse und Blattmasse bedeckt waren. In der vorliegenden Arbeit werden die Lufttemperaturen, die Bodentemperatur in $10 \mathrm{~cm}$ Tiefe und die Temperaturen in Saxifraga oppositifolia-Polstern an einem grobkörnigen Standort (Geröll von rund $10 \mathrm{~cm}$ Durchmesser) und an einem sandigen Standort angegeben. Folgende Abkürzungen werden verwendet: 200 cm Luft, 50 cm Luft, Saxi-Geröll, Saxi-Sand, $10 \mathrm{~cm}$ Boden. Die Messzeit des Grant Squirrel-Datenloggers entspricht nicht exakt der schneefreien Zeit. Es wurde jedoch versucht, die Station möglichst rasch nach der Schneeschmelze in Betrieb zu setzen. Das Messintervall betrug eine Stunde.

Im Zuge des Experimentes zu den Auswirkungen von erhöhten Temperaturen auf Gletschervorfeldpflanzen (Erschbamer 2007) wurden seit 1996 an diesem Standort ganzjährig auch Bodenoberflächentemperaturen mit Hilfe von Optic StowAway- bzw. Tidbit-Datenloggern (TBI32-20+50; Onset Computer Corporation, Inc., Pocasset, MA, USA) gemessen. Als Strahlungsschutz wurden Aluminiumkappen verwendet, die freien Luftdurchzug erlaubten. Das Abtastintervall betrug 15 Minuten. In den Jahren 1996 und 2007 war die Datenregistrierung teilweise unterbrochen, sodass die meisten Klimaparameter nicht berechnet werden konnten. In den übrigen Jahren waren nur kleinere Datenlücken von weniger als einem Tag bzw. einigen wenigen Tagen aufgetreten. Die kurzen Zeiträume wurden bei der Ermittlung der Mittelwerte vernachlässigt.

Die Auswertung der Daten erfolgte mit den Programmen EXCEL und SPSS 18.0 für MS Windows. Jahres-, Monats- bzw. Tagesmittelwerte, absolute Maxima und Minima werden angegeben. Die potentiell mögliche Vegetationszeit wurde nach Molau \& Mølgaard (1996) als „growing degree days“ (GDD) definiert, d.h. Tage mit Tagesmittelwerten über $2{ }^{\circ} \mathrm{C}$. Als Indikator für Schneefreiheit/Schneeschmelze wurden Tagesmittelwerte von über $0{ }^{\circ} \mathrm{C}$ gewertet („thawing degree days“-TDD, Molau \& Mølgaard 1996). Für den Trend über die Jahre hinweg wurde das Bestimmtheitsmaß $\mathrm{R}^{2}$ berechnet.

\section{Ergebnisse}

Temperaturen und Luftfeuchtigkeit in den Vegetationsperioden 1996-2011

Mittelwerte, absolute Maxima und Minima der Temperatur während der Vegetationsperiode sind in Tab. 1 dargestellt. In 2 m Höhe betrugen die mittleren Lufttemperaturen während der Vegetationsperiode rund 7,0 \pm $0,7^{\circ} \mathrm{C}$, in $50 \mathrm{~cm}$ Höhe $7,15 \pm 0,6^{\circ} \mathrm{C}$. In den Saxifraga-Polstern und in $10 \mathrm{~cm}$ Bodentiefe wurden signifikant höhere Temperaturen gemessen $(p \leq 0,05)$. Die Mittelwerte betrugen dabei im Pflanzenpolster auf Geröll 8,99 \pm $0,6^{\circ} \mathrm{C}$, auf Sand $9,5 \pm 0,8{ }^{\circ} \mathrm{C}$ und im Boden 
Tab. 1: Mittelwerte, absolute Maxima und Minima während der Vegetationsperiode im Gletschervorfeld des Rotmoosferners (1971er Moräne) in den Jahren 1996 - 2011. Die Messungen der Lufttemperatur erfolgten in $200 \mathrm{~cm}$ und $50 \mathrm{~cm}$ Höhe, die Bestandstemperaturen in Saxifraga oppositifolia-Polstern auf Geröll bzw. Sand und die Bodentemperaturen in $10 \mathrm{~cm}$ Tiefe

\begin{tabular}{|c|c|c|c|c|c|c|}
\hline Jahr & & $200 \mathrm{~cm}$ Luft & $50 \mathrm{~cm} \mathrm{Luft}$ & Saxi-Geröll & Saxi-Sand & $10 \mathrm{~cm}$ Boden \\
\hline & Mittel & 6,04 & 6,47 & 9,27 & 9,19 & 8,74 \\
\hline 1996 & Max & 18,3 & 19,7 & 28,8 & 29,8 & 21,5 \\
\hline \multirow[t]{2}{*}{ 6.6.-3.9. } & Min & $-4,5$ & $-4,6$ & 0,1 & $-0,3$ & 0,9 \\
\hline & Mittel & 7,48 & 7,45 & 8,80 & 9,70 & 7,95 \\
\hline 1997 & Max & 18,5 & 17,8 & 26,3 & 24,5 & 20,6 \\
\hline \multirow[t]{2}{*}{ 23.7.-30.9. } & Min & $-2,6$ & $-2,6$ & $-0,5$ & 0,6 & 0,7 \\
\hline & Mittel & 6,57 & 6,57 & 8,46 & 9,99 & 7,71 \\
\hline 1998 & Max & 20,9 & 20,2 & 31,8 & 27,9 & 21,6 \\
\hline \multirow[t]{2}{*}{ 1.7.-30.09. } & Min & $-6,7$ & $-6,2$ & $-1,9$ & 0,4 & $-0,1$ \\
\hline & Mittel & 7,13 & 7,39 & 8,79 & 8,93 & 8,21 \\
\hline 1999 & $\operatorname{Max}$ & 16,7 & 17,9 & 31,9 & 26,8 & 17,6 \\
\hline \multirow[t]{2}{*}{ 14.7.-30.9. } & Min & $-0,9$ & $-0,7$ & 0 & 0 & 1,4 \\
\hline & Mittel & 6,60 & 7,01 & 9,14 & 10,57 & 8,68 \\
\hline 2000 & Max & 18,7 & 20,2 & 31 & 27,1 & 19,3 \\
\hline \multirow[t]{2}{*}{ 17.6.-6.9. } & Min & $-3,1$ & $-3,1$ & $-0,3$ & 0,6 & 0,7 \\
\hline & Mittel & 6,09 & 6,38 & 8,41 & 8,04 & 7,96 \\
\hline 2001 & $\operatorname{Max}$ & 19,3 & 20,7 & 30,3 & 27,8 & 18,9 \\
\hline \multirow[t]{2}{*}{ 30.6.-21.9. } & Min & $-5,2$ & $-5,1$ & $-1,3$ & $-1,3$ & 0,2 \\
\hline & Mittel & 6,42 & 6,51 & 8,68 & 8,63 & 7,77 \\
\hline 2002 & Max & 16,2 & 17,2 & 29,1 & 26,7 & 19,2 \\
\hline \multirow[t]{2}{*}{ 4.7.-23.9. } & Min & $-3,8$ & $-3,9$ & -1 & $-1,2$ & 0,5 \\
\hline & Mittel & 8,42 & 8,54 & 10,89 & 10,11 & 9,87 \\
\hline 2003 & Max & 19,6 & 21,2 & 33,8 & 30,1 & 21,7 \\
\hline \multirow[t]{2}{*}{ 6.6.-30.9. } & Min & $-3,2$ & $-3,2$ & $-0,3$ & $-0,8$ & 1,1 \\
\hline & Mittel & 7,00 & 7,30 & 8,73 & 9,40 & 7,91 \\
\hline 2004 & $\operatorname{Max}$ & 16,2 & 18 & 33,3 & 26,9 & 21,3 \\
\hline \multirow[t]{2}{*}{ 15.7.-29.9. } & Min & $-5,1$ & $-4,9$ & $-0,9$ & 0,2 & 0,1 \\
\hline & Mittel & 6,92 & 7,04 & 8,56 & 9,25 & 8,64 \\
\hline 2005 & Max & 19,2 & 20,5 & 36,1 & 34 & 23,5 \\
\hline 12.6.-25.9. & Min & $-4,3$ & $-4,6$ & $-1,6$ & $-0,4$ & 1,6 \\
\hline
\end{tabular}




\begin{tabular}{|c|c|c|c|c|c|c|}
\hline Jahr & & $200 \mathrm{~cm} \mathrm{Luft}$ & $50 \mathrm{~cm} \mathrm{Luft}$ & Saxi-Geröll & Saxi-Sand & $10 \mathrm{~cm}$ Boden \\
\hline & Mittel & 7,65 & 7,98 & 9,32 & 10,44 & 9,35 \\
\hline 2006 & Max & 18,2 & 20,1 & 35,8 & 31,2 & 22,3 \\
\hline \multirow[t]{2}{*}{ 24.6.-27.9. } & Min & $-3,2$ & $-3,4$ & $-0,5$ & 0,6 & 1,6 \\
\hline & Mittel & 6,57 & 7,01 & 8,79 & 10,18 & 8,90 \\
\hline 2007 & Max & 16,3 & 18,2 & 28,1 & 26,5 & 19,2 \\
\hline \multirow[t]{2}{*}{ 20.6.-15.7. } & Min & $-2,1$ & $-1,9$ & 0 & 0,8 & 2,2 \\
\hline & Mittel & 6,83 & 6,97 & 9,01 & 9,19 & 8,61 \\
\hline 2008 & Max & 18,5 & 19,4 & 30,1 & 28,6 & 19,6 \\
\hline \multirow[t]{2}{*}{ 10.6.-26.9. } & Min & -8 & $-7,9$ & $-3,4$ & $-2,3$ & 0,6 \\
\hline & Mittel & 7,98 & 7,73 & 9,45 & 10,23 & 9,07 \\
\hline 2009 & Max & 19,3 & 18,2 & 24,3 & 27,5 & 19,2 \\
\hline \multirow[t]{2}{*}{ 27.6.-30.9. } & Min & $-3,3$ & $-3,4$ & 0,4 & 0,5 & 1,8 \\
\hline & Mittel & 6,31 & 6,63 & 9,15 & 8,16 & 8,11 \\
\hline 2010 & Max & 19,9 & 22,4 & 37,2 & 39,7 & 22,3 \\
\hline \multirow[t]{2}{*}{ 3.7.-30.9. } & Min & $-5,8$ & $-6,1$ & 0,3 & -3 & 0,4 \\
\hline & Mittel & 7,74 & 7,49 & 8,42 & 9,46 & 8,60 \\
\hline 2011 & Max & 20,9 & 19,7 & 31,2 & 28,6 & 20,8 \\
\hline 24.6.-30.9. & Min & $-4,6$ & $-4,6$ & $-1,1$ & 0,4 & 0,4 \\
\hline
\end{tabular}

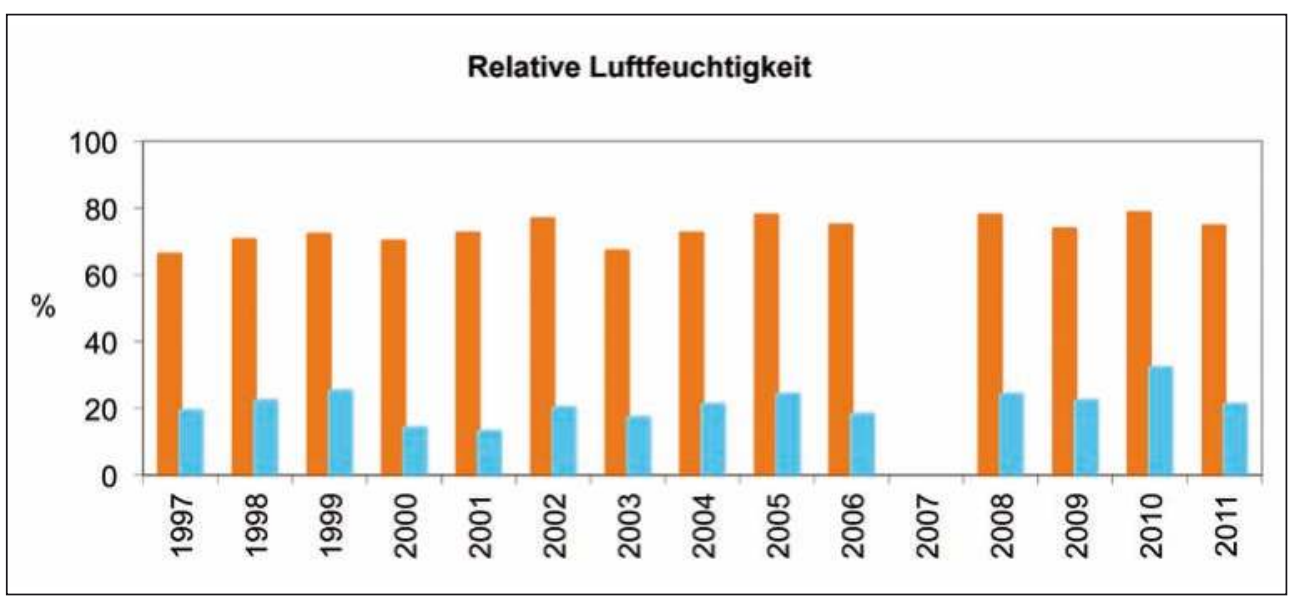

Abb. 2: Relative Luftfeuchtigkeit in \%, gemessen während der Vegetationsperiode im Gletschervorfeld des Rotmoosferners (1971er Moräne) in $200 \mathrm{~cm}$ Höhe; rot = Mittelwerte, blau = mittlere Minima 
$8,5 \pm 0,6{ }^{\circ} \mathrm{C}$. Signifikante Unterschiede $(\mathrm{p} \leq 0,05)$ waren auch zwischen dem SandStandort und den Bodentemperaturen zu vermerken. Das absolute Maximum wurde mit 39,7 ${ }^{\circ} \mathrm{C}$ am Sand-Standort erreicht (2010), während die Lufttemperatur zu diesem Zeitpunkt nur maximal $19,9^{\circ} \mathrm{C}$ erreichte. Das absolut höchste Maximum der Lufttemperatur betrug $20,9{ }^{\circ} \mathrm{C}$ im Sommer 2011. Die absoluten Minima in der Vegetationszeit lagen in den Saxifraga-Polstern zwischen $-3,4$ und $-3,0^{\circ} \mathrm{C}$, in $2 \mathrm{~m}$ Höhe betrug das absolute Minimum allerdings $-8,0^{\circ} \mathrm{C}$ (2008). Der Frost reichte in der Vegetationszeit kaum in den
Boden hinein, hier betrug das absolute Minimum nur $-0,1^{\circ} \mathrm{C}$.

Die Mittelwerte der relativen Luftfeuchtigkeit in $2 \mathrm{~m}$ Höhe reichten von 65 bis $79 \%$ (Abb. 2), das absolute Minimum betrug $13 \%$, die absoluten Maxima erreichten $98 \%$ bzw. $100 \%$.

\section{Bodenoberflächentemperaturen}

Die mittlere Jahrestemperatur, berechnet über die Periode von 1998-2011, betrug an der Bodenoberfläche $2,2{ }^{\circ} \mathrm{C}$ (Tab. 2), mit einer

Tab. 2: Mittlere Monatstemperaturen, absolute Maxima und Minima 1998-2011 an der Bodenoberfläche im Bereich der 1971er Moräne des Gletschervorfeldes

\begin{tabular}{lccc}
\hline 1998-2011 & Mittel & Max & Min \\
\hline Jänner & $-1,3$ & 0 & $-7,0$ \\
\hline Februar & $-1,2$ & $-0,1$ & $-4,7$ \\
\hline März & $-0,9$ & 0,1 & $-3,9$ \\
\hline April & $-0,5$ & 0,1 & $-1,7$ \\
\hline Mai & 0,3 & 23,6 & $-3,1$ \\
\hline Juni & 6,0 & 31,6 & $-3,7$ \\
\hline Juli & 9,2 & 35,4 & $-1,7$ \\
\hline August & 9,7 & 36,1 & $-1,1$ \\
\hline September & 5,5 & 32,6 & $-3,4$ \\
\hline Oktober & 1,3 & 28,3 & $-7,4$ \\
\hline November & $-0,9$ & 12,3 & $-10,5$ \\
\hline Dezember & $-0,6$ & 22,2 & $-4,6$ \\
\hline Jahr & $\mathbf{2 , 2}$ & & $-10,5$ \\
\hline Extremwerte & & 36,1 & $(2001)$ \\
\hline
\end{tabular}


Schwankungsbreite von $1,3{ }^{\circ} \mathrm{C}$ (1998) und $4,7^{\circ} \mathrm{C}$ (2010, Abb. 3). Das absolute Maximum betrug im Sommer 2011 36,1 ${ }^{\circ} \mathrm{C}$ (am 20. August), das absolute Minimum resultierte mit $-10,5{ }^{\circ} \mathrm{C}$ (Tab. 2) am 24. November 2001. Der absolut tiefste Wert während der gesamten Untersuchungszeit wurde mit $-11,5^{\circ} \mathrm{C}$ im Jahre 1997 (am 29. Oktober) an der Bodenoberfläche registriert. In den
Sommermonaten Juli und August wurden Mittelwerte von $9,2{ }^{\circ} \mathrm{C}$ und $9,7^{\circ} \mathrm{C}$ erreicht (Tab. 2). Die tiefsten Temperaturen wurden jeweils im Jänner, Oktober und November gemessen. Frost konnte allerdings in jeder Jahreszeit beobachtet werden: Im Juli und August beispielsweise lagen die absoluten Minima bei $-1,7^{\circ} \mathrm{C}$ bzw. $-1,1^{\circ} \mathrm{C}$.

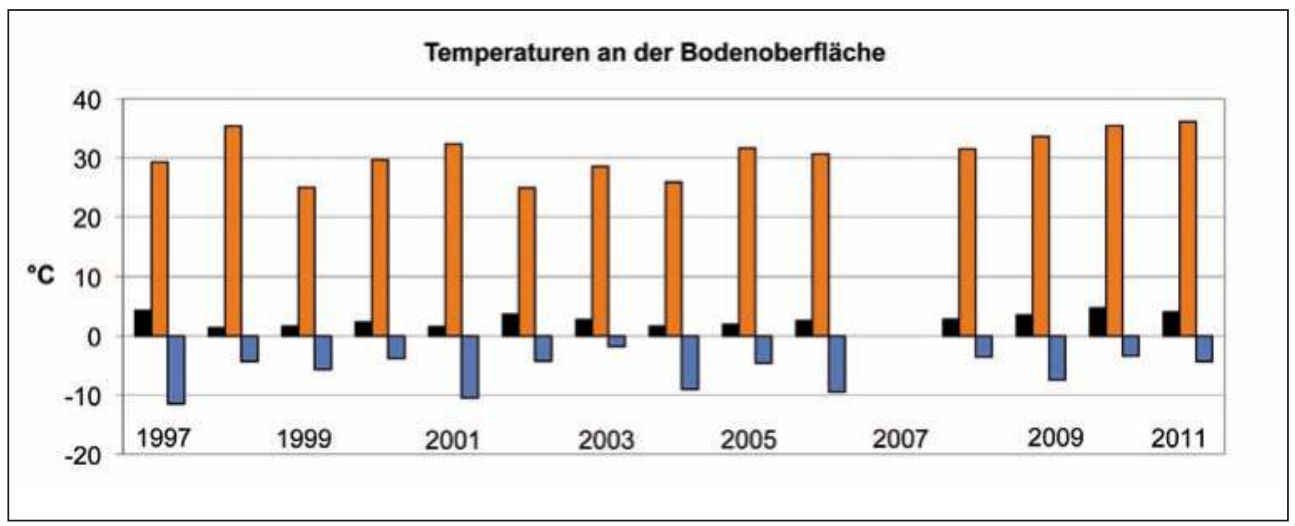

Abb. 3: Temperaturen an der Bodenoberfläche auf der 1971er Moräne des Gletschervorfeldes: Jahresmittel (schwarz), absolute Maxima (orange) und Minima (blau) in den Jahren 1997-2011. Für 2007 liegen nur teilweise Daten vor, daher können hier keine Werte angegeben werden

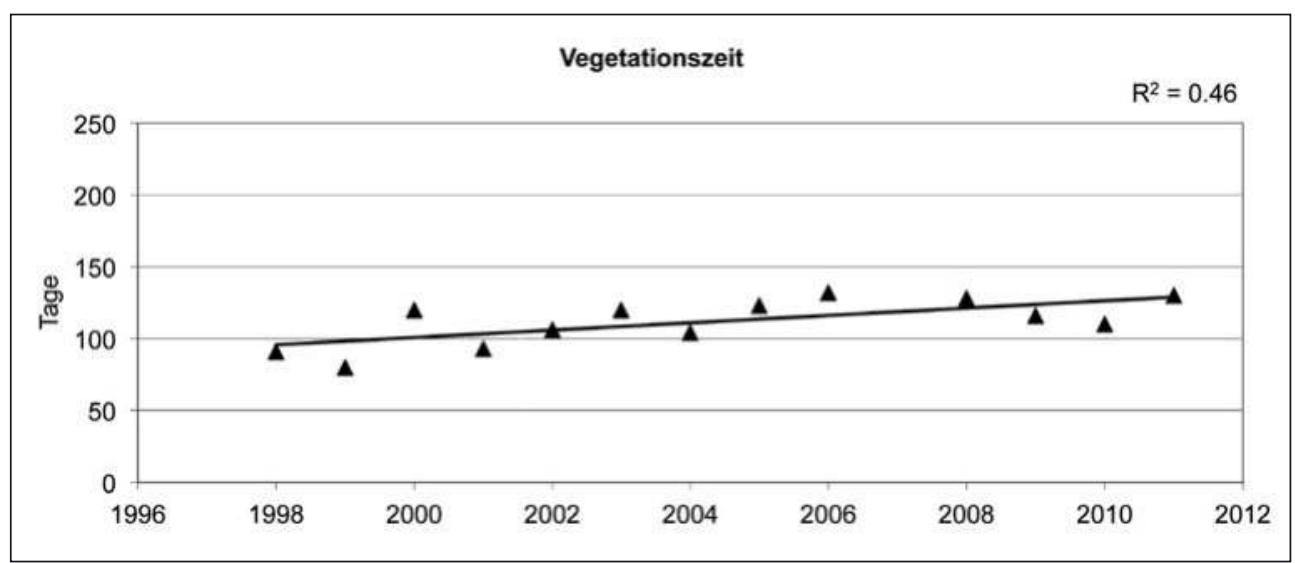

Abb. 4: Vegetationszeit in Tagen (Tage mit Mittelwerten von $>2{ }^{\circ} \mathrm{C}$ ) von 1997-2011 mit Trendlinie (Bestimmtheitsmaß $\mathrm{R}^{2}=0,46$ ) 


\section{Dauer der Vegetationszeit}

Die Vegetationszeit (GDD, Tagesmittel > $2{ }^{\circ} \mathrm{C}$ ) dauerte im Durchschnitt $112 \pm 16$ Tage, wobei über die Untersuchungsperiode hinweg ein leicht ansteigender Trend zu erkennen ist $\left(R^{2}=0,46 ; A b b .4\right)$. Die schneefreie Zeit (TDD, Tagesmittel $>0{ }^{\circ} \mathrm{C}$ ) betrug im Durchschnitt $137 \pm 38$ Tage, wobei vor allem in einigen Jahren eine lange schneefreie Zeit bis in den November festzustellen war. Die Zeit der Ausaperung im Frühjahr/Frühsommer (Abb. 5) war sehr unterschiedlich (Tab. 3). Die frühesten Ausaperungstermine konnten in den Jahren 2000, 2003, 2005, 2007, 2008 und 2011 beobachtet werden. In diesen Jahren waren die Untersuchungsflächen bereits ab Mai schneefrei. Der absolut früheste Beginn der Vegetationsperiode war 2007 bereits ab 12. Mai mit Tagesmitteltemperaturen von
Tab. 3: Beginn der Vegetationsperiode in den Jahren 1998-2012 auf der 1971er Moräne des Gletschervorfeldes

\begin{tabular}{cc}
\hline Jahr & Beginn Vegetationsperiode \\
\hline $\mathbf{1 9 9 8}$ & 27. Juni \\
\hline $\mathbf{1 9 9 9}$ & 29. Juni \\
\hline $\mathbf{2 0 0 0}$ & 23. Mai \\
\hline $\mathbf{2 0 0 1}$ & 30. Juni \\
\hline $\mathbf{2 0 0 2}$ & 10. Juni \\
\hline $\mathbf{2 0 0 3}$ & 31. Mai \\
\hline $\mathbf{2 0 0 4}$ & 30. Juni \\
\hline $\mathbf{2 0 0 5}$ & 27. Mai \\
\hline $\mathbf{2 0 0 6}$ & 7. Juni \\
\hline $\mathbf{2 0 0 7}$ & 12. Mai \\
\hline $\mathbf{2 0 0 8}$ & 31. Mai \\
\hline $\mathbf{2 0 0 9}$ & 13. Juni \\
\hline $\mathbf{2 0 1 0}$ & 9. Juni \\
\hline $\mathbf{2 0 1 1}$ & 25. Mai \\
\hline $\mathbf{2 0 1 2}$ & 2. Juni \\
\hline
\end{tabular}

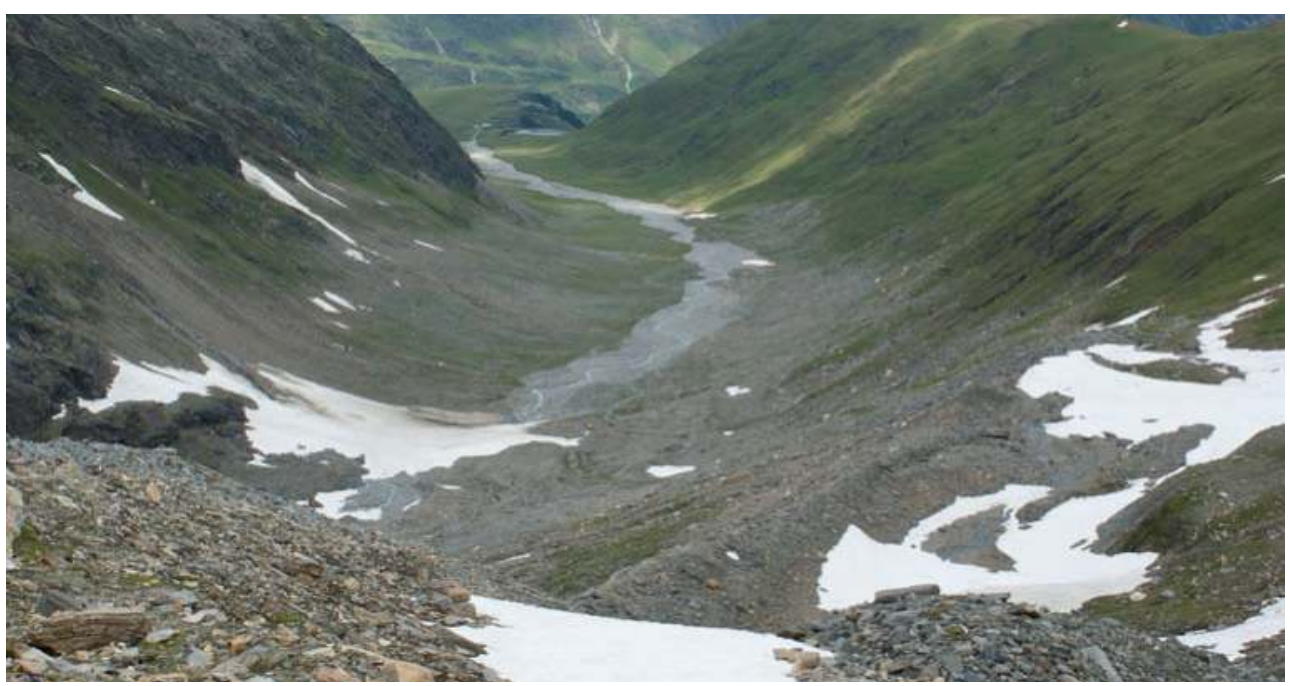

Abb. 5: Ausaperungsmuster im Rotmoostal, von der Liebener Rippe aus betrachtet. Deutlich zu sehen ist die Lawine von den Seelenkögeln herab, die Jahr für Jahr unterhalb der Versuchsfläche der 1971er Moräne eine sehr späte Ausaperung bewirkt (Foto: Eva-Maria Koch, 09.07.09) 


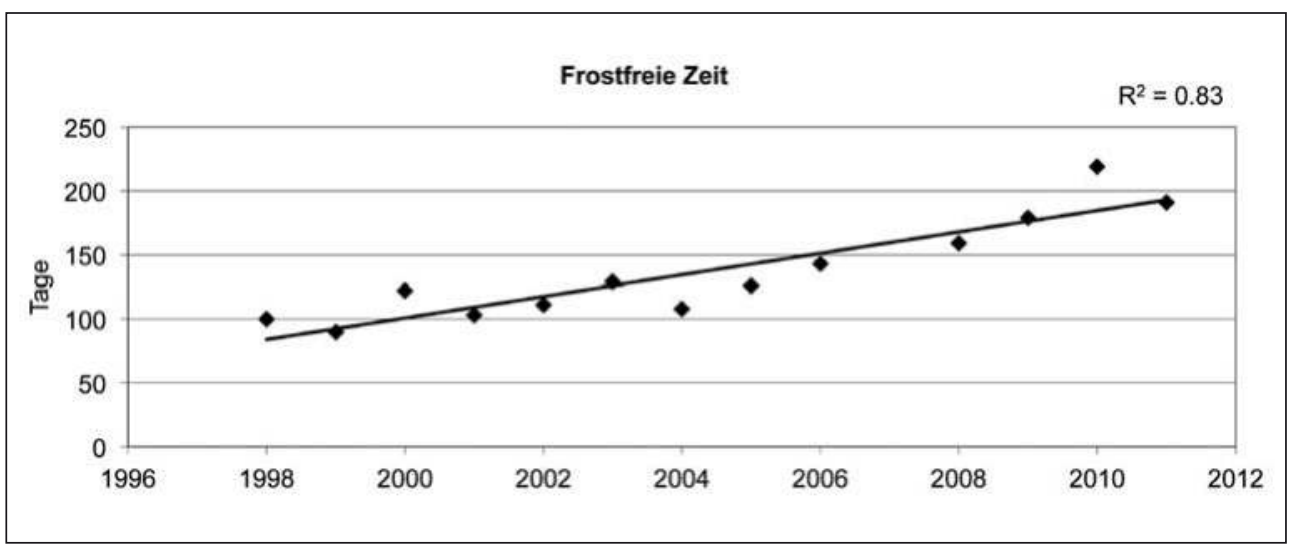

Abb. 6: Frostfreie Zeit in Tagen (Tage mit Mittelwerten von $>0^{\circ} \mathrm{C}$ ) von 1997-2011 mit Trendlinie (Bestimmtheitsmaß $\mathrm{R}^{2}=0,83$ )

$>2{ }^{\circ} \mathrm{C}$ (Tab. 3). Insgesamt ergab sich auch hinsichtlich schneefreier Zeit ein ansteigender Trend über den gesamten Messzeitraum $\left(\mathrm{R}^{2}=0,83\right.$, Abb. 6).

Einige typische Jahresgänge der Bodenoberflächentemperaturen sind in den Abb. 7 und 8 dargestellt. Die winterliche Schneedecke bewirkte in der Regel eine Bodenoberflächentemperatur von knapp unter $0{ }^{\circ} \mathrm{C}$ bis unter $-2{ }^{\circ} \mathrm{C}$. Tiefere Temperaturen waren im Un- tersuchungszeitraum eher selten. Ein Beispiel dafür zeigt Abb. 7 für die Winterperiode 2001-2002, für welche Tagesmittelwerte von bis zu $-10,5^{\circ} \mathrm{C}$ berechnet wurden.

Zwischen Bodenoberflächen- und Lufttemperaturen in $2 \mathrm{~m}$ Höhe bestehen höchst signifikante Unterschiede ( $\mathrm{p}<0,0001)$. Die Unterschiede hinsichtlich Tagesmittelwerte sind in Abb. 9 für die Sommermonate 2000, 2005 und 2010 dargestellt.

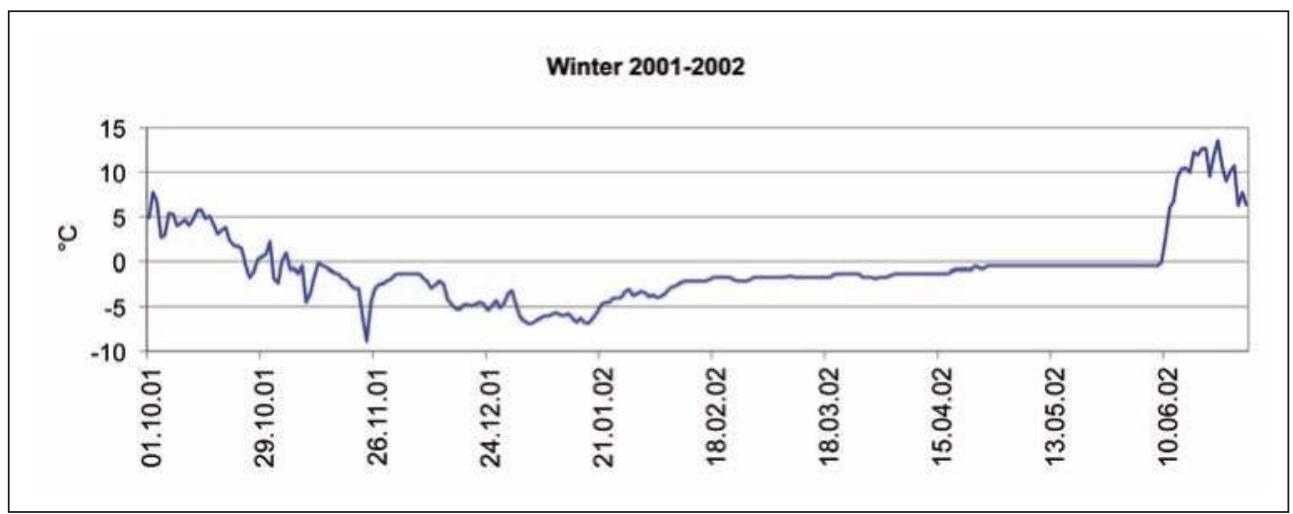

Abb. 7: Bodenoberflächentemperaturen in der Winterperiode 2001-2002 und im Juni 2002. Angegeben sind die Tagesmittelwerte 


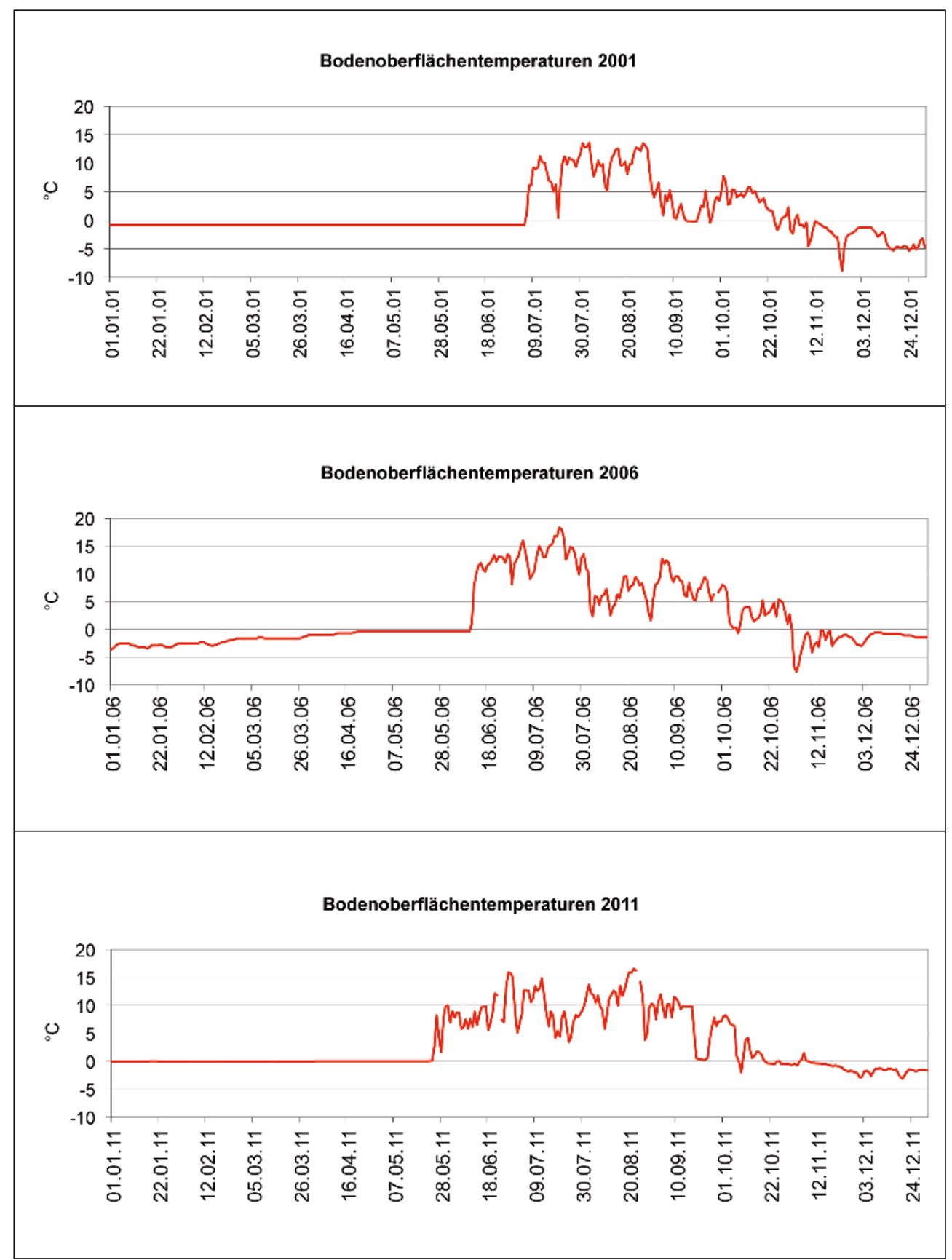

Abb. 8: Bodenoberflächentemperaturen der Jahre 2001, 2006 und 2011 auf der 1971er Moräne im Gletschervorfeld des Rotmoosferners. Angegeben sind die Tagesmittelwerte 


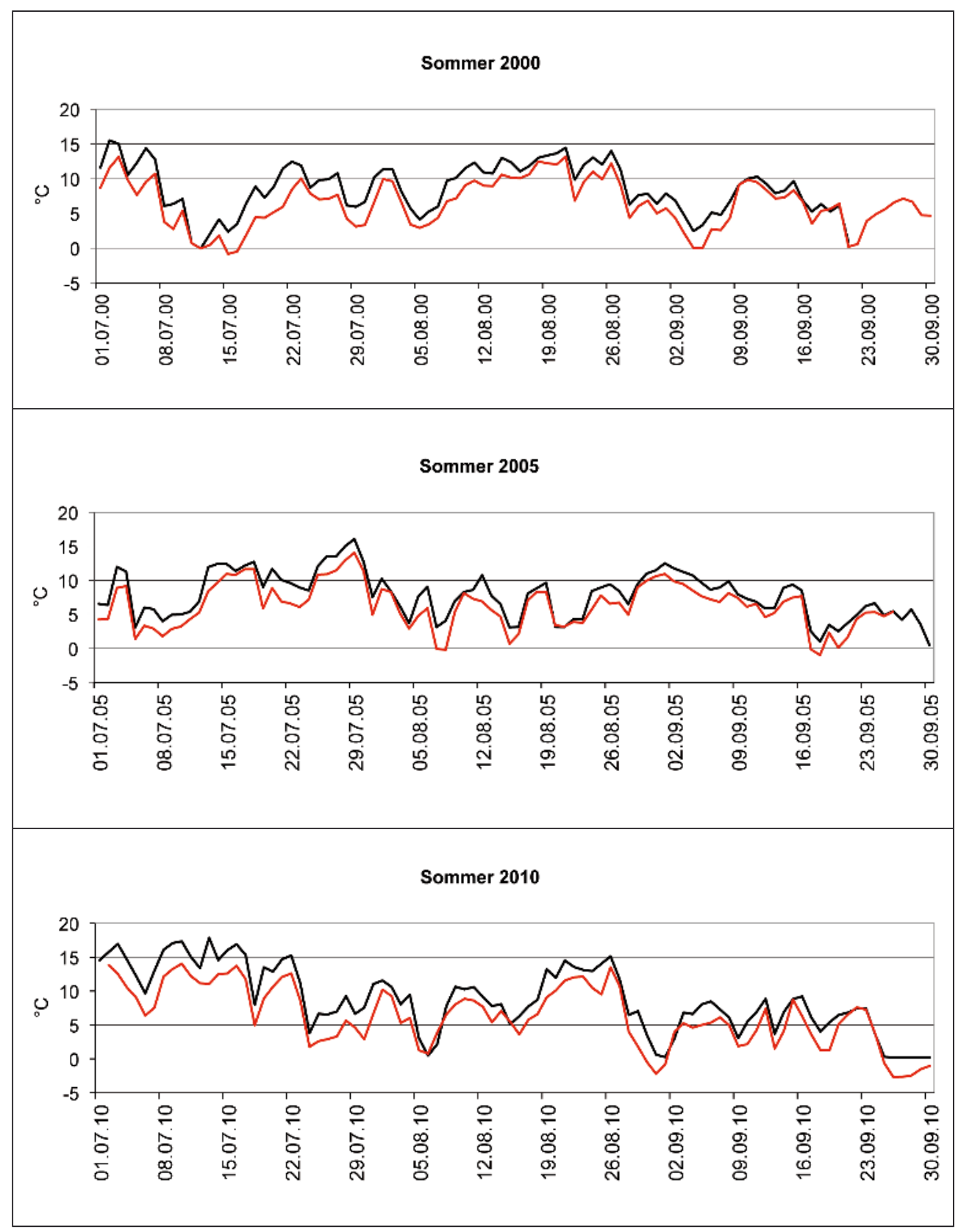

Abb. 9: Verlauf der Lufttemperatur in $2 \mathrm{~m}$ Höhe (rot) und der Bodenoberflächentemperatur (schwarz) auf der 1971er Moräne im Gletschervorfeld des Rotmoosferners für die Monate Juli, August, September 2000, 2005 und 2010 


\section{Diskussion}

Wie erwartet gab es höchst signifikante Unterschiede zwischen den Luft- und Bodenoberflächentemperaturen bzw. den Luft- und Bodentemperaturen, ebenso wie auch zwischen den Luft- und Pflanzentemperaturen. Auf die höhere Erwärmung der Pflanzenorgane, der Bodenoberfläche und des Bodens wurde bereits vielfach hingewiesen (Körner 2003; Larcher \& Wagner 2009, 2010; Larcher 2012; Neuner \& Buchner 2012). Die Topographie und die Eigenschaften des Substrates (z. B. Körnigkeit, Porenanteil, Lagerungsdichte, Wassergehalt; Scheffer/Schachtschabel 1992) bzw. die Struktur der Vegetation und ihre ökophysiologischen Besonderheiten bestimmen dabei die Variabilität und die Spanne der Temperaturunterschiede (Graham et al. 2012). Die sandige Bodenoberfläche bewirkt offensichtlich eine stärkere Erwärmung des Saxifraga oppositifolia-Polsters im Vergleich zu jenem auf grobkörnigem Material. Die Steine, zwischen denen letzterer wuchs, ließen wohl eine intensivere Luftbewegung im Polster zu. Allerdings waren die Unterschiede zwischen grob- und feinkörnigem Vorkommen von Saxifraga oppositifolia statistisch nicht signifikant. Bei allen Temperaturdaten ist zu bedenken, dass die Messergebnisse bereits über sehr kurze Distanzen - im Meterbereich (Scherrer \& Körner 2011), teilweise sogar schon im Zentimeterbereich (Graham et al. 2012) - stark variieren können.

Vergleicht man die Lufttemperaturen in 2 m Höhe im Gletschervorfeld des Rotmoos- ferners mit jenen des Patscherkofel-Gipfelbereichs (2247 m Meereshöhe), so sind die Mittelwerte am Patscherkofel (Zeitraum 1995-2009, Larcher \& Wagner 2010) im Juli und August um $0,7^{\circ} \mathrm{C}$ bis $0,9^{\circ} \mathrm{C}$ höher als im Gletschervorfeld. Im Vergleich dazu sind die Lufttemperaturen am Mittelbergferner (Ötztaler Alpen, 2850 m Meereshöhe; Larcher $\&$ Wagner 2010) im Juli und August um $2,2{ }^{\circ} \mathrm{C}$ bzw. $1,9^{\circ} \mathrm{C}$ kälter als im Gletschervorfeld des Rotmoosferners. Diese Unterschiede zu niedriger bzw. höher gelegenen Stationen entsprechen sehr gut der Temperaturabnahme mit der Höhe, die durchschnittlich $0,60{ }^{\circ} \mathrm{C}$ bis $0,65^{\circ} \mathrm{C}$ pro 100 Höhenmeter ausmacht (Franz 1979).

Für das untersuchte Gletschervorfeld im Rotmoostal konnten verhältnismäßig lange Vegetationszeiten von durchschnittlich mehr als 3 Monaten beobachtet werden. Im Vergleich dazu wurden aus dem Gletschervorfeld des Schaufelferners im Stubaital auf $2880 \mathrm{~m}$ Meereshöhe nur 5 Wochen bis 2 Monate Vegetationszeit angegeben (Larcher et al. 2010). Unter einer winterlichen Schneedecke von mehr als $50 \mathrm{~cm}$ sinkt die Temperatur selten unter $-5^{\circ} \mathrm{C}$ ab (Aulitzky et al. 1982, Sakai \& Larcher 1987). Dies zeigte sich auch im Gletschervorfeld des Rotmoosferners. Stärkere Fröste mit mittleren Minima an der Bodenoberfläche von $-4{ }^{\circ} \mathrm{C}$ bis $-6^{\circ} \mathrm{C}$ traten im Gletschervorfeld des Rotmoosferners öfters im Spätherbst und in der ersten Winterhälfte bei noch geringer bis fehlender Schneedecke auf. Im Spätwinter war das Gebiet meist schneebedeckt, die Temperaturen lagen dann knapp unter $0{ }^{\circ} \mathrm{C}$. 
Das Mikroklima hängt ganz wesentlich von der Strahlung am Standort ab (Körner et al. 2003): Längere Besonnung führt zu höheren Temperaturen und einer längeren Vegetationsperiode, aber auch zu stärkeren Frösten, wenn die Schneedecke fehlt. So konnten beispielsweise Körner et al. (2003) auf der Hohen Mut in 2592 m Meereshöhe im Jahr 1999 eine Vegetationsperiode von 160 Tagen ermitteln und für das Jahr 2000 ein absolutes Minimum von $-15,2{ }^{\circ} \mathrm{C}$ in $10 \mathrm{~cm}$ Bodentiefe messen (Jänner 2000). Auf der 1971er Moräne im Gletschervorfeld des Rotmoosferners dauerte die Vegetationsperiode im Jahr 1999 ca. 100 Tage. Das absolute Minimum der Temperatur an der Bodenoberfläche betrug im Gletschervorfeld im Jänner 2000 nur $-3,9^{\circ} \mathrm{C}$.

Während der Vegetationsperiode gab es immer wieder einzelne Frostereignisse und es stellt sich die Frage nach der Gefährdung der Pflanzen. Die Frostresistenz der Pflanzen variiert sehr stark je nach Lebensform (Taschler $\&$ Neuner 2004) und ist abhängig vom Entwicklungsstadium der Pflanze (Marcante et al. 2012, Ladinig et al. 2013, Neuner et al. 2013). Marcante et al. (2012) zeigten, dass vor allem Keimlinge und Jungpflanzen eine geringe Frostresistenz aufweisen und bereits bei $-2,5{ }^{\circ} \mathrm{C}$ zugrunde gehen (die Resistenz wurde als $\mathrm{LT}_{50}$ bestimmt, d.h. nach einer Expositionszeit von 4 Stunden waren $50 \%$ der Proben letal geschädigt). Für Keimlinge der Pionierarten und deren Jungpflanzen (z.B. Saxifraga aizoides, Oxyria digyna und Artemisia genipi) könnten demnach die gemessenen Frostereignisse in der Vegetationszeit bereits letal gewesen sein, ebenso für Poa alpina-
Keimlinge. Eine adulte Poa alpina-Pflanze ist hingegen ziemlich frostresistent ( $\mathrm{LT}_{50}$ : $\left.-9,8^{\circ} \mathrm{C} \pm 2,7^{\circ} \mathrm{C}\right)$. Die Sensitivität der Entwicklungsstadien von alpinen Pflanzen gegenüber Frost ist jedoch artspezifisch. So weisen beispielsweise adulte Pflanzen von Saxifraga aizoides und Oxyria digyna eine geringere Frostresistenz auf im Vergleich zu ihren Keimlingen (Marcante et al. 2012). Außerdem tolerieren die vegetativen Organe der alpinen Pflanzen um $2-5^{\circ} \mathrm{C}$ niedrigere Fröste im Vergleich zu den reproduktiven Teilen (Neuner et al. 2013, Ladinig et al. 2013).

Hinsichtlich Hitzeschäden scheint es zumindest in den vergangenen Jahren keine Gefährdung gegeben zu haben. Die untersuchten Entwicklungsstadien der Gletschervorfeldarten wiesen wesentlich höhere Hitzeresistenzen auf (z.B. $\mathrm{LT}_{50}:+46,2^{\circ} \mathrm{C}$ für Keimlinge; Silvia Marcante, unpubl. Daten) im Vergleich zu den absoluten Maxima, die während der Untersuchungszeit an der Bodenoberfläche $\left(36,1{ }^{\circ} \mathrm{C}\right)$ oder in den Pflanzenpolstern $\left(39,7{ }^{\circ} \mathrm{C}\right)$ gemessen wurden. Hitzeschäden können allerdings in alpinen Habitaten auftreten und wurden beispielsweise an Blättern von Minuartia recurva (Buchner \& Neuner 2003) und Saxifraga paniculata (Neuner et al. 1999-B16) nachgewiesen.

Insgesamt betrachtet zählt die Temperatur zu den primären Faktoren, welche die Besiedelung im Gletschervorfeld beeinflussen. Allerdings zeigten die Arbeiten von Erich Schwienbacher (unpubl. Daten des FWF-Projektes P19090) und Erschbamer et al. (2012), dass die Trockenheit der obersten Bodenschichten entscheidend ist sowohl für die Keimung als 
auch für die Etablierung der Keimlinge. Auch Interaktionen zwischen der Feuchtigkeit des Bodens und den Bodentemperaturen werden angenommen (Graham et al. 2012). Hier besteht auf jeden Fall noch weiterer Forschungsbedarf.

\section{Literatur}

Aulitzky, H., Turner, H. \& Mayer, H. (1982) Bioklimatische Grundlagen einer standortsgemäßen Bewirtschaftung des subalpinen Lärchen-Arvenwaldes. Mitt. Eidg. Anst. Forst. Versuchswes. 58: 327-580.

Buchner, O. \& Neuner, G. (2003) Variability of heat tolerance in alpine plant species measured at different altitudes. Arct., Antarc., Alp. Res. 35: 411-420.

Cernusca, A. (1976) Bestandesstruktur, Bioklima und Energiehaushalt von alpinen Zwergstrauchbeständen. OEcol. Plant. 11: 71-102.

Erschbamer, B. (2007) Winners and losers of climate change in a central alpine glacier foreland. Arct., Antarc., Alp. Res. 39: 237-244.

Erschbamer, B., Bösch, D., Fleisch, M., Peintner, U. \& Schwienbacher, E. (2012) Keimung und Etablierung im Gletschervorfeld in Abhängigkeit von abiotischen und biotischen Faktoren. Ber. ReinholdTüxen-Gesell. 24: 89-102.

Franz, H. (1979) Ökologie der Hochgebirge. Ulmer, Stuttgart.
Graham, E.A., Rundel, P.W., Kaiser, W., Lam, Y., Stealey, M. \& Yuen, E.M. (2012) Fine-scale patterns of soil and plant surface temperatures in an alpine fellfield habitat, White Mountains, California. Arct., Antarct., Alp. Res. 44: 288-295.

Koch, E.-M. \& Kaufmann, R. (2010) Die tierische Besiedlung von Gletschermoränen. In: Glaziale und periglaziale Lebensräume im Raum Obergurgl, Koch, E.-M., Erschbamer, B. (Hg.), Alpine Forschungsstelle Obergurgl 1, Innsbruck University Press, Innsbruck, S. 165-183.

Körner, Ch. (2003) Alpine Plant Life. $2^{\text {nd }}$ edn. Springer, Berlin.

Körner, Ch., Paulsen, J. \& Pelaez-Riedl, S. (2003) A bioclimatic characterisation of Europe's alpine areas. In: Alpine Biodiversity in Europe, Nagy, L., Grabherr, G., Körner, Ch., Thompson, D.B.A. (Hg.) Springer, Berlin, S. 13-28.

Körner, Ch. \& Larcher, W. (1988) Plant life in cold climates. In: Plants and Temperature, Long S.F., Woodward F.I. (Hg.) Symp. Soc. Exp. Biol. 42, Cambridge, The Company of Biologists Ltd, S. 25-57.

Ladinig, U., Hacker, J., Neuner, G. \& Wagner, J. (2013) How endangered is sexual reproduction of high-mountain plants by summer frosts? - Frost resistance, frequency of frost events and risk assessment. Oecologia, accepted.

Larcher, W. (2012) Bioclimatic temperatures in the High Alps. In: Plants in Alpine Regions. Cell Physiology of Adaptionand Survival Strategies, Lütz, C. (Hg.) Springer, Wien, New York, S. 21-27. 
Larcher, W. \& Wagner, J. (2004) Lebensweise der Alpenrosen in ihrer Umwelt: 70 Jahre ökophysiologische Forschung in Innsbruck. Ber. nat.-med. Verein Innsbruck 91: 251-291.

Larcher, W. \& Wagner, J. (2009) High mountain bioclimate: temperatures near the ground recorded from the timberline to the nival zone in the Central Alps. Contrib. Nat. Hist. 12: 857-874.

Larcher, W., Kainmüller, C. \& Wagner, J. (2010) Survival types of high mountain plants under extreme temperatures. Flora 205: 3-18.

Larcher, W. \& Wagner, J. (2010) Temperatures in the life zones of the Tyrolean Alps. Österr. Akademie der Wissenschaften, Sitzungsber. Abt. I 213: 31-51.

Marcante, S., Sierra-Almeida, A., Spindelböck, J.P., Erschbamer, B. \& Neuner, G. (2012) Frost as a limiting factor for recruitment and establishment of early development stages in an alpine glacier foreland? J. Veg. Sci. 23: 858-868.

Molau, U. \& Mølgaard, P. (1996) The ITEX manual. Danish Polar Center, Copenhagen, Denmark.

Nagl, F. \& Erschbamer, B. (2010) Vegetation und Besiedelungsstrategien. In: Glaziale und periglaziale Lebensräume im Raum Obergurgl, Koch, E.-M., Erschbamer, B. (Hg.), Alpine Forschungsstelle Obergurgl 1, Innsbruck University Press, Innsbruck, S. 121-163.

Neuner, G., Braun, V., Buchner, O. \& Taschler, D. (1999) Leaf rosette closure in the alpine rock species Saxifraga paniculata
Mill.: significance for survival of drought and heat under high irradiation. Plant Cell Environ. 22: 1539-1548.

Neuner, G. \& Buchner, O. (2012) Dynamics of tissue heat tolerance and thermotolerance of PS II in alpine plants. In: Plants in Alpine Regions. Cell Physiology of Adaption and Survival Strategies, Lütz, C. (Hg.) Springer, Wien, New York, S. 61-74

Neuner, G., Erler, E., Ladinig, U., Hacker, J. \& Wagner, J. (2013) Frost resistance of reproductive tissues during various stages of development in high mountain plants. Phys. Plant. Doi: 10.1111/j.13993054.2012.01616.x

Raffl, C., Mallaun, M., Mayer, R. \& Erschbamer, B. (2006) Vegetation succession pattern and diversity changes in a glacier valley, Central Alps, Austria. Arct., Antarct., Alp. Res. 38: 421-428.

Sakai, A. \& Larcher, W. (1987) Frost Survival of Plants: Responses and Adaptation. Ecol. Stud. 62, Springer, Berlin, Heidelberg, New York.

Scheffer/Schachtschabel (1992) Lehrbuch der Bodenkunde. Schachtschabel, P., Blume, H.-P., Brümmer, G., Hartge, K.-H., Schwertmann, U. (Hg.) Fischer, W.R., Renger, M., Strebel, O. (Mitarbeit) Ferdinand Enke Verlag, Stuttgart.

Scherrer, D. \& Körner, Ch. (2011) Topographically controlled thermal-habitat differentiation buffers alpine plant diversity against climate warming. J. Biogeography 38: 406-416. 
Taschler, D. \& Neuner, G. (2004) Summer frost resistance and freezing patterns measured in situ in leaves of major alpine plant growth forms in relation to their upper distribution boundary. Plant Cell Environ. 27: 737-746.

Taschler, D., Beikircher, B. \& Neuner, G. (2004) Frost resistance and ice nucleation in leaves of five woody timberline species measured in situ during shoot expansion. Tree Physiol. 24: 331-337.

\section{Verzeichnis der Autorin}

Brigitta Erschbamer

Institut für Botanik

Universität Innsbruck

Sternwartestr. 15, 6020 Innsbruck

Brigitta.Erschbamer@uibk.ac.at 
Daniel Erhart

\section{Die Lebewelt der Ötztaler Ache}

Tab. A1: Artenliste Algen, Ötztaler Ache

\section{„Blaualgen“ (Cyanophyceae)}

Chamaesiphon polonicus (ROSTAF.) HANSG.

Chamaesiphon subglobosus (ROSTAF.) LEMM.

Homoeothrix gracilis (HANSG.) KOM.\& KOV.

Homoeothrix janthina (BORN. et FLAH.) STARM.

Homoeothrix varians GEITLER

Hydrococcus cesatii RABENH.

Phormidium autumnale AG. ex GOM.

\section{Goldalgen (Chrysophyceae)}

Hydrurus foetidus (VILL.) TREV.

Phaeodermatium rivulare HANSG.

\section{Grünalgen (Chlorophyceae)}

Ulothrix zonata KÜTZING

\section{Rotalgen (Rhodophyceae)}

Audouinella hermannii (ROTH) DUBY

Lemanea fluviatilis (DILLW.) AG.

\section{Kieselalgen (Bacillariophyceae)}

Achnanthes daonensis L.-B.

Achnanthes minutissima KÜTZ.

Cymbella minuta HILSE 
Anhang Kapitel 6 I Die Ötztaler Ache

\section{Kieselalgen (Bacillariophyceae)}

Cymbella silesiaca BLEISCH

Cymbella sinuata GREGORY

Diatoma hyemalis (ROTH) HEIBERG

Diatoma mesodon (EHR.) KÜTZ.

Fragilaria arcus KÜTZING

Fragilaria capucina var. gracilis (OEST.) HUST.

Fragilaria capucina var. rumpens (KÜTZ.) L.-B.

Fragilaria capucina var. vaucheriae (KÜTZ.) L.-B.

Fragilaria construensf. venter (EHR.) GRUN.

Fragilaria virescens RALFS

Gomphonema micropus KÜTZING

Gomphonema olivaceum var. minutissimum HUST.

Gomphonema olivaceum var. olivaceoides (HUST.) L.-B.

Meridion circulare AGARDH

Navicula gregaria DONKIN

Navicula minuscula var. minuscula GRUNOW

Navicula suchlandtii HUSTEDT

Nitzschia capitellata HUSTEDT

Nitzschia dissipata (KÜTZ.) GRUN.

Nitzschia pura HUSTEDT

Tabellaria flocculosa (ROTH) KÜTZ. 
Tab. A2: Artenliste Makrozoobenthos, Ötztaler Ache

\section{Oligochaeta}

\section{Naididae}

Nais elinguis

Nais cf. stolci

Nais variabilis

\section{Propappidae}

Propappus volki

\section{Ephemeroptera}

\section{Baetidae}

Baetis alpinus

\section{Heptageniidae}

Rhithrogena hybrida-Gr.

Rhithrogena cf. loyolaea

Rhithrogena nivata

Rhithrogena cf. puthzi

\section{Plecoptera}

\section{Perlodidae}

Dictyogenus alpinum

Isoperla grammatica

Isoperla obscura

Perlodes microcephalus 
Anhang Kapitel 6 I Die Ötztaler Ache

\section{Plecoptera}

\section{Perlidae}

Dinocras megacephala

\section{Taeniopterygidae}

Rhabdiopteryx alpina

Rhabdiopteryx neglecta

Trichoptera

Limnephilidae

Allogamus auricollis

Drusus biguttatus

\section{Diptera}

\section{Chironomidae}

Brillia bifida

Cardiocladius capucinus

Chaetocladius piger-Gr.

Diamesa cf. cinerella

Diamesa cinerellalzernyi-Gr.

Diamesa dampfi-Gr.

Diamesa cf. hamaticornis

Diamesa latitarsis-Gr.

Diamesa steinboecki

Eukiefferiella brevicalcar

Eukiefferiella fittkauil minor 
Anhang Kapitel 6 I Die Ötztaler Ache

\section{Diptera}

Orthocladiini COP

Orthocladius (Euorthocladius) frigidus

Orthocladius (Euorthocladius) rivicola

Orthocladius (Euorthocladius) rivicola-Gr.

Pseudodiamesa branickii

Tvetenia bavarica

\section{Simuliidae}

Prosimulium rufipes

Simulium (Simulium) monticola

\section{Blephariceridae}

Hapalothrix lugubris 


\section{Hartl, R. Kaufmann, N. Schallhart, B. Erschbamer}

Das Mikroklima waldfreier Standorte in der subalpinen, alpinen und subnivalen Stufe in Obergurgl

Tab. A1: Monatsmittel, -maxima, -minima und Anzahl der frostfreien Tage (TDD) in $2 \mathrm{~m}$ Höhe (Lufttemperatur) und in $10 \mathrm{~cm}$ Bodentiefe (Bodentemperatur), gemittelt über den Untersuchungszeitraum 20002011

\begin{tabular}{|c|c|c|c|c|c|c|c|c|c|}
\hline \multirow[b]{2}{*}{ Standort } & \multirow[b]{2}{*}{ Monat } & \multicolumn{4}{|c|}{ Lufttemperatur } & \multicolumn{4}{|c|}{ Bodentemperatur } \\
\hline & & Mittel & Max & Min & TDD & Mittel & $\operatorname{Max}$ & Min & TDD \\
\hline \multirow[t]{12}{*}{1} & $\mathrm{~J}$ & $-5,6$ & 9,3 & $-21,1$ & 0,9 & 0,2 & 0,7 & $-0,2$ & 19,3 \\
\hline & $\mathrm{F}$ & $-5,4$ & 8,4 & $-23,0$ & 0,5 & 0,2 & 0,8 & $-0,2$ & 17,8 \\
\hline & M & $-2,8$ & 11,2 & $-23,0$ & 2,2 & 0,1 & 0,8 & $-0,3$ & 19,5 \\
\hline & A & 1,1 & 15,7 & $-17,1$ & 8,7 & 0,2 & 3,8 & $-0,3$ & 21,5 \\
\hline & M & 6,1 & 21,7 & $-7,2$ & 23,1 & 3,4 & 14,3 & $-0,2$ & 29,5 \\
\hline & $\mathrm{J}$ & 9,6 & 24,1 & $-4,8$ & 27,6 & 8,3 & 16,0 & 2,5 & 30,0 \\
\hline & $\mathrm{J}$ & 10,9 & 24,6 & $-0,8$ & 30,7 & 9,5 & 15,7 & 6,1 & 31,0 \\
\hline & A & 10,6 & 24,4 & $-1,0$ & 30,5 & 9,6 & 16,2 & 5,9 & 31,0 \\
\hline & S & 6,8 & 22,7 & $-5,8$ & 23,6 & 7,2 & 13,1 & 2,9 & 30,0 \\
\hline & $\mathrm{O}$ & 4,2 & 21,3 & $-13,9$ & 21,0 & 4,0 & 9,0 & 1,1 & 31,0 \\
\hline & $\mathrm{N}$ & $-1,1$ & 14,1 & $-16,8$ & 7,5 & 1,4 & 5,8 & $-0,2$ & 27,9 \\
\hline & $\mathrm{D}$ & $-4,8$ & 7,5 & $-21,6$ & 2,0 & 0,4 & 1,3 & $-0,7$ & 21,3 \\
\hline \multirow[t]{12}{*}{2} & $\mathrm{~J}$ & $-6,4$ & 7,4 & $-21,5$ & 6,0 & $-0,1$ & 0,4 & $-0,6$ & 15,3 \\
\hline & F & $-6,3$ & 6,9 & $-23,7$ & 5,4 & $-0,2$ & 0,4 & $-0,7$ & 9,8 \\
\hline & $\mathrm{M}$ & $-3,5$ & 9,6 & $-23,0$ & 7,0 & $-0,2$ & 0,4 & $-0,7$ & 8,7 \\
\hline & A & $-0,1$ & 13,2 & $-17,6$ & 9,8 & $-0,2$ & 6,8 & $-0,6$ & 6,5 \\
\hline & M & 5,6 & 21,6 & $-7,6$ & 22,9 & 3,0 & 12,3 & $-0,7$ & 19,8 \\
\hline & $\mathrm{J}$ & 9,1 & 23,7 & $-5,2$ & 27,8 & 8,2 & 14,0 & 1,2 & 30,0 \\
\hline & $\mathrm{J}$ & 10,2 & 29,3 & $-0,8$ & 30,5 & 9,4 & 14,1 & 3,8 & 31,0 \\
\hline & A & 10,3 & 23,6 & $-1,4$ & 30,5 & 9,1 & 14,2 & 4,1 & 31,0 \\
\hline & $S$ & 6,5 & 22,0 & $-5,9$ & 29,5 & 6,3 & 11,7 & 2,0 & 30,0 \\
\hline & $\mathrm{O}$ & 3,4 & 21,1 & $-14,5$ & 30,5 & 3,0 & 9,1 & 0,2 & 31,0 \\
\hline & $\mathrm{N}$ & $-1,5$ & 14,7 & $-16,8$ & 10,5 & 0,6 & 6,3 & $-0,7$ & 22,9 \\
\hline & $\mathrm{D}$ & $-5,2$ & 7,0 & $-22,1$ & 6,4 & 0,1 & 0,8 & $-0,7$ & 19,2 \\
\hline
\end{tabular}


Anhang Kapitel 7 I Mikroklimatisches Monitoring in Obergurgl

\begin{tabular}{rrrrrrrrrr}
\hline & \multicolumn{3}{c}{ Luftemperatur } & \multicolumn{7}{c}{ Bodentemperatur } \\
\hline Standort & Monat & Mittel & Max & Min & TDD & Mittel & Max & Min & TDD \\
\hline & & & & & & & & & \\
& & $-6,4$ & 7,0 & $-22,4$ & 3,6 & $-2,5$ & 0,4 & $-11,2$ & 2,8 \\
& J & $-6,9$ & 7,3 & $-24,5$ & 2,6 & $-2,7$ & $-0,1$ & $-10,6$ & 2,4 \\
& F & $-4,4$ & 10,8 & $-22,8$ & 3,5 & $-1,7$ & 0,8 & $-10,7$ & 4,6 \\
& M & $-0,9$ & 13,9 & $-18,6$ & 6,9 & $-0,1$ & 4,2 & $-2,9$ & 12,9 \\
A & 4,3 & 20,0 & $-7,4$ & 19,7 & 2,0 & 10,1 & $-0,7$ & 21,6 \\
& M & 8,0 & 22,5 & $-7,1$ & 25,4 & 6,5 & 12,5 & $-0,6$ & 29,5 \\
& J & 9,3 & 24,1 & $-1,8$ & 28,9 & 8,4 & 14,1 & 3,7 & 31,0 \\
& J & 8,9 & 22,3 & $-2,4$ & 29,6 & 8,6 & 13,3 & 3,2 & 31,0 \\
A & 5,1 & 20,5 & $-6,7$ & 21,3 & 5,2 & 11,0 & 0,8 & 30,0 \\
& S & 2,9 & 19,3 & $-15,1$ & 19,5 & 2,0 & 8,2 & $-1,6$ & 25,8 \\
& O & $-2,4$ & 11,7 & $-18,2$ & 6,1 & $-0,6$ & 4,6 & $-5,9$ & 6,3
\end{tabular}

$4 a$

J
F
M
A
M
J
J
A
S
O
N
D

$\begin{array}{rrrr}0,0 & 0,8 & -1,2 & 16,9 \\ 0,0 & 0,3 & -0,7 & 15,0 \\ 0,0 & 0,8 & -0,7 & 17,5 \\ 0,4 & 10,0 & -0,7 & 20,6 \\ 3,9 & 12,9 & -0,2 & 27,6 \\ 8,6 & 15,3 & 1,1 & 30,0 \\ 10,7 & 16,3 & 5,0 & 31,0 \\ 10,7 & 16,1 & 5,4 & 31,0 \\ 7,7 & 13,0 & 2,4 & 30,0 \\ 4,3 & 9,8 & 0,7 & 31,0 \\ 1,2 & 5,7 & -0,2 & 27,3 \\ 0,3 & 1,2 & -0,7 & 19,6\end{array}$

$4 b$

$\begin{array}{lrrrr}\text { J } & -8,3 & 6,5 & -25,2 & 5,7 \\ \text { F } & -8,5 & 5,4 & -29,1 & 5,1 \\ \text { M } & -5,2 & 9,3 & -26,8 & 5,7 \\ \text { A } & -1,2 & 10,3 & -21,8 & 7,3 \\ \text { M } & 3,0 & 16,7 & -9,3 & 17,3 \\ \text { J } & 7,5 & 20,6 & -7,0 & 25,5 \\ \text { J } & 8,8 & 21,5 & -2,6 & 28,5\end{array}$




\begin{tabular}{|c|c|c|c|c|c|c|c|c|c|}
\hline \multirow[b]{2}{*}{ Standort } & \multirow[b]{2}{*}{ Monat } & \multicolumn{4}{|c|}{ Lufttemperatur } & \multicolumn{4}{|c|}{ Bodentemperatur } \\
\hline & & Mittel & Max & Min & TDD & Mittel & Max & Min & TDD \\
\hline & A & 8,8 & 21,9 & $-3,4$ & 29,4 & & & & \\
\hline & S & 5,1 & 19,8 & $-10,3$ & 21,7 & & & & \\
\hline & $\mathrm{O}$ & 2,1 & 18,0 & $-19,6$ & 16,7 & & & & \\
\hline & $\mathrm{N}$ & $-3,3$ & 9,8 & $-20,8$ & 5,0 & & & & \\
\hline & $\mathrm{D}$ & $-7,2$ & 7,6 & $-27,9$ & 4,6 & & & & \\
\hline \multirow[t]{12}{*}{5} & $\mathrm{~J}$ & $-7,6$ & 7,1 & $-24,0$ & 0,1 & 0,1 & 0,8 & $-0,7$ & 16,9 \\
\hline & F & $-7,6$ & 9,3 & $-26,0$ & 0,0 & 0,0 & 0,8 & $-0,7$ & 14,3 \\
\hline & M & $-5,2$ & 12,4 & $-25,0$ & 0,2 & 0,1 & 0,3 & $-0,2$ & 15,5 \\
\hline & A & $-1,6$ & 12,3 & $-20,0$ & 2,9 & 0,1 & 10,2 & $-0,3$ & 12,4 \\
\hline & M & 3,1 & 16,6 & $-10,6$ & 14,5 & 2,9 & 13,7 & $-0,3$ & 17,9 \\
\hline & $\mathrm{J}$ & 7,2 & 20,1 & $-7,4$ & 23,3 & 9,0 & 16,8 & $-0,2$ & 29,3 \\
\hline & $\mathrm{J}$ & 8,5 & 23,6 & $-2,9$ & 27,9 & 10,9 & 17,5 & 2,9 & 31,0 \\
\hline & A & 8,5 & 21,0 & $-3,6$ & 28,8 & 11,1 & 18,0 & 4,5 & 31,0 \\
\hline & $S$ & 4,8 & 19,7 & $-8,0$ & 19,6 & 8,2 & 13,3 & 2,8 & 30,0 \\
\hline & $\mathrm{O}$ & 2,3 & 17,4 & $-17,5$ & 16,4 & 4,4 & 9,8 & 1,1 & 31,0 \\
\hline & $\mathrm{N}$ & $-3,2$ & 10,5 & $-19,6$ & 3,5 & 1,4 & 5,9 & $-0,1$ & 29,8 \\
\hline & $\mathrm{D}$ & $-6,9$ & 7,2 & $-24,8$ & 0,3 & 0,4 & 1,3 & $-0,7$ & 23,0 \\
\hline \multirow[t]{12}{*}{6} & $\mathrm{~J}$ & $-7,8$ & 7,3 & $-23,2$ & 3,2 & $-1,1$ & 0,0 & $-4,9$ & 2,8 \\
\hline & F & $-8,2$ & 5,5 & $-25,9$ & 2,5 & $-1,2$ & $-0,1$ & $-3,9$ & 2,5 \\
\hline & M & $-5,4$ & 8,9 & $-23,6$ & 3,2 & $-0,9$ & $-0,1$ & $-3,4$ & 2,8 \\
\hline & A & $-1,8$ & 12,2 & $-18,2$ & 5,5 & $-0,4$ & $-0,1$ & $-1,1$ & 2,7 \\
\hline & M & 2,7 & 16,5 & $-10,6$ & 16,2 & 0,3 & 13,3 & $-0,7$ & 5,3 \\
\hline & $\mathrm{J}$ & 6,8 & 20,5 & $-7,8$ & 23,3 & 7,4 & 16,4 & $-0,6$ & 25,6 \\
\hline & $\mathrm{J}$ & 8,6 & 21,0 & $-2,7$ & 28,6 & 10,5 & 18,3 & 3,3 & 31,0 \\
\hline & A & 8,2 & 21,0 & $-3,3$ & 28,5 & 9,8 & 16,5 & 2,5 & 31,0 \\
\hline & S & 4,7 & 19,8 & $-7,0$ & 22,4 & 5,4 & 12,2 & 0,2 & 30,0 \\
\hline & $\mathrm{O}$ & 2,6 & 17,5 & $-15,9$ & 20,3 & 1,3 & 9,2 & $-0,7$ & 21,5 \\
\hline & $\mathrm{N}$ & $-2,8$ & 10,5 & $-19,6$ & 7,2 & $-0,5$ & 4,6 & $-3,4$ & 3,5 \\
\hline & $\mathrm{D}$ & $-6,6$ & 5,7 & $-23,2$ & 3,5 & $-0,8$ & $-0,1$ & $-3,9$ & 2,8 \\
\hline
\end{tabular}


Anhang Kapitel 7 I Mikroklimatisches Monitoring in Obergurgl

\begin{tabular}{|c|c|c|c|c|c|c|c|c|c|}
\hline \multirow[b]{2}{*}{ Standort } & \multirow[b]{2}{*}{ Monat } & \multicolumn{4}{|c|}{ Lufttemperatur } & \multicolumn{4}{|c|}{ Bodentemperatur } \\
\hline & & Mittel & Max & Min & TDD & Mittel & $\operatorname{Max}$ & Min & TDD \\
\hline \multirow[t]{12}{*}{7} & $\mathrm{~J}$ & $-8,2$ & 8,4 & $-24,2$ & 8,7 & $-0,5$ & 0,4 & $-2,5$ & 0,1 \\
\hline & $\mathrm{F}$ & $-8,3$ & 9,1 & $-23,8$ & 7,6 & $-1,1$ & $-0,1$ & $-3,9$ & 0,0 \\
\hline & M & $-5,6$ & 10,4 & $-24,1$ & 8,5 & $-1,2$ & $-0,1$ & $-3,9$ & 0,0 \\
\hline & A & $-2,3$ & 14,7 & $-21,5$ & 9,1 & $-0,6$ & $-0,1$ & $-2,0$ & 0,0 \\
\hline & M & 2,5 & 20,0 & $-10,3$ & 17,0 & 0,0 & 6,7 & $-0,7$ & 1,8 \\
\hline & $\mathrm{J}$ & 5,9 & 22,4 & $-9,0$ & 23,0 & 4,8 & 13,0 & $-0,2$ & 23,4 \\
\hline & $\mathrm{J}$ & 7,6 & 23,8 & $-4,4$ & 26,2 & 9,2 & 14,1 & 1,2 & 31,0 \\
\hline & A & 7,0 & 21,9 & $-5,1$ & 26,3 & 9,4 & 14,5 & 2,8 & 31,0 \\
\hline & $S$ & 3,4 & 19,8 & $-10,5$ & 17,9 & 6,1 & 11,8 & 0,7 & 30,0 \\
\hline & $\mathrm{O}$ & 1,2 & 15,8 & $-19,5$ & 12,2 & 2,2 & 7,9 & 0,3 & 31,0 \\
\hline & $\mathrm{N}$ & $-4,2$ & 11,3 & $-21,1$ & 5,3 & 0,5 & 2,5 & $-0,2$ & 24,7 \\
\hline & $\mathrm{D}$ & $-7,9$ & 6,6 & $-25,7$ & 7,4 & 0,1 & 0,8 & $-0,7$ & 12,9 \\
\hline \multirow[t]{12}{*}{8} & $\mathrm{~J}$ & $-8,9$ & 7,3 & $-25,4$ & 5,9 & $-3,0$ & 0,3 & $-8,4$ & 2,8 \\
\hline & $\mathrm{F}$ & $-9,6$ & 8,5 & $-28,0$ & 5,2 & $-3,1$ & $-0,1$ & $-10,1$ & 2,5 \\
\hline & $\mathrm{M}$ & $-7,2$ & 10,3 & $-24,6$ & 5,8 & $-1,5$ & 4,8 & $-7,9$ & 2,8 \\
\hline & A & $-3,7$ & 12,8 & $-22,0$ & 6,5 & 1,2 & 13,1 & $-1,5$ & 9,5 \\
\hline & M & 0,3 & 13,7 & $-12,6$ & 12,7 & 4,5 & 15,8 & $-0,2$ & 25,4 \\
\hline & $\mathrm{J}$ & 4,4 & 16,4 & $-10,0$ & 21,4 & 8,1 & 16,4 & 0,7 & 30,0 \\
\hline & $\mathrm{J}$ & 6,0 & 19,0 & $-6,0$ & 23,8 & 9,3 & 17,3 & 2,5 & 31,0 \\
\hline & A & 5,8 & 18,6 & $-6,3$ & 23,5 & 9,0 & 17,5 & 2,0 & 31,0 \\
\hline & $S$ & 2,4 & 16,0 & $-9,4$ & 17,1 & 6,5 & 14,9 & 1,4 & 30,0 \\
\hline & $\mathrm{O}$ & 0,5 & 14,5 & $-17,6$ & 13,5 & 3,6 & 11,4 & 0,2 & 31,0 \\
\hline & $\mathrm{N}$ & $-4,5$ & 10,8 & $-20,4$ & 7,5 & 0,4 & 6,6 & $-2,5$ & 19,7 \\
\hline & $\mathrm{D}$ & $-8,2$ & 10,6 & $-25,9$ & 5,6 & $-1,5$ & 0,3 & $-6,9$ & 5,0 \\
\hline
\end{tabular}


